


\section{Compressive Strength of Concrete}

Edited by Pavel Krivenko 

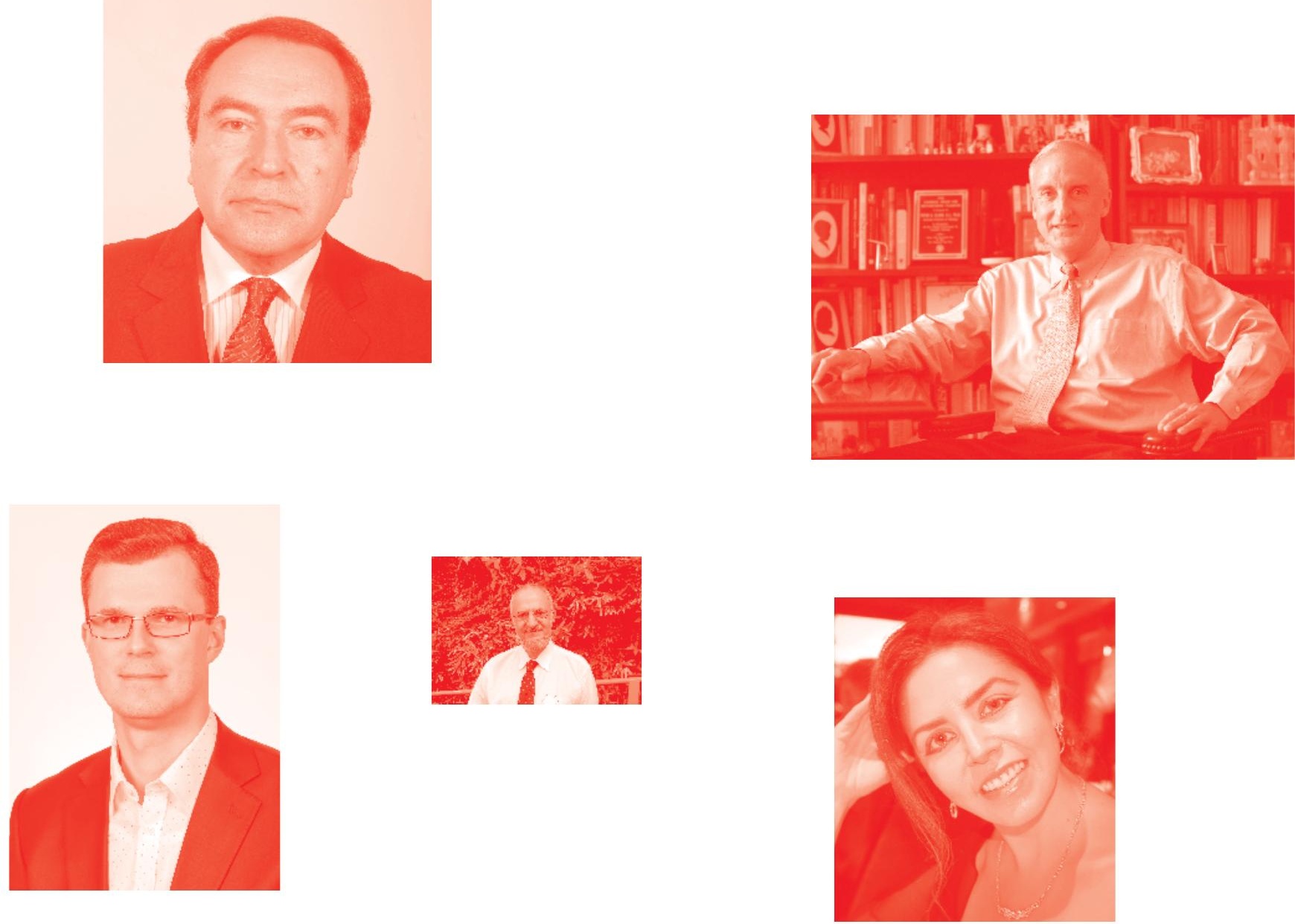

Supporting open minds since 2005
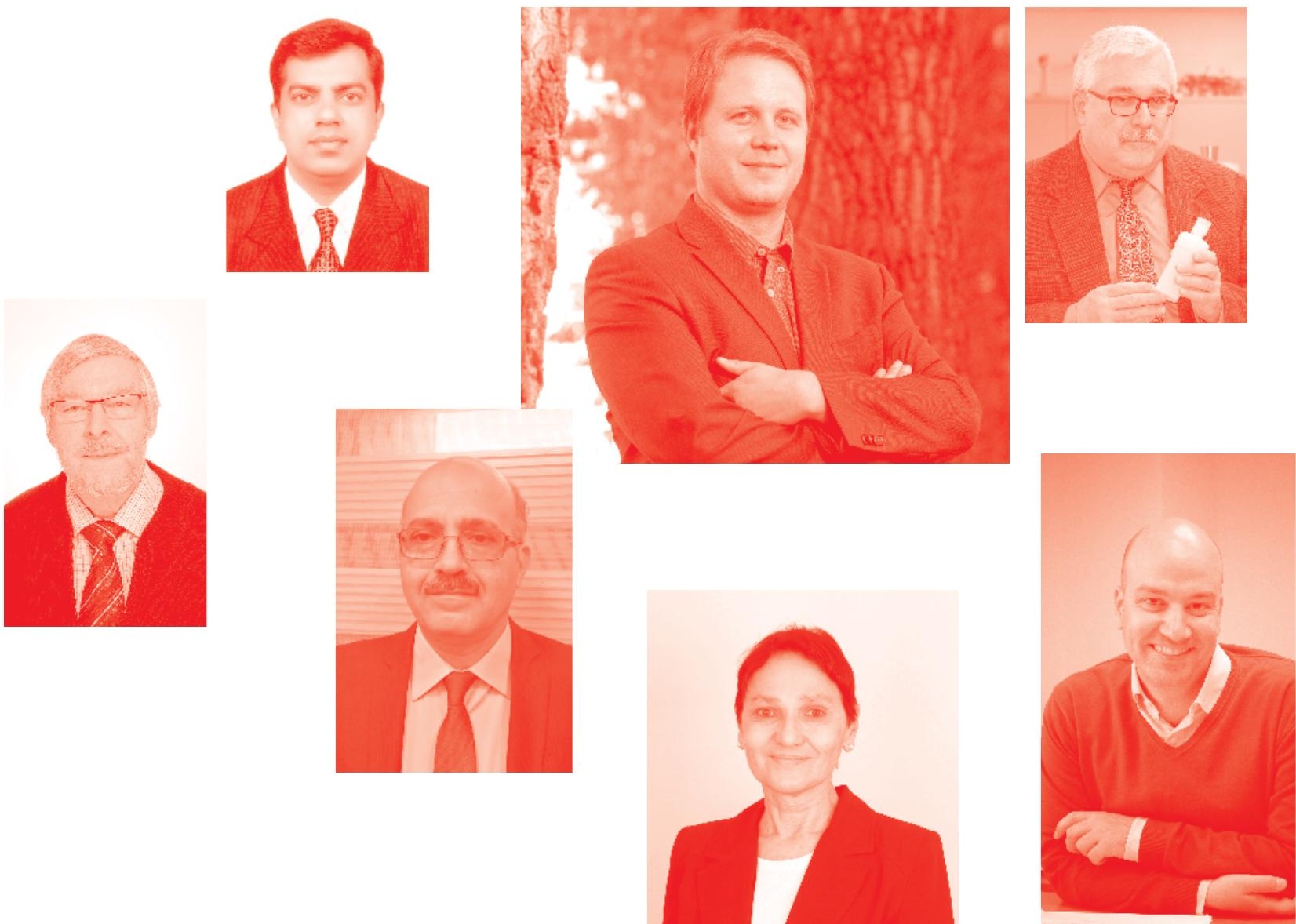
Compressive Strength of Concrete

http : //dx . doi . org/10.5772/intechopen. 80174

Edited by Pavel Krivenko

\section{Contributors}

Alireza Farzampour, Saman Hedjazi, Zine El Abidine Rahmouni, Nadia Tebbal, Ivan Janotka, Pavel Martauz, Michal Bacuvcik, Vojtech Vaclavik, Cristian Druta, Pascal Forquin, Pavlo Kryvenko, Oleh Petropavlovskyi, Oleksandr Kovalchuk, Vasyl Ivanychko

(-) The Editor(s) and the Author(s) 2020

The rights of the editor(s) and the author(s) have been asserted in accordance with the Copyright, Designs and Patents Act 1988. All rights to the book as a whole are reserved by INTECHOPEN LIMITED . The book as a whole (compilation) cannot be reproduced, distributed or used for commercial or non-commercial purposes without INTECHOPEN LIMITED's written permission. Enquiries concerning the use of the book should be directed to INTECHOPEN LIMITED rights and permissions department (permissions@intechopen.com).

Violations are liable to prosecution under the governing Copyright Law .

\section{(cc) BY}

Individual chapters of this publication are distributed under the terms of the Creative Commons Attribution 3.0 Unported License which permits commercial use, distribution and reproduction of the individual chapters, provided the original author(s) and source publication are appropriately acknowledged. If so indicated, certain images may not be included under the Creative Commons license. In such cases users will need to obtain permission from the license holder to reproduce the material. More details and guidelines concerning content reuse and adaptation can be found at http : //www . intechopen . com/copyright-policy . html.

\section{Notice}

Statements and opinions expressed in the chapters are these of the individual contributors and not necessarily those of the editors or publisher. No responsibility is accepted for the accuracy of information contained in the published chapters. The publisher assumes no responsibility for any damage or injury to persons or property arising out of the use of any materials, instructions, methods or ideas contained in the book.

First published in London, United Kingdom, 2020 by IntechOpen IntechOpen is the global imprint of INTECHOPEN LIMITED, registered in England and Wales, registration number: 11086078 , 7th floor, 10 Lower Thames Street, London,

EC3R 6AF, United Kingdom

Printed in Croatia

British Library Cataloguing-in-Publication Data

A catalogue record for this book is available from the British Library

Additional hard and PDF copies can be obtained from orders@intechopen.com

Compressive Strength of Concrete

Edited by Pavel Krivenko

p. cm.

Print ISBN 978-1-78985-567-8

Online ISBN 978-1-78985-568-5

eBook (PDF) ISBN 978-1-78985-942-3 


\section{We are IntechOpen, \\ the world's leading publisher of Open Access books}

Built by scientists, for scientists

\section{$4,700+$}

Open access books available

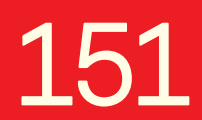

Countries delivered to
$120,000+$

International authors and editors

Our authors are among the

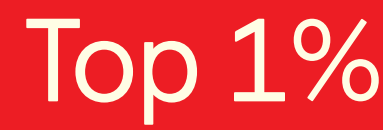

most cited scientists

Contributors from top 500 universities
$135 \mathrm{M}+$

Downloads

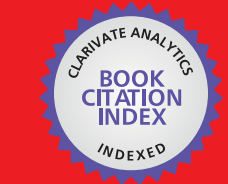

WEB OF SCIENCE ${ }^{\mathrm{MM}}$

Selection of our books indexed in the Book Citation Index in Web of Science ${ }^{\mathrm{TM}}$ Core Collection (BKCI)

\section{Interested in publishing with us? \\ Contact book.department@intechopen.com}

Numbers displayed above are based on latest data collected.

For more information visit www.intechopen.com 



\section{Meet the editor}

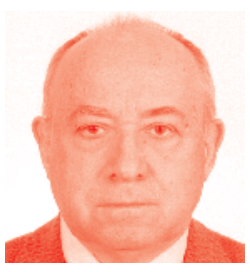

Pavel Krivenko, DSc(Eng), is currently a professor at the Department of Technology of Building Structures and Products, and Director of the Scientific Research Institute for Binders and Materials of the Kyiv National University of Construction and Architecture, Kyiv, Ukraine. He graduated from the Dnepropetrovsk Civil Engineering Institute with a diploma in Engineering in Building Materials Technology, Dnepropetrovsk, Ukraine (1961). He received his $\mathrm{PhD}$ (Eng) from the Kyiv Civil Engineering Institute (1971) and his DSc(Eng) from the Kyiv Polytechnical Institute, Kyiv, Ukraine (1986). His research interests include the synthesis of alkali-activated cements and materials based on them. He has published more than 20 books and more than 1000 papers in international journals and conference proceedings. He is a principal investigator in a number of national and international projects in Ukraine and abroad. He is a member of three RILEM Technical Committees on alkali-activated materials, a board member of three international journals, winner of the State Prize of Ukraine in the field of Science and Engineering (2001), and supervisor of five DSc(Eng) and $23 \mathrm{PhD}$ theses. 



\section{Contents}

Preface

Section 1

Structure and Compressive Strength

Chapter 1

The Influence of Interfacial Transition Zone on Strength of Alkali-Activated Concrete by Pavel Krivenko, Oleh Petropavlovskyi, Oleksandr Kovalchuk and Oleksandr Gelevera

Chapter 2

Concrete Microstructure Characterization and Performance by Cristian Druta

Chapter 3

Compressive Strength of Lightweight Concrete

by Saman Hedjazi

Chapter 4

Investigation of the Quasi-Static and Dynamic Confined Strength of Concretes by Means of Quasi-Oedometric Compression Tests by Pascal Forquin

\section{Section 2}

Compressive Strength and Durability

Chapter 5

Compressive Behavior of Concrete under Environmental Effects by Alireza Farzampour

Chapter 6

Mechanical Behavior of High-Performance Concrete under

Thermal Effect

by Zine El Abidine Rahmouni and Nadia Tebbal

Chapter 7

Fundamental Properties of Industrial Hybrid Cement Important for Application in Concrete by Ivan Janotka, Pavel Martauz, Michal Bačuvčík and Vojtěch Václavík 



\section{Preface}

Concrete is one of the oldest construction materials on Earth, and is the most widely used because of its excellent properties such as high compressive strength, good workability, durability, and availability of constituent materials. A contemporary science on concrete is based on extensive experience obtained from many years of theoretical studies and practical uses. This reflects a variety of growing requirements on performance properties and durability, as well as specific requirements to constituent materials and technology, which account for a growing necessity to reduce negative impacts on the environment.

Cement, being a basic concrete constituent, is a complicated system varying in properties and functions. As a result, the majority of problems associated with concrete technology can be dealt with through a deeper understanding of the processes taking place during hydration and hardening of cement and which, in their turn, cause the formation of the structure and properties of concrete.

Compressive Strength of Concrete contains seven chapters written by researchers and experts in the field. This book provides the state of the art on current progress in understanding the processes that result in the production of high-performance and economically and ecologically efficient concrete.

The book chapters are organized in two sections. The first section mainly focuses on the structure and strength formation of concrete; the second section looks at the relationship between strength and durability under environmental impact.

Chapter 1 is dedicated to the influence of the interfacial transition zone on the formation of strength characteristics of concrete made from alkali-activated cement.

Chapter 2 describes the influence of the interfacial transition zone on the strength characteristics of concrete made from ordinary Portland cement.

Chapter 3 deals with the compressive strength of structural lightweight concrete made using lightweight expanded glass aggregate.

Chapter 4 deals with the application of energy-efficient industrial hybrid cement concrete with high sulfate resistance and reduced shrinkage.

Chapter 5 describes the compressive behavior of concrete under environmental effects.

Chapter 6 provides insight into the mechanical behavior of high-performance concrete subjected to temperatures up to $1000^{\circ} \mathrm{C}$.

Chapter 7 describes the fundamental long-term properties of industrial hybrid cement concrete. 
I would like to show my sincere gratitude to the academicians, scientists, concrete technologists, and colleagues and friends globally who have contributed significantly to the broader area of concrete technology. My sincere appreciation and acknowledgment is also given to the published works of researchers on the subject, which have been referred in this book. I am also extremely grateful to IntechOpen for publishing the book in an excellent format. Finally, I wish to acknowledge Ms. Sara Debeuc for providing valuable assistance in bringing out this book.

Pavel Krivenko

D.Sc Professor, Kyiv National University of Construction and Architecture, Kyiv, Ukraine 
Section 1

\section{Structure and Compressive Strength}





\title{
The Influence of Interfacial Transition Zone on Strength of Alkali-Activated Concrete
}

\author{
Pavel Krivenko, Oleh Petropavlovskyi, \\ Oleksandr Kovalchuk and Oleksandr Gelevera
}

\begin{abstract}
A process of structure formation taking place in the interfacial transition zone (ITZ) "cement stone-aggregate" was studied on a variety of concretes made with artificial and real aggregates. The study of these processes in the case of artificial aggregate prepared from a mixture of clay loam and alkali-activated slag cement showed that not only active $\mathrm{SiO}_{2}$ and $\mathrm{Na}_{2} \mathrm{O}$ but also other substances of both cement and aggregate are involved in the formation of the ITZ. This results in the formation of alkaline and alkaline-alkali-earth aluminosilicate hydrates which strengthen the ITZ and improve strength and durability of the concrete. Thus, the alkali-silica reaction (ASR) transforms from a destructive one (negative effect) into a constructive one (positive effect). The study on the ITZ in the alkali-activated cement concretes made with real alkali-susceptible aggregates selected from crushed basalt rock, glassy waste product from basalt fiber production, crushed perlite rock, and expanded perlite suggested to make a conclusion on the possibility to prevent the destructive processes in the ITZ through the addition of the metakaolin additive into the cement composition in quantities of $5-10 \%$ by mass. These conclusions were supported by the long-term testing of strength of these concretes, by measuring the deformations "shrinkage-expansion" as well as the results of study on hardness of the ITZ.
\end{abstract}

Keywords: alkali-activated cement, alkali-aggregate reaction (AAR), alkali-silica reaction (ASR), alkali-susceptible aggregate, alkaline and alkaline-alkali-earth aluminosilicate hydrates, basalt rock, interfacial transition zone (ITZ), metakaolin, perlite rock, Portland cement

\section{Introduction}

Nowadays, concrete is recognized as one of the basic constructional materials. However, strict requirements to its performance properties, in particular durability, are not met in all cases allowing big concerns to occur. With worsening of the ecological situation and larger volumes of use of off-standard materials as concrete constituents, durability became a main criterion of concrete quality. One poorly studied and "hidden" reason explaining low durability of concrete in some cases is the so-called internal corrosion occurring in a cement paste/aggregate interfacial transition zone (ITZ) in concrete, where the cement paste with thicknesses of a few 
microns comes into interaction with the aggregate. The ITZ is considered as the strength-limiting phase in concrete.

The ITZ is formed in the process of redistribution of the substances of the cement and aggregate and a result of the reaction "alkali-silicic acid." Depending upon a composition of the formed hydration products, this reaction can be either a destructive (negative effect) one or a constructive (positive effect) one [1-5]. It is believed [6-9] that destructive corrosion of concrete can occur as a result of chemical interaction of alkalis $\mathrm{Na}_{2} \mathrm{O}+\mathrm{K}_{2} \mathrm{O}$ of the cements with amorphous silica present in particles of aggregates. Not only amorphous silica but also other substances of aggregate constituents-microcrystalline quartz, micas, clay minerals-can enter into interaction with alkalis. This changes a phase composition of the hydration products in the ITZ, resulting in either its weakening or occurrence of critical deformations of expansion. The problem is that these processes are very slow and signs of corrosion can appear after months and in most cases after years of service [9-16].

An alkali can come into concrete in case of cements with the increased contents of alkaline oxides $\left(\mathrm{Na}_{2} \mathrm{O}+\mathrm{K}_{2} \mathrm{O}\right)$ (over $\left.0.6 \%\right)$. The higher quantities of alkalis in concrete can be attributed to the wider use of chemical, mineral, and organic additives and admixtures containing them. Alkalis can also come from outside, for example, with seawater, de-icing chemicals, etc. [17, 36-38]. Also, in recent years more and more widely spread are the alkali-activated cements [18-20], in which the alkali contents $(1.5-5.5 \%$ by mass) are much higher than the values permissible for Portland cements (no more than $\mathrm{NaO}+\mathrm{K}_{2} \mathrm{O}=0.6 \%$ by mass). This can in the future initiate an alkali-silica reaction (ASR) in case of alkalisusceptible aggregates.

The results of first observations of cases of severe concrete damage as a result of alkali-aggregate reaction were reported by E.A. Stephenson as long ago as in 1916. In 1940 Stanton [21] observed the alkali-aggregate in the concrete used for diverting dam in California. In the recent years, this problem attracted attention of many researchers, which not only studied and continue to study a mechanism of corrosion process but showed main factors which could affect the alkali-silica reaction [1,39-40]. Among these factors are the higher alkali contents of cement, the higher cement content of concrete, quantity of alkali-susceptible aggregates, temperature and humidity, permeability of concrete, ingress of alkalis from outside, mineral composition of aggregates, etc.

All these allowed to develop measures on how to prevent or weaken the alkalisilica reaction. Among such measures are the use of cements containing additives with latent hydraulic activity or pozzolanic materials, such as granulated blastfurnace slag (GBFS), fly ash, microsilica, volcanic glass, and metakaolin. So, Malek and Roy [22] studied a role of $\mathrm{Al}_{2} \mathrm{O}_{3}$ and made a conclusion on its positive role in transformation of the ASR from a destructive one into a constructive one. As a result of the so-called "constructive" reaction, the insoluble alkaline and alkalinealkali-earth aluminosilicate hydrates, analogs to natural zeolites $(\mathrm{CaO})$ $\mathrm{Na}_{2} \mathrm{O} \cdot \mathrm{Al}_{2} \mathrm{O}_{3} \cdot \mathrm{nSiO}_{2} \cdot \mathrm{mH}_{2} \mathrm{O}$, can be formed in the ITZ. These conclusions were further supported by numerous researchers [23-30], which provided practical solutions on struggle with the ASR through addition in the cement composition of $\mathrm{Al}_{2} \mathrm{O}_{3}$ containing additives. However, this oxide is contained in aggregates as well [31-35]. For this reason, the structure formation processes in the ITZ flow with participation of not only substances of cement components, but of substances of aggregate constituents as well, which always contain finely dispersed clay particles.

The purpose of this research was to study the influence of the processes flowing in the interfacial transition zone in the alkali-activated cement concretes made with different aggregates on their properties. 


\section{Materials and testing techniques}

In order to study the structure formation processes in the interfacial transition zone, an artificial (model) granular aggregate was used: the granules were prepared from the following mix-clay loam, $75 \%$ by mass; granulated blast-furnace slag, $25 \%$ by mass; and alkaline component $\left(\mathrm{Na}_{2} \mathrm{CO}_{3}\right.$ solution $), 15 \%$ by mass, without any firing. The preparation process was as follows: all constituents were mixed, and granules $10-20 \mathrm{~mm}$ in size were formed, which then were allowed to harden for 28 days in normal conditions.

The concrete cube specimens $(10 \times 10 \times 10 \mathrm{~cm})$ from the alkali-activated cement (granulated blast-furnace slag, $92 \%$ by mass, and $\mathrm{Na}_{2} \mathrm{CO}_{3}, 8 \%$ by mass) and these granules to be used as aggregate were prepared and were subjected to steam curing at $\mathrm{t}=90 \pm 2{ }^{\circ} \mathrm{C}$ for $8 \mathrm{~h}$. The ITZ was studied at an age of 28 days.

To study properties of the concrete made using real aggregates, the following cement compositions were chosen:

- Portland cement (OPC) + water

- Alkali-activated Portland cement (OPC + soluble silicate)

- Alkali-activated slag cement (GBFS + soluble silicate)

- Alkali-activated slag cement (GBFS + sodium metasilicate $\left(\mathrm{Na}_{2} \mathrm{O} \cdot \mathrm{SiO}_{2} \cdot 5 \mathrm{H}_{2} \mathrm{O}\right)$ )

- Alkali-activated slag cement (GBFS + sodium carbonate $\mathrm{Na}_{2} \mathrm{CO}_{3}$ )

Used as aggregates were:

- Crushed basalt rock

- Glassy waste product from basalt fiber production

- Crushed perlite rock

- Expanded perlite

Chemical composition of the constituent materials is given in Tables 1-3.

The alkaline activators were added in a form of solution; those were:

- Soluble silicate $\mathrm{Ms}=2.9 . \rho=1.3 \mathrm{~g} / \mathrm{cm}^{3}$

- Sodium metasilicate $\left(\mathrm{Na}_{2} \mathrm{O} \cdot \mathrm{SiO}_{2} \cdot 5 \mathrm{H}_{2} \mathrm{O}\right)$ with $\rho=1.25 \mathrm{~g} / \mathrm{cm}^{3}$

- Sodium carbonate $\left(\mathrm{Na}_{2} \mathrm{CO}_{3}\right)$ with $\rho=1.18 \mathrm{~g} / \mathrm{cm}^{3}$

Specific surface area of the granulated blast-furnace slag was $300-330 \mathrm{~m}^{2} / \mathrm{kg}$ and that of the metakaolin, $1800 \mathrm{~m}^{2} / \mathrm{kg}$.

Grain sizes of the aggregates were within ranges of 3-5 mm.

\subsection{Test methods}

Thin sections were cut directly from the beam specimens of the composition "cement-aggregate" taken as 1:2 which were used to study the interfacial transition zone. 


\begin{tabular}{lcccccccccccc}
\hline \multirow{2}{*}{ Material } & \multicolumn{4}{c}{ Mass percentage of oxides } & \multicolumn{2}{c}{$\boldsymbol{\Sigma} \%$} & $\mathbf{M}_{\mathbf{o}}$ & $\mathbf{M}_{\mathbf{a}}$ \\
\cline { 2 - 11 } & $\mathrm{SiO}_{2}$ & $\mathrm{Al}_{2} \mathrm{O}_{3}$ & $\mathrm{CaO}$ & $\mathbf{M g O}$ & $\mathrm{Fe}_{2} \mathrm{O}_{3}$ & $\mathrm{SO}_{3}$ & $\mathrm{Na}_{2} \mathrm{O}+\mathrm{K}_{2} \mathrm{O}$ & $\mathrm{LOI}$ & & & \\
\hline GBFS & 39.0 & 5.9 & 47.7 & 5.56 & 0.29 & 1.48 & 0.1 & 0.5 & 100.53 & 1.19 & 0.151 \\
\hline OPC & 21.82 & 5.30 & 65.91 & 1.11 & 4.86 & 0.99 & 0.22 & 0.2 & 100.41 & - & - \\
\hline Metakaolin & 55.05 & 35.40 & 3.01 & 0.92 & 4.27 & 0.28 & - & 0.07 & 99.00 & - & - \\
\hline Clay loam & 92.10 & 3.50 & 5.29 & - & 0.87 & - & - & 2.12 & 103.88 & - & - \\
\hline
\end{tabular}

Table 1.

A chemical composition of the constituent materials.

\begin{tabular}{lccccccc}
\hline $\begin{array}{l}\text { Resulted density, } \\
\mathbf{g} / \mathbf{c m}^{3}\end{array}$ & $\begin{array}{c}\text { Silicate } \\
\text { modulus }\end{array}$ & \multicolumn{2}{c}{$\begin{array}{c}\text { Content calculated on dry } \\
\text { matter, } \mathbf{g}\end{array}$} & \multicolumn{3}{c}{$\begin{array}{c}\text { Mass percentage of } \\
\text { oxides }\end{array}$} \\
\cline { 3 - 7 } & & $\begin{array}{c}\text { In } \mathbf{1} \mathbf{~ o f} \\
\text { solution }\end{array}$ & $\begin{array}{c}\text { In } \mathbf{1} \text { kg of } \\
\text { solution }\end{array}$ & $\mathrm{SiO}_{2}$ & $\mathbf{R}_{2} \mathbf{O}_{3}$ & $\mathbf{N a}_{2} \mathbf{O} \quad \mathrm{CaO}$ \\
\hline 1.40 & 2.96 & 539.9 & 385.6 & 28.5 & 0.19 & 9.37 & 0.15 \\
\hline
\end{tabular}

Table 2.

Characterization of the soluble silicate.

\begin{tabular}{|c|c|c|c|c|}
\hline \multirow[t]{3}{*}{ Oxides } & \multicolumn{4}{|c|}{ Mass percentage of oxides } \\
\hline & \multicolumn{2}{|r|}{ Basalt } & \multicolumn{2}{|c|}{ Perlite } \\
\hline & Basalt rock & $\begin{array}{l}\text { Glassy waste product from } \\
\text { basalt fiber production }\end{array}$ & Perlite rock & Expanded perlite \\
\hline $\mathrm{SiO}_{2}$ & 50.200 & 50.050 & 72.820 & 76.730 \\
\hline $\mathrm{Al}_{2} \mathrm{O}_{3}$ & 14.000 & 15.350 & 12.500 & 13.160 \\
\hline $\mathrm{Fe}_{2} \mathrm{O}_{3}$ & 6.340 & 6.230 & 0.650 & 0.680 \\
\hline $\mathrm{FeO}$ & 8.670 & 7.000 & 0.900 & 0.950 \\
\hline $\mathrm{TiO}_{2}$ & 1.620 & 2.680 & 0.110 & 0.110 \\
\hline $\mathrm{MnO}$ & 0.240 & 0.300 & 0.030 & 0.030 \\
\hline $\mathrm{CaO}$ & 8.350 & 9.210 & 1.070 & 1.120 \\
\hline $\mathrm{MgO}$ & 6.600 & 5.580 & 0.170 & 0.180 \\
\hline $\mathrm{P}_{2} \mathrm{O}_{5}$ & 0.320 & - & 0.007 & - \\
\hline $\mathrm{K}_{2} \mathrm{O}$ & 0.710 & 0.770 & 4.510 & 4.740 \\
\hline $\mathrm{Na}_{2} \mathrm{O}$ & 2.270 & 2.180 & 2.100 & 2.210 \\
\hline $\mathrm{SO}_{3}$ & 0.080 & 0.150 & 0.050 & 0.040 \\
\hline LOI & 0.550 & - & 4.750 & - \\
\hline$\Sigma, \%$ & 99.950 & 99.500 & 99.667 & 99.950 \\
\hline
\end{tabular}

Table 3.

Chemical composition of the aggregates.

The ITZ was studied with the help of a scanning electron microscope.

A hardness and elemental distribution in the ITZ were studied as well.

The metakaolin, taken in quantities $5-15 \%$ by mass, was chosen as an additive to retard the ASR. 
Strength determination was done on beam specimens $(4 \times 4 \times 16 \mathrm{~cm})$ prepared from the concrete mixture "cement-aggregate" taken as 1:2 by mass, except for the specimens made using the expanded perlite as aggregate. Since mean densities of crushed basalt, glassy waste product from basalt fiber production, perlite rock, and cement were more or less close to each other, that of the expanded perlite was different-it was by 10 times lower. For this reason, in order to maintain in all specimens under study an equal volume of cement matrix, the proportions

between the cement and expanded perlite in the concrete were taken as 1:0.2 by mass. After preparation, the specimens were kept for 2 days in normal condition and then in a thermostat at temperatures of 20 and $65^{\circ} \mathrm{C}$ and relative humidity (RH) of about $100 \%$.

Autogenous deformations were measured using a device with a dial indicator with a scale $0.01 \mathrm{~mm}$. The basic measurements were taken at an age of 2 days.

A state of the interfacial transition zones, as was earlier mentioned, is determined, first of all, by the composition and properties of the hydration products as well as by the interface bond strength due to a mutual penetration of the substances of various constituents of the concrete mixture [31,35]. However, because of small dimensions of the subjects to be studied, the examination of the hydration products in the interfacial transition zones is difficult. For this reason, a spectral imaging in $\mathrm{X}$-ray microanalysis was applied.

The presence and distribution of chemical elements that were supposed to present in the composition of the hydration products, occurring in the interfacial transition zone, was determined using this examination technique [41]. The elemental $(\mathrm{Na}, \mathrm{Al}, \mathrm{Si}$, and $\mathrm{Ca}$ ) distribution was done using the X-ray images and their concentrations-by an intensity of the characteristic lines. The concentration curves of elemental distribution were plotted in accordance with the results of qualitative analysis. A width of the section under study was $200 \mu \mathrm{m}$. The measurement of microhardness was done with the use of a microhardness measuring apparatus with a diamond pyramid.

\section{Results and conclusions}

\subsection{The structure formation process in the ITZ "alkali-activated cement-alkali-susceptible aggregate"}

\subsubsection{Concrete mixture "alkali-activated cement-artificial alkali-susceptible aggregate"}

The study of the ITZ structure formation in the concrete mixture "artificial granular aggregate-GBFS- $\mathrm{Na}_{2} \mathrm{CO}_{3}$ solution" taken in the following proportions, 8:1.95:0.5 by mass calculated on $\mathrm{Na}_{2} \mathrm{CO}_{3}$ dry matter, showed that the highest values of microhardness were characteristic of the interfaces between the cement paste and granules. This can be attributed to strong adhesion of the cementation material to an activated matter of the clay loam-based loamy granules and formation of the hydration products which determine high-performance properties of the concrete. Bond strength in the interfacial transition zones of the steam-cured concrete is 3.8 $\mathrm{MPa}$ and after 3 years-4.5 MPa.

The structure of the ITZ in the steam-cured alkali-activated cement concrete at an age of 28 days was dense. The boundary of the interface in some regions discontinues, testifying to a mutual penetration of these regions and blurring the border between the cement stone and aggregate.

The study of the 3-year-old concrete showed that the ITZ in this case is itself a close interlacement of substances included in the cement paste and the granule and 


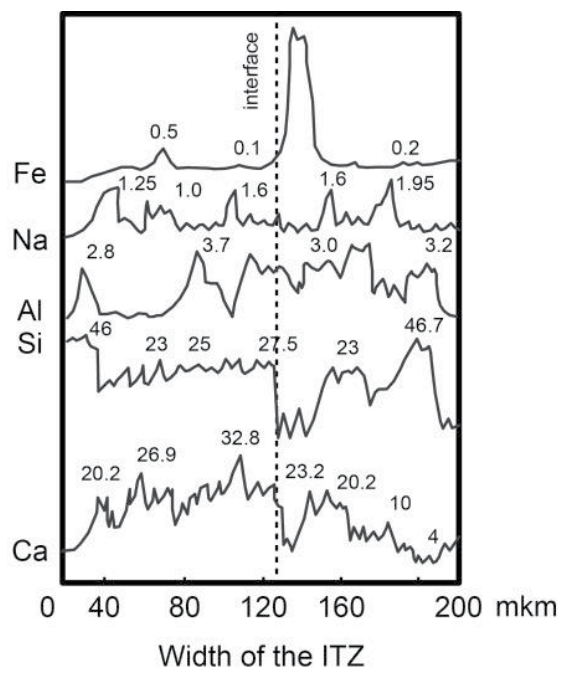

(a)

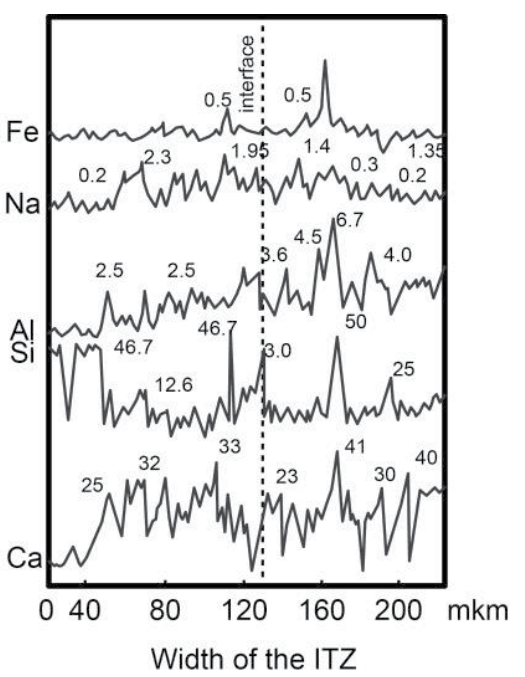

(b)

Figure 1.

The concentration curves of elemental distribution in the cement paste/granular aggregate interfacial transition zones in the steam-cured alkali-activated cement concrete: (a) at age of 28 days; (b) at age of 3 years [42].

is characteristic of the presence of the clearly visible (expressed) new phases. The interface is not visible (absent).

A comparative analysis of the obtained concentration curves of elemental distribution (Figure 1) suggested to conclude that sodium, aluminum, silicon, calcium, and iron are present over the whole width of the ITZ in the steam-cured alkaliactivated cement concrete. Sodium and silicon were distributed homogeneously over the interface, iron is contained in small quantities (Figure 1a). The distribution of $\mathrm{Ca}$ and $\mathrm{Al}$ is inhomogeneous. So, the content of calcium is reducing in two times as far as closer to the granule, and that of aluminum-increasing in the same direct. Evidently, it is attributed to the fact that the hydration products in the cement paste are represented chiefly by low-basic calcium silicate hydrates and partially by the hydrogarnets, so far as the alkaline aluminosilicate hydrates are formed in the granules along with the abovementioned.

On the contrary to the investigated concentration curves of elemental ( $\mathrm{Ca}$ and $\mathrm{Al}$ ) distribution in the ITZ of the 3-year-old alkali-activated cement, concrete is characteristic of homogeneous uniform elemental ( $\mathrm{Ca}$ and $\mathrm{Al}$ ) distribution over the width of the interface (Figure 1b). The earlier observed aggregations of calcium near the cement paste and aluminum granules are absent. Calcium is homogeneously distributed over the interface, and quantity of aluminum approaching to the cement paste of the concrete greatly increased. After 3 years of hardening of the alkali-activated cement concrete, the curves of elemental distribution of all elements are characterized by high-frequency oscillations of concentrations, which can be an evidence of the increase of the interface bond strength and compaction the structure of the interface.

Evidently, change of the state of the ITZ in time can be attributed to physicalchemical processes occurring in the concrete. Above such phenomena as adsorption, diffusion, and others, a chemical interaction of the substances contained in various cements and aggregates took place, leading to formation of the hydration products of the alkaline, alkali-earth, and mixed alkaline-alkali-earth aluminosilicate composition—such compounds like aluminosilicates of sodium and calcium. 
The presence of such interaction is supported by the statistical correlation analysis of the obtained data [42]. Analysis of the concentration curves suggested to draw a conclusion on a correlation dependence between the chemical elements in the interface.

The coefficients of correlation were calculated by methods of pair and multiple correlation.

A comparative evaluation of the obtained data showed that in early ages of hardening of the steam-cured alkali-activated slag cement concrete with artificial granular aggregate in transition zone, the elements $\mathrm{Na}$ and $\mathrm{Si}, \mathrm{Al}$ and $\mathrm{Si}, \mathrm{Al}$ and $\mathrm{Ca}$, $\mathrm{Na}$ and $\mathrm{Al}$, and $\mathrm{Ca}$ and $\mathrm{Si}$ are combined; their coefficients of pair correlation are significant. The closest bound in that case characterizes a coefficient of pair correlation for $\mathrm{Si}$ and $\mathrm{Ca}$, which amounts for 0.782 before interface line and 0.689 after the interface line. This can serve as evidence of the presence of calcium silicates in the ITZ. However, the values of the coefficients of multiple correlation for $\mathrm{Na}, \mathrm{S}$, and $\mathrm{Ca} / \mathrm{R}_{\mathrm{Na}} \mathrm{Si}, \mathrm{Ca} /$ and for $\mathrm{Al}, \mathrm{Si}$, and $\mathrm{Ca} / \mathrm{R}_{\mathrm{Al}}, \mathrm{Si}$, Ca $/$ for all interface exceed 0.6. That showed that $\mathrm{Si}$ and $\mathrm{Ca}$ so far as $\mathrm{Al}$ and $\mathrm{Na}$ could incorporate in such compounds as alumina silicates of sodium and calcium.

Analysis of individual coefficients of multiple correlation, which characterize a bond between two elements in that time, a third element present at a constant level, showed that these coefficients differ in value from the coefficients of pair correlation. This difference is a proof of the interaction of all elements and their interdependence. So, for example, at constant $\mathrm{Si}$, a local coefficient of correlation for $\mathrm{Na}$ and $\mathrm{Al}$ is equal to 0.26 and at constant $\mathrm{Ca}-0.96$, which is caused by great influence of silicon ( $\mathrm{Si}$ ) on the bond "Na-Al." Almost similar action is rendered by sodium on the bond "Al-Si." This can be seen from comparison of the corresponding local coefficients of correlation. Moreover, the bond between $\mathrm{Al}$ and $\mathrm{Si}$ is strongly affected by $\mathrm{Ca} / \mathrm{R}_{\mathrm{Al}, \mathrm{Si}, \mathrm{Ca}}=0.114$, in its turn closely connected with bonded Si.

It is worth mentioning that the coefficients of pair correlation for $\mathrm{Na}$ and $\mathrm{Ca}$ in the case under study are insignificant. However, this is not witnesses the absence of the bond between them, since the individual local coefficient of multiple correlation by alumina is 0.950 . Evidently, this bond is considerably affected by aluminum $\mathrm{Al}$, which is much stronger attained by $\mathrm{Na}$.

An interrelation between all elements under study is observed and after interface line from the side of the granule.

The presence of such bond witnesses the appearance of the cement paste/granule interface in the alkali-activated cement concrete of chemical compounds of alkaline, alkali-earth, and mixed alkaline-alkali-earth aluminosilicate composition.

Investigation of specimens of steam-cured alkali-activated cement concrete at the age of 3 years showed that also in this case the compounds containing uniformly/homogeneously interrelated elements, $\mathrm{Na}, \mathrm{Al}, \mathrm{Si}$, and $\mathrm{Ca}$ (all correlation coefficients before the interface line and after it are significant), are present over the ITZ. Moreover, the coefficients of pair correlation for $\mathrm{Na}$ and $\mathrm{Al} / \zeta_{\mathrm{Na}}, \mathrm{Al}=0.682$ $0.707 /, \mathrm{Na}$ and $\mathrm{Si} / \zeta_{\mathrm{Na}} \mathrm{Si}=0.796 /$, and especially for $\mathrm{Na}$ and $\mathrm{Ca} / \zeta_{\mathrm{Na}}, \mathrm{Ca}=0.580$ 0.620 / at simultaneous increase of common coefficients of multiple correlation significantly increased. A conclusion was made that the aluminum affects the Na-Ca bond and calcium the $\mathrm{Na}-\mathrm{Al}$ bond. This conclusion is supported by a difference of individual coefficients of correlation between these elements from the coefficients of pair correlation. All this is an evidence that quantities of the compounds of mixed alkaline-alkali-earth alkaline aluminosilicate composition increased in the ITZ. The higher correlation between all elements in time is caused by growth of the hydration products in the ITZ and, hence, densification and strengthening of the interface itself. 
The alkali-activated cement concrete with the artificial granular aggregate had a dense structure and was characteristic of high bond strength of the granules with the cement paste. A dense structure of the alkali-activated cement concrete under study, as well as the composition of the hydration products, determine high physical-mechanical properties of such concrete, which, in their turn, determine performance properties.

\subsubsection{The processes of structure formation in the ITZ "alkali-activated cement-natural sustainable aggregate"}

The structure formation processes in the ITZ of the concretes made using real aggregates were studied on beam specimens $(4 \times 4 \times 16 \mathrm{~cm})$, which were subjected to continuous steam curing for 360 days at temperatures of 38 and $65 \pm 3^{\circ} \mathrm{C}$.

Micro photos of the ITZs in different concretes made from various cements and aggregates are shown in Figures 2-7.

Thin plates for the examination with the help of an electron microscope were cut directly from the beam specimens $(4 \times 4 \times 16 \mathrm{~cm})$.

As it follows from Figure 2, significant signs of corrosion in the concretes from traditional (ordinary) Portland cement with crushed basalt rock are seen, the lowest corrosion being in the case with the metakaolin additive (Figure $\mathbf{2 b}$ ).

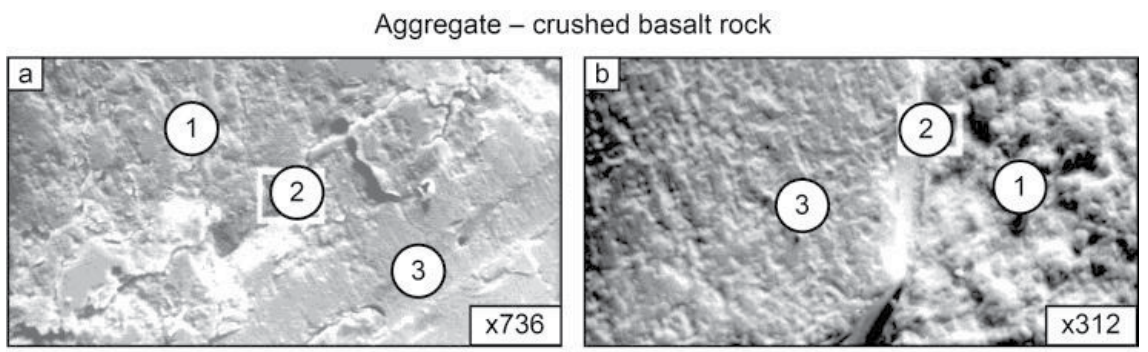

Aggregate - crushed perlite rock
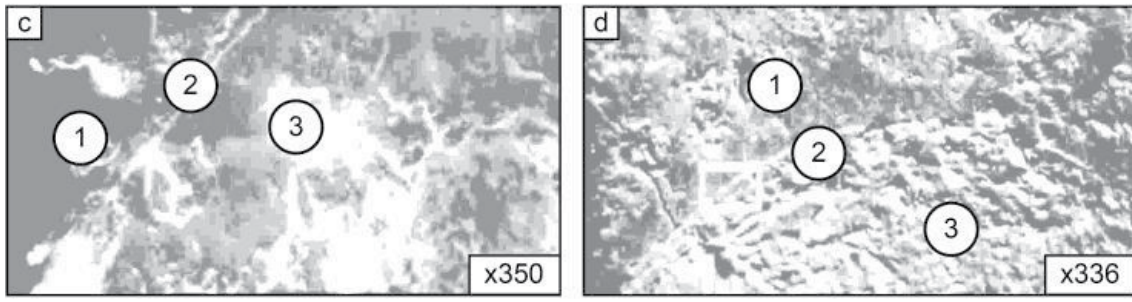

Aggregate - expanded perlite
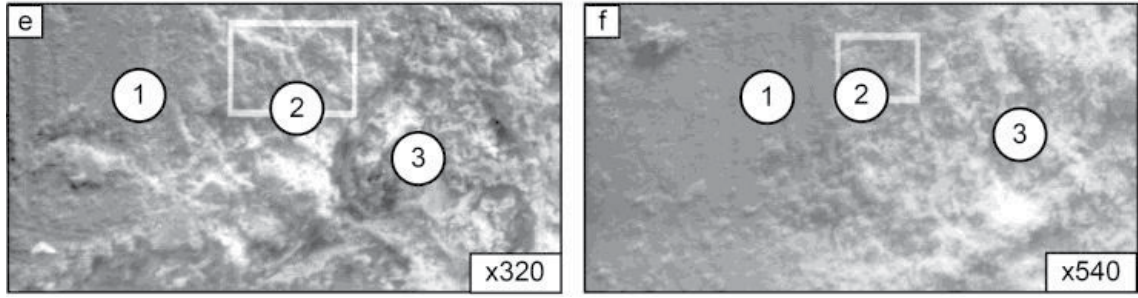

Figure 2.

SEM images of the ITZ concrete_- "Portland cement-water-agregate" (a, c, e) without metakaolin additive; $(b, d, f)$ with metakaolin additive; 1 , cement stone; $2, I T Z ; 3$, aggregate. Curing conditions-9o days of steam curing at $t=65^{\circ} \mathrm{C}$. 

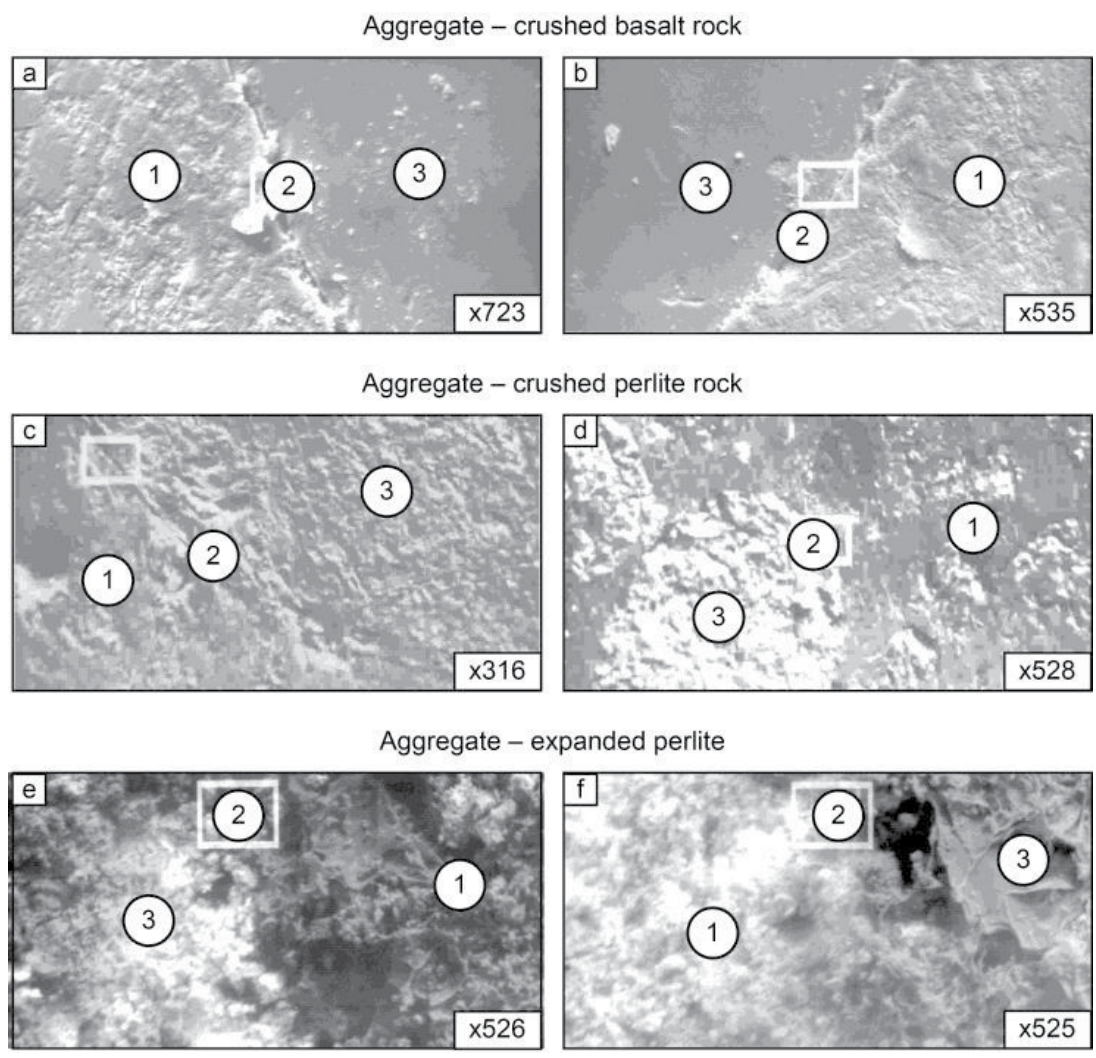

Figure 3.

SEM images of the ITZ concrete_-Portland cement-soluble silicate-agregate" $(a, c, e)$ without metakaolin additive; $(b, d, f)$ with metakaolin additive; 1 , cement paste; 2, ITZ; 3 , aggregate. Curing conditions-9o days of steam curing at $t=65^{\circ} \mathrm{C}$.

The signs of corrosion in the concretes from traditional (ordinary) Portland cement with crushed perlite rock and expanded perlite are, respectively, lower in all cases than those in the case of the crushed basalt rock (Figure $2 \mathbf{e}, \mathbf{f}$ ). This can be attributed to the presence in perlite (both expanded and not expanded) of active $\mathrm{Al}_{2} \mathrm{O}_{3}$ with the glassy phase, which amounts to $90-97 \%$, whereas a quantity of a glassy phase in the crushed basalt rock is only $8-12 \%$. Thus, though a total quantity of $\mathrm{Al}_{2} \mathrm{O}_{3}$ in the crushed basalt rock and perlite is almost close $(14.0 \%$ and $12.5-$ $13.2 \%$, respectively) (Table 3 ), active $\mathrm{Al}_{2} \mathrm{O}_{3}$ is contained in the perlite in much higher amounts. Moreover, in compliance with [4, 41], it may be allowed that a part of the products of corrosion depose in a pore space of the perlite, thus eliminating a little bit their deleterious action.

The compositions of the alkali-activated Portland cement with high-modulus soluble silicate as alkaline activator are given in Figure 3. Metakaolin was used as a modifying additive. Analysis of the micro photos showed that the hydration reaction products are mostly observed in the composition with the crushed basalt rock without additive (Figure 3a). The additive of metakaolin improves the picture. The ITZ became sharp and clear (Figure $3 \mathbf{b}$ ).

In the compositions with the crushed perlite rock and expanded perlite using alkali-activated Portland cement with soluble silicate some signs of corrosion are present in the ITZ in the additive-free compositions and are practically absent in the compositions with the metakaolin additive (Figure 3c-f). 


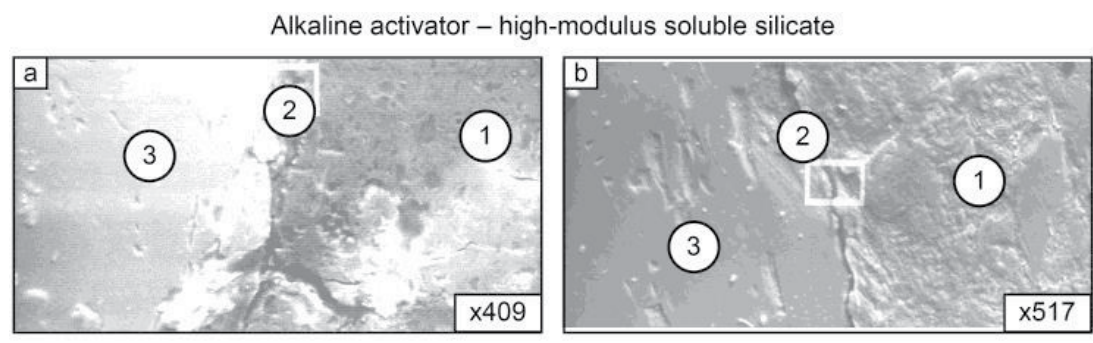

Alkaline activator - sodium metasilicate
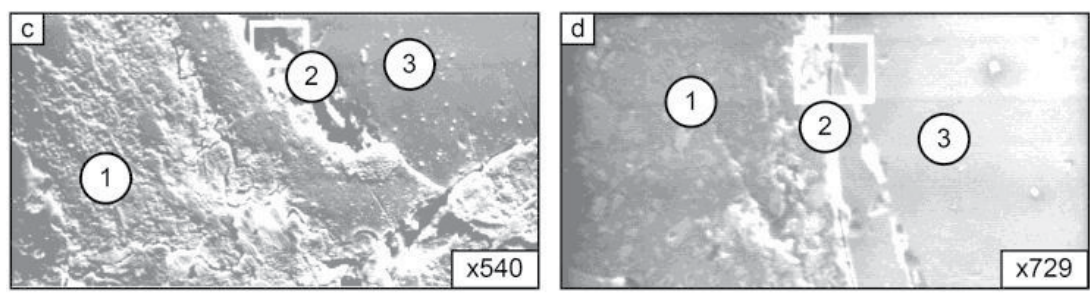

Alkaline activator - sodium carbonate
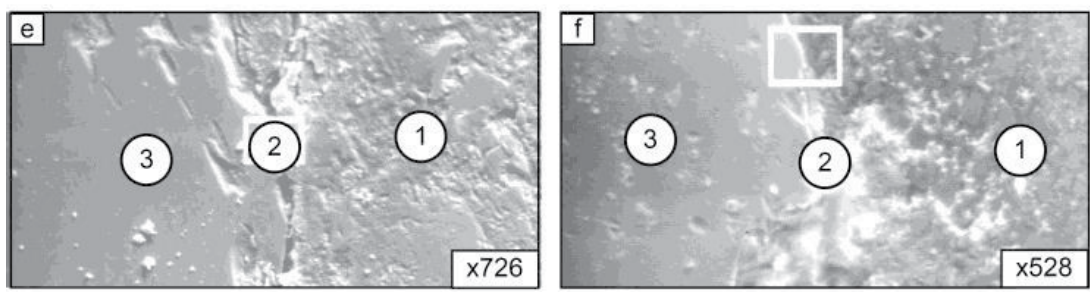

Figure 4.

SEM images of the ITZ concrete-“GBFS-alkaline component-basalt rock” $(a, c, e)$ without metakaolin additive; $(b, d, f)$ with metakaolin additive; 1 , cement paste; 2, ITZ; 3, aggregate. Curing conditions_-9o days of steam curing at $t=65^{\circ} \mathrm{C}$.

The nature of flow of corrosion processes in the alkali-activated slag compositions with high-modulus soluble silicate is mostly similar to the compositions using alkali-activated Portland cement (Figure 4a, b).

Reducing of silicate modulus of soluble silicate down to Ms = 1 (sodium metasilicate) and the use of solution of sodium carbonate (Figure 4a, e) leads to decreasing of corrosion products in the ITZ in the additive-free compositions compared to compositions using high-modulus soluble silicate (Figure $\mathbf{4 a}$ ). The metakaolin additive influenced positively on slowing of corrosion processes in the ITZ (Figure 4b, d, f).

The influence of the curing conditions of the specimens on the development of the corrosion processes is shown in Figures 5 and 6, where results of observation of compositions using traditional (ordinary) and alkali-activated Portland cement with crushed basalt rock are given, which cured for 90 days at $\mathrm{t}=20,38$, and $65^{\circ} \mathrm{C}$ and $\mathrm{RH}=100 \%$.

It is shown that in this period at $\mathrm{t}=20^{\circ} \mathrm{C}$, there are practically no any signs of corrosion in the ITZ "cement stone-aggregate" in both compositions, both with and without the metakaolin additive, being fixed (Figure 5a, b). ITZ в additive-free compositions at $\mathrm{t}=38^{\circ} \mathrm{C}$ (Figures 5c, 6c ) are a little bit less expressed and even less at $\mathrm{t}=65^{\circ} \mathrm{C}$ (Figures 5e, 6e). The presence of the kaolin makes the ITZ more clearly expressed (Figures $\mathbf{5 d}, \mathbf{f}$ and $\mathbf{6 d}, \mathbf{f}$ ).

The study on microhardness of the ITZ in the concretes with crushed basalt rock showed that the metakaolin additive within the alkali-activated cements intensifies constructive corrosion (Figure 7). 
Curing temperature $-20^{\circ} \mathrm{C}$
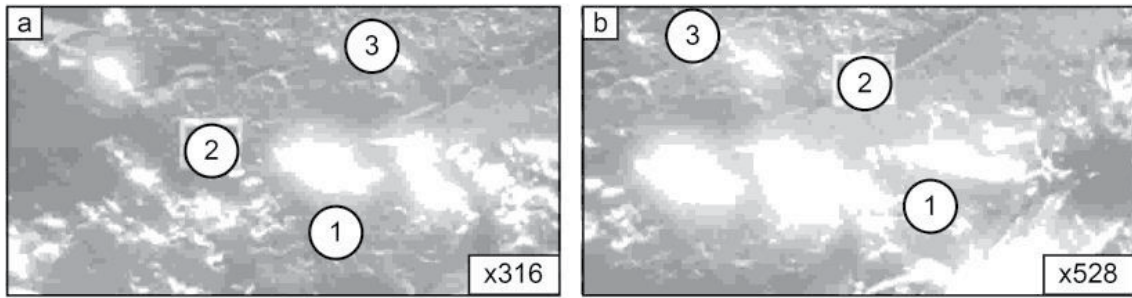

Curing temperature $-38^{\circ} \mathrm{C}$
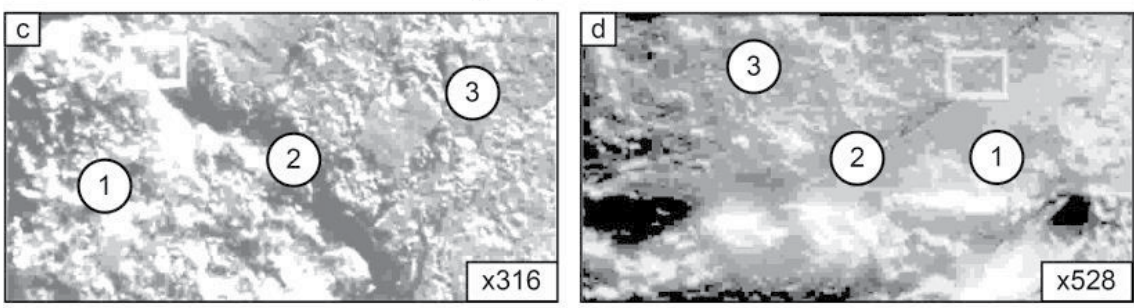

Curing temperature $-65^{\circ} \mathrm{C}$
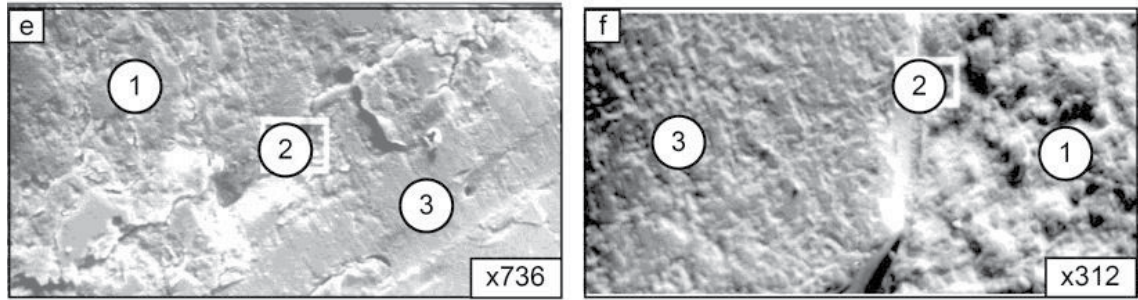

Figure 5 .

SEM images of the ITZ concrete_-Portland cement-water-crushed basalt rock" $(a, c, e)$ without metakaolin additive; $(b, d, f)$ with metakaolin additive; 1 , cement paste; $2, I T Z ; 3$, aggregate. Curing conditions at $t=20$, $38,65^{\circ} \mathrm{C} 90$ days after steam curing.

Thus, taking into account micro photos of the cement paste/alkali-susceptible aggregate ITZ, the following conclusions can be drawn:

- At $\mathrm{t}=20^{\circ} \mathrm{C}$ at an age of 90 days, all concrete specimens under study, not depending upon a cement type and kind of aggregate, showed clear presence of destructive processes in the ITZ.

- At $\mathrm{t}=38^{\circ} \mathrm{C}$ at an age of 90 days in additive-free compositions, except for those with perlite, in most cases there are fixed disturbance of sharpness and integrity of the ITZ. The addition of the metakaolin to the traditional (ordinary) Portland cement and alkali-activated cements reduces a quantity of undesirable reaction products in the ITZ.

At the temperature $\mathrm{t}=65^{\circ} \mathrm{C}$ at an age of 90 days, disturbance of the ITZ is much more clearly expressed than that at $\mathrm{t}=38^{\circ} \mathrm{C}$, chiefly, in the concretes from cement without additives. Exceptions are the concretes with perlite, where the products of corrosion, probably, could distribute in a pore space of the aggregate and, above all, perlites are represented, chiefly, by a glassy phase with rather high contents of active alumina, which can bind rather effectively free alkalis, reducing, in this way, a risk of active silica-aggregate reaction. The metakaolin additive in all cases influences positively on reducing deposits of the products of corrosion in the ITZ. 
Curing temperature $-20^{\circ} \mathrm{C}$
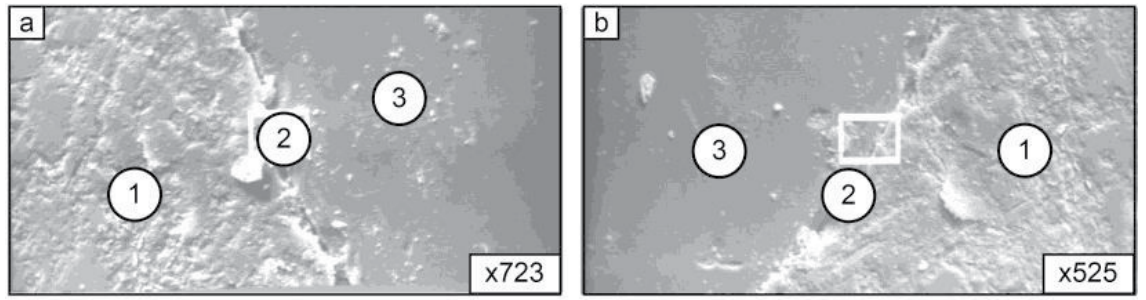

Curing temperature $-38^{\circ} \mathrm{C}$
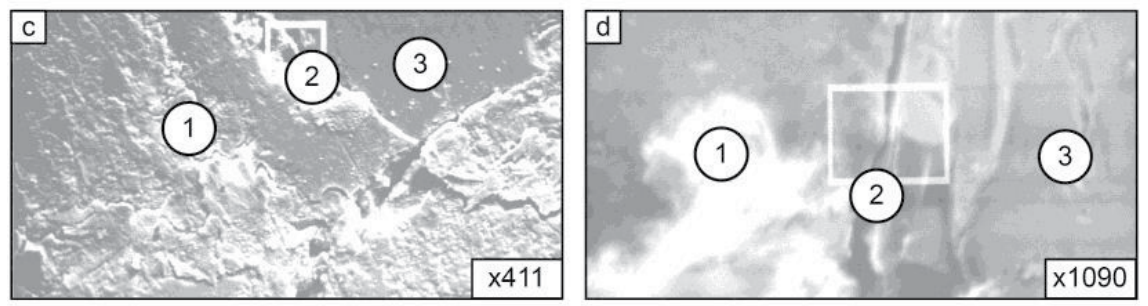

Curing temperature $-65^{\circ} \mathrm{C}$
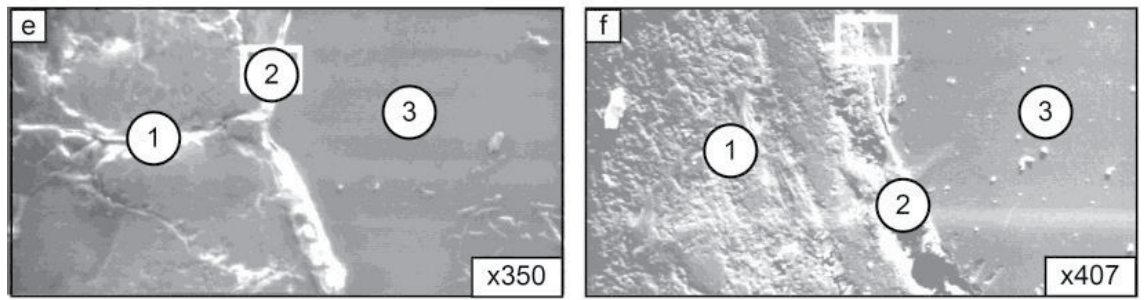

Figure 6.

Micro photos of the ITZ concrete-"Portland cement + soluble glass-basalt rock" $(a, c, e)$ without metakaolin additive; $(b, d, f)$ with metakaolin additive; 1 , cement paste; $2, I T Z ; 3$, aggregate. Curing conditions at $t=20$, $38,65^{\circ} \mathrm{C} 90$ days after steam curing.

XRD patterns of the specimens, modeling the cement stone/alkali-susceptible aggregate ITZ, are shown in Figures 8-11.

Thus, in Figure 8 the diffraction characteristic of composition on the basis of basalt and Portland cement (ordinary and alkali-activated) after their hardening in the conditions of continuous steam curing for 360 days is represented.

Corresponding to the XRD analysis data, a phase composition of the hydrated dispersions based on ordinary Portland cement and basalt (Figure 8, curve 2), modeling the ITZ, is represented, chiefly, by the following hydrate new formations: high-basic calcium silicate hydrates of the $\mathrm{C}_{6} \mathrm{~S}_{3} \mathrm{H}(\mathrm{d}=0.335-0.284-0.246-0.237-$ $0.225-0.180 \mathrm{~nm}), \mathrm{C}_{2} \mathrm{SH}(\mathrm{d}=0.284-0.270-0.246-0.190-0.180 \mathrm{~nm})$ types, and lowbasic phases of the $\mathrm{C}_{3} \mathrm{~S}_{2} \mathrm{H}_{3}(\mathrm{~d}=0.56-0.284-0.184 \mathrm{~nm})$ type. The presence of $\mathrm{Ca}(\mathrm{OH})_{2}(\mathrm{~d}=0.487-0.311-0.261-0.193-0.180 \mathrm{~nm})$ and $\mathrm{CaCO}_{3}(\mathrm{~d}=0.303-0.229-$ $0.21-0.193-0.188 \mathrm{~nm}$ ) also was fixed. Also there are set weak lines of the $\mathrm{C}_{2} \mathrm{AH}_{4}$ $(\mathrm{d}=7.17-0.376-0.266-0.258-0.246 \mathrm{~nm})$ type. It is well-known that via the presence of chemically active silica and alkalis, in this case $\mathrm{Ca}(\mathrm{OH})$, which is present in the pores of the hardened concrete, a deleterious reaction "alkali-silicic acid" takes place actively with formation of alkaline metal silicate gel in the aggregate/cement stone ITZ. XRD analysis is not fixing X-ray amorphous phase of calcium silicate gel, which may be forming in the ITZ and weakening it, but taking into elemental distribution in the ITZ and extremely high expansion deformations of composite materials with basalt (up to $2.15 \mathrm{~mm} / \mathrm{m}$ ), such possibility exists and mostly is confirmed by the higher contents of $\mathrm{Ca}$ and $\mathrm{Si}$ in the ITZ. 
The Influence of Interfacial Transition Zone on Strength of Alkali-Activated Concrete DOI: http://dx.doi.org/10.5772/intechopen.90929

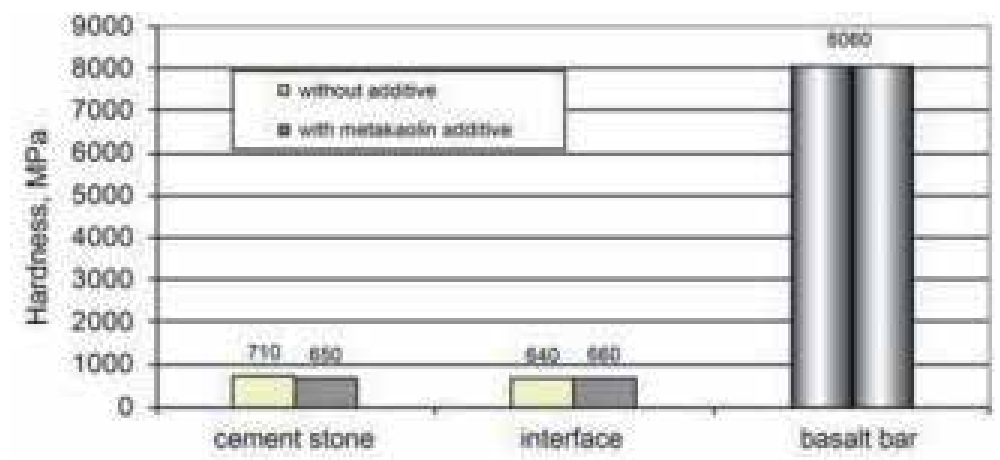

(a)

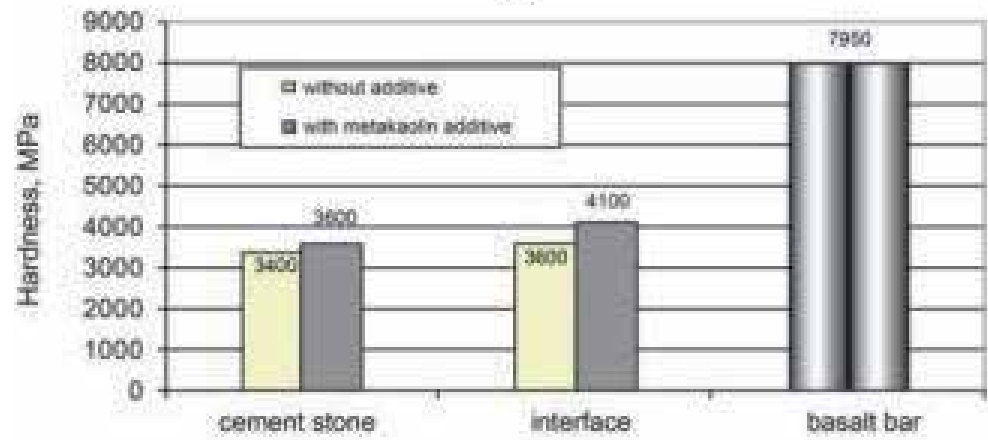

(b)

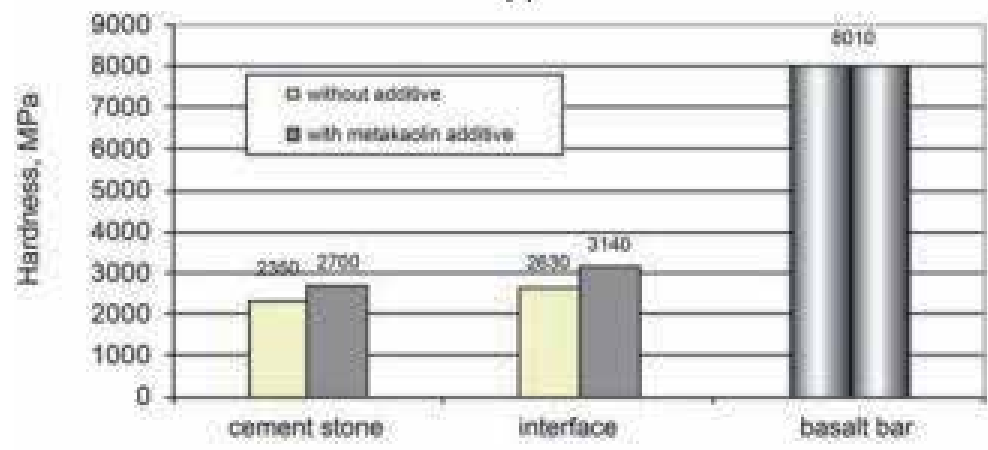

(c)

Figure 7.

Hardness of the ITZ "cement stone-basalt" (a) cement stone + water; (b) cement stone + soluble silicate; (c) GBFS + soluble silicate. Curing conditions-6o days of continuous steam curing at $t=65^{\circ} \mathrm{C}$.

Use in the composition with basalt of the alkali-activated Portland cement leads to the changes in diffraction picture of the ITZ model (Figure 8, curve 3). Thus, hydration depth of Portland cement is rising, resulting in reducing intensiveness of the diffraction lines. Transformation of phase formation processes took place in the direct of formation of low-basic silicate hydrates of calcium $\mathrm{CSH}(\mathrm{I})(\mathrm{d}=0.283-0.270-0.247-0.179 \mathrm{~nm})$ type and tobermorite $(\mathrm{d}=0.560-0.307-0.299-0.283-0.227-0.208-0.183 \mathrm{~nm})$. The reflexes of $\mathrm{Ca}(\mathrm{OH})_{2}$ are totally absent.

In the ITZ silica, content reduces rapidly; at the same time, the quantity of aluminum and sodium is rising. Thus it is possible to make a conclusion about synthesis in the ITZ of sodium and mixed sodium-calcium alumina silicates, confirming by the results of X-ray diffractogram analysis (Figure 9, curve 2). Thus, 

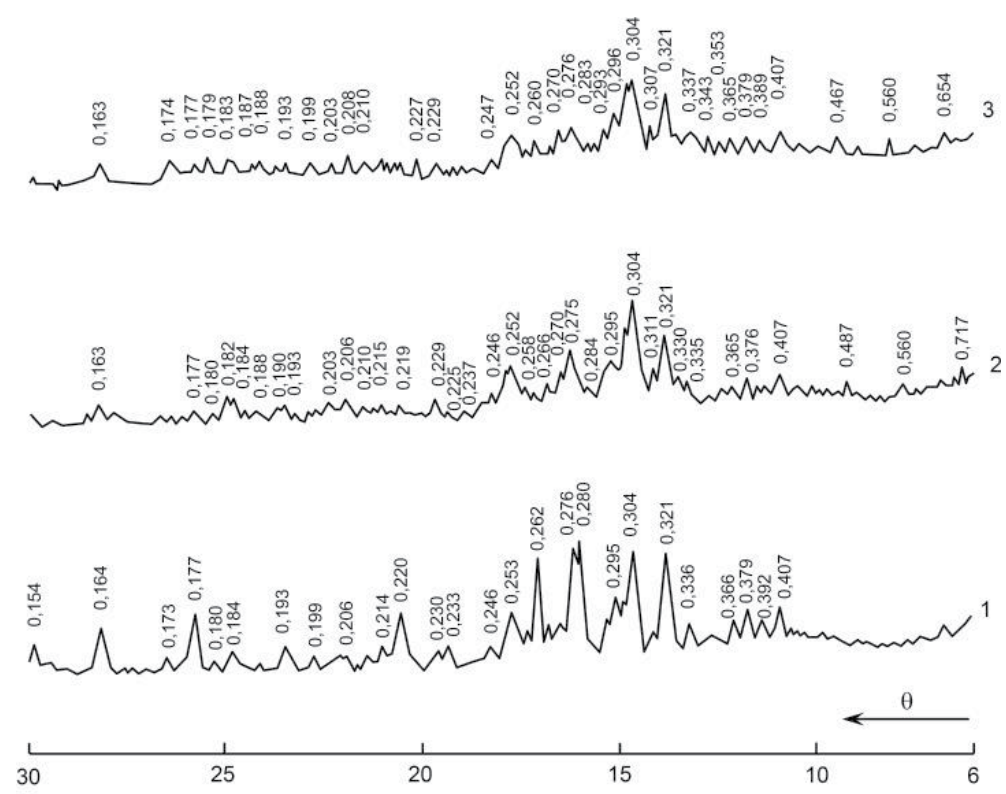

Figure 8.

XRD patterns of the ITZ of model systems: (1) "Portland cement-basalt"; (2) "Portland cement-basalt-water"; (3) "Portland cement-basalt-soluble silicate." Curing conditions- 360 days at $t=65 \pm 3{ }^{\circ} \mathrm{C}$ and $\mathrm{RH}=100 \%$.

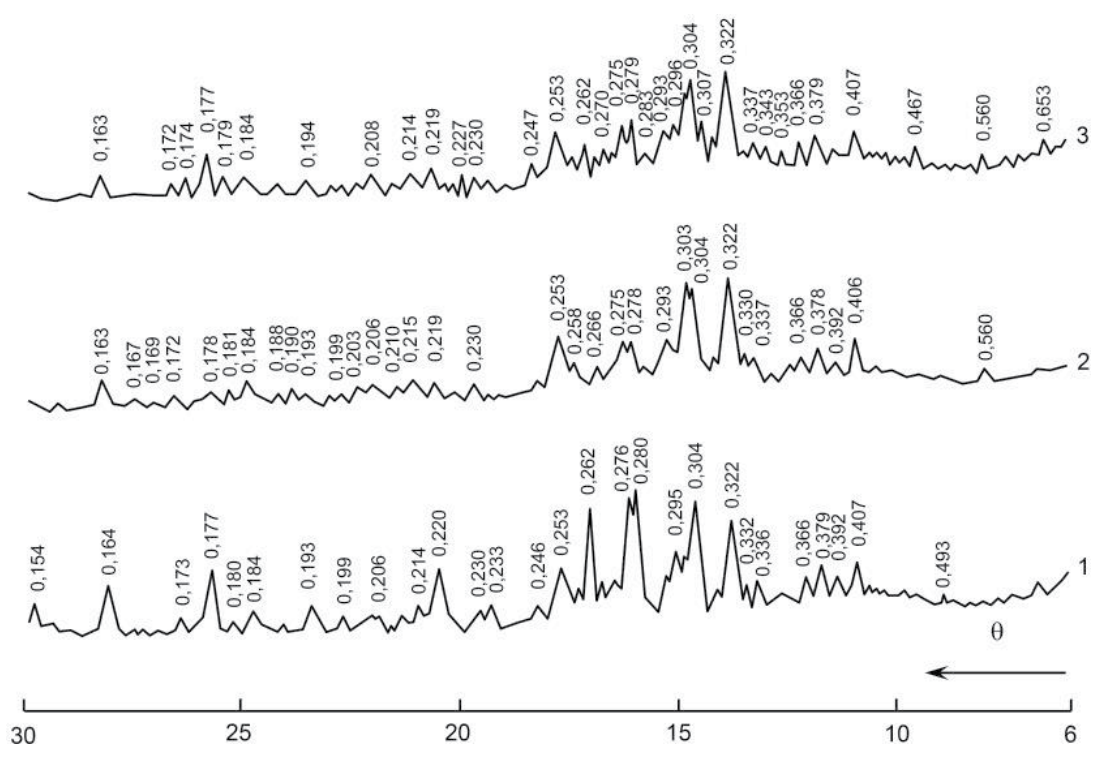

Figure 9.

XRD patterns of the ITZ of model systems: (1) "Portland cement-metakaolin-basalt"; (2) "Portland cementmetakaolin-basalt-water"; (3) "Portland cement-metakaolin-basalt-soluble silicate." Curing conditions360 days at $t=65 \pm 3{ }^{\circ} \mathrm{C}$ and $\mathrm{RH}=100 \%$.

at curve 3 appears lines of the $\mathrm{Na}_{2} \mathrm{O} \cdot \mathrm{Al}_{2} \mathrm{O}_{3} \cdot 4 \mathrm{SiO}_{2} \cdot 2 \mathrm{H}_{2} \mathrm{O}(\mathrm{d}=0.56-0.343-0.293-$ $0.252-0.174 \mathrm{~nm})$ and $2 \mathrm{Na}_{2} \mathrm{O} \cdot 2 \mathrm{CaO} \cdot 5 \mathrm{Al}_{2} \mathrm{O}_{3} \cdot 10 \mathrm{SiO}_{2} \cdot 10 \mathrm{H}_{2} \mathrm{O}(\mathrm{d}=0.654-0.467-0.353-$ $0.283-0.270 \mathrm{~nm}$ ) phases.

Introducing of the metakaolin additive to ordinary Portland cement mixes with water significantly not changing diffraction picture (Figure 9, curve 3). However, as it seems from Figure 9, in the ITZ significantly reducing content of $\mathrm{Ca}$, and also 
The Influence of Interfacial Transition Zone on Strength of Alkali-Activated Concrete DOI: http://dx.doi.org/10.5772/intechopen.90929

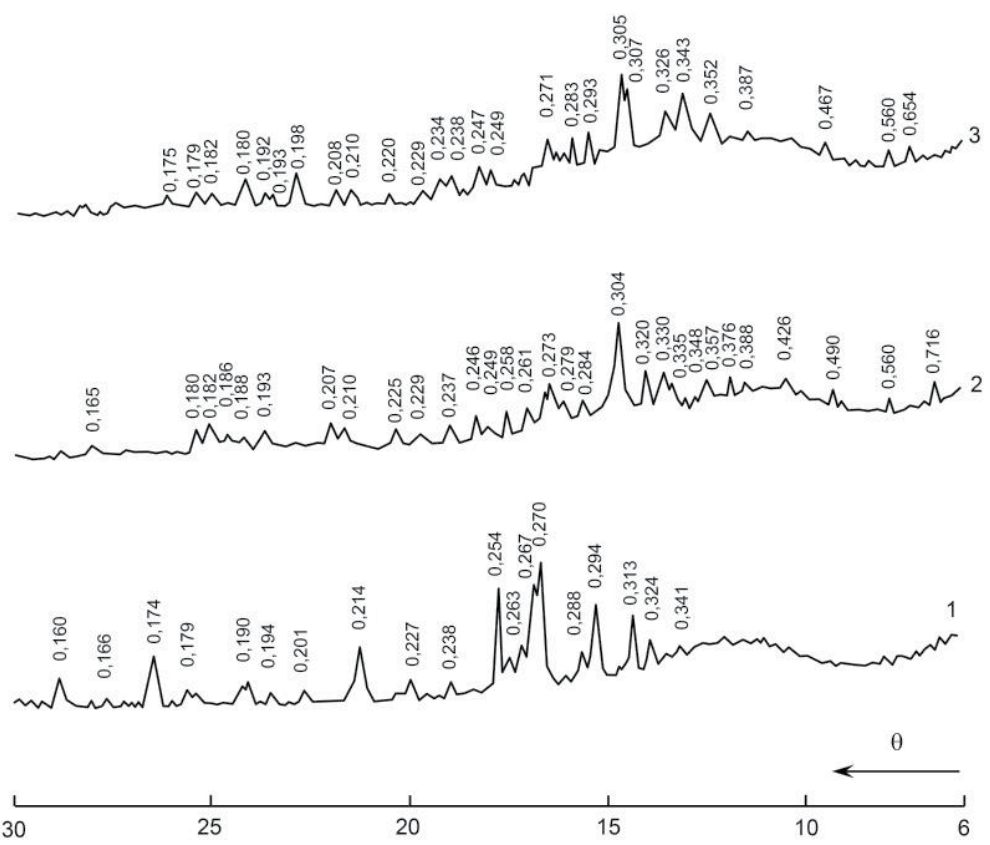

Figure 10.

XRD patterns of the ITZ of model systems: (1) "Portland cement-perlite"; (2) "Portland cement-perlite-water"; (3) "Portland cement-perlite-soluble silicate." Curing conditions- 360 days at $t=65 \pm 3{ }^{\circ} \mathrm{C}$ and $\mathrm{RH}=100 \%$.

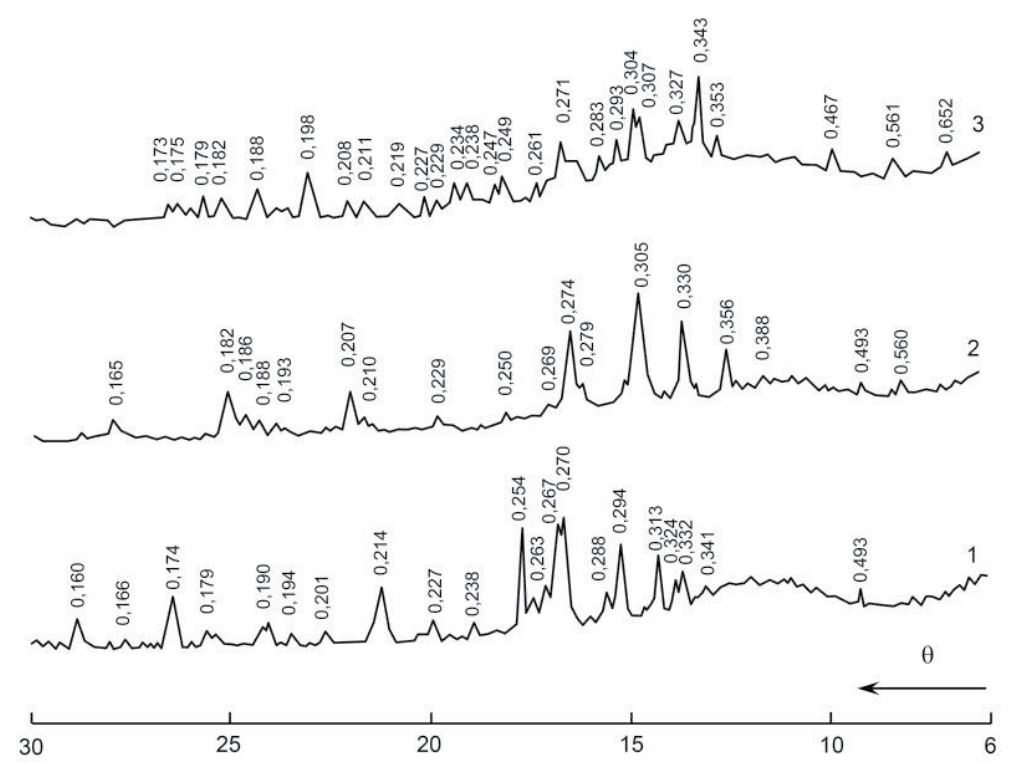

Figure 11.

XRD patterns of the ITZ of model systems: (1) "Portland cement-metakaolin-perlite"; (2) "Portland cementwater-metakaolin-perlite"; (3) "Portland cement-soluble silicate + metakaolin-perlite." Curing conditions360 days at $t=65 \pm 3{ }^{\circ} \mathrm{C}$ and $\mathrm{RH}=100 \%$.

hydroxide ions, significantly reduces risk of corrosion processes in the ITZ in destructive form. This correlates well with the data in [9], corresponding to which the presence of active alumina in the Portland cement stone significantly reduces alkali concentration in the pore space of Portland cement stone.

The last consideration is absolutely confirmed in the case of replacement of ordinary Portland cement by alkali-activated Portland cement with the metakaolin additive. Thus, 


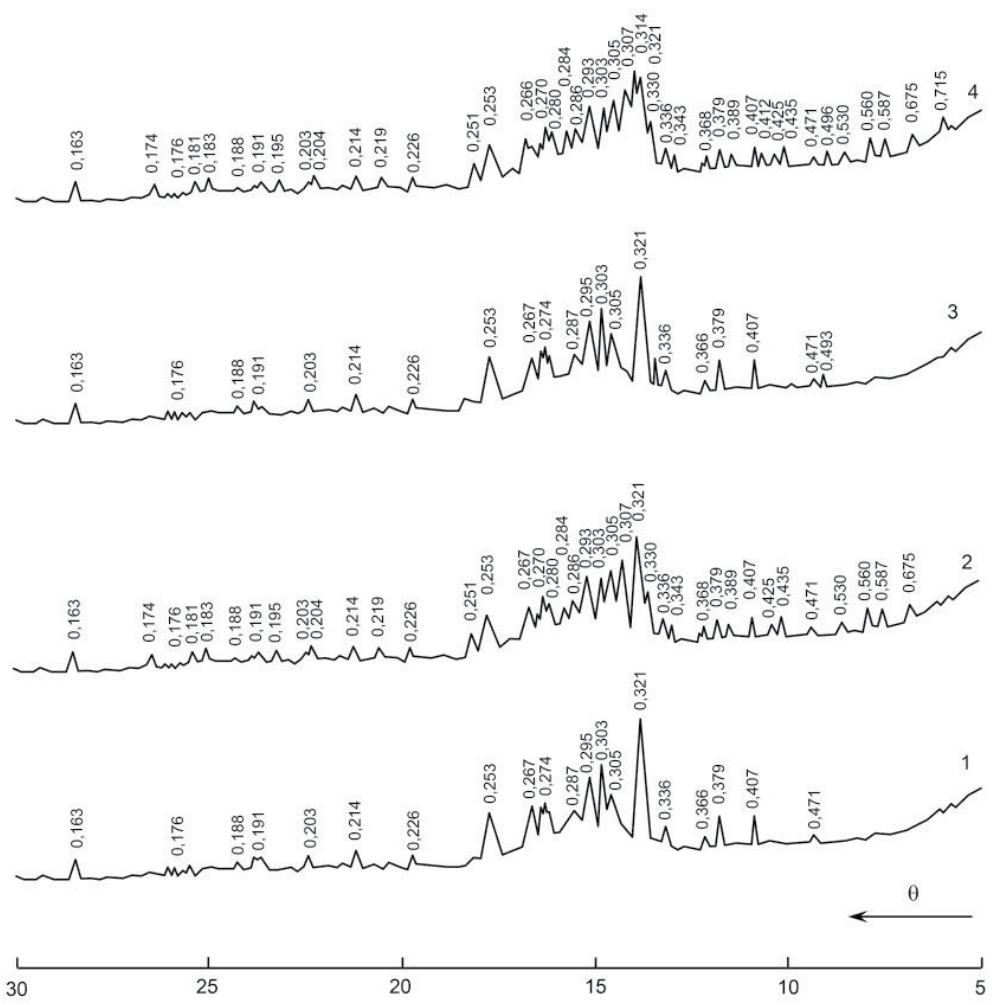

Figure 12.

XRD patterns of the ITZ of model systems: (1) “GBFS-basalt”; (2) “GBFS-soluble silicate-basalt”; (3) “GBFSmetakaolin-basalt”; (4) “GBFS-soluble silicate-metakaolin-basalt." Curing conditions-36o days at $t=65 \pm 3^{\circ} \mathrm{C}$ and $\mathrm{RH}=100 \%$.

according to Figure 9, curve 2, hydration of Portland cement deepens, forming finegrained crystalline structure. The zeolite-like new formations- $\mathrm{Na}_{2} \mathrm{O} \cdot \mathrm{Al}_{2} \mathrm{O}_{3} \cdot 4 \mathrm{SiO}_{2} \cdot 2 \mathrm{H}_{2} \mathrm{O}$ $(\mathrm{d}=0.561-0.343-0.293-0.251-0.174 \mathrm{~nm}), \mathrm{Na}_{2} \mathrm{O} \cdot \mathrm{Al}_{2} \mathrm{O}_{3} \cdot 3 \mathrm{SiO}_{2} \cdot 2 \mathrm{H}_{2} \mathrm{O}(\mathrm{d}=6.53-5.87-4.36-$ $2.86-2.19 \mathrm{~nm})$ and $2 \mathrm{Na}_{2} \mathrm{O} \cdot 2 \mathrm{CaO} \cdot 5 \mathrm{Al}_{2} \mathrm{O}_{3} \cdot 10 \mathrm{SiO}_{2} \cdot 10 \mathrm{H}_{2} \mathrm{O}(\mathrm{d}=0.654-0.467-0.353-0.285-$ $0.269 \mathrm{~nm}$ ) —are synthesizing in the ITZ, which is proven by increasing of $\mathrm{Al}$ and $\mathrm{Na}$ and reducing of Ca content in the ITZ.

Use of alkali-activated slag cement is characterized by the more active synthesis in the alkali-susceptible aggregate/cement stone ITZ of the low-basic hydrate new formations as silicate, so as alumina silicate composition (Figure 12). This process becomes greatly active exactly in the presence of metakaolin additive. Thus, in the model system of the ITZ "alkali-activated slag cement stone-basalt aggregate," there are fixed zeolite-like new formations of the $\mathrm{Na}_{2} \mathrm{O} \cdot \mathrm{Al}_{2} \mathrm{O}_{3} \cdot 4 \mathrm{SiO}_{2} \cdot 2 \mathrm{H}_{2} \mathrm{O}(\mathrm{d}=0.56-$ $0.343-0.293-0.252-0.174 \mathrm{~nm})$ and $\mathrm{Na}_{2} \mathrm{O} \cdot \mathrm{Al}_{2} \mathrm{O}_{3} \cdot 3 \mathrm{SiO}_{2} \cdot 2 \mathrm{H}_{2} \mathrm{O}(\mathrm{d}=0.653-0.587-$ $0.436-0.286-0.219 \mathrm{~nm})$ types as well as low-basic silicate hydrates CSH(I) $(\mathrm{d}=0.530-0.304-0.28-0.181 \mathrm{~nm})$ and xonotlite $6 \mathrm{CaO} \cdot 6 \mathrm{SiO}_{2} \cdot \mathrm{H}_{2} \mathrm{O}(\mathrm{d}=0.425-0.389-$ $0.368-0.330-0.307-0.284-0.270-0.204-0.195 \mathrm{~nm}$ ). That is confirmed by analysis of the elemental distribution in the ITZ of the taken composition (Figure 12). Thus, in the presence of metakaolin additive, reflexes of the mentioned above new formations became sharper. Moreover, there is fixed new formation $2 \mathrm{Na}_{2} \mathrm{O} \cdot 2 \mathrm{CaO} \cdot 3 \mathrm{Al}_{2} \mathrm{O}_{3} \cdot 10 \mathrm{SiO}_{2} \cdot 12 \mathrm{H}_{2} \mathrm{O}$ type $(\mathrm{d}=0.715-0.495-0.412-0.314-0.266 \mathrm{~nm})$, which is also classified as zeolites (Figure 12, curve 4).

Metakaolin additive reduces Ca content not only in the ITZ but also in cement stone, showing possibility of synthesis of the aluminosilicate hydrates of mixed sodium-calcium composition not only in the ITZ but in the cement matrix as well. 
It is known that there exist no absolutely inert aggregates. All aggregates more or less react to the cement stone. But in some cases in the ITZ, destructive processes took place, with "negative effect of corrosion," meaning with gradual destruction, and in other cases-structure formation processes with the "positive effect of corrosion," meaning without destruction and moreover with improvement state of the ITZ.

In the alkali-activated cement concretes, especially cements containing the metakaolin additive, at the surface of the aggregates appears a dense film of new formation mostly represented by alumina silicate hydrate composition, which prevents further admission of new portions of alkalis to the aggregate. Thus a way, due to the partial corrosion of aggregate at the initial stages, on its surface it is forming protective dense and impermeable capsule.

On the contrary to alkali-activated cement concretes, in ordinary Portland cement concretes, gel-like new formations in the ITZ act as semipermeable films. That means that alkalis are able to easy penetrate through new formations to aggregate grain and new products of corrosion are accumulating under that film, increasing osmotic pressure and leading to the degradation of ITZ and destruction of concrete in general.

Thus, in the result of provided studies, the effectiveness of introduction into the alkali-activated cement compositions with alkali-susceptible aggregates of active alumina represented by metakaolin was proven, which makes it possible to bond extra alkalis effectively and regulate structure formation processes in the cement stone/alkali-susceptible aggregate ITZ, using partial surface corrosion of the aggregate for synthesis in the interface of the zeolite-like hydrate phases.

\subsection{Physical-mechanical properties of concretes}

\subsubsection{Concrete mixture "Portland cement + water"}

The results of determination of compressive and bending strengths of the concrete specimens made using the Portland cement as well as their autogenous deformations are given in Table 4.

Taking into account data from the Table 4, depending upon curing conditions of compositions and using as a criteria corrosion in the ITZ and the admissible values of expansion of the specimens not exceeding $1 \mathrm{~mm} / \mathrm{m}(0.1 \%)$ [42] with simultaneous consideration of their strength characteristics, the following conclusions can be drawn.

\subsubsection{Curing conditions: $t=20^{\circ} \mathrm{C}, \mathrm{RH}=100 \%$}

Curing of Portland cement specimens at $\mathrm{t}=20^{\circ} \mathrm{C}$ more or less considerable corrosion in all control ages (28-180 days) for all composition is not fixed, not depending upon composition of the specimens. Strength (compressive and bending) characteristics of the specimens in these curing conditions at the given ages tended to increase.

Reducing of shrinkage in the concretes made with basalt aggregates at an age of 90 and 180 days compared to that in 28-day age is set as insignificant, which witnesses the beginning of a reverse process, meaning free development of corrosion processes in the ITZ of the concretes made using aggregates.

The metakaolin additive considerably decreased autogenous deformations of shrinkage of the Portland cement containing specimens compared to additive-free compositions, losing at the same time strength of the specimens compared to additive-free compositions. 


\begin{tabular}{|c|c|c|c|c|c|c|c|c|}
\hline \multirow[t]{2}{*}{$\mathrm{L} / \mathrm{S}^{\mathbf{1}}$} & \multirow[t]{2}{*}{ Additive } & \multirow[t]{2}{*}{ Temperature, ${ }^{\circ} \mathrm{C}$} & \multicolumn{3}{|c|}{$\begin{array}{l}\text { Strength compressive/ } \\
\text { bending, MPa, age, days }\end{array}$} & \multicolumn{3}{|c|}{$\begin{array}{c}\text { Shrinkage (expansion) } \\
\text { deformations, } \mathrm{mm} / \mathrm{m} \text {, age, days }{ }^{2}\end{array}$} \\
\hline & & & 28 & 90 & 180 & 28 & 90 & 180 \\
\hline \multicolumn{9}{|c|}{ "Portland cement + water + crushed basalt rock" } \\
\hline \multirow[t]{2}{*}{36} & - & 20 & $\frac{70.1}{7.1}$ & $\frac{76.0}{9.3}$ & $\frac{77.7}{11.1}$ & -0.50 & -0.44 & -0.40 \\
\hline & & 65 & $\frac{75.9}{9.4}$ & $\frac{72.8}{9.2}$ & $\frac{70.9}{9.0}$ & +0.15 & +0.69 & +1.08 \\
\hline \multirow[t]{2}{*}{38} & Metakaolin & 20 & $\frac{64.2}{6.8}$ & $\frac{75.2}{6.7}$ & $\frac{76.6}{7.0}$ & -0.41 & -0.30 & -0.23 \\
\hline & & 65 & $\frac{69.0}{7.2}$ & $\frac{56.3}{6.9}$ & $\frac{52.0}{6.7}$ & +0.10 & +0.52 & +0.74 \\
\hline
\end{tabular}

"Portland cement + water + chopped waste of basalt fiber production"

\begin{tabular}{ccccccccc}
\hline 45 & - & 20 & $\frac{39.8}{10.2}$ & $\frac{40.8}{12.2}$ & $\frac{45.9}{11.1}$ & -0.46 & -0.41 & -0.30 \\
\cline { 3 - 7 } & 65 & $\frac{52.7}{11.9}$ & $\frac{50.3}{7.8}$ & $\frac{48.4}{7.9}$ & +0.11 & +0.55 & +0.99 \\
\hline \multirow{2}{*}{48} & Metakaolin & 20 & $\frac{45.4}{9.8}$ & $\frac{50.8}{12.1}$ & $\frac{52.2}{11.6}$ & -0.38 & -0.34 & -0.20 \\
\cline { 3 - 7 } & 65 & $\frac{46.4}{8.9}$ & $\frac{40.0}{7.9}$ & $\frac{38.8}{7.2}$ & +0.13 & +0.48 & +0.59 \\
\hline
\end{tabular}

"Portland cement + water + crushed perlite rock"

\begin{tabular}{|c|c|c|c|c|c|c|c|c|}
\hline \multirow[t]{2}{*}{51} & - & 20 & $\frac{68.2}{7.0}$ & $\frac{76.0}{9.0}$ & - & -0.51 & -0.56 & - \\
\hline & & 65 & $\frac{73.8}{9.3}$ & $\frac{72.8}{9.0}$ & - & +0.11 & +0.23 & - \\
\hline \multirow[t]{2}{*}{53} & Metakaolin & 20 & $\frac{66.4}{6.8}$ & $\frac{73.1}{6.9}$ & - & -0.48 & -0.49 & - \\
\hline & & 65 & $\frac{53.0}{7.1}$ & $\frac{54.3}{6.9}$ & - & +0.07 & +0.18 & - \\
\hline
\end{tabular}

"Portland cement + water + expanded perlite"

\begin{tabular}{ccccccccc}
\hline 37 & - & 20 & $\frac{31.0}{1.4}$ & $\frac{34.1}{2.0}$ & - & -0.65 & -0.70 & - \\
\cline { 3 - 7 } & & 65 & $\frac{36.4}{2.5}$ & $\frac{37.2}{1.9}$ & - & -0.41 & -0.35 & - \\
\hline 38 & Metakaolin & 20 & $\frac{29.2}{2.0}$ & $\frac{35.0}{2.3}$ & - & -0.53 & $-0.59-$ & -0.27 \\
\cline { 3 - 7 } & & 65 & $\frac{36.1}{2.4}$ & $\frac{37.7}{2.3}$ & - & -0.29 & & - \\
\hline
\end{tabular}

${ }^{1} L / S$, liquid-to-cement ratio.

${ }^{2}$ A minus sign (-), shrinkage; plus sign (+), expansion of the specimens in relation to a basic measurement.

Table 4.

Strength characteristics and autogenous deformations of the concretes using cement system "OPC + water" vs. curing conditions and concrete mixture design.

\subsubsection{Curing conditions: $t=65^{\circ} \mathrm{C}, R H=100 \%$}

The most considerable changes, so as it was expected, were found in the structure of the ITZ of the specimens made using Portland cement curing at $t=65^{\circ} \mathrm{C}$. So, 
The Influence of Interfacial Transition Zone on Strength of Alkali-Activated Concrete DOI: http://dx.doi.org/10.5772/intechopen.90929

\begin{tabular}{|c|c|c|c|c|c|c|c|c|}
\hline \multirow[t]{2}{*}{$\mathrm{L} / \mathrm{S}^{1}$} & \multirow[t]{2}{*}{ Additive } & \multirow[t]{2}{*}{ Temperature ${ }^{\circ} \mathrm{C}$} & \multicolumn{3}{|c|}{$\begin{array}{l}\text { Strength compressive/ } \\
\text { bending, MPa, age, days }\end{array}$} & \multicolumn{3}{|c|}{$\begin{array}{c}\text { Shrinkage (expansion) } \\
\text { deformations, } \mathbf{m m} / \mathrm{m} \text {, age, } \\
\text { days }^{2}\end{array}$} \\
\hline & & & 28 & 90 & 180 & 28 & 90 & 180 \\
\hline \multicolumn{9}{|c|}{ "Portland cement + soluble silicate + crushed basalt rock" } \\
\hline \multirow[t]{2}{*}{354} & - & 20 & $\frac{59.8}{5.1}$ & $\frac{76.0}{4.8}$ & $\frac{128.2}{6.4}$ & -0.63 & -0.55 & -0.51 \\
\hline & & 65 & $\frac{115.5}{7.0}$ & $\frac{128.1}{6.5}$ & $\frac{132.0}{6.4}$ & +0.18 & +0.70 & +0.81 \\
\hline \multirow[t]{2}{*}{354} & Metakaolin & 20 & $\frac{92.1}{5.0}$ & $\frac{106.0}{5.3}$ & $\frac{117.7}{6.3}$ & -0.61 & -0.49 & -0.36 \\
\hline & & 65 & $\frac{111.1}{7.1}$ & $\frac{126.9}{7.7}$ & $\frac{130.0}{7.3}$ & +0.09 & +0.45 & +0.48 \\
\hline \multicolumn{9}{|c|}{ "Portland cement + soluble silicate + chopped off-size basalt fibers" } \\
\hline \multirow[t]{2}{*}{454} & - & 20 & $\frac{44.0}{8.9}$ & $\frac{69.6}{8.7}$ & $\frac{81.9}{10.9}$ & -0.47 & -0.41 & -0.38 \\
\hline & & 65 & $\frac{93.9}{10.3}$ & $\frac{93.5}{11.4}$ & $\frac{88.7}{9.1}$ & +0.12 & +0.63 & +0.72 \\
\hline \multirow[t]{2}{*}{454} & Metakaolin & 20 & $\frac{62.4}{5.8}$ & $\frac{73.3}{6.9}$ & $\frac{88.0}{9.3}$ & -0.58 & -0.60 & -0.57 \\
\hline & & 65 & $\frac{90.9}{11.2}$ & $\frac{103.8}{12.0}$ & $\frac{109.8}{11.8}$ & +0.10 & +0.44 & +0.46 \\
\hline
\end{tabular}

"Portland cement + high-modulus soluble silicate + crushed perlite rock"

\begin{tabular}{|c|c|c|c|c|c|c|c|c|}
\hline \multirow[t]{2}{*}{51} & - & 20 & $\frac{75.2}{6.1}$ & $\frac{79.3}{5.9}$ & - & -1.10 & -1.15 & - \\
\hline & & 65 & $\frac{88.0}{6.8}$ & $\frac{91.0}{7.4}$ & - & +0.16 & +0.18 & - \\
\hline \multirow[t]{2}{*}{52} & Metakaolin & 20 & $\frac{73.7}{6.2}$ & $\frac{76.1}{6.2}$ & - & -0.64 & -0.67 & - \\
\hline & & 65 & $\frac{88.9}{7.1}$ & $\frac{93.0}{7.3}$ & - & -0.04 & +0.10 & - \\
\hline
\end{tabular}

"Portland cement + high-modulus soluble silicate + expanded perlite"

\begin{tabular}{|c|c|c|c|c|c|c|c|c|}
\hline \multirow[t]{2}{*}{36} & - & 20 & $\frac{39.9}{2.0}$ & $\frac{42.3}{2.3}$ & - & -1.22 & -1.26 & - \\
\hline & & 65 & $\frac{44.4}{2.7}$ & $\frac{45.5}{2.5}$ & - & -0.68 & -0.66 & - \\
\hline \multirow[t]{2}{*}{37} & Metakaolin & 20 & $\frac{37.7}{2.1}$ & $\frac{43.5}{2.2}$ & - & -0.79 & -0.83 & - \\
\hline & & 65 & $\frac{44.2}{2.7}$ & $\frac{47.0}{2.8}$ & - & -0.38 & -0.34 & - \\
\hline
\end{tabular}

${ }^{1} L / S$, liquid-to-cement ratio.

${ }^{2}$ A minus sign (-), shrinkage; plus sign (+), expansion.

Table 5 .

Strength characteristics and autogenous deformations of the concretes using cement system "OPC + soluble glass" vs. curing conditions and concrete mixture design.

at an age of 180 days in the concrete specimens with crushed basalt rock without admixture, extremely high (dangerous) values of expansion-1.08-1.17 mm/mwere found, reflexing in some drop of strength characteristics, both compressive 
and bending, of the specimens compared to those concretes of 28-day age at $\mathrm{t}=65^{\circ} \mathrm{C}$. The addition of the metakaolin additive allowed to reduce the expansion values at an age of 180 days to the safer level $-0.74 \mathrm{~mm} / \mathrm{m}$.

\begin{tabular}{|c|c|c|c|c|c|c|c|c|}
\hline \multirow[t]{2}{*}{$L / S^{1}$} & \multirow[t]{2}{*}{ Additive } & \multirow[t]{2}{*}{ Temperature, ${ }^{\circ} \mathrm{C}$} & \multicolumn{3}{|c|}{$\begin{array}{c}\text { Strength compressive/ } \\
\text { bending, } \mathrm{MPa} \text {, age, days }\end{array}$} & \multicolumn{3}{|c|}{$\begin{array}{c}\text { Shrinkage (expansion) } \\
\text { deformations, } \mathrm{mm} / \mathrm{m} \text {, age, } \\
\text { days }^{2}\end{array}$} \\
\hline & & & 28 & 90 & 180 & 28 & 90 & 180 \\
\hline \multicolumn{9}{|c|}{ “GBFS + high-modulus soluble silicate + crushed basalt stone" } \\
\hline \multirow[t]{2}{*}{0.36} & - & 20 & $\frac{61.7}{6.1}$ & $\frac{78.0}{6.0}$ & $\frac{108.0}{7.2}$ & -1.21 & -1.01 & -0.78 \\
\hline & & 65 & $\frac{103.3}{8.0}$ & $\frac{116.0}{7.4}$ & $\frac{120.1}{7.0}$ & +0.58 & +0.88 & +0.91 \\
\hline \multirow[t]{2}{*}{0.36} & Metakaolin & 20 & $\frac{81.3}{6.2}$ & $\frac{95.0}{6.3}$ & $\frac{103.7}{6.6}$ & -1.19 & -0.85 & -0.73 \\
\hline & & 65 & $\frac{100.3}{8.8}$ & $\frac{115.0}{8.2}$ & $\begin{array}{c}119.8 \\
9.0\end{array}$ & +0.44 & +0.46 & +0.47 \\
\hline \multicolumn{9}{|c|}{ "GBFS + high-modulus soluble silicate + glassy waste product of basalt fibers production" } \\
\hline \multirow[t]{2}{*}{0.45} & - & 20 & $\frac{92.0}{10.7}$ & $\frac{94.9}{10.9}$ & $\frac{95.0}{11.1}$ & -0.83 & -0.86 & -0.82 \\
\hline & & 65 & $\frac{102.0}{12.0}$ & $\frac{100.3}{9.0}$ & $\frac{97.2}{8.9}$ & +0.63 & +0.86 & +0.87 \\
\hline \multirow[t]{2}{*}{0.45} & Metakaolin & 20 & $\frac{78.0}{12.1}$ & $\frac{88.7}{11.9}$ & $\frac{99.8}{12.0}$ & -0.66 & -0.63 & -0.65 \\
\hline & & 65 & $\frac{108.0}{10.8}$ & $\frac{111.0}{11.3}$ & $\frac{115.2}{11.2}$ & +0.41 & +0.44 & +0.45 \\
\hline \multicolumn{9}{|c|}{ "GBFS + high-modulus soluble silicate + crushed perlite rock" } \\
\hline \multirow[t]{2}{*}{0.50} & - & 20 & $\frac{81.0}{5.9}$ & $\frac{85.0}{5.8}$ & - & -1.17 & -1.20 & - \\
\hline & & 65 & $\frac{94.8}{6.9}$ & $\frac{97.0}{7.3}$ & - & +0.12 & +0.15 & - \\
\hline \multirow[t]{2}{*}{0.51} & Metakaolin & 20 & $\frac{79.8}{6.0}$ & $\frac{82.0}{6.1}$ & - & -0.71 & -0.73 & - \\
\hline & & 65 & $\frac{95.2}{7.2}$ & $\frac{98.9}{7.2}$ & - & -0.13 & +0.09 & - \\
\hline \multicolumn{9}{|c|}{ "GBFS + high-modulus soluble silicate + expanded perlite" } \\
\hline \multirow[t]{2}{*}{0.35} & - & 20 & $\frac{37.0}{1.7}$ & $\frac{40.2}{2.2}$ & - & -1.33 & -1.40 & - \\
\hline & & 65 & $\frac{42.4}{2.5}$ & $\frac{43.3}{2.4}$ & - & -0.75 & -0.67 & - \\
\hline \multirow[t]{2}{*}{0.36} & Metakaolin & 20 & $\frac{35.4}{2.0}$ & $\frac{40.3}{2.3}$ & - & -0.87 & -0.89 & - \\
\hline & & 65 & $\frac{42.1}{2.1}$ & $\frac{44.8}{2.5}$ & - & -0.37 & -0.34 & - \\
\hline
\end{tabular}

Table 6.

Strength characteristics and autogenous deformations of the concretes using cement system "GGBS + soluble glass" vs. curing conditions and concrete mixture design. 


\subsubsection{Concrete mixture "Portland cement + soluble silicate"}

The results of determination of compressive and bending strengths of the concrete specimens made using the alkali-activated Portland cement as well as their autogenous deformations are given in Table 5 . The characteristics are varied depending on composition and curing conditions.

\subsubsection{Concrete mixture "GBFS + soluble silicate"}

The results of determination of compressive and bending strengths of the concrete specimens made using the alkali-activated slag cement with high-modulus soluble silicate, sodium metasilicate, and sodium carbonate as alkaline activators as well as their autogenous deformations are given in Table 6 . The characteristics are varied depending on composition and curing conditions.

The development of shrinkage/expansion deformations of the concrete containing "GBFS + soluble silicate" as cement and crushed basalt rock as aggregate suggested to conclude that at almost complete similarity of regularities, they differ from that made using the alkali-activated Portland cement only in absolute values of characteristics-those are in some cases a little bit higher. A value of maximal expansion of the concrete containing "GBFS + soluble silicate" as cement and crushed basalt rock as aggregate within the ranges of experiment was 0.45$0.91 \mathrm{~mm} / \mathrm{m}$ (Table 6) and those in the case of the alkali-activated Portland cement $-0.46-0.81 \mathrm{~mm} / \mathrm{m}$ (Table 5).

A character of strength gain of all compositions for all temperature regimes is stable and without any drops (Table 6).

\section{Conclusions}

The processes of structure formation in the ITZ "alkali-activated cementartificial aggregate" are studied. It is set that the interface between them practically disappears, which indicates about penetration of the elements and blurring the border between the cement stone and the aggregate.

It is established that the positive result of the processes of such interaction of the substances of cement elements and aggregate is the formation of alkaline and alkaline-alkali-earth alumina silicate hydrates-analogs of natural zeolites, transforming a destructive process of concrete corrosion into the constructive.

Comparative studies of the processes of the structure formation of the ITZ in the alkali-activated cement concretes with different alkali-susceptible aggregates confirmed that $\mathrm{Al}_{2} \mathrm{O}_{3}$ plays a determining role in these constructive processes.

It is shown that the addition of the metakaolin additive as an $\mathrm{Al}_{2} \mathrm{O}_{3}$-containing additive provides inhibition of alkaline corrosion processes, which is confirmed by long-term testing of strength characteristics and deformation (shrinkage/expansion) of concretes using different alkali-activated cements and alkali-susceptible natural aggregates. 


\section{Author details}

Pavel Krivenko*, Oleh Petropavlovskyi, Oleksandr Kovalchuk and

Oleksandr Gelevera

Scientific Research Institute for Binders and Materials, Kyiv National University of Construction and Architecture, Kyiv, Ukraine

*Address all correspondence to: pavlo.kryvenko@gmail.com

\section{IntechOpen}

(C) 2020 The Author(s). Licensee IntechOpen. This chapter is distributed under the terms of the Creative Commons Attribution License (http://creativecommons.org/licenses/ by/3.0), which permits unrestricted use, distribution, and reproduction in any medium, provided the original work is properly cited. (cc) BY 


\section{References}

[1] Stark J, Wicht B. Alkali-KieselsäureReaktion. Weimar: Verlag; 2008

[2] Krivenko PV. Peculiarity of formation of the contact zone (slag alkaline cement mineral wool). In: Second International Symposium on Cement and Concrete Technology; Istanbul, Turkey; 2000. pp. 553-559

[3] Schäfer E. Einfluss der reaktionen verschiedener zementhauptbestandteile auf den alkalihaushalt der porenlösung des zementsteins [Diss]. Verlag Nicht Ermittelbar; 2006

[4] Ramlochan T, Thomas M, Gruber KA. The effect of metakaolin on alkali-silica reaction in concrete. Cement and Concrete Research. 2000; 30(3):339-344

[5] Krivenko PV. Structure-forming processes in the interfacial transition zone "alkali activated slag cementaggregate”. Tsement, Leningrad, USSR; 1991;11-13:64-70

[6] Stark J, Wicht B. Dauerhaftigkeit von Beton. Basel, Switzerland: Birkhauser Verlag; 2001

[7] Visser JHM. Fundamentals of alkalisilica gel formation and swelling: Condensation under influence of dissolved salts. Cement and Concrete Research. 2018;105:18-30. DOI: 10.1016/ j.cemconres.2017.11.006

[8] Lindgård J, Andiç-Çakir Ö, Fernandes I, Rønning TF, Thomas MDA. Alkali-silica reactions (ASR): Literature review on parameters influencing laboratory performance testing. Cement and Concrete Research. 2012;42:223-243. DOI: 10.1016/j. cemconres.2011.10.004

[9] Fournier B, Bérubé M-A. Alkaliaggregate reaction in concrete: $\mathrm{A}$ review of basic concepts and engineering implications. Canadian Journal of Civil
Engineering. 2000;27:167-191. DOI: 10.1139/199-072

[10] Gifford PM, Gillott JE. Alkali-silica reaction (ASR) and alkali-carbonate reaction (ACR) in activated blast furnace slag cement (ABFSC) concrete. Cement and Concrete Research. 1996; 26:21-26

[11] Pignatelli R, Comi C, Monteiro PJM. A coupled mechanical and chemical damage model for concrete affected by alkali-silica reaction. Cement and Concrete Research. 2013;53:196-210. DOI: 10.1016/j.cemconres.2013.06.011

[12] Poyet S, Sellier A, Capra B, Foray G, Torrenti JM, Cognon H, et al. Chemical modelling of alkali silica reaction: Influence of the reactive aggregate size distribution. Materials and Structures. 2007;40:229-239. DOI: 10.1617/ s11527-006-9139-3

[13] Dunant CF, Scrivener KL. Micromechanical modelling of alkalisilica-reaction-induced degradation using the AMIE framework. Cement and Concrete Research. 2010;40: 517-525. DOI: 10.1016/j.cemconres. 2009.07.024

[14] Esposito R, Hendriks MAN. Literature review of modelling approaches for ASR in concrete: A new perspective. European Journal of Environmental and Civil Engineering. 2017;8189:1-21. DOI: 10.1080/ 19648189.2017.1347068

[15] Multon S, Sellier A, Cyr M. Chemomechanical modeling for prediction of alkali silica reaction (ASR) expansion. Cement and Concrete Research. 2009; 39:490-500. DOI: 10.1016/j.cemconres. 2009.03.007

[16] Li K, Coussy O. Concrete ASR degradation: From material modeling to 
structure assessment. Concrete Science and Engineering. 2002;4:35-46.

Available from: https://www.researchga te.net/publication/281155830

[17] Gartiser S, Rudolf R.

Machbarkeitsstudie zur Formulierung von Anforderungen fuer ein neues Umweltzeichen fuer Enteisungsmittel fuer Strassen und Wege. In: Anlehnung an DIN EN ISO 14024-

Forschungsbericht 20095 308/04; UBA-FB 000404. TEXTE 09/03; 2003

[18] Glukhovsky V. Soil Silicates. Kyiv: Gossizdat; 1959

[19] Glukhovsky V, Krivenko P, et al. Alkaline and Alkaline-Alkali-earth Hydraulic Binders and Concretes. Kyiv: Vyscha Shkola; 1979

[20] Krivenko P. Why alkaline activation-60 years of the theory and practice of alkali-activated materials. Journal of Ceramic Science and Technology. 2017;8(3):323-333

[21] Stanton T. Expansion of concrete through reaction between cement and aggregate. Proceedings of the American Society for Engineering Education. 1940;66:1781-1811

[22] Malek RIA, Roy DM. Effect of slag cements and aggregate type on alkaliAggregate reaction and its mechanism. In: Proceedings of the 6th International Conference, Alkalies in Concrete, Research and Practice; Technical University of Denmark, Copenhagen; 22-25 June, 1983. pp. 223-230

[23] Krivenko P et al. Mechanism of preventing the alkali-aggregate reaction in alkali activated cement concretes. Cement and Concrete Composites. 2014;45:157-165

[24] Li Z et al. Mitigating the autogenous shrinkage of alkali-activated slag by metakaolin. Cement and Concrete Research. 2019;122:30-41
[25] Shi C. Alkali-aggregate reaction of alkali-slag cements. Concrete and Cement Products. 1988;4:14-16

[26] Nixon PJ, Sims I. RILEM

Recommendations for the Prevention of Damage by Alkali-Aggregate Reactions in New Concrete Structures. RILEM State-of-the-Art Report. Dordrecht, The Netherlands: Springer; 2016

[27] Lee G, Ling TC, Wong YL, Poon CS. Effects of crushed glass cullet sizes, casting methods and pozzolanic materials on ASR of concrete blocks. Construction and Building Materials. 2011;25(5):2611-2618

[28] Shi C, Shi Z, Hu X, Zhao R, Chong $\mathrm{L}$. A review on alkali-aggregate reactions in alkali-activated mortars/ concretes made with alkali-reactive aggregates. Materials and Structures. 2015;48:621-628

[29] Fernandez-Jimenez A, Puertas F. The alkali-silica reaction in alkaliactivated granulated slag mortars with reactive aggregate. Cement and Concrete Research. 2002;32:1019-1024

[30] Puertas F, Palacios M, Gil-Maroto A, Vazquez T. Alkali-aggregate behaviour of alkali-activated slag mortars: Effect of aggregate type. Cement and Concrete Composites. 2009;31:277-284

[31] Garcia-Lodeiro I, Palomo A, Fernandez-Jimenez A. Alkali-aggregate reaction in activated fly ash systems. Cement and Concrete Research. 2007; 37:175-183

[32] Angulo-Ramírez DE, De Gutierrez RM, Medeiros M. Alkaliactivated Portland blast furnace slag cement mortars: Performance to alkaliaggregate reaction. Construction and Building Materials. 2018;179:49-56

[33] Hay R, Ostertag CP. On utilization and mechanisms of waste aluminium in 
mitigating alkali-silica reaction (ASR) in concrete. Journal of Cleaner Production. 2019;212:864-879

[34] Rashidian-Dezfouli H, Afshinnia K, Rangaraju PR. Efficiency of ground glass fiber as a cementitious material, in mitigation of alkali-silica reaction of glass aggregates in mortars and concrete. Journal of Building Engineering. 2018;15:171-180

[35] Shi Z, Shi C, Zhang J, Wan S, Zhang Z, Ou Z. Alkali-silica reaction in waterglass-activated slag mortars incorporating fly ash and metakaolin. Cement and Concrete Research. 2018; 108:10-19

[36] Shi Z, Shi C, Wan S, Ou Z. Effect of alkali dosage on alkali-silica reaction in sodium hydroxide activated slag mortars. Construction and Building Materials. 2017;143:16-23

[37] Saha AK, Sarker PK. Mitigation of the potential alkali-silica reaction of FNS using ground FNS as a supplementary binder. Advances in Cement Research. 2019. Ahead of Print

[38] Saha AK, Sarker PK. Potential alkali silica reaction expansion mitigation of ferronickel slag aggregate by fly ash. Structural Concrete. 2018;19:1376-1386

[39] Saha AK, Khan MNN, Sarker PK, Shaikh FA, Pramanik A. The ASR mechanism of reactive aggregates in concrete and its mitigation by fly ash: A critical review. Construction and

Building Materials. 2018;171:743-758

[40] Leemann A, Le Saout G, Winnefeld F, Rentsch D, Lothenbach B. Alkali-silica reaction: The influence of calcium on silica dissolution and the formation of reaction products. Journal of the American Ceramic Society. 2011; 94:1243-1249

[41] Rumynina G, Stenchenko S. O geotermalnom sinteze shhelochnykh, shhelochezemelnykh i shhelochnoshhelochnozemelnykh alyumosilikatov v kontaktnikh zonakh shlakoshhelochnogo betona. In: Proceedings of the Poverkhnostnye Yavleniya v Disperstnykh Sistemakh. Naukova Dumka: Kiev; 1974

[42] Petrenko I, Rumynina G.

Korrelyaczionnyj analiz pri issledovanii kontaktnykh zon v shlakoshhelochny'kh betonakh. In: Proceedings of the Primenenie Matematicheskogo Modelirovaniya Dlya Optimizaczii Tekhnologicheskikh i Konstruktivnykh Reshenij v Stroitel'stve; Odessa; 1975 



\title{
Concrete Microstructure Characterization and Performance
}

\author{
Cristian Druta
}

\begin{abstract}
Microstructural characteristics such as the interfacial transition zone (ITZ) and cracking patterns from compressive strength testing are main features that characterize concrete behavior. Certain materials such as blast furnace slag or fly ash introduced in the concrete mix aid in improving its strength and durability. Others such as nanosilica particles may affect only the microstructure of the paste without making any significant improvement in the strength of the ITZ or pasteaggregate bond. Additionally, in situ investigation of the microstructures of fresh cement paste can greatly enhance knowledge of the development properties of concrete at an early age (e.g., setting and hydration), which can be helpful for improvement of the quality of concrete. Common technologies such as Scanning Electron Microscope (SEM) are currently employed in petrographic analysis of cementitious materials and concrete microstructure.
\end{abstract}

Keywords: microstructure, damage, interface, compressive strength, transition zone

\section{Introduction}

Although the technology of producing concrete is relatively simple the microstructure of the resultant product is highly complex. Concrete microstructure is defined as the microscopical detailing of the concrete components from its macrostructure. To better understand the mechanisms that intrinsically control durability of Portland cement concrete (PCC) it is necessary to define and understand those factors affecting concrete microstructure. Typically, the microstructure is a consequence of both the concrete formulation and the processes taking place during mixing, placing and curing. Past studies have already established that deterioration originates in the concrete at the micro- or sub-microscopic level, i.e., in its microstructure $[1,2]$.

Several current studies on concrete failure indicated that an often major cause of variability of the properties and performance of the hardened concrete was the inadequate dispersion of cement paste in the fresh concrete [3]. In this way, harmful impurities that permeate or diffuse throughout the hardened concrete may initiate its deterioration due to a variation in the ability of the concrete to restrict their transport. Moreover, the cement particles tend to irregularly coagulate and cluster in the mix leading to uneven regions of dense and high porosity hardened paste because of poor dispersion and inhomogeneity during mixing and placing. This holds true even for high density microstructures resulting when using of low 
water/cement (w/c) ratios. The development of a dense homogeneous microstructure is also affected by the pattern packing of the cement particles and aggregate. Thus, the microstructure developed during the mixing, setting and hardening process will directly affect the resulting properties and performance of concrete. Microstructural development is also controlled by a combination of uniform dispersion of cement particles, mineral admixtures and aggregates along with cement hydration. Moreover, developments occurring at a micro- or sub-microscopic level in the concrete matrix influence aspects such as early or retarded setting, drying shrinkage, permeability, frost damage, excessive bleeding, and/or inadequate strength. Understanding the concrete behavior at these small scale levels is the initial and most important step toward achieving the means to control its microstructure and influence on performance [3].

Additionally, the examination of concrete microstructure either in transmitted or reflected energy is a valuable tool in the study of concrete microstructure. These methods can be used in inspecting various concrete specimens to determine potential defects or material characteristics. For example, water/cement ratios can be determined by comparing paste porosity with a series of carefully prepared reference samples. In this chapter, the physical interface between aggregate and cement paste and the aggregate fracture were studied. The Scanning Electron Microscope (SEM) capable of acquiring micro-scale level images was used to quantify the ITZ cracking for normal and self-consolidating concrete. The X-ray Computed Tomography (CT) system was employed to visualize the coarse aggregate distribution in the concrete specimens and their fracture pattern. SEM is a device that creates highly magnified 2-D images of structures to analyze their various components interactions and potential flaws using accelerated electrons. The X-ray CT technique uses high energy beams which penetrate samples of different thicknesses then stacks up the acquired images to reconstruct a 3-D model of the scanned sample for structural analysis.

\section{Research methodology}

The first part of this section addresses the development of microstructure and its control of performance with a focus on the normal (NC) and self-consolidating concrete (SCC). The second part details the damage caused by steel projectiles of different sizes impacting large concrete specimens at various speeds.

\subsection{Concrete microstructure characterization and performance comparison}

This research study had four objectives: (1) To investigate the bonding between coarse aggregates and cement paste; (2) To evaluate fresh SCC test methods slump flow and U-tube; (3) To compare NC and SCC splitting tensile strength and compressive strength; and (4) To visualize the distribution of coarse aggregate in NC and SCC concrete specimens. The SEM imaging was employed to investigate the bonding between the cement paste and coarse aggregate of the two types of concrete by studying their interfacial transition zone (ITZ). The ITZ, which is mostly comprised of calcium hydroxide, is a narrow and fuzzy cement paste area surrounding the aggregate particles. Being a very porous region due to a high water content, the ITZ tends to increase with the aggregate size. Moreover, due to its weaker structure compared to the bulk paste in the concrete this transition zone directly affects the concrete properties, especially its strength and stiffness. The aggregate distribution throughout the specimens and the fracture patterns of the NC and SCC specimens tested for compressive strength were visualized using the 
X-ray tomography imaging system. The standard compressive strength test method depicts typical fracture patterns indicative of the mix strength or existing problems with the testing equipment.

Additional information on materials and admixtures used for preparing the specimens can be found in Druta et al. [4]. Table 1 presents the mix proportions for casting the SCC specimens. The type I Portland cement was replaced by blast furnace slag (25\%), fly ash (15\%), and silica fume (5\%). Similar mix proportions and equal amount batches were prepared for casting cylindrical NC samples and conduct slump tests without incorporating any mineral admixtures.

\begin{tabular}{lcccccc}
\hline $\begin{array}{l}\text { W/C } \\
\text { ratio }\end{array}$ & $\begin{array}{c}\text { Water } \\
(\mathbf{k g})\end{array}$ & $\begin{array}{c}\text { Cement } \\
(\mathbf{k g})\end{array}$ & $\begin{array}{c}\text { Fine Agg. } \\
(\mathbf{k g})\end{array}$ & $\begin{array}{c}\text { Coarse Agg. } \\
(\mathbf{k g})\end{array}$ & $\begin{array}{c}\text { HRWR } \\
(\mathbf{m l})\end{array}$ & $\begin{array}{c}\text { VMA } \\
(\mathbf{m l})\end{array}$ \\
\hline 0.3 & 3 & 5.5 & 16.3 & 21.1 & 340 & 0 \\
\hline 0.4 & 4 & 5.5 & 16.3 & 21.1 & 100 & 15 \\
\hline 0.45 & 4.5 & 5.5 & 16.3 & 21.1 & 80 & 25 \\
\hline 0.5 & 5 & 5.5 & 16.3 & 21.1 & 50 & 50 \\
\hline 0.6 & 6 & 5.5 & 16.3 & 21.1 & 20 & 100 \\
\hline
\end{tabular}

Table 1.

Self-consolidating concrete mix design.

Splitting tensile and compressive strength tests were performed on both types of concrete, whereas U-box and slump flow tests were conducted to evaluate the filling ability and the self-compactability of the SCC, respectively [5, 6]. The slump flow test, currently used for fresh SCC, is a good indicator of concrete consistency and ability to self-consolidate $[6,7]$. For SCC, instead of measuring the drop in height of the fresh concrete the average of two perpendicular diameters (R1 and R2) of the spread concrete is determined. A good self-consolidation is achieved for a spread of $600 \mathrm{~mm}$ or larger, up to $800 \mathrm{~mm}$, within a time period of $60 \mathrm{~s}$ [4].

Figure 1 illustrates the filling ability apparatus that comprises an approximately $700 \mathrm{~mm}$ tall tube with a round bottom divided into two equal sections by a middle wall incorporating a sliding gate. Once the left section is filled with concrete the sliding gate is lifted allowing the fresh concrete to flow freely in the right section through a specially designed grate provided with closely spaced rebars. The height levels of the concrete in both sections are measured, then followed by a height difference calculation. An adequate SCC filling and compactability is achieved if a difference of $30 \mathrm{~mm}$ or less between $\mathrm{H} 1$ and $\mathrm{H} 2$ is recorded.

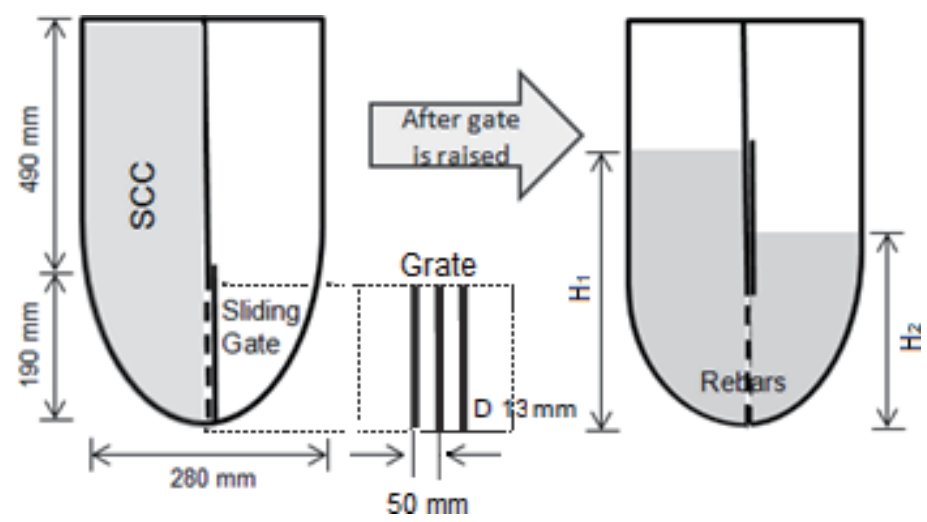

Figure 1.

U-box schematic for testing SCC. 


\subsection{Evaluating the bond between coarse aggregate and cement paste}

The SCC was extensively researched in the past decades to find ways to enhance its performance $[8,9]$. The general focus of those efforts was the improvement of the interface properties between paste and aggregates. That improvement has led to the manufacturing and use of higher strength and enhanced durability concretes $[10,11]$. The physical interface between aggregate and cement paste and the aggregate fracture patterns were investigated in the second phase of this study. First, the ITZ cracking behavior for the two types of concrete was quantified using the SEM capable of acquiring micro-scale level images. Secondly, a visualization of the coarse aggregate distribution in the specimens and their fracture pattern were performed by employing the X-ray Computed Tomography (CT) system [2]. In addition, a comparison of the number of air voids in the NC and SCC was conducted on six rectangular samples with the dimensions of $70 \times 70 \times 12 \mathrm{~mm}$. The samples were cut from concrete cylinders at $0.3,0.45$, and 0.6 water-cement ratios and analyzed under a digital stereo-zoom microscope.

To determine the characteristics of the interfaces between aggregates and paste for both SCC and NC, small samples of $25.5 \mathrm{~mm}$ diameter and $4 \mathrm{~mm}$ thick were obtained from untested cylinders of both types of concretes at three different

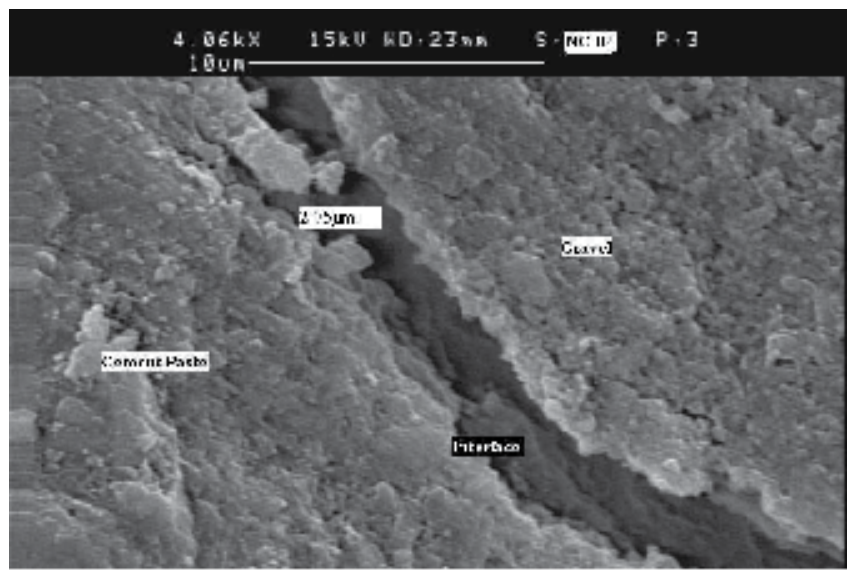

(a)

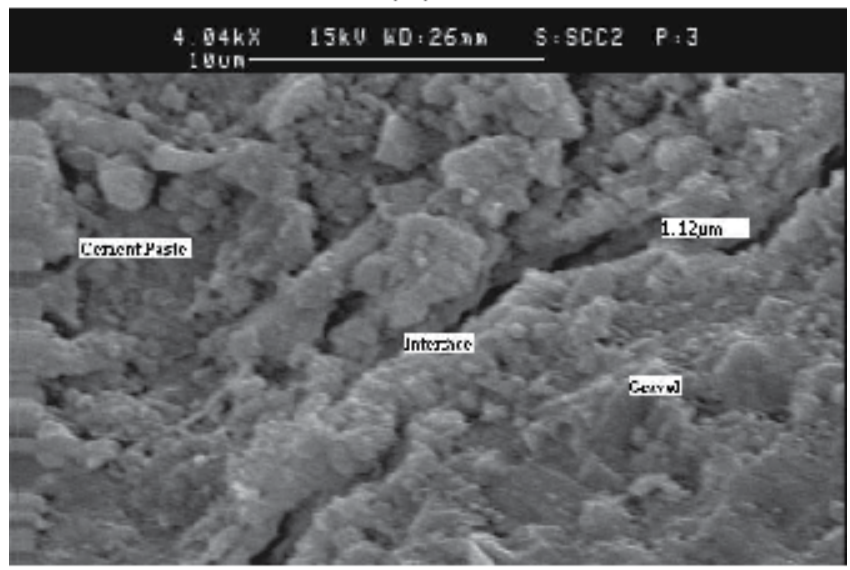

(b)

Figure 2.

Photomicrographs of (a) normal concrete and $(b)$ self-consolidating concrete physical interfaces $(w / c=0.40)$. 
water-cement ratios of $0.3,0.4$, and 0.6 after 60 days of curing. The SEM was used to capture pictures of each w/c ratio sample at different ITZ locations. Smaller crack widths within their physical interface were observed from the acquired SEM photomicrographs for SCC samples compared the NC samples as showed in Figure 2. This finding indicated that a better aggregate-paste bonding was achieved in the transition zone for SCC compared to NC.

The use of silica fume led to a lower porosity and less growth of calcium hydroxide in the ITZ resulting in an increase in tensile and compressive strength of the SCC when compared to NC. Typically, silica fume has a "filler effect" in the concrete structure that reduces internal bleeding in the fresh concrete while enhancing the aggregate-paste bond strength [12]. It also renders its structure more homogeneous due to a reduction of the large pores in the ITZ. The split tensile strength tests revealed a larger number of broken aggregate particles in SCC than in $\mathrm{NC}$ when the fractured surfaces of the concrete samples were inspected. Furthermore, the strength of the ITZ was also enhanced by the addition of silica fume, as some of the aggregate fracture occurred at the physical interface instead within the transition zone.

Table 2 shows the specimens' cracks widths from the images acquired at each water/cement ratio. The SEM image analysis indicated that a tendency for the cracks to shrink existed for lower w/cm ratios. However, a certain relationship between the interface crack widths and the water-cement ratios for either type of concrete was not found. Establishing a quantitative relationship between the crack width and strength, if any, has to be further investigated.

\begin{tabular}{lcc}
\hline w/c ratio & NC width range $(\mu \mathrm{m})$ & SCC width range $(\mu \mathrm{m})$ \\
\hline 0.3 & $0.62-1.75$ & $0.01-0.75$ \\
\hline 0.4 & $0.63-5.63$ & $0.01-1.12$ \\
\hline 0.6 & $1.23-3.38$ & $0.01-0.61$ \\
\hline
\end{tabular}

Table 2.

Interfaces crack widths for normal and self-consolidating concretes.

\subsection{Analysis of fracture patterns}

The X-ray computed tomography (CT) was employed to examine the internal structure and fracture patterns of the concrete specimens tested in compression [4]. Using the CT radiographic inspection technique objects are reconstructed from their cross sectional images. Over the years, nondestructive evaluations using CT imaging of the microstructure of concrete [13], soil [14, 15], rock [16], and asphalt concrete $[17,18]$ have been largely used. Compression tested specimens have exhibited similar fracture patterns, i.e., cone at one end and vertical columns, as types 2 and 3 patterns described in the ASTM C 39 test method. Figure 3 shows tomographic images of the 3D reconstructed SCC and NC specimens acquired from the top, middle and bottom. Images reveal concrete structural damage and fracture patterns along with the aggregate fracture throughout the tested specimens. The SCC specimens did not exhibit any segregation.

Several sectional images of $100 \times 200 \mathrm{~mm}$ tensile split cylindrical specimens were visually inspected to identify fractured aggregate. The analysis showed that the percentage of fractured aggregate for SCC was about 15-25\% (9-15 out of 60) while for NC was around 10\% (4-6 out of 60) after determining that each section facet contained around 60 coarse aggregate particles. The number of broken aggregate particles from three tested specimens was averaged to calculate the fracture 

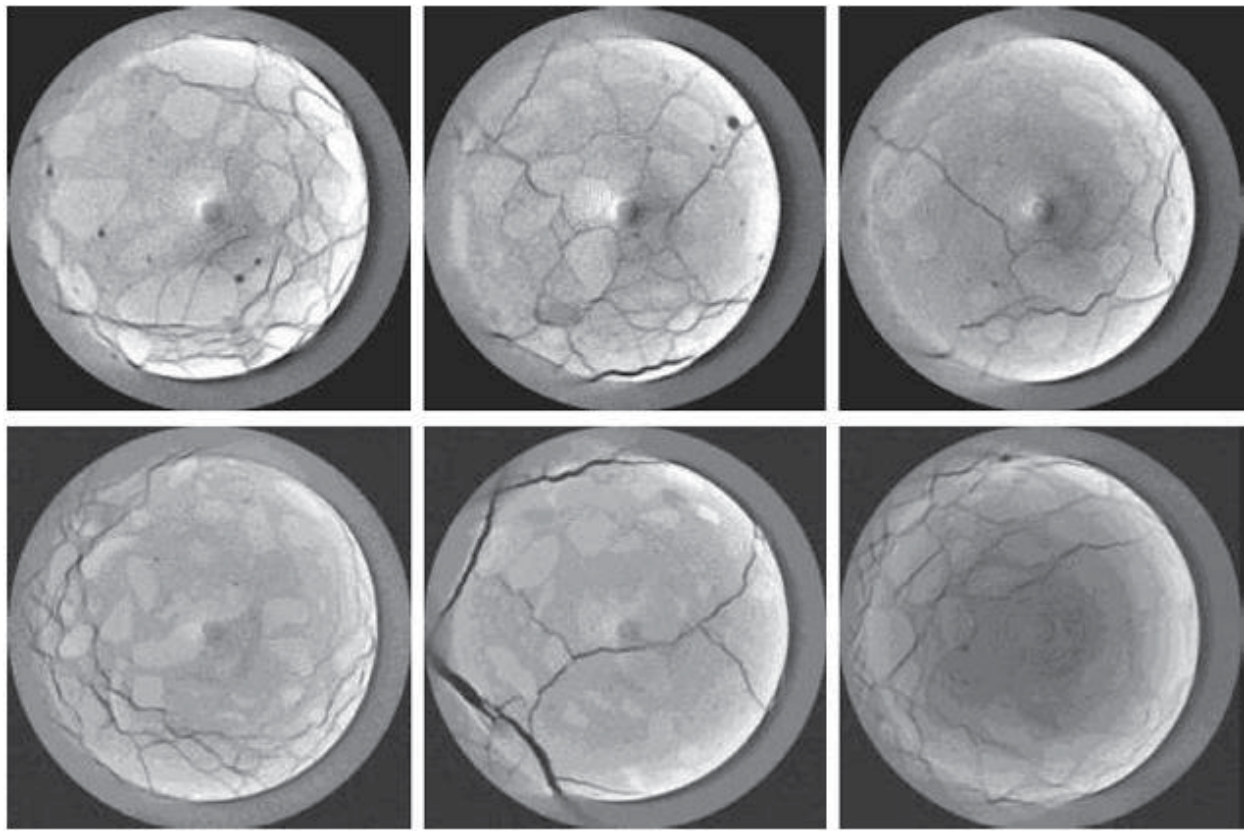

Figure 3.

Tomographic images of SCC (top row) and NC (bottom row) specimens after being tested in compression (from left to right: top, middle, and bottom of specimen).

percentages. The greater number of fractured aggregate in the SCC specimens was another indication of a better bonding between aggregate and cement paste.

\subsection{Evaluation of air void content}

The air entrainment was reduced in the SCC mix with the addition of finely divided mineral admixtures, such as fly ash and silica fume. Samples with the dimensions of $80 \times 80 \times 12 \mathrm{~mm}$ were acquired from both types of concretes at w/cm ratios of $0.30,0.45$, and 0.60 to study their air-entrained properties. Air voids larger than 200 microns only were considered for the analysis. The measurements showed that SCC samples exhibited half the amount of air voids compared to NC. Visual analyses of the "air voids" sizes and shapes revealed that SCC had smaller and more round-shaped voids than NC which presented slightly larger and irregular shaped voids (by 15-20\%) (Figure 4).

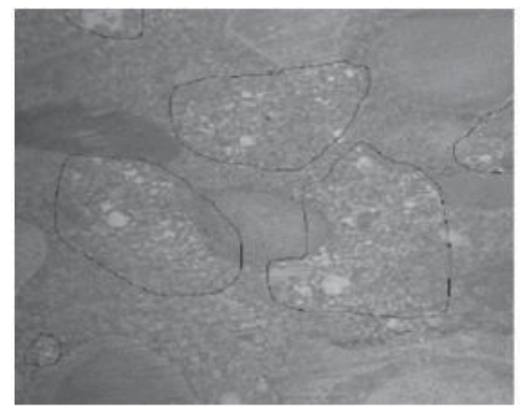

(a)

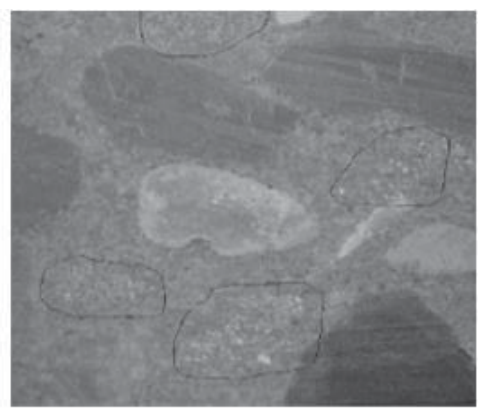

(b)

Figure 4.

Distribution of air voids (white spots) in: (a) NC and (b) SCC.

Moreover, while the air voids in the SCC appeared more clustered in certain areas of the cut specimen, the voids in NC were relatively well dispersed in the 
specimens. These data indicate that the lower air void content also contributed to an increase in strength of the SCC as cracks initiate more easily in the cement paste with higher air voids. Some of these air voids represent "flaws" in the cement paste at the aggregate-paste boundary possibly forming microcracks or "bond cracks" in the ITZ which ultimately lead to the failure of the concrete due to the propagation of microcracks under localized tensile stresses.

\subsection{Conclusions}

This research verified that SCC achieved self-compactability and adequate flow under its own weight, without external vibration or compaction based on the mix proportion parameters and the materials used. The study also showed that splitting tensile and compressive strengths in SCC were higher than those of normal vibrated concrete due to the addition of chemical and mineral admixtures. Compressive strength had an average increase of over $60 \%$, whereas the splitting tensile strength showed a $30 \%$ increase. The ratio between the splitting and compressive strength was similar to values found in the literature. Also, a better bonding between aggregate and cement paste was achieved in SCC due to the use of chemical and mineral admixtures, as the material has shown smaller aggregate-matrix interface microcracks than normal concrete. This characteristic affected both the splitting tensile and compressive strengths. Another indicator of the stronger aggregate-paste bonding was the greater percentage of the fractured aggregate in SCC (20-25\%) compared to the $10 \%$ for normal concrete. Moreover, when compared to NC, the number of air voids in SCC was lower and they appeared relatively smaller and more rounded. These factors have contributed as well to the increase in strength of the SCC.

\section{Concrete microstructure damage by projectile impact}

Penetration of projectiles into concrete target was investigated in this research by using both experimental and simulation methods. The over-all objectives of the project included: (a) Building up an experimental facility to conduct the penetration test; (b) Developing of a rational constitutive model to incorporate distributed damage effects; (c) Enhancing of the model implementation by combining the Finite Element Method (FEM) and the Discrete Element Method (DEM) so that post-fracture behavior can be simulated; and (d) Developing of methods to backcalculate model constants from comparing experimental with simulation results.

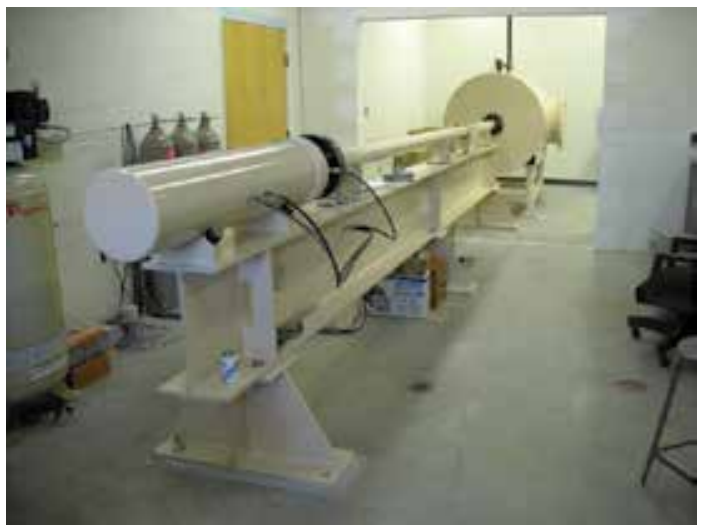

Figure 5 .

Gas operated facility for testing concrete samples. 
The equipment assembled for testing concrete specimens of different sizes and strengths is showed in Figure 5. It contains a gas tank that can be filled at various pressures, a launch tube, a gas expansion tank, and specimen housing chamber.

A three-dimensional penetration model was constructed using ABAQUS as shown in Figure 6. The concrete target was tentatively modeled as $40 \times 40 \times$ $100 \mathrm{~cm}$ blocks and penetrated by high speed projectiles made of rigid materials. No deformation is assumed for the projectile when penetrating the target. The concrete is assumed to be an elasto-plastic material with damage property. 8-node linear brick elements are used for the FEM mesh. An unbounded boundary domain is defined by using 8-node linear infinite elements, which are connected with concrete specimen at the periphery (Figure 6).

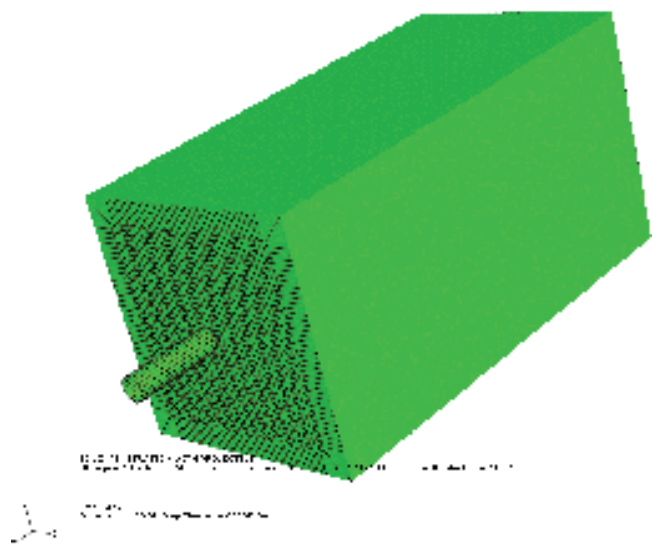

Figure 6.

FEM modeling of concrete target impacted by projectile.

The microstructure of concrete specimen is considered by assigning different material properties to the three components of the mixture, aggregate, mortar (hydration products plus fine aggregate particles) and air void. These components are discriminated by utilizing image analysis techniques shown in Figure 7(a) and (b). Pixel intensity value determines what component each pixel belongs to. When meshing the domain to be modeled, the properties of the material between two scanned images are assumed to be the same as the front image.

\subsection{Concrete damage}

A reduction in the elastic stiffness of concrete is the result of damage typically associated with the failure mechanisms of the concrete (cracking and crushing). According to the scalar-damage theory, the isotropic stiffness degradation is characterized by a single degradation variable, $d$. Based on continuum damage mechanics notions, the effective stress is defined as Eq. (1).

$$
\bar{\sigma}=\mathrm{D}_{0}^{e l}:\left(\varepsilon-\varepsilon^{p l}\right)
$$

The Cauchy stress is related to the effective stress through the scalar degradation relation per Eq. (2).

$$
\sigma=(1-d) \bar{\sigma}
$$

The stress-strain relations are governed by scalar damaged elasticity given in Eq. (3), where $\mathrm{D}_{0}{ }^{e l}$ is the elastic stiffness of the undamaged material; $\mathrm{D}^{e l}=(1-d)$ 

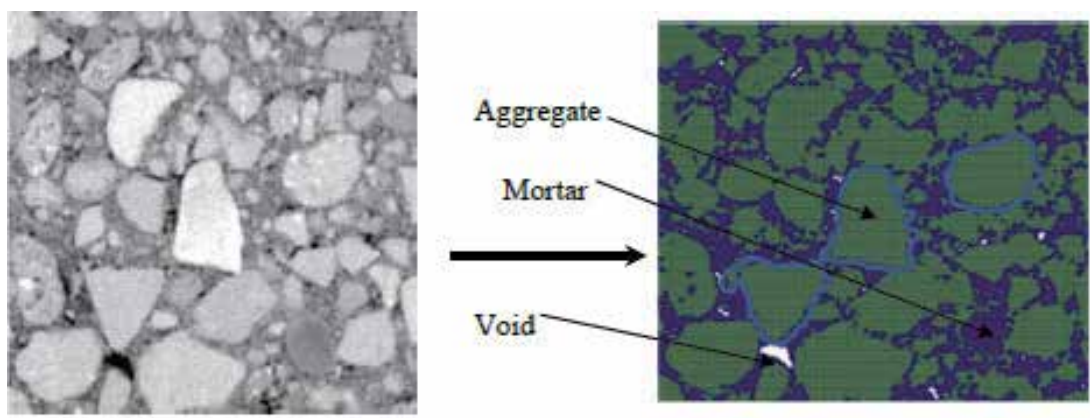

(a)
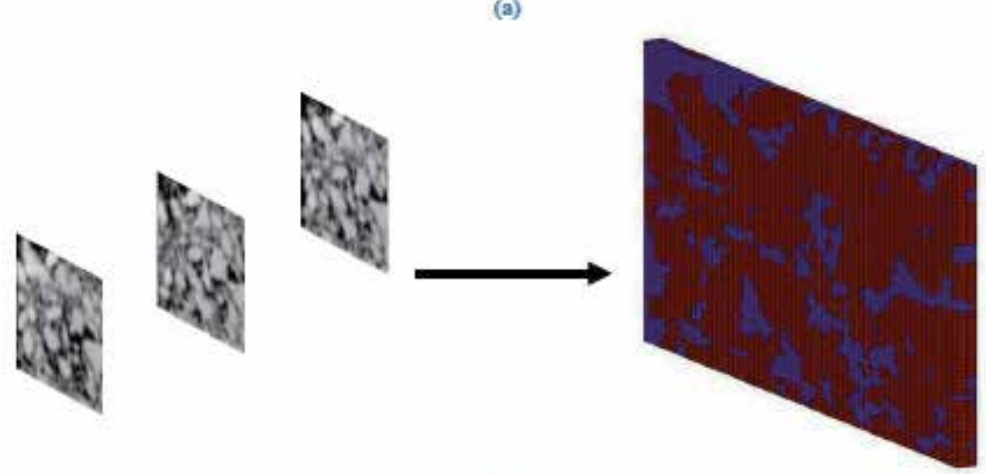

(b)

Figure 7.

$3 D$ microstructure of concrete specimen (a) and the image-based reconstruction (b).

$\mathrm{D}_{0}{ }^{e l}$ is the elastic stiffness due to damage; and $d$ is the scalar stiffness variable due to degradation. A $d$ value of zero indicates undamaged material while one shows a fully damaged material.

$$
\sigma=(1-d) \mathrm{D}_{0}^{e l}:\left(\varepsilon-\varepsilon^{p l}\right)
$$

The constitutive behavior of concrete was illustrated using the concrete damaged plasticity model. The model describes the inelastic behavior of concrete based on the concepts of isotropic damaged elasticity in combination with isotropic tensile and compressive plasticity. Moreover, the scalar damaged elasticity combined with the non-associated multi-hardening plasticity describe the irreversible damage that occurs during the fracturing process. The main ingredients of the model are summarized below.

\subsection{Strain rate decomposition}

Additive strain rate decomposition is assumed for the rate-independent model according to Eq. (4).

$$
\dot{\varepsilon}=\dot{\varepsilon}^{e l}(\text { elastic })+\dot{\varepsilon}^{p l}(\text { elastic })
$$

For any given cross-section of the material, the ratio of the effective loadcarrying area (i.e., the total area minus the damaged area) to the overall section area is represented by the $(1-d)$ factor. Thus, the effective stress is equivalent to the Cauchy stress, $\sigma$, if there is no damage, $d=0$. When damage occurs, however, the effective stress is larger than the Cauchy stress because the external loads are supported by the effective stress area. Therefore, the plasticity problem can be 
conveniently formulated using the effective stress component. The development of the degradation variable is governed by a set of hardening variables, $\tilde{\varepsilon}^{p l}$ (plastic strains), and the effective stress, $d=\mathrm{d}\left(\bar{\sigma}, \tilde{\varepsilon}^{p l}\right)$.

\subsection{Hardening variables}

Two hardening variables, $\tilde{\varepsilon}_{\mathrm{t}}^{p l}$ and $\tilde{\varepsilon}_{\mathrm{c}}^{p l}$, defined as equivalent plastic strains in tension and compression, respectively, can be used to independently characterized a material damaged states in tension and compression. Generally, increasing values of the hardening variables may lead to microcracking and crushing in concrete. These variables also control the degradation of the elastic stiffness and the progression of the yield surface, as well as affecting the dissipated fracture energy required to generate microcracks.

Also, a yield function, $\mathrm{F}\left(\bar{\sigma}, \tilde{\varepsilon}^{p l}\right)$, that represents a surface in effective stress space, will determines the states of failure or damage. For the inviscid plasticdamage model, it is represented by Eq. (5).

$$
\mathrm{F}\left(\bar{\sigma}, \tilde{\varepsilon}^{p l}\right)<0
$$

\section{DEM modeling}

Penetration test is also modeled using the Discrete Element Method (DEM). DEM was first introduced by Cundall [19] in the early 1970s. It was originally applied on rocks, then extended to granular material, which triggered much wider uses in different kinds of material like fluid, soil, and composites. DEM has not received much attention in penetration simulation before 1990. Before 1990, Heuze's overview $[20,21]$ indicated that only 3 computer programs based their theory on DEM. However, DEM has its intrinsic advantages, especially related to penetration simulation, when compared to other numerical simulation methods, such as FEM-based on continuum meshing. DEM allows transitioning from continuum to discontinuum to be easily simulated, while handling fracturing and large deformation conveniently.

The geometry of a projectile is one of the key factors affecting the penetration process. A number of studies have addressed the shape effects including those on flat nose [22-24], ogive [25], and spherical ball [26]. Zhu and Zhang [27] compared the effects on penetration using projectiles of ogive and flat nose shape. While most researchers consider projectiles as rigid, others investigated the effects due to a deformable projectile. As for the impact velocity, Nishida [26] studied the penetration at a low velocity of $16 \mathrm{~m} / \mathrm{s}$ while most others focused on velocities larger than $100 \mathrm{~m} / \mathrm{s}$.

DEM is also used in the theoretical formulation of PFC3D (a particle modeling software) known as particle-flow model. Particles of arbitrary shapes that displace independent of each other and occupy a finite amount of space constitute the basic element of the model. The model uses a finite normal stiffness to represent the contact stiffness, while the interaction between the particles, which are assumed rigid, is defined using a soft contact approach. Force-Displacement Law and Motion Law are the two primary rules to define the mechanical computation. The former law is used to calculate the contact force and momentum between two entities based on their relative displacement. It should be noted that the momentum part could only be modeled in the parallel bond model for contacts. The second law, also referred as Newton's second law, governs how force and momentum determine the particle translational and rotational motion. 


\subsection{Projectile model}

In order to build the required cone shape mono-size balls are decreased in size from tail to tip. To keep a compact status inside the projectile the overlap of balls and large stiffness were purposely assigned. The balls forming the projectile were clumped into one object using the PFC3Dclump function. The created object does not allow any relative movements for the balls constituting the projectile. The friction between projectile and the target varies with their relative velocity and is defined by Eq. (6), where the static friction was determined by using the idealized infinite velocity Chen [28].

$$
f=f_{\text {inf }}+\left(f_{\text {stat }}-f_{\text {inf }}\right) e^{\gamma * v e l}
$$

where $f_{\text {inf }}$ is the friction with idealized infinite velocity and $f_{\text {stat }}$ is the static friction.

Figure 8 illustrates a projectile model used to simulate penetration velocity versus depth relationship established by Forrestal et al. and their corresponding microscopic scale parameters. A model of a projectile created in PFC3D is showed in Figure 9. Most experiments use the cylindrical projectile shape which allows the convenient monitoring of symmetric damage. However, cubic specimens are used in simulations due to their simple geometry. By using large dimensions, the corner or boundary effects can be minimized. Although a semi-infinite target can be used in the classic penetration theory, a DEM simulation only accepts finite size targets, with its specific dimension needing to be determined to eliminate the size effect.

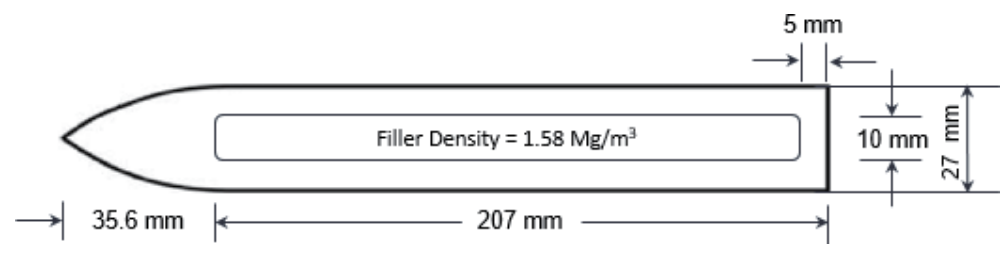

Figure 8.

Geometry of projectile used in test (Forrestal et al., 1994).

For both projectile and target, there are several major parameters contributing to the entire penetration process significantly. The major variables for projectile are mass $(\mathrm{m})$, diameter (dia), nose shape, and impact velocity (vel). The former three are set in the projectile geometric and mechanical property file, while the last variable is input in the main code for penetration simulation. Key variables for target are macro Young's modulus (E), Poisson's ratio $(\nu)$, compressive strength $\left(\sigma_{c}\right)$, and tensile strength $\left(\sigma_{t}\right)$. They together represent the mechanical characteristics of the material.

PFC3D provides an optimized calibration sequence for some major control variables to minimize the iterations for parallel bond.

1. Matching the material's Young's modulus by varying $E_{\mathrm{c}}$ and $\bar{E}_{\mathrm{c}}$.

2. Matching the Poisson's ratio by varying $k_{\mathrm{n}} / k_{\mathrm{s}}$ and $\bar{k}_{\mathrm{n}} / \bar{k}_{\mathrm{s}}$.

3. Varying the mean normal and shear strength, $\bar{\sigma}_{\mathrm{c}}$ and $\bar{\tau}_{\mathrm{c}}$, as well as their standard deviation, to obtain the strength envelope for both compression and tension.

4. Properties, such as post-peak behavior or crack-initiation stress, can also be obtained by adjusting related variables, such as friction coefficient to match with those from the real samples; for conciseness purpose however, they are not presented in this paper. 


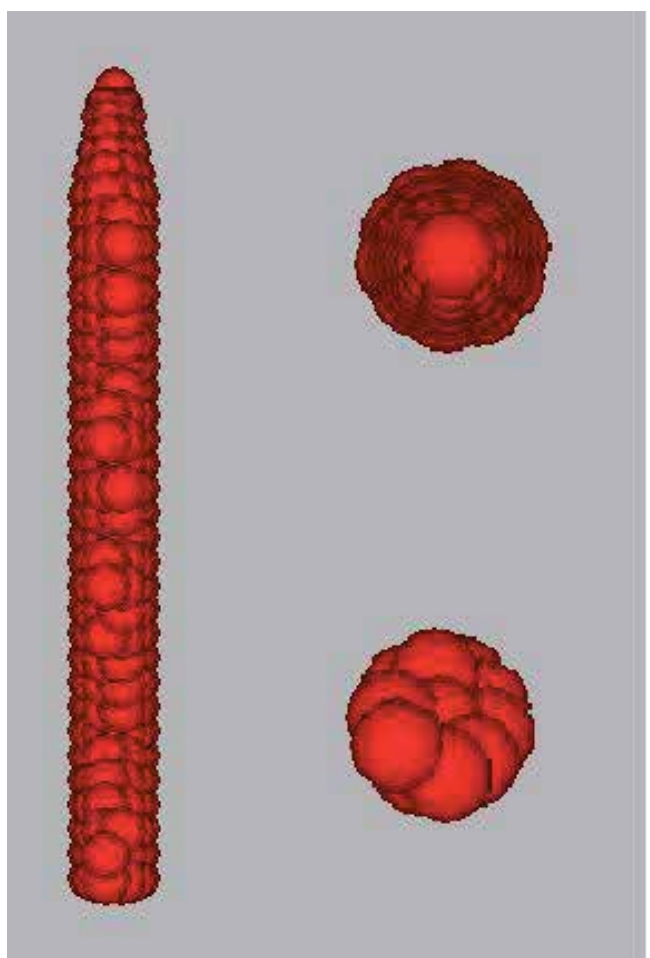

Figure 9.

Projectile model created in DEM.

\subsection{Normal and shear strength calibration for parallel bond}

Normal strength and shear strength $\left(\bar{\sigma}_{\mathrm{c}}\right.$ and $\left.\bar{\tau}_{\mathrm{c}}\right)$ for parallel bond are the two major micro-parameters contributing to the material's compressive strength. Three typical calibration tests were carried out: varying normal strength, varying shear strength, and varying both with a constant relative ratio. The relationship between compressive strength and microstrength is shown in the Figure 10.

\section{sign - microstrength}

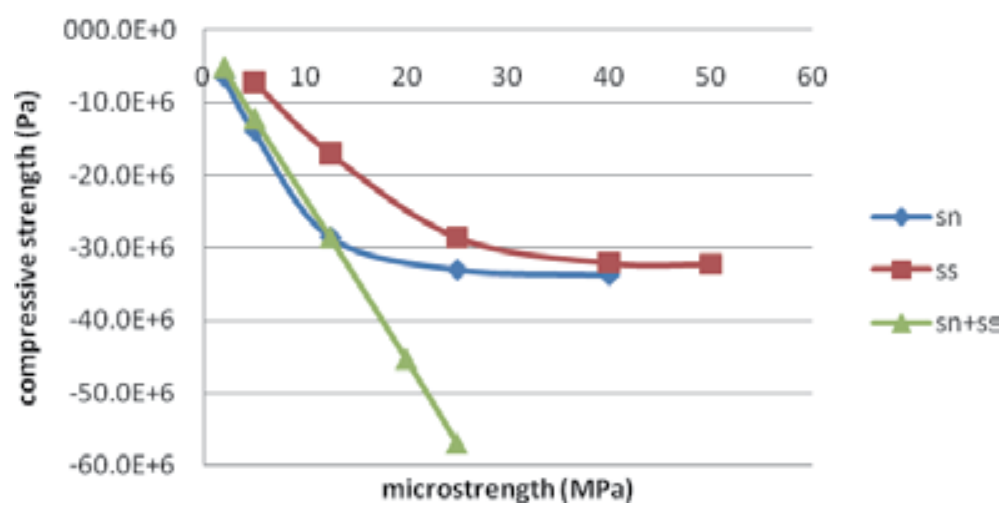

Figure 10.

Relation between macro-compressive strength and micro-strength. 
As illustrated in Figure 10, the macro compressive strength depends on both normal and shear strength of the contact balls, while normal strength contributes a little more. An important feature for this case is that it is the smaller one of these two micro-parameters controls the upper limit of the macro-strength, i.e. the compressive strength cannot increase when either one of the micro strengths stay at a constant level.

For Young's modulus and Poisson's ratio, neither the normal nor the shear strength of particles has much contribution in the normal range. However, when both these two micro strengths decrease to very small values, the Young's modulus and Poisson's ratio have a little more influence.

The empirical discoveries found in the above calibration test can be used to form concrete target with the required mechanical property, although the calibration still needs to be conducted step by step. This is because different micro-variable changes may result in similar macro-property, and the changing magnitudes probably vary widely as other parameters vary.

\section{Experimental results}

Two types of concrete targets were made for penetration testing, i.e., the frusta of either a pyramid or a cone (Figure 11). The pyramid and cone shapes were intended to save materials in the rear end of the samples. The larger-area side was subjected to the projectile penetration. The frustum of pyramid had dimensions of $12^{\prime \prime} \times 12^{\prime \prime}$ in the larger-end side and $13^{\prime \prime}$ in depth, while the cylinders were 6 " and $11^{\prime \prime}$ in diameter and $11^{\prime \prime}$ in height. Both types of concrete targets were cast in 5000 psi and 8000 psi uniaxial compressive strengths. For verification purposes of the gas operated facility the first two shots were on two 2500 psi concrete cylinders $\left(6^{\prime \prime} \times 12^{\prime \prime}\right)$. Limestone aggregate (\#67) was used for the 5000 psi samples while (\#78) was used for the 8000 psi samples.
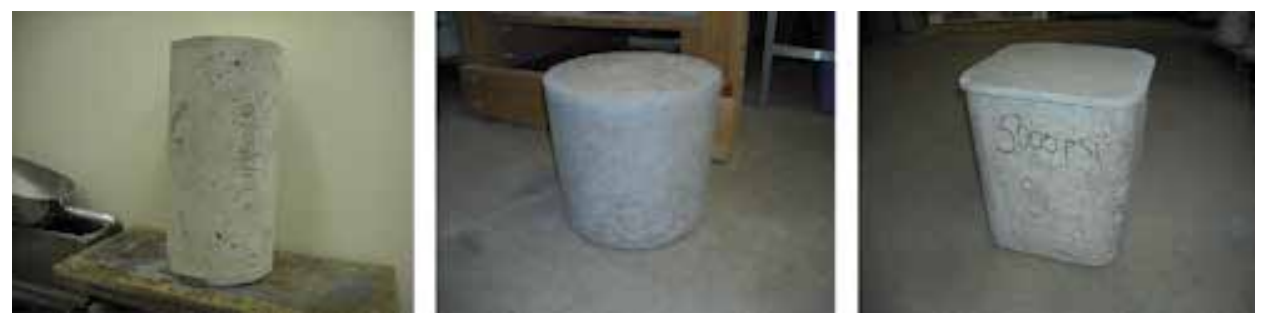

Figure 11.

Types of concrete targets used for penetration testing.

Projectiles of three different diameters $(12,20$, and $30 \mathrm{~mm})$ were used for penetration into the concrete targets and were launched using the same pressures (1200 psi) to assess their speeds, penetration depths, and target damage.

Figure 12 shows an example of the projectile after impacting the concrete targets, the damaged concrete targets and location of projectiles after the impact. Some target specimens were shattered by the projectile and the penetration of the projectile were not observed. This was primarily due to the size of concrete specimen relative to that of the projectile. However, as projectile size decreases (or concrete specimen size increases), the phenomena of projectile penetrating through concrete target become more likely to occur. 

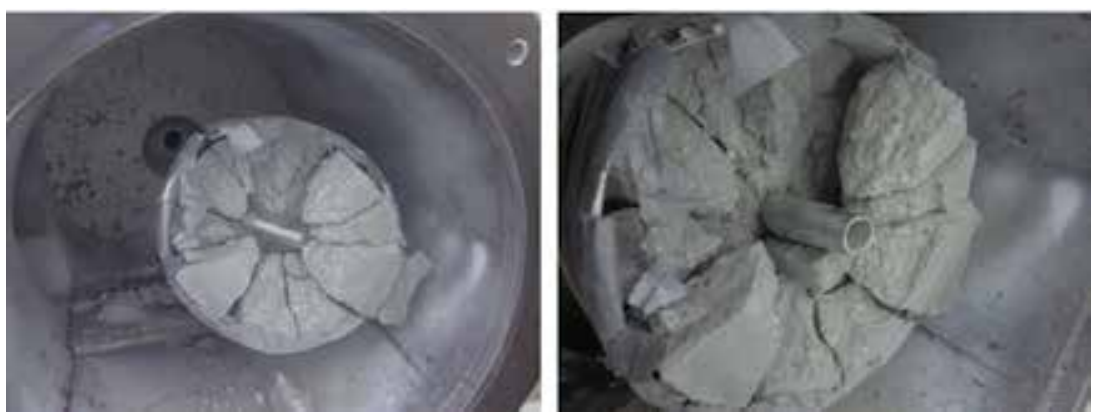

Figure 12.

8000 psi cylinder impacted by $30 \mathrm{~mm}$ diameter and $218 \mathrm{~g}$ projectile at $v=360 \mathrm{~m} / \mathrm{s}$.

\subsection{Comparison between FEM simulation results and laboratory test results without considering the microstructure of the target}

It is worth mentioning that both the mass and diameter of the projectiles influence the penetration depths. However, the major factor to determine the penetration depth is the velocity of the projectile. For example, in tests 7 and 8 , the two projectiles have similar masses and diameters, but the projectile with higher velocity $(405 \mathrm{~m} / \mathrm{s})$ has a penetration depth of $51 \mathrm{~mm}$ which is almost twice the depth of the one with lower velocity $(360.5 \mathrm{~m} / \mathrm{s})$. This fact is also revealed by the simulation results, pertaining to the same tests, in which the projectile having a higher velocity has a $106 \mathrm{~mm}$ penetration depth, while the one with lower velocity has a $51 \mathrm{~mm}$ penetration depth. The major reason for the inconsistency between the simulation results and the test results is that the material properties including microstructure were not varied for different materials (Table 3 ).

\begin{tabular}{lccc}
\hline Test \# & Target type & Test penetration depth $(\mathbf{m m})$ & Simulated penetration depth $(\mathbf{m m})$ \\
\hline 1 & Cyl $\left(11^{\prime \prime} \times 11^{\prime \prime}\right)$ & 80 & 84 \\
\hline 2 & Cyl $\left(11^{\prime \prime} \times 11^{\prime \prime}\right)$ & 96 & 83 \\
\hline 6 & Cyl $\left(11^{\prime \prime} \times 11^{\prime \prime}\right)$ & 87 & 150 \\
\hline 7 & Cyl $\left(6^{\prime \prime} \times 12^{\prime \prime}\right)$ & 27 & 18 \\
\hline 8 & Cyl $\left(6^{\prime \prime} \times 12^{\prime \prime}\right)$ & 51 & 106 \\
\hline
\end{tabular}

Table 3.

Penetration depth comparison between test data and simulation (Zhou et al., 2009).

\subsection{Comparison between simulation results and laboratory test results with microstructure incorporated for the concrete target}

As previously mentioned, the $6^{\prime \prime} \times 12^{\prime \prime}$ concrete cylinders were X-ray CT scanned and cross-section images showing their internal structure were obtained for each specimen. An image analysis code has been developed to reconstruct the internal structure of the target specimen using the x-ray CT slices. Thus, different constituents of concrete are identified respectively, based on the gray levels of a cross-section image. In addition to the reconstruction of the internal structure, the program also maps each pixel of the image onto the mesh of the digital model as shown in Figure 13. For each of the two $6^{\prime \prime} \times 12^{\prime \prime}$ concrete specimens, 100 slices 

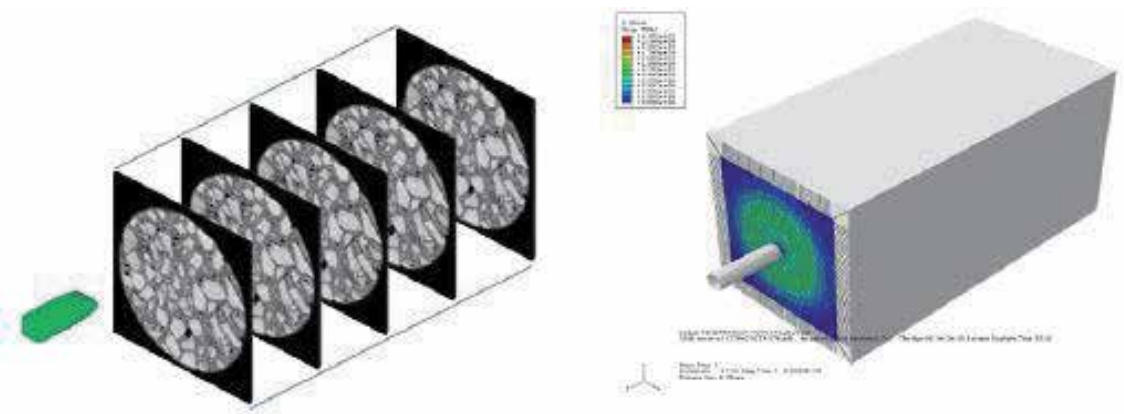

Figure 13.

Internal structure reconstruction of the concrete specimen.

(cross-section images) were stacked together and processed to generate their respective digital specimen. Elements pertaining to different components of the mixture (i.e., aggregates and cement paste) were assigned different material properties in the simulation. The aggregates were treated as elastic material with high elastic stiffness, whereas the cement paste was treated as an elasto-plastic material with low elastic stiffness and shear damage factor to control the damage of the material.

\subsection{Effect of projectile mass on the simulated penetration}

The effect of the projectile mass on the penetration was assessed by considering three different masses in the simulation $-0.2,0.4$, and $0.6 \mathrm{~kg}$, respectively. Other properties of the projectiles were kept the same. The simulation data are presented in Figure 14. From the figure it can be noticed that the projectile penetration depth increases as its mass increases (a) whereas the penetration speed decreases at smaller rates for larger mass projectiles (b).

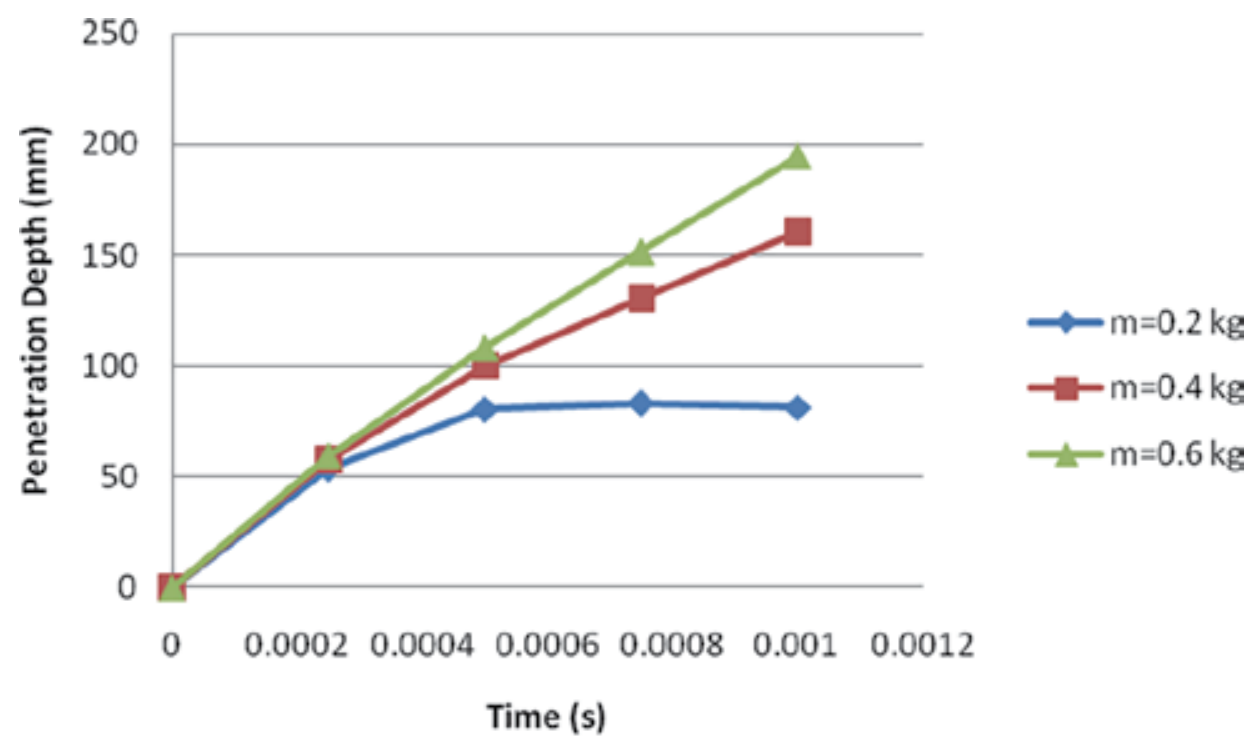

(a) 


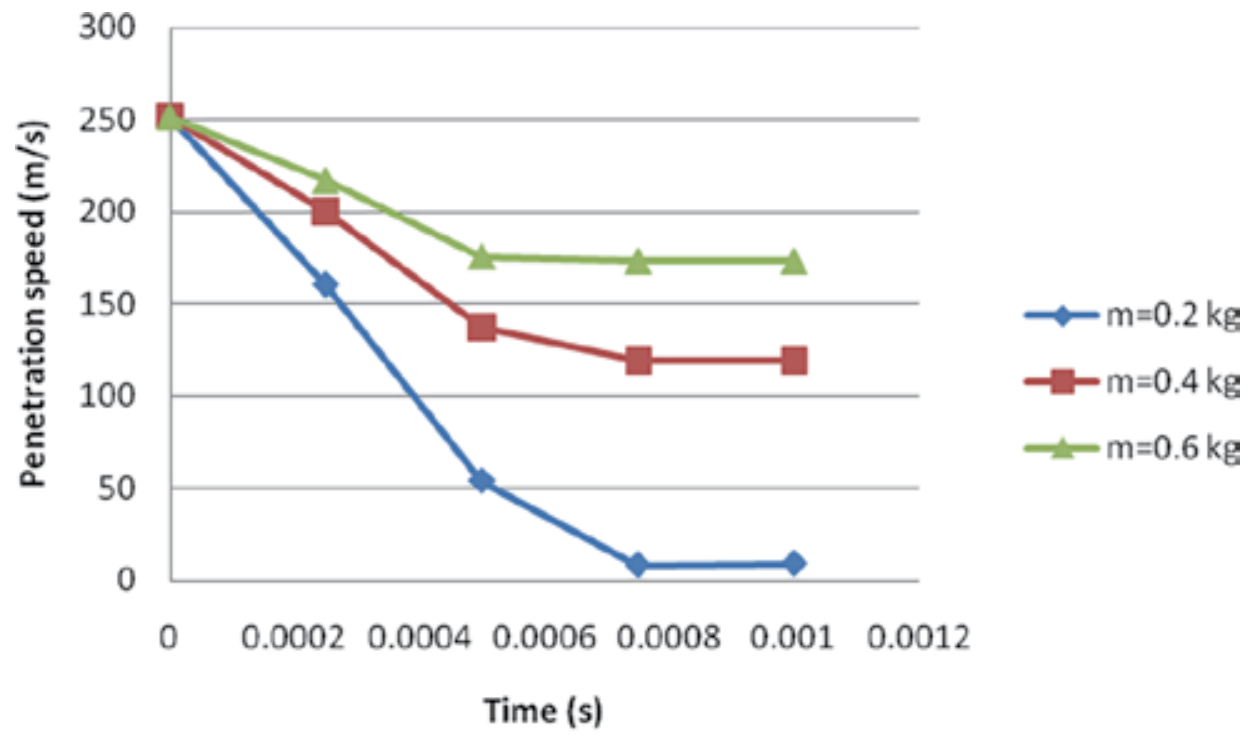

(b)

Figure 14 .

Penetration depth and speed reduction of projectiles with different masses. (a) projectile penetration depth increases as its mass increases whereas $(b)$ the penetration speed decreases at smaller rates for larger mass projectiles.

\subsection{Visualization of DEM simulation}

After creating the target and projectile models, it is convenient to assign different striking velocities to the projectile and perform penetration simulation. Through PFC3D coding, the entire penetration process can be simulated at selected time steps (Figure 15).
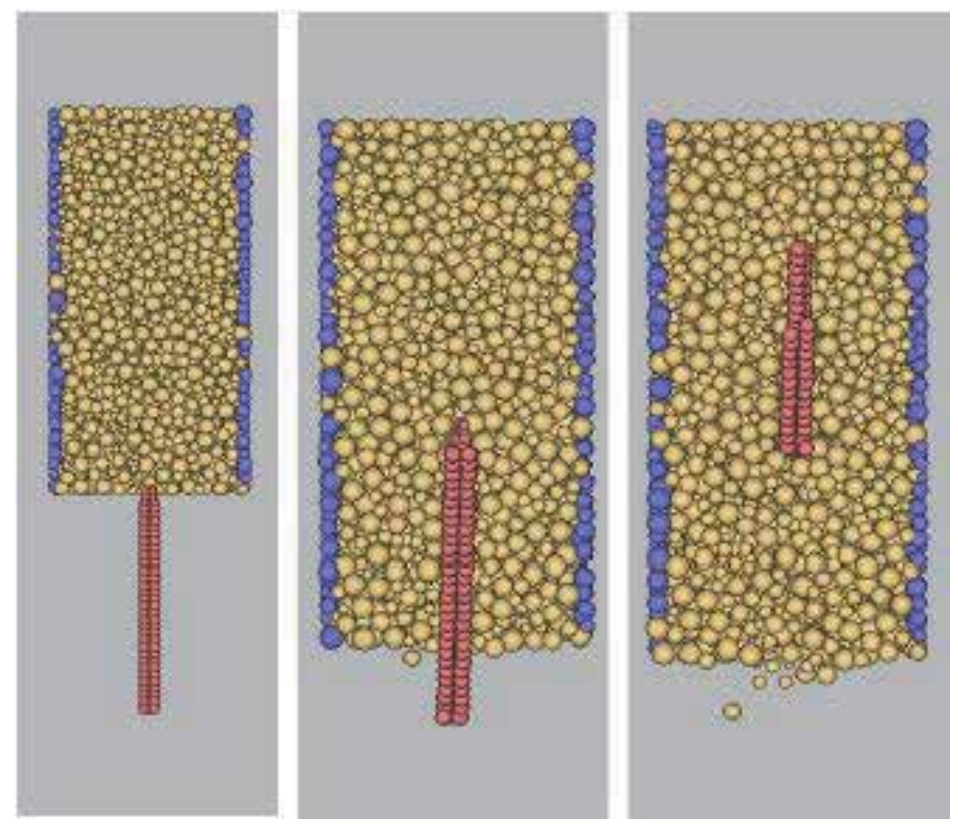

Figure 15.

Visualization of the penetration process using DEM (Zhou et al., 2009). 
In the figure above, the concrete slab perforation process at selected time steps was initiated at a striking velocity of $500 \mathrm{~m} / \mathrm{s}$. Different steps correspond to different times, which can be obtained from the simulation history record. As shown, widespread cracking, progressive gross failure, and fragmentation during penetration can be visualized.

\section{Conclusions}

Penetration of projectile into concrete target was investigated in this research by using both experimental methods and numerical simulations. A lab test system which is able to launch steel projectile into cement concrete targets was successfully built. Projectile package driven by propellant gas enables a steel projectile to penetrate into cement concrete targets at different speeds. Finite Element Method (FEM) was utilized to simulate the penetration process of projectile into a concrete target. A projectile is considered as rigid material with no deformation during the penetration process. Cement concrete targets can be modeled using a concrete damaged plasticity model. Several major effects are estimated by FEM simulation including diameter, mass and initial speed of the projectile. Additionally, numerical simulation using Discrete Element Method (DEM) was employed to simulate the penetration process of projectile into cement concrete target. A calibration method was developed to obtain microscopic parameters from macroscopic parameters of concrete. Penetration process can be modeled using the time history of the depth, initial velocity and deceleration of the projectile then compare results with empirical predictions results of previously conducted simulations.

\section{Author details}

\section{Cristian Druta}

Virginia Tech Transportation Institute, Blacksburg, USA

*Address all correspondence to: cdruta1@vt.edu

\section{IntechOpen}

(C) 2020 The Author(s). Licensee IntechOpen. This chapter is distributed under the terms of the Creative Commons Attribution License (http://creativecommons.org/licenses/ by/3.0), which permits unrestricted use, distribution, and reproduction in any medium, provided the original work is properly cited. (c) BY 


\section{References}

[1] Iwama K, Higuchi K, Maekawa K. Multi-scale modelling of deteriorating concrete at elevated temperature and collapse simulation of underground ducts. In: 10th International Conference on Fracture Mechanics of Concrete and Concrete Structures FraMCoS-X. 2019

[2] Mehta PK, Monteiro PJM.

Microstructure, Properties, and Materials. New York, London: The McGraw-Hill Companies, Inc.; 2006

[3] Roy DM, Idorn GM. Concrete Microstructure. In: Rep. SHRP-C-340, Strategic highway research program. Washington. D.C.: National Research Council; 1993

[4] Druta C, Wang L, Stephen Lane D. Tensile strength and paste-aggregate bonding characteristics of selfconsolidating concrete. Construction and Building Materials. 2014;55:89-96

[5] Kuder K, Lehman D, Berman J, Hannesson G, Shogren R. Mechanical properties of self-consolidating concrete blended with high volumes of fly ash and slag. Construction and Building Materials. 2012;34:285-295

[6] Khayat KH, Guizani Z. Use of viscosity-modifying admixture to enhance stability of fluid concrete. ACI Materials Journal. 1997;94(4):332-340

[7] Ozyildirim C, Davis RT. Bulb-T beams with self-consolidating concrete on route 33 in Virginia. Journal of the Transportation Research Board. 2007; 2020:76-82

[8] Gesoglu M, Guneyisi E, Ozbay E. Properties of self-compacting concretes made with binary, ternary, and quaternary cementitious blends of fly ash, blast furnace slag, and silica fume. Construction and Building Materials. 2009;23:1847-1854
[9] Castel A, Vidal T, Francois R. Bond and cracking properties of selfconsolidating concrete. Construction and Building Materials. 2010;24:1222-1231

[10] Bijen JM, de Rooij M. Aggregatematrix interfaces. In: Presented at International Conference on Concretes. Dundee, Scotland; 1999

[11] Herman G. Image Reconstruction from Projections: The Fundamentals of Computerized Tomography. New York: Academic Press; 1980

[12] Mindess S, Young JF, Darwin D. Concrete. Upper Saddle River, NJ 07458: Prentice Hall; 2003

[13] Hall C, Colston SL, Jupe AC, Jacques SDM, Livingston R, Ramadan AO. Non-destructive tomographic energy-dispersive diffraction imaging of the interior of bulk concrete. Cement and Concrete Research. 2000;30(3):491-495

[14] Shi BM, Wu Y, Chen Z, Inyang JH. Monitoring of internal failure evolution insoils using computerization X-ray tomography. Engineering Geology. 1999;54(3):321-328

[15] Rogasik HC, Wendroth JW, Young O, Joschko IM, Ritz MK. Discrimination of soil phases by dual energy X-ray tomography. Soil Science Society of America Journal. 1999;63(4): 741-751

[16] Verhelst F, Vervoort ADB, Marchal G. X-ray computerized tomography, determination of heterogeneities in rock samples. In: Proceedings of the 8th International Congress on Rock Mechanics. Tokyo, Japan: A. A. Balkema; 1995. pp. 105-109

[17] Wang L, Frost JD, Shashidhar N. Microstructure study of westrack mixes 
from X-ray tomography images. Journal of the Transportation Research Board. 2001;1767:85-94

[18] Wang L, Frost JD, Voyiadjis G, Harman TP. Quantification of damageparameters using X-ray tomography images. Journal of Mechanics and Materials. 2002;35: 777-790

[19] Cundall PA, Strack ODL. Discrete numerical model for granular assemblies. Geotechnique. 1979;24: 4843-4848

[20] Heuze FE. An overview of projectile penetration into geological materials, with emphasis on rocks. International Journal of Rock Mechanics and Mining Science and Geomechanics Abstracts. 1990;27(1):1-14

[21] Zhang D, Zhu F. Application of beam-particle model to the problem of concrete penetration. Explosion shock wave. 2005;25(1):85-89

[22] Kusano N, Aoyagi T, Aizawa J, Ueno H, Morikawa H, Kobayashi N. Impulsive local damage analyses of concrete structure by the distinct element method. Nuclear Engineering and Design. 1992;138(1):105-110

[23] Sawamoto Y, Tsubota H, Kasai Y, Koshika N, Morikawa H. Analytical studies on local damage to reinforced concrete structures under impact loading by discrete element method. Nuclear Engineering and Design. 1998; 179(2):157-177

[24] Magnier SA, Donze FV. Numerical simulations of impacts using a discrete element method. Mechanics of Cohesive-frictional Materials. 1998;3(3): 257-276

[25] Ng T-T. Numerical Simulations for Penetration Process of Concrete Target Using the Discrete Element Method, New Orleans, LA, USA. New York, NY, USA: ASME; 1993, 1993
[26] Nishida M, Tanaka K, Matsumoto Y. Discrete element method simulation of the restitutive characteristics of a steel spherical projectile from a particulate aggregation. JSME International Journal Series A Solid Mechanics and Material Engineering. 2004;47(3):438-447

[27] Zhu F, Zhang D. Numerical simulation of perforation in plain concrete panel with nose shape of perforators. Journal Impact Factor. 2005;24:4843-4848

[28] Chen EP. Penetration into dry porous rock: A numerical study on sliding friction simulation. Theoretical and Applied Fracture Mechanics. 1989; 11(2):135-141 



\title{
Chapter 3
}

\section{Compressive Strength of Lightweight Concrete}

\author{
Saman Hedjazi
}

\begin{abstract}
This chapter has been prepared with the hope that its readers will become interested in lightweight concrete (LWC). Therefore, after a brief background of lightweight concrete, different types of LWC will be introduced and then LWC made of lightweight aggregates (LWA) will be specifically discussed. Compressive strength and density of LWC are the main points of interest in this chapter. In addition to conventional compression test, a nondestructive test (NDT) method will be used to assess the compressive strength of a variety of lightweight concrete mixes. A case study has been designed and conducted including an experimental program on the LWC made of expanded glass aggregate. The experimental program includes about 150 specimens, incorporating different unit weight for the entire specimens. In the end, it can be observed that the properties of LWC depend on the properties of the used LWA, and therefore for each specific type of lightweight aggregate, a brand new equation will be required for prediction of concrete compressive strength. The author hopes that the present chapter and the discussed case study on LWC would attract the attention of researchers to the importance of LWC in the future of construction industry.
\end{abstract}

Keywords: lightweight aggregate, lightweight concrete, nondestructive testing, compressive strength, expanded glass aggregate

\section{Introduction}

Concrete is a mixture made of aggregates, water, cement, and different additives. The "lightweight" term can be added to different types of concrete which are all common in one specification, and that is "lower density" than normal weight concrete (NWC). This reduction in density is achievable by different methods such as using lightweight aggregate (LWA) in concrete, foamed concrete (FC), and autoclaved aerated concrete (AAC) or by any other techniques that reduce the final specific weight of the product, and thus the achieved weight is less than what we have in NWC mixtures. Whereas NWC weighs from 2240 to $2450 \mathrm{~kg} / \mathrm{m}^{3}$, lightweight concrete weighs $\sim 300-2000 \mathrm{~kg} / \mathrm{m}^{3}$, but the practical range of density for lightweight concrete is $500-1850 \mathrm{~kg} / \mathrm{m}^{3}$. Before talking about the background of LWC, we prefer to explain a little more about the different types of LWC and their mechanical properties. 


\subsection{Lightweight aggregate concrete (LWAC)}

There are a variety of lightweight aggregates that can be used in the production of LWAC, such as natural materials, like volcanic pumice, and the thermal-treated natural raw materials like expanded glass, clay, shale, etc. LECA is an example of expanded clay and Poraver is an example of expanded glass aggregates. There are also other types, which are aggregates made of industrial by-products such as fly ash, like Lytag. The final properties of the LWC will depend on the type and mechanical properties of LWA used in the concrete mixture.

\subsection{Foamed concrete (FC)}

With incorporation of considerable amount of entrained air (20\% to 50\%) in concrete, foamed concrete is produced which is a workable, low-density, pumpable, self-levelling, and self-compacting LWC. Foamed concrete is used more as a nonstructural concrete for filling voids in infrastructures, a good thermal insulation, and filler for space in buildings with less increase in the dead load.

\subsection{Autoclaved aerated concrete (AAC)}

AAC, or also named as autoclaved gas concrete, to which a foaming agent is added, was first produced in 1923 in Sweden and is one of the oldest types of LWC. AAC construction systems were then popular all around the world because of its ease of use.

\subsection{Structural and nonstructural lightweight concrete}

Lightweight aggregate concretes (LWAC) can be used for structural applications, according to the American Concrete Institute (ACI). To be considered as structural lightweight concrete (SLWC), the minimum 28-day compressive strength and maximum density are $17 \mathrm{MPa}$ and $1840 \mathrm{~kg} / \mathrm{m}^{3}$, respectively. The practical range for the density of SLWC is between 1400 and $1840 \mathrm{~kg} / \mathrm{m}^{3}$. LWC made of a material with lower densities and higher air voids in the cement paste are considered as nonstructural lightweight concrete (NSLWC) and will most likely be used for its insulation and lower weight properties. LWC with compressive strength less than $17 \mathrm{MPa}$ is also considered as NSLWC. There are several benefits with using LWAC such as improved thermal specifications, better fire resistance, and dead load reduction which results in lower cost of labor, transportation, formworks, etc., especially in precast concrete construction industry. With the reduction of the concrete density, the properties of the concrete change fundamentally. For two specimens of concrete with the same compressive strength, but one made of LWC and the other one made of NWC, the tensile strength, ultimate strains, and shear strengths are all lower in LWC than NWC, while the amount of creep and shrinkage is higher for LWC. LWC are also less stiff than the equivalent NWC. However, there are benefits in using LWC such as reduction in dead load that results in slight reduction in the depth of a beam or slab. It is also observed that the elastic modulus of LWC is lower than the equivalent strength of NWC, but when considering the deflection of a slab or beam, this is counteracted by the reduction in dead load.

In the present chapter after the discussion about the lightweight concrete and its properties, we will study about the compressive strength of LWC and the 
methods for evaluation and prediction of compressive strength of LWC. Further a case study of LWC made of LWA will be conducted and presented for a better understanding of the properties of LWC. In the end the conclusion of the chapter will be drawn.

\section{Background of lightweight concrete}

Concrete is a relatively heavy building material; therefore many experiments have been conducted throughout the twentieth century to decrease its weight without impairing other properties. During the 1920s and 1930s, many different types of lightweight concrete were developed, e.g., Durisol, Siporex, Argex, and Ytong. Probably the most famous and first type of autoclaved gas concrete was Ytong. It was invented by the Swedish architect, Johan Axel Eriksson, assistant professor at the Royal Institute of Technology in Stockholm. In the early 1920s, Eriksson experimented with different samples of gas concrete and put the mixtures in an autoclave to speed up the curing process. In November 1929, the industrial production of Ytong blocks began. The name combines the $y$ of Yxhult, the town where the first Swedish factory was located, and the end of betong, the Swedish word for concrete. The material was very popular in Sweden from 1935 onward, with a true breakthrough immediately after World War II, when it became one of the most important building materials in the country. Also, the manufacturing process was exported to other countries such as Norway, Germany, the UK, Spain, Poland, Israel, Canada, Belgium, and even Japan. The autoclaved gas concrete Siporex was developed in Sweden in 1935. The LWAC, Argex, was first produced in Denmark in 1939 under the international brand name Leca. Starting with an annual production in Copenhagen of $20,000 \mathrm{~m}^{3}$, the total production throughout Europe had increased by 1972 to nearly 6 million $\mathrm{m}^{3}$ per year (adopted from postwar building materials "postwa rbuildingmaterials.be”).

The later type of LWC which is called LWAC is one of the most popular one among them and from that time until today has been the subject of many research works around the word. Even today there are many ongoing extensive research programs on SLWC and NSLWC made of LWA. In the present chapter, we focus on LWAC, and for the case study, we will discuss a part of the ongoing research of the author on LWAC [1]. Categorized examples of the research works conducted recently have been discussed below:

\subsection{LWC including recycled lightweight aggregate}

In 2013, a research was conducted on producing concrete containing recycled aggregates obtained from crushed structural and nonstructural lightweight concrete [2]. The mechanical properties of this concrete were investigated. Concrete compositions made of recycled lightweight concrete aggregates (RLCA) were measured for their compressive strength, modulus of elasticity, tensile strength, and abrasion resistance. The influence of the properties of the aggregates on concrete properties were discussed including concrete density, compressive strength, structural efficiency, splitting tensile strength, modulus of elasticity, and abrasion resistance. This research proved that it is possible to produce structural recycled lightweight concrete from crushed, structural, and nonstructural LWC with densities below 
$2000 \mathrm{~kg} / \mathrm{m}^{3}$. Improvements in mechanical properties can be seen when the LWA is replaced with RLCA. The study concluded that recycled lightweight aggregate is a potential alternative to conventional LWC.

\subsection{LWC including expanded clay aggregates}

In 2015, other researchers studied the properties of LWC consisting of cinder and light expanded clay aggregates (LECA) [3]. By replacing coarse aggregate with blended lightweight aggregates such as cinder and LECA, there was a reduction in weight and, respectively, a decrease in compressive strength, but they were able to use cinder and LECA as a replacement for normal coarse aggregate to reduce the cost, while the compressive strengths were close to the strengths of NWC. The average compressive strength for samples that included the abovementioned LWA was $39.2 \mathrm{~N} / \mathrm{mm}^{2}$, while the average compressive strength for NWC was 43.4 N/mm². The density of the LWC varied from 1800 to $1950 \mathrm{~kg} / \mathrm{mm}^{3}$ and the density for the NWC was $2637 \mathrm{~kg} / \mathrm{m}^{3}$. The slump from the fresh concrete mix and the average compressive and tensile strength of the hardened concrete were analyzed in the research.

\subsection{LWC including foam glass aggregates}

Similar research presented on waste materials showcased that waste materials can be reused as construction materials, in 2016 [4]. Foam glass and high-impact polystyrene (HIPS) are materials they collected through the processing of waste materials. The glass foam is found from a glass cutlet, and the polystyrene is collected from butadiene modified rubber. They investigated the compressive and flexural strength, water absorption, and bulk density of the proposed concrete mixtures. LWC with foamed glass aggregates was affected by the amount of aggregate. Larger amounts of aggregate cause a decrease in compressive and bending strength and an increase in absorption. The addition of HIPS improved the compressive strength; however, it did not have a significant influence on water absorption. In 2017, Kurpinska and Ferenc studied on the physical properties of lightweight cement composites consisting of granulated ash aggregate (GAA) and granulated expanded glass aggregate (GEGA) [5]. This study showcased the significant impact of grain type and size on the physical properties of lightweight concrete. After the mechanical properties of 15 different mixtures were calculated and measured, they utilized a finite element modeling program to study the possibility of applying this type of LWC in structural elements, extenders, and insulation material.

\subsection{LWC including expanded glass aggregates}

In 2017, the material properties and effects of crushed and expanded waste glass aggregates on LWC properties were evaluated [6]. In this study, an image-based approach is used to extract the characterization of the materials. Pore measurement and pore structures of each material type were evaluated using a microscope, 3D, and X-ray micro-computed tomography. Thermal conductivity for the material was measured. There results showed that crushed and expanded waste glass aggregates are supported as alternatives for lightweight aggregates. LWC with a density less than $2000 \mathrm{~kg} / \mathrm{m}^{3}$, including crushed waste aggregate, have shown to have a compressive strength over $38 \mathrm{MPa}$. This was considered as effective lightweight concrete, and it satisfied the desired mechanical properties. 


\subsection{LWC including expanded glass aggregates and expanded clay aggregates}

An experimental investigation on the compressive strength and durability of LWC with fine expanded glass (FEG) and expanded clay aggregates (ECA) using different micro-fillers including ground quartz sand and silica fume was conducted in 2018 [7]. Based on their research, ECA is one of the most popular aggregates for SLWC, and using this aggregate is important for sustainable development in the construction industry. The relationships between compressive strength and density of concrete mixtures with different proportions of LWA were explored. The effects of fine LWA on density and compressive strength of LWAC were also analyzed. They could reach to compressive strengths of 39.5-101 MPa for the mixtures containing EGA and 43.8-109 MPa for mixtures containing ECA. The density of the mixtures containing EGA and ECA are $1458-2278$ and $1588-2302 \mathrm{~kg} / \mathrm{m}^{3}$, respectively. Different compressive strength-density relationships were obtained for LWC containing EGA and LWC containing ECA even though the compositions had the same amount of cement, water to cement ratio, micro filler, and total volume of LWA. While understanding the basic mechanical properties (density and compressive strength) of concrete containing LWA such as ECA and EGA was the main goal of this study, it was concluded that the application of expanded glass aggregate (EGA) in concrete is still in its early stages.

As in the present book, compressive strength of concrete is the main subject of discussion; later in this chapter, we will discuss a case study on compressive strength of a specific type of LWC containing EGA implementing a NDT method in addition to the conventional compression test. Therefore in the next section, we will briefly talk about the usage of NDT in the evaluation of compressive strength and properties of concrete.

\section{Nondestructive testing methods}

Nondestructive testing (NDT) methods are widely used in the investigation of the mechanical properties and integrity of concrete structures. As seen in Table 1, provided by AASHTO [8], the following techniques are used for detecting defects in

\begin{tabular}{lllllll}
\hline $\begin{array}{l}\text { The capability of defect detection } \\
\begin{array}{l}\text { Method based } \\
\text { on }\end{array}\end{array}$ & Cracking & Scaling & Corrosion & $\begin{array}{l}\text { Wear and } \\
\text { abrasion }\end{array}$ & $\begin{array}{l}\text { Chemical } \\
\text { attack }\end{array}$ & $\begin{array}{l}\text { Voids in } \\
\text { grout }\end{array}$ \\
\hline Strength & $\mathrm{N}$ & $\mathrm{N}$ & $\mathrm{P}$ & $\mathrm{N}$ & $\mathrm{P}$ & $\mathrm{N}$ \\
\hline Sonic & $\mathrm{F}$ & $\mathrm{N}$ & $\mathrm{Gb}$ & $\mathrm{N}$ & $\mathrm{N}$ & $\mathrm{N}$ \\
\hline Ultrasonic & $\mathrm{G}$ & $\mathrm{N}$ & $\mathrm{F}$ & $\mathrm{N}$ & $\mathrm{P}$ & $\mathrm{N}$ \\
\hline Magnetic & $\mathrm{N}$ & $\mathrm{N}$ & $\mathrm{F}$ & $\mathrm{N}$ & $\mathrm{N}$ & $\mathrm{N}$ \\
\hline Electrical & $\mathrm{N}$ & $\mathrm{N}$ & $\mathrm{G}$ & $\mathrm{N}$ & $\mathrm{N}$ & $\mathrm{N}$ \\
\hline Nuclear & $\mathrm{N}$ & $\mathrm{N}$ & $\mathrm{F}$ & $\mathrm{N}$ & $\mathrm{N}$ \\
\hline Thermography & $\mathrm{N}$ & $\mathrm{Gb}$ & $\mathrm{Gc}$ & $\mathrm{N}$ & $\mathrm{N}$ \\
\hline Radar & $\mathrm{N}$ & $\mathrm{Gb}$ & $\mathrm{Gc}$ & $\mathrm{N}$ & $\mathrm{N}$ \\
\hline Radiography & $\mathrm{F}$ & $\mathrm{N}$ & $\mathrm{F}$ & $\mathrm{N}$ & $\mathrm{N}$ \\
\hline Good; F fair; $P$ & $=$ poor; $N=$ not suitable; Gb= beneath bituminous surfacing; Gc = detects delamination. \\
\hline
\end{tabular}

Table 1.

Capability of investigating techniques for detecting defects in concrete structures in field use [8]. 
concrete structures for field use. In the present study, ultrasonic pulse velocity (UPV) method is used to evaluate the properties of LWC. Ultrasonic techniques measure the velocity of a pulse, generated from a piezoelectric transducer in concrete, and this measurement assesses the mechanical properties of a concrete. Based on research and correlations, the pulse velocity relates items such as compressive strength or corrosion [1]. As seen in Table 1, UPV detects corrosion in reinforcement; however, it is not studied in this report.

\subsection{Ultrasonic pulse velocity (UPV)}

AASHTO states that the accurate measurement of the concrete's strength depends on several factors and is best determined experimentally [8]. In the present work in addition to the conventional compression test, UPV is utilized to explore the properties of concrete. In general UPV tests are used to distinguish the material and integrity of concrete sample being tested. This technique enhances quality control and detection of defects. In the field, UPV verifies concrete uniformity, detects internal imperfections and finds the imperfections' depth, estimates the deformation moduli and compressive strength, and monitors characteristic variations in concrete throughout time [9]. From observations, certain factors influence UPV. The theory for elasticity for homogeneous and isotropic materials states that the pulse velocity of compressional waves ( $\mathrm{P}$-waves) is indirectly proportional to the square root of the dynamic modulus of elasticity, Ed, and inversely proportional to the square root of its density, $\rho$ [10]. The aggregate type used in a mixture has a significant influence on the elastic modulus; therefore for our current LWA, a significant change in the pulse velocity is expected. To differentiate results, correlations need to be analytically determined. As an example an expression for the modulus of elasticity of concrete and its relation between the compressive strength (fc), the oven-dried density, and the Ec itself is suggested by EN 1992-1-1, Eurocode 2 [11]. This relationship suggests that UPV and fc are not unique and are affected by factors such as the type and size of aggregate, physical properties of the cement paste, curing conditions, mixture composition, concrete age, voids/cracks and moisture content [12]. Factors influencing the UPV method are presented in Table 2 [13]. Constituents of the concrete and its moisture content, age, and voids/ cracks impact UPV significantly. Previous works have shown that a correlation between the compressive strength in concrete and the ultrasonic pulse velocity must be determined for each particular concrete mix [13, 14]. Finding a general

\begin{tabular}{|c|c|c|c|}
\hline \multirow[t]{6}{*}{ Constituents of concrete } & \multirow[t]{2}{*}{ Aggregate } & Size & Average influence \\
\hline & & Type & High influence \\
\hline & \multirow[t]{2}{*}{ Cement } & Percentage & Moderate influence \\
\hline & & Type of cement & Moderate influence \\
\hline & \multirow[t]{2}{*}{ Other constituents } & Fly ash content & Average influence \\
\hline & & Water/cement ratio & High influence \\
\hline \multicolumn{3}{|c|}{ Humidity degree/moisture content } & Average influence \\
\hline \multirow[t]{3}{*}{ Other factors } & & Reinforcements & Moderate influence \\
\hline & & Age of concrete & Moderate influence \\
\hline & & Voids, crack & High influence \\
\hline
\end{tabular}

Table 2.

Influencing factors for UPV method. 
correlation between fc and UPV will be an enhancement for inspection and assessment of structures made of LWC.

Therefore based on the previous studies, it is recommended that for each type of LWA used in LWC, the researchers conduct an experimental program to drive a brand new relation between UPV and compressive strength of concrete, which is not the focus of the present chapter. Hence in the present chapter, we have presented some of the most recent proposed equations, relating UPV to compressive strength of LWC, and presented some of the available equations relating UPV to compressive strength of LWC and NWC for those interested to compare the configurations of the equations and to initial their research for the specific types of LWA of interest.

\subsection{Utilizing UPV to find the compressive strength}

During the last decades, many researchers presented different methods for the evaluation of compressive strength for LWA concrete versus UPV. The LWA in those studies consists of different types of natural or man-made LWA such as recycled lightweight concrete aggregates (RLCA), light expanded clay aggregate (LECA), high-impact polystyrene (HIPs), granulated ash aggregate (GAA), granulated expanded glass aggregate (GEGA), foam expanded glass aggregate (FEG), expanded clay aggregate (ECA), and expanded glass aggregate (EGA). In the literature several factors that influence the relation between compressive strength and UPV were examined. Most important analyzed factors included the cement type and content, amount of water, type of admixtures, initial wetting conditions, type and volume of aggregate, and the partial replacement of normal weight coarse and fine aggregates by LWA. As a result, simplified expression was proposed to estimate the compressive strength of different types of LWAC and its composition. The dependence of UPV and the modulus of elasticity were also explored in many of works [13]. They presented the expression below for a wide range of SLWC with compressive strength varying from 20 to $80 \mathrm{MPa}$. UPV and density are measured in meters per second and $\mathrm{kg} / \mathrm{m}^{3}$. From the regression analysis, $K u p v$ can be a constant equal to $54.6,54.3,0.86$, etc. and is a correlation coefficient. Values of UPV and strength measurements were performed on cubed concrete specimen in their study:

$$
f c=\left(\frac{U P V}{K u p v * p^{0.5}}\right)^{\frac{2}{3}}
$$

where $\mathrm{fc}$ is the compressive strength of concrete (MPa), UPV is the ultrasonic pulse velocity $(\mathrm{m} / \mathrm{s})$, KUPV is a constant representing the correlation coefficient, and $\rho$ is the dry density of specimen $\left(\mathrm{kg} / \mathrm{m}^{3}\right)$. In the research presented elsewhere [9], equations for LWC containing fibers were proposed to estimate the concrete compressive strength from respective UPV values. The equations presented below are the compressive strength of concrete at days 7 and 28 , respectively:

$$
\begin{aligned}
& \mathrm{f}_{\mathrm{c}}=1.269 \exp \cdot(0.841 \mathrm{v})(7 \text { days }) \\
& \mathrm{f}_{\mathrm{c}}=0.888 \exp \cdot(0.88 \mathrm{v})(28 \text { days })
\end{aligned}
$$

where $\mathrm{f}_{\mathrm{c}}$ is the compressive strength of concrete (MPa) and $\mathrm{v}$ is the pulse velocity $(\mathrm{m} / \mathrm{s})$. Other types of equations were presented in 2015 [10], which contributed the coarse aggregate content as a ruling factor in the relationships presented. In the developed equations, the fc was represented for a compressive cube strength measured in MPa. The variable, $v$, is UPV and it was measured in 


\begin{tabular}{ccc}
\hline No. & Proposed equations & Author, year \\
\hline 1 & $\mathrm{fc}=1.2 \times 10^{-5} \times \mathrm{UPV}^{1.7447}$ & Kheder, 1999 \\
\hline 2 & $\mathrm{fc}=36.75 \times \mathrm{UPV}-129.077$ & Qasrawri, 2000 \\
\hline 3 & $\mathrm{fc}=21.5 \times \mathrm{UPV}^{6} 2$ & AIJ, 1983 \\
\hline 4 & $\mathrm{fc}=0.6401 \times \mathrm{UPV}^{2.5654}$ & Ali-benyahia, 2017 \\
\hline 5 & $\mathrm{fc}=0.0316$ exp $\left(1.3^{*} \mathrm{UPV}\right)$ & Atici, 2011 \\
\hline 6 & $\mathrm{fc}=0.5208 \times \mathrm{UVP}^{5}$ & Khan, 2012 \\
\hline 7 & $\mathrm{fc}=50.163 \times \mathrm{UPV}-178.2$ & Kim, 2012 \\
\hline 8 & $\mathrm{fc}=0.0136 \times \mathrm{UPV}-21.34$ & Najim, 2017 \\
\hline 9 & $\mathrm{fc}=38.05 \times \mathrm{UPV}-316.76 \times \mathrm{UPV}+681.62$ & Rashid, 2017 \\
\hline 10 & $\mathrm{fc}=0.854 \exp (1.28882 \times \mathrm{UPV})$ & Trtniket et al., 2009 \\
\hline
\end{tabular}

Table 3.

Proposed equations for finding the compressive strength of concrete using UPV [15].

kilometers per second. The expressions are presented below for different coarse aggregate (CA) contents:

For CA (coarse aggregate content) $=1000 \mathrm{~kg} / \mathrm{m}^{3}$

$$
f_{c}=8.88 \exp \cdot(0.42 v)
$$

For $\mathrm{CA}=1200 \mathrm{~kg} / \mathrm{m}^{3}$

$$
f_{c}=0.06 \exp \cdot(1.6 v)
$$

For $\mathrm{CA}=1300 \mathrm{~kg} / \mathrm{m}^{3}$

$$
f_{c}=1.03 \exp \cdot(0.87 v)
$$

For $\mathrm{CA}=1400 \mathrm{~kg} / \mathrm{m}^{3}$

$$
f_{c}=1.39 \exp \cdot(0.78 v)
$$

Table 3 showcases some of the different equations generated by researchers in the last decades to predict compressive strength of concrete, fc, in terms of UPV [15].

\section{Experimental program}

In this section an experimental program was developed and conducted by the author and his graduate student to investigate the compressive strength of LWAC containing a specific type of expanded glass aggregate (EGA), to better showcase the properties of LWAC [1].

\subsection{Lightweight and normal weight aggregates}

\subsubsection{NWA}

Tables 4 and 5 consist of the sieve analyses for the normal weight gravel and coarse sand, respectively, which were measured according to ASTM C136-01 [16]. 
The NWA's absorption capacity, specific gravity, and moisture content are evaluated according to ASTM C 127-01 [17] and ASTM C 566 [18]. Table 6 includes aggregate properties such as specific gravity, absorption capacity, moisture content, and fineness modulus (FM). In Figures 1 and 2, the individual aggregates are shown. The maximum normal weight aggregate size was $9.53 \mathrm{~mm}\left(3 / 8^{\prime \prime}\right)$.

\begin{tabular}{lcccc}
\hline Sieve analysis & \multicolumn{5}{c}{ Sample size (SS): 2.27 kg } \\
\hline Sieve size & Weight retained (kg.) & \% retained & \% coarser & \% finer \\
\hline $19 \mathrm{~mm}$ & 0 & 0 & 0 & 0 \\
\hline $13 \mathrm{~mm}$ & 0 & 0 & 0 & 0 \\
\hline $9 \mathrm{~mm}$ & 0.047 & 2.073 & 2.073 & 97.93 \\
\hline No. 4 & 1.6 & 70.49 & 72.56 & 27.4 \\
\hline No. 8 & 0.5 & 21.622 & 94.18 & 5.82 \\
\hline No. 10 & 0.021 & 0.92 & 95.1 & 4.9 \\
\hline Passing & 0.112 & 4.9023 & 99.99 & 0.001 \\
\hline Sum of SS & 2.27 & & & \\
\hline
\end{tabular}

Table 4 .

Sieve analysis for normal weight gravel mix.

\begin{tabular}{lccc}
\hline Sieve analysis & \multicolumn{3}{c}{ Sample size (SS): $\mathbf{1 0 0 0} \mathbf{g}$} \\
\hline Sieve no. & Weight retained (g) & \% retained & \% finer \\
\hline 8 & 5 & 0.5 & 99.5 \\
\hline 10 & 49.5 & 5.45 & 94.55 \\
\hline 16 & 283 & 33.75 & 66.25 \\
\hline 20 & 286.5 & 62.4 & 37.6 \\
\hline 30 & 364.5 & 98.85 & 1.15 \\
\hline 40 & 11 & 99.95 & 0.05 \\
\hline pan & 0.5 & 100 & 0 \\
\hline Sum of SS & 1000 & & \\
\hline
\end{tabular}

Table 5.

Sieve analysis for normal weight coarse sand.

\begin{tabular}{|c|c|c|c|c|c|}
\hline \multirow[t]{2}{*}{ Property } & \multicolumn{2}{|c|}{ Normal weight aggregates } & \multicolumn{2}{|c|}{ Lightweight aggregates } & \multirow[b]{2}{*}{$\begin{array}{c}\text { Poraver } \\
(2-4 \mathrm{~mm})\end{array}$} \\
\hline & $\begin{array}{l}\text { Gravel mix } \\
\quad(\mathrm{GM})\end{array}$ & $\begin{array}{l}\text { Coarse sand } \\
\text { (CS) }\end{array}$ & $\begin{array}{c}\text { Poraver } \\
(0.25-0.5 \mathrm{~mm})\end{array}$ & $\begin{array}{l}\text { Poraver } \\
(1-2 \mathrm{~mm})\end{array}$ & \\
\hline $\begin{array}{l}\text { Specific gravity } \\
\left(\text { ton } / \mathrm{m}^{3}\right)\end{array}$ & 2.4 & 2.75 & 0.55 & 0.36 & 0.32 \\
\hline $\begin{array}{l}\text { Absorption } \\
\text { capacity (\%) }\end{array}$ & 2.3 & 1.87 & 19 & 9 & 9 \\
\hline $\begin{array}{l}\text { Moisture content } \\
(\%)\end{array}$ & 4.5 & 6.4 & 0.5 & 0.5 & 0.5 \\
\hline Fineness modulus & 3.64 & 2.9 & 1.92 & 3.81 & 4.7 \\
\hline
\end{tabular}

Table 6.

LWA and NWA properties. 


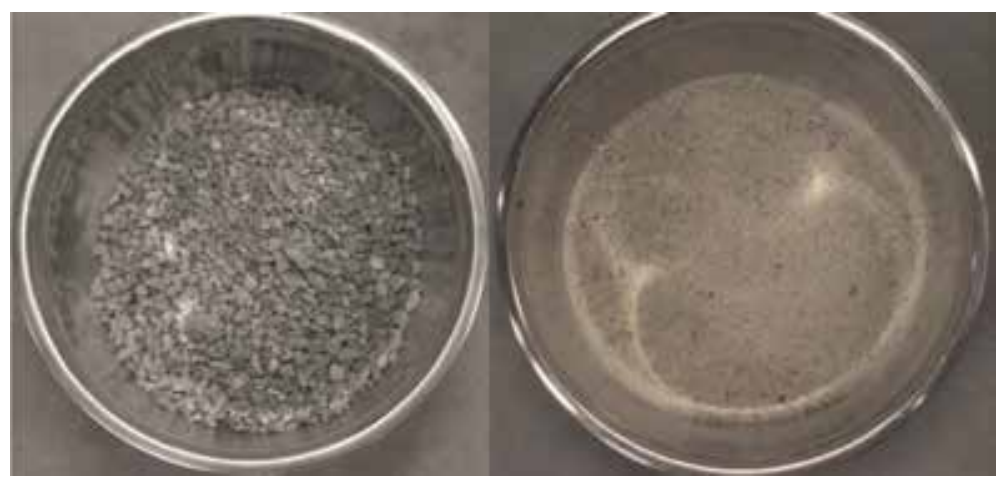

Figure 1.

NWA, from left to right, normal weight gravel mix, and coarse sand.
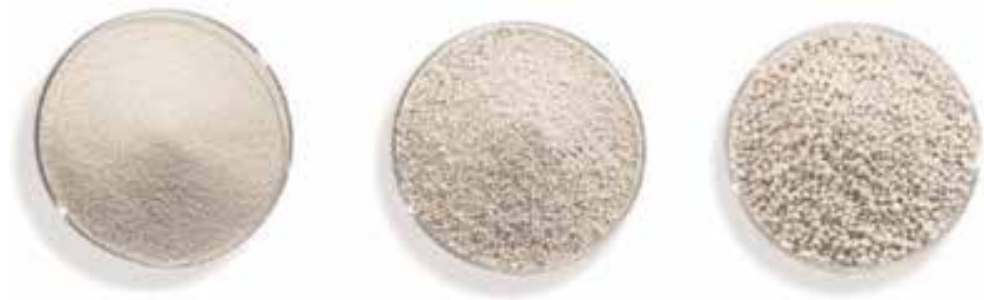

Figure 2.

LWA, from left to right, Poraver $0.25-0.5,1-2$, and 2-4 $\mathrm{mm}$.

\subsubsection{LWA}

The LWA used in this study is Poraver, [19] which is an expanded glass granule. The material is pressure resistant, durable and dimensionally stable, $100 \%$ mineral, spherical in shape, ecological, and not hazardous to health. According to the Poraver technical data sheet, the aggregate is lightweight according to ASTM C330, C331, and C332 and DIN EN 13055-1. Mineral casting and polymer concrete, plaster and dry mortar, lightweight panels, automotive, 3D printing, and other additional practices are practical applications of this material. The aggregate sizes and properties of the LWA are presented in Table 6. The Poraver technical data sheet provided the absorption capacity and moisture content on delivery and specific gravity for the LWA [19].

\subsection{Mix proportion}

The experimental work includes various concrete mixes consisting of lightweight EGA, and these concrete mixes were created with partial or total replacement of NWA with LWA. The ACI 211.2-98 guide for LWC was followed for mix designing [20]. In this study, the control of the cement content is intended to properly understand the compressive strength for different concrete mixes without being influenced by the cementitious material effects. Many combinations of aggregates were tested and the optimum aggregate sizes to increase the compressive strength were selected. The mix proportions of the LWAC mixes are found in Table 7. The cement type used was Ordinary Portland cement CEM I $42.5 \mathrm{~N}$. In the presented tables, Poraver size $0.25-0.5$ is referred to as LWA (fine), while the LWA sizes, 1-2 and 2-4 mm, are considered as LWA (coarse). 


\begin{tabular}{|c|c|c|c|c|c|c|c|c|}
\hline \multirow{2}{*}{$\begin{array}{l}\text { Mix } \\
\text { label }\end{array}$} & \multirow{2}{*}{$\mathrm{w} / \mathrm{c}$} & \multirow{2}{*}{$\begin{array}{l}\text { Cement } \\
(\mathrm{g})\end{array}$} & \multirow{2}{*}{$\begin{array}{l}\text { Water } \\
(\mathrm{g})\end{array}$} & \multirow{2}{*}{$\begin{array}{l}\text { GM } \\
(\mathrm{g})\end{array}$} & \multirow{2}{*}{$\begin{array}{l}\text { CS } \\
(\mathrm{g})\end{array}$} & \multirow{2}{*}{$\begin{array}{l}\text { LWA } \\
\begin{array}{l}(0.25-0.5 \mathrm{~mm}) \\
(\mathrm{g})\end{array}\end{array}$} & \multirow{2}{*}{$\begin{array}{c}\text { LWA } \\
\begin{array}{c}(1-2 \mathrm{~mm}) \\
(\mathrm{g})\end{array}\end{array}$} & \multirow{2}{*}{$\begin{array}{c}\text { LWA } \\
\begin{array}{c}(2-4 \mathrm{~mm}) \\
(\mathrm{g})\end{array}\end{array}$} \\
\hline & & & & & & & & \\
\hline 1 & 0.29 & 685 & 199 & 304 & 2545 & - & - & 154 \\
\hline 2 & 1.88 & 576 & 1084 & 658 & 1275 & - & - & 2631 \\
\hline 3 & 0.31 & 576 & 177 & 3284 & 508 & - & - & 767 \\
\hline 4 & 0.47 & 576 & 272 & 2631 & 1021 & - & 658 & 254 \\
\hline 5 & 0.47 & 576 & 272 & 658 & 1021 & 254 & 658 & - \\
\hline 6 & 0.7 & 576 & 404 & 1973 & 767 & 508 & 329 & - \\
\hline 7 & 0.7 & 576 & 404 & 658 & 1021 & 254 & 658 & - \\
\hline 8 & 0.47 & 576 & 272 & 3284 & 1021 & 181 & - & - \\
\hline 9 & 0.47 & 576 & 272 & 3284 & 767 & 167 & - & - \\
\hline 10 & 0.47 & 576 & 272 & 3284 & 508 & 253 & - & - \\
\hline 11 & 0.47 & 576 & 272 & 3284 & 254 & 340 & - & - \\
\hline 12 & 0.47 & 576 & 272 & 3284 & 340 & 421 & - & - \\
\hline
\end{tabular}

Table 7 .

Mix proportions.

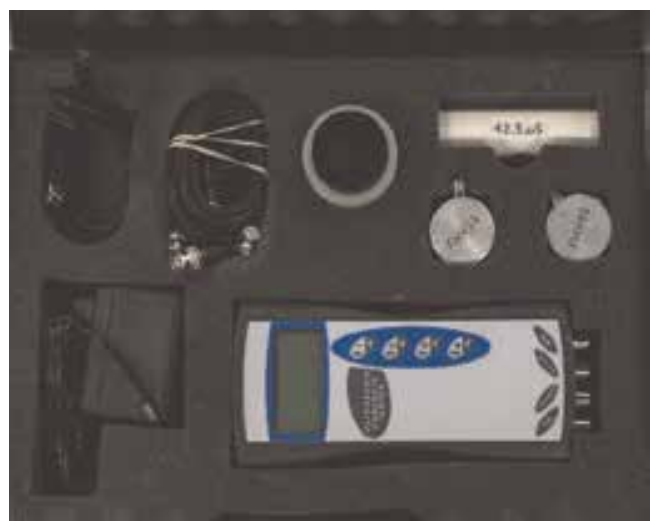

Figure 3.

Ultrasonic pulse velocity instrument.

\subsection{Test methods}

ASTM C 192 was used as the guide for making and curing concrete test specimens in the laboratory [21]. The specimens were demolded after 24 hours and submerged underwater until a day before testing. UPV (Figure 3) and the axial compression machine (ACM) in Figure 4 were used to determine the compressive strength of concrete at days 7 and 28.

\subsection{Results and discussion}

In general it was observed that with increase in the amount of LWA in the concrete mixture, the compressive strength and UPV of LWC decrease, which was expected. In Figure 5, the relationship between UPV and fc (measured with ACM), at the age of 7 and 28 days for the LWC is presented. It can be observed that the results are scattered and more tests and specimens and concrete mixtures will be 


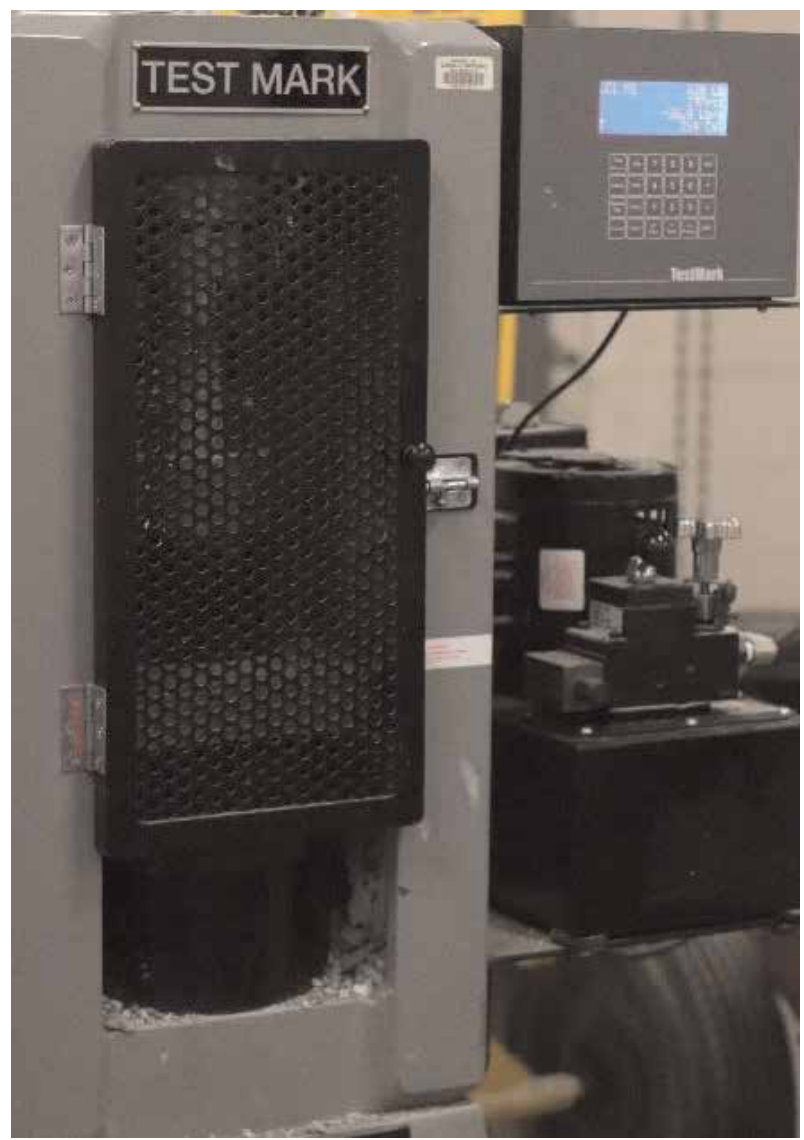

Figure 4 .

Compression test machine.

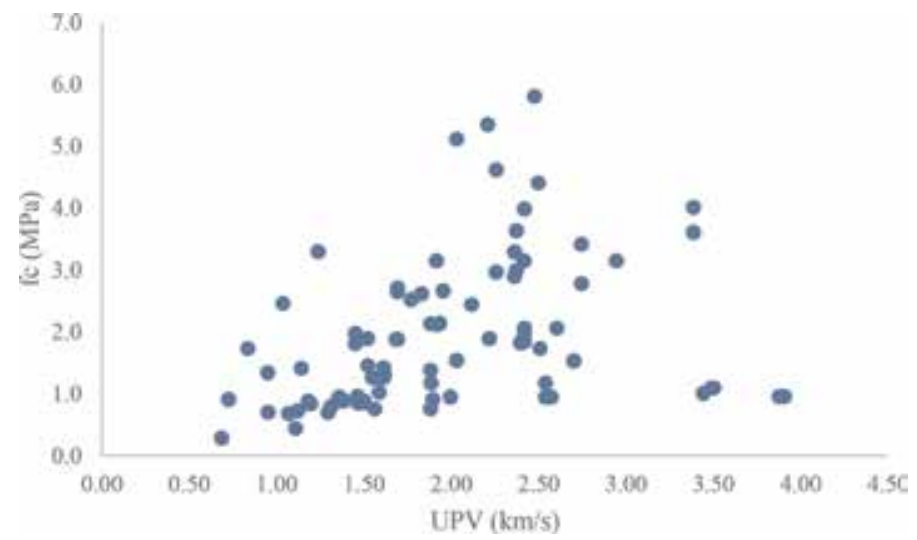

Figure 5 .

$U P V$ versus fc for $L W C$ tested at days 7 and 28.

required to be able to establish a solid relationship between UPV and compressive strength for this type of LWAC. The best empirical relation obtained from curve fitting analyses for this study can be written as below:

$$
f_{c}=0.8 \exp (0.335 \mathrm{v})
$$




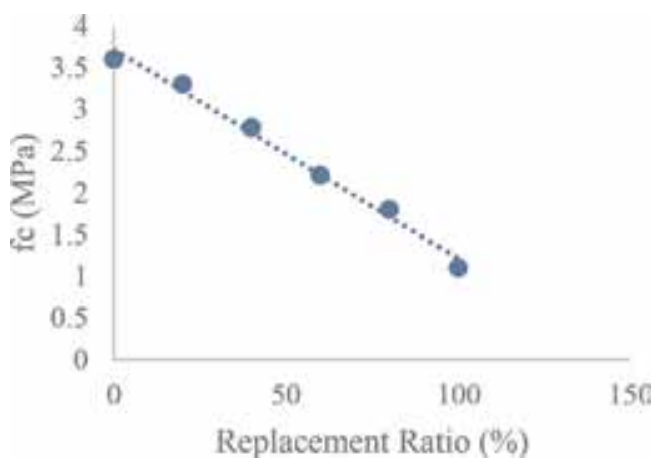

Figure 6.

fc versus $R R$ for $L W C$.

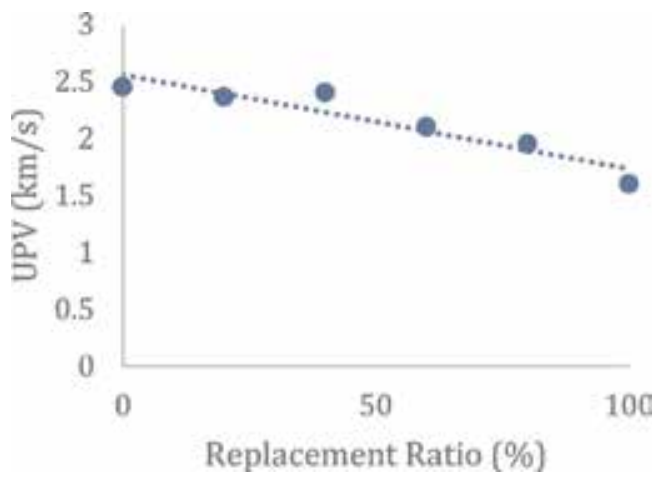

Figure 7.

$U P V$ versus $R R$ for $L W C$.

where $f_{c}$ is the compressive strength of concrete $(\mathrm{MPa})$ and $v$ is the pulse velocity $(\mathrm{km} / \mathrm{s})$.

To be able to investigate the effect of the LWA content in the mix proportions, we have selected the mixes with constant w/c ratio of 0.47 and gradually replaced the NWA with LWA (Table 8). Figure 6 depicts the relation between fc and replacement ratio (RR) or LWA content for these individual mix proportions. From this figure, it can be observed that for the LWC in this study, as the LWA content increases, fc decreases. Figure 7 shows the relation between UPV and RR or LWA content for these individual mix proportions. From this figure, it can be observed that for the LWC in this study, as the LWA content increases, UPV decreases as expected.

\begin{tabular}{ccccccccc}
\hline Mixes & RR & w/c & Cement (g) & Water (g) & GM (g) & CS (g) & LWA, coarse (g) & LWA, fine (g) \\
\hline $12 \mathrm{a}$ & 0 & 0.47 & 576 & 272 & 3284 & 1275 & - & 0 \\
\hline $12 \mathrm{~b}$ & 20 & 0.47 & 576 & 272 & 3284 & 1021 & - & 254 \\
\hline $12 \mathrm{c}$ & 40 & 0.47 & 576 & 272 & 3284 & 767 & - & 508 \\
\hline $12 \mathrm{~d}$ & 60 & 0.47 & 576 & 272 & 3284 & 508 & - & 767 \\
\hline $12 \mathrm{e}$ & 80 & 0.47 & 576 & 272 & 3284 & 254 & - & 1021 \\
\hline $12 \mathrm{f}$ & 100 & 0.47 & 576 & 272 & 3284 & 0 & - & 1275 \\
\hline
\end{tabular}

Table 8.

Comparison between different LWA contents. 
The relationship between UPV, fc (compressive strength), and dry density for the mix proportions in Table $\mathbf{8}$ is presented in Figures $\mathbf{8}$ and 9. It can be observed that for the LWC in this study, as the dry density increases, UPV and fc also increase, but the results are scattered when working with LWC. To be able to compare these results from those of NWC, mixes of NWC with similar compositions but without any LWA were produced, and results were presented in Figures 10 and 11. It is observed that the result for the relationship between UPV, fc and, dry density for LWC is more scattered than similar test result for NWC.

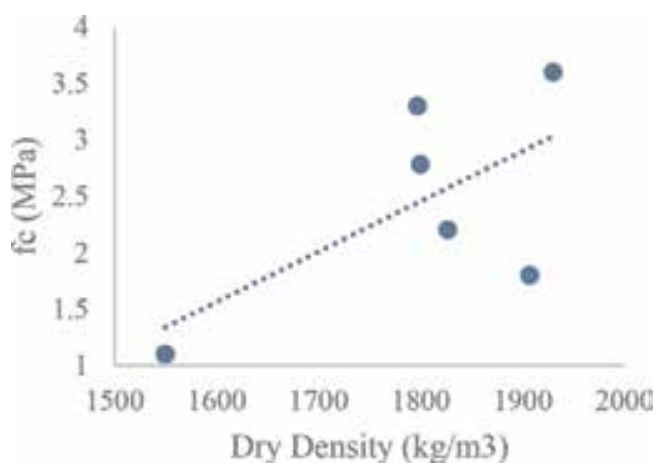

Figure 8.

fc versus dry density for LWC.

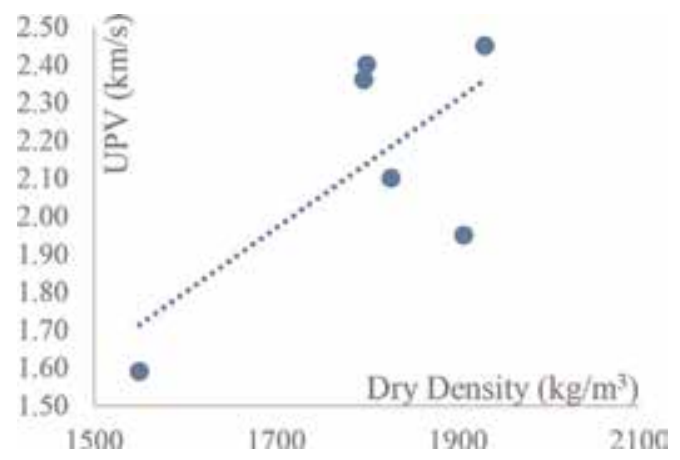

Figure 9.

$U P V$ versus dry density for $L W C$.

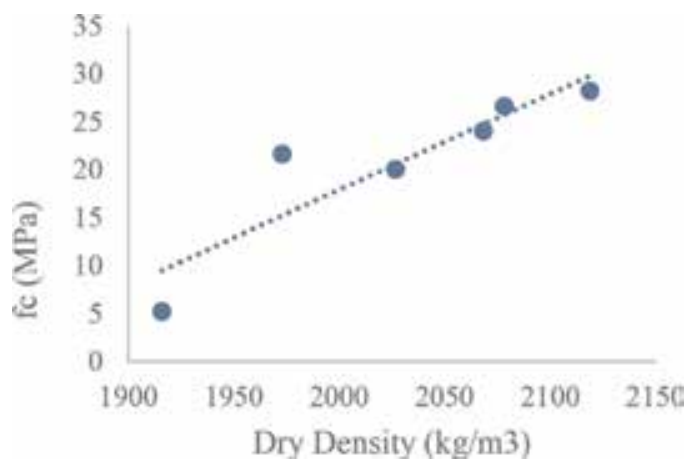

Figure 10.

fc versus dry density for NWCUPV versus dry density for NWC. 


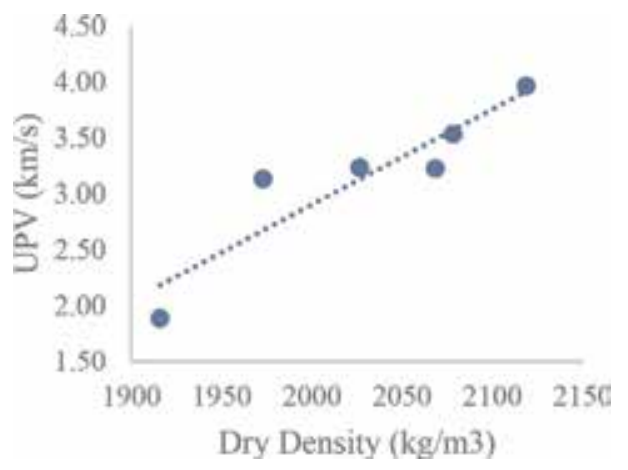

Figure 11.

UPV versus dry density for NWC.

\section{Conclusions}

There are different types of LWC available in the industry that depending on the method which is used for production of each type, the properties of the LWC can be completely different. Lightweight aggregate concrete (LWAC), foamed concrete (FC), and autoclaved aerated concrete (AAC) are among the most common types. On the other hand, structural and nonstructural lightweight concrete can be produced for different purposes. Lightweight aggregate concrete, such as the one discussed in this study, are being used nowadays in the advancement of concrete technology, but it is proven that each type of LWA needs to be tested before being used in structures and even for nonstructural purposes. Compressive strength of LWC is an important characteristic of LWC that can be measured or predicted with few methods such as NDT methods. Ultrasonic pulse velocity was utilized to assess the compressive strength, fc, of the LWC containing EGA in the present study. In this chapter it was observed that LWA can replace NWA to achieve smaller bulk densities and UPV can be used as a method for evaluation of compressive strength of LWC. Based on the case study conducted in the present chapter, it was showcased that as the dry density of the LWC decreased, UPV and fc decreased, respectively. Comparisons of actual fc values obtained from CTM proved UPV can be related to fc, and the results showed similar characteristics to previous works, while the previous work's equations cannot be used for the aggregates used in this study. The results of the present study are limited to the mix design and materials that were used in this work, and it should be noted that these results cannot be extended to other types, sizes, etc. of aggregates and different mix designs. 


\section{Author details}

\section{Saman Hedjazi}

Department of Civil Engineering and Construction, Georgia Southern University, Statesboro, GA, USA

*Address all correspondence to: shedjazi@georgiasouthern.edu

\section{IntechOpen}

(C) 2019 The Author(s). Licensee IntechOpen. This chapter is distributed under the terms of the Creative Commons Attribution License (http://creativecommons.org/licenses/ by/3.0), which permits unrestricted use, distribution, and reproduction in any medium, provided the original work is properly cited. (c) BY 


\section{References}

[1] Collins C. Investigation on the properties of lightweight concrete consisting of expanded glass aggregate pulse velocity method [Master Project]. GA, USA: Georgia Southern University; 2019

[2] Bogas AJ, Brito J, Figueiredo JM. Mechanical characterization of concrete produced with recycled lightweight expanded clay aggregate concrete. Journal of Cleaner Production. 2015;89: 187-195

[3] Kumar AR, Prakash P. Mechanical properties of structural light weight concrete by blending cinder and LECA. International Advanced Research Journal in Science, Engineering Technology. 2015;2(10):64-67

[4] Dachowski R, Kostrzewa P. The use of waste materials in the construction industry. Procedia Engineering. 2016; 161:754-758

[5] Kurpinska M, Ferenc T. Effect of porosity on physical properties of lightweight cement composite with foamed glass aggregate. ITM Web of Conferences; 15, 06005; 2017

[6] Chung SY, Elrahman MA, Sikora P, Rucinska T, Horszczaruk E, Stephan D. Evaluation of the effects of crushed and expanded waste glass aggregates on the material properties of lightweight concrete using image-based approaches. Materials (Basel). 2017;10(12):1354

[7] Rumsys D, Spundulis E, Bacinskas D, Kaklauskas G. Compressive strength and durability properties of structural lightweight concrete with fine expanded glass and/or clay aggregates. MDPI, Materials. 2018;11:2434

[8] AASHTO: American Association for State Highway and Transportation Officials. The Manual for Bridge Evaluation, 3rd ed., Section 5: Material
Testing. Washington, DC: Highways Subcommittee on Bridges and Structures; 2018. pp. 5-i-5-18

[9] Mohamad-Ali AA, Abdullah MD, Chkheiwer AH. Estimating of compressive strength of different types of concrete by nondestructive tests. International Journal of Advances in Mechanical and Civil Engineering. 2016;3(5)

[10] Al-Nu'man BS, Aziz BR, Abdulla SA, Khaleel SE. Compressive strength formula for concrete using ultrasonic pulse velocity. International Journal of Advances in Mechanical and Civil Engineering. 2015;26(1):9-13

[11] EN 1992. Eurocode 2: Design of concrete structures-Part 1-1: General rules and rules for buildings. European Committee for Standardization CEN; 2004

[12] Chingalata C, Budescu M, Lupasteanu R, Lupasteanu V, Scutaru MC. Assessment of the Concrete Compressive Strength using Nondestructive Methods. Vol. 63(67). Iași, Romania: Gheorghe Asachi Technical University; 2017

[13] Bogas AJ, Gomes GM, Gomes A. Compressive strength evaluation of structural lightweight concrete by non-destructive ultrasonic pulse velocity method. Ultrasonics. 2013;53: 962-972

[14] ASTM C597-02. Standard Test Method for Pulse Velocity Through Concrete. Pennsylvania: ASTM International; 2002

[15] Ju M, Park K, Oh H. Estimation of compressive strength of high strength concrete using non-destructive technique and concrete core strength. Applied Science. 2017;7:1249 
[16] ASTM C136-01. Standard Test

Method for Sieve Analysis of Fine and

Coarse Aggregates. West

Conshohocken, PA: ASTM

International; 2001

[17] ASTM C127-01. Standard Test

Method for Density, Relative Density

(Specific Gravity), and Absorption of

Coarse Aggregate. West Conshohocken,

PA: ASTM International; 2001

[18] ASTM C566. Standard Test Method for Total Evaporable Moisture Content of Aggregate by Drying. West

Conshohocken, PA: ASTM

International; 2004

[19] Poraver® Blähglas. Home. Available from: https://www.poraver.com/us/ poraver/ [Accessed: 06 March 2019]

[20] ACI 211.2-98. Selecting proportions for structural lightweight concrete.

Farmington Hills: American Concrete Institute (ACI); 1998

[21] ASTM C 192/C 192M-06. Standard Practice for Making and Curing Concrete Test Specimens in the Laboratory. West Conshohocken, PA: ASTM International; 2006 


\title{
Investigation of the Quasi-Static and Dynamic Confined Strength of Concretes by Means of Quasi-Oedometric Compression Tests
}

\author{
Pascal Forquin
}

\begin{abstract}
For the two last decades, the quasi-oedometric compression testing method has been widely employed to characterize the quasi-static and dynamic confined response of concrete and rock-like materials. It consists of compressing a cylindrical specimen tightly enclosed in a thick confinement vessel for determining the hydrostatic and deviatoric behaviors of these materials under pressure ranging from few tens to a thousand of MPa. Large capacity hydraulic press can be used for quasistatic loading whereas large-diameter Split-Hopkinson Pressure Bar can be employed to characterize the dynamic response of the tested samples. This chapter describes the principle of this testing technique, the processing method, validation tools provided in the literature and some key-results obtained regarding the influence of concrete composition, particles reinforcement, free water content and the loading-rates on the hydrostatic and deviatoric behaviors of concretes.
\end{abstract}

Keywords: concrete, high pressure, metallic vessel, mechanical testing, quasi-oedometric compression test

\section{Introduction}

In many applications, geomaterials or other rock-like materials (concretes, mortars, rocks, granular materials, ice, etc.) are subjected to an intense loading characterized by high levels of pressure and high or very high rates of loading [1]. For instance, we can mention the vulnerability of concrete structures subjected to hard impact [2] in which the shear resistance and compaction law (irreversible diminution of the volume) of concrete under high pressure is known to condition the penetration of the projectile into thick targets [3-7]. One may also mention the issue of rock blasting in open quarries for the production of aggregates and sand where controlling the block size distribution is an important objective [8], the use of percussive drilling tools in civil engineering that induce high stresses beneath the indenter [9-11] or the dynamic compaction of soils. In all these applications, the geomaterial is subjected to very high confinement pressures ranging from few tens to several hundreds of MPa. A good grasp of the behavior of geomaterials under confined compression is essential to any understanding and modeling of their 
performances in order to improve the efficiency of the protective solutions or the industrial applications of concern.

Triaxial tests have been developed for half a century to characterize the mechanical behavior of concretes [12] and rocks [13] under high confinement levels. It consists in applying a purely hydrostatic pressure on a cylindrical specimen by means of a fluid followed by an additional axial compression. In this case, the stress tensor is defined with the two components $\left(\sigma_{\text {radial }}, \sigma_{\text {axial }}\right)$ :

$$
\bar{\sigma}=\left[\begin{array}{ccc}
\sigma_{\text {radial }} & 0 & 0 \\
0 & \sigma_{\text {radial }} & 0 \\
0 & 0 & \sigma_{\text {axial }}
\end{array}\right]\left(\overrightarrow{U_{r}}, \overrightarrow{U_{\theta}}, \overrightarrow{U_{z}}\right),
$$

where $\left(\overrightarrow{U_{r}}, \overrightarrow{U_{\theta}}, \overrightarrow{U_{z}}\right)$ corresponds to the frame attached to the cylindrical sample. The deviatoric stress is defined as the axial stress (in absolute value) on withdrawal of the lateral pressure exerted by the confinement fluid:

$$
\sigma_{\text {deviatoric }}=\left|\sigma_{\text {axial }}-\sigma_{\text {radial }}\right| \text {, }
$$

and the hydrostatic pressure is defined by averaging the three principle stresses:

$$
P_{\text {hydrostatic }}=\frac{-\sigma_{\text {axial }}+2 \sigma_{\text {radial }}}{3}
$$

The deviatoric strength is usually taken as the maximum deviatoric stress reached during the test and a series of triaxial tests performed at different lateral pressure provides several end-points that makes possible to deduce the limit state curves of the tested sample under static loading [14] or dynamic loading [15]. During the last decade, triaxial tests have been conducted in the 3SR laboratory with a high-capacity triaxial press (the GIGA press) able to generate a maximum confining pressure of $0.85 \mathrm{GPa}$ and an axial stress of $2.3 \mathrm{GPa}$ applied to cylindrical concrete specimen $7 \mathrm{~cm}$ in diameter and $14 \mathrm{~cm}$ long. As observed with quasi-oedometric compression tests $[16,17]$, the triaxial experiments conducted with dried, partially-saturated and fully-saturated ordinary concrete samples revealed that, under high confinement, the presence of free water in the sample affects the volumetric stiffness and reduces a lot the strength capacity $[18,19]$. The role of water to cement ratio [20], cement matrix porosity [21], coarse aggregate size [22] and shape [23] in concrete samples under high triaxial compression loading was also explored with the same triaxial test apparatus. However, triaxial tests present some limitations which make them costly and difficult to perform specially under dynamic loading conditions. Indeed, they demand a very high pressure chamber (100-1000 MPa) coupled to a rigid load frame and they require impermeability between the confining fluid and the specimen that is not easy to carry out, in particular under high loading-rates. Figure 1 provides several limit state curves obtained from triaxial tests conducted with ordinary concrete (Common concrete), high strength concrete (CRE140) and with several types of ultra-high strength (reactive powder) concretes (BPR200, BPR300, BPR 600) [24]. These experimental results illustrate the sharp increase of concrete strength as a function of the applied hydrostatic pressure. The levels of axial stress and radial stress needed to reach any points in Figure 1 can be easily deduced considering the following equations (cf. red solid arrows and blue dotted arrows):

$$
\begin{aligned}
& \left|\sigma_{\text {axial }}\right|=P_{\text {hydrostatic }}+\frac{2}{3} \sigma_{\text {deviatoric }}, \\
& \left|\sigma_{\text {radial }}\right|=P_{\text {hydrostatic }}-\frac{1}{3} \sigma_{\text {deviatoric }} .
\end{aligned}
$$




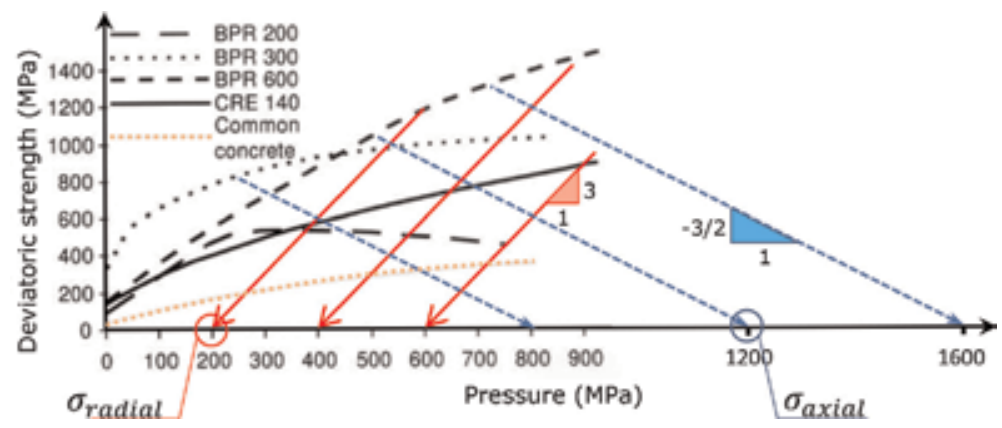

Figure 1.

Limit state curves obtained from triaxial tests performed on ordinary concrete (Common concrete), high strength concrete (CRE140) and ultra-high strength concretes (BPR200, BPR300, BPR 600) [24] and corresponding levels of axial and radial stresses to be reached during the test.

Thus, it can be remarked that the last point of the "Common concrete" curve requires relatively close levels of radial stress and axial stress (respectively, about 700 and $1000 \mathrm{MPa}$ ) due to the small mean stress difference at this end of the test, the last point of BPR600 requires much smaller level of radial stress (about $400 \mathrm{MPa}$ ) and much higher level of axial stress (more than $1800 \mathrm{MPa}$ ). In conclusion, it appears that the level of axial and radial stresses to be applied during a triaxial or quasi-oedometric tests may need to be adapted as function of the level of the desired hydrostatic pressure and as function of the expected level of strength of the tested material.

The quasi-oedometric compression (QOC) testing method provides a very attractive alternative to triaxial tests. It is based on the use of a cylindrical sample, a confinement cell that is usually designed as a simple metallic ring, two compression plugs and an interface product that should be used to fill the gap between the sample and the inner surface of the cell. Once the sample is inserted in the confinement cell and the compression plugs are put in contact with the top and bottom surfaces of the sample, an axial compression is applied. The specimen tends to expand under the effect of its radial expansion and exerts a lateral pressure against the confinement cell. In the course of the test, a rise of both axial and radial stresses is observed in the specimen, which gives a possible reading of the mean stress difference as a function of the level of applied pressure (the so-called deviatoric behavior) and of the diminution of the sample volume with the level of hydrostatic pressure (the so-called compaction law).

A strong limitation must be underlined at that point: since the test is driven only by the axial strain, it provides a single loading path (i.e. the "quasi-oedometric loading path") corresponding to an almost "1D” uniaxial-strain loading path. However, it cannot be concluded whether the variation of the strength is provoked mainly by the variation of the axial strain independently of the pressure level or by the change of hydrostatic pressure independently of the level of axial strain neither whether the mechanical response might be changed by subjecting the sample to a different loading path.

The QOC testing technique has been continuously developed for concretes during the last three decades. Among the proposed experimental devices, one may cite the technique developed by Bažant et al. [25] (Figure 2(a)) where a cylindrical concrete specimen is placed in a hole and compressed. However, the lateral pressure exerted between the sample and the inner surface of the hole could not be measured during the test. Burlion [26] devised an instrumented vessel of $53 \mathrm{~mm}$ as interior diameter and $140 \mathrm{~mm}$ as exterior diameter, which was considered stressed in its elastic domain (Figure 2(b)). An interface product was used between the vessel 


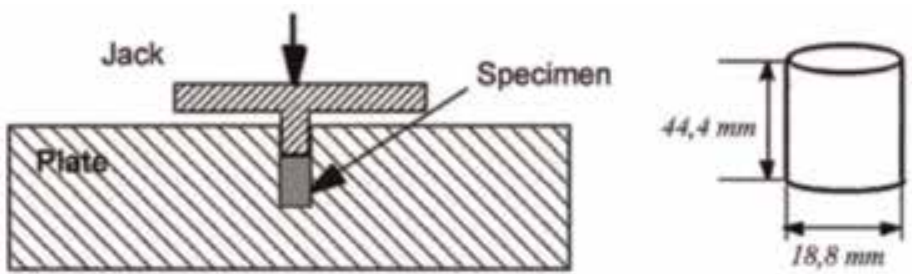

(a)
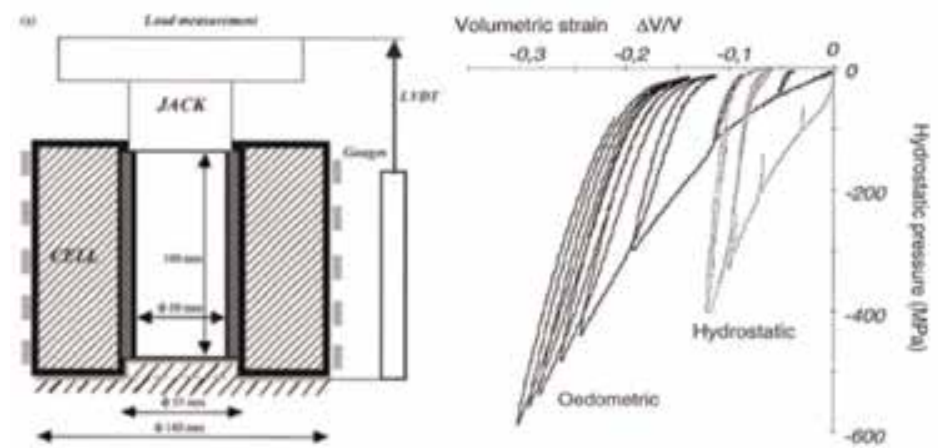

(b)

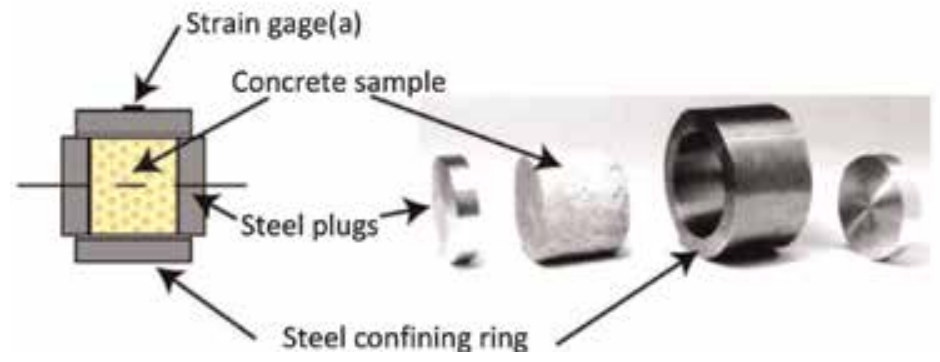

(c)

Figure 2.

Quasi-oedometric compression testing devices applied to concrete. (a) Technique method developed by Bažant et al. [25]. (b) Instrumented vessel used in [27], (c) smaller confining cells used under quasi-static and dynamic loading conditions [28].

and the specimen to fill the gap between the sample and the vessel, which allows for correcting any possible defects of cylindricality of the sample. The interface product was an epoxy bi-component resin, Chrysor ${ }^{\circledR}$ C6120, commonly used for structural applications, and once polymerized, eliminates any internal play. The radial stress in the specimen was deduced from the measurements provided by strain-gauges attached to the outer surface of the vessel [27] based on the well-known analytical solution of an elastic tube subjected to a uniform pressure applied against its whole inner surface. So, the 'barrel' deformation of the vessel was not taken into account in this analysis. Smaller confining cells, 30 or $50 \mathrm{~mm}$ as inner diameter and 50 or $70 \mathrm{~mm}$ as outer diameter, were used in [28] to test a micro-concrete under quasi-static and dynamic loadings (Figure 2(c)). A maximum axial strain up to $-30 \%$ was reached before unloading. Later, a new processing method was proposed in [29] and applied to these experimental data to evaluate the level of radial stress in the specimen from the hoop strain measured on the outer surface of the confining cell, taking into account the sample shortening. Both deviatoric and hydrostatic responses of this microconcrete were obtained from the processed data, which showed a quite limited influence of the rate of loading on the strength, even at a strain-rate of $400 \mathrm{~s}^{-1}$ [30].

The testing procedure and data processing method were substantially improved in several works and applied to successively investigate the influence of particles size and shape [31,32] and of the porosity [6] on the confined behavior of 
particle-reinforced cement composites, but also to analyze the role plaid by free-water on the quasi-static and dynamic confined responses of microconcrete $[16,30]$, ordinary concrete [33] and high-performance concrete [34] and to study the effect of coarse aggregates strength on the static and dynamic behavior of concrete under high confinement [35].

In this chapter, the principle of QOC tests, the data processing technique and some validation tools are presented. Next, some main obtained results are gathered. Finally, all this data allows highlighting the main microstructural parameters influencing the mechanical behavior of concretes under quasi-static or dynamic quasi-oedometric compression loadings.

\section{Principle and data processing of QOC tests}

\subsection{Mounting procedure}

The introduction of the sample into the confining ring constitutes a very delicate stage. Indeed, to be sure that the entire gap between the sample and the inner surface of the ring is filled, it is necessary to cover the inner volume of the ring prior to inserting the sample. In addition, the sample needs to be carefully introduced without any contact with the confining cell under pain to block the sample into the ring by bow buttress. For this purpose, a special procedure was developed, as detailed in [16], to align the ring, the sample and the two plugs. First, the concrete sample is scotch tape to the upper plug. A special device (Figure 3) is used to introduce the concrete specimen within the ring previously partially filled by the bi-components epoxy resin named “Chrysor ${ }^{\circledR}$ C6120”. During this stage, this resin is slowly extruded out and the internal gap between the specimen and the ring is totally fulfilled by the Chrysor ${ }^{\circledR}$, which hardens in less than 24 hours. Next, the lower and upper frames are disassembled and the assembly is ready for testing.

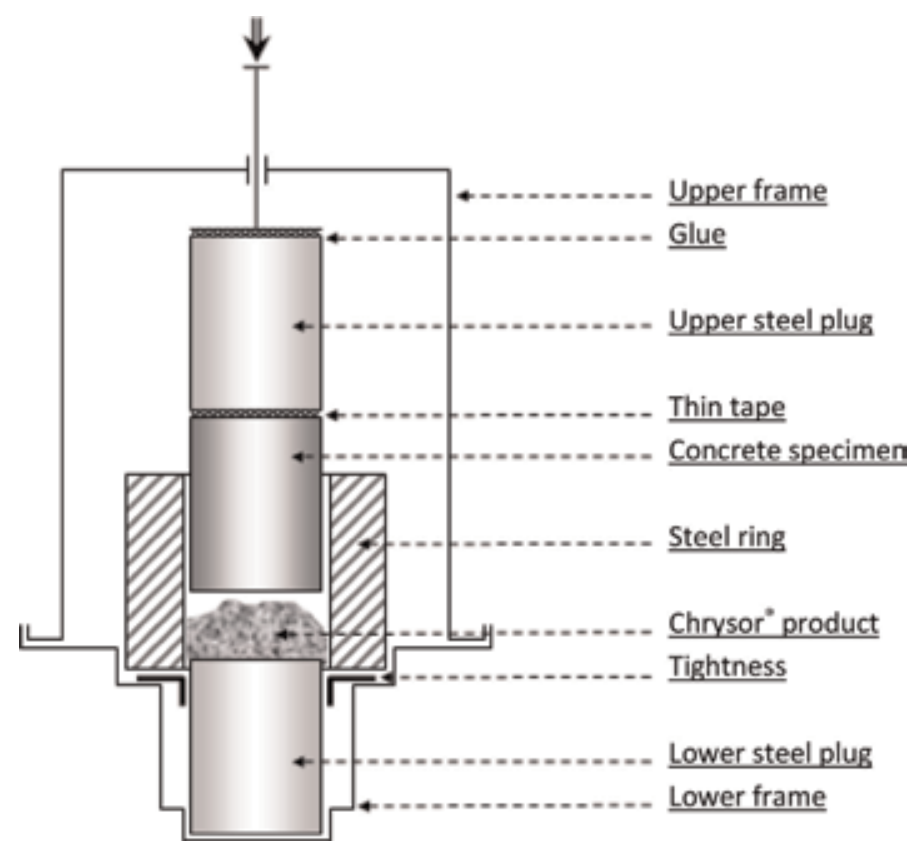

Figure 3.

Schematic of the device to set the sample, the ring and the steel plugs [16]. 


\subsection{Description of experimental configurations}

The list of concrete grades, maximum aggregate size, types of experimental set-up (hydraulic press or SHPB device), dimensions of samples and confining cells used in several works are gathered in Table 1. It can be remarked that the sample diameter is usually about five times larger than the maximum aggregate size. The length to diameter ratio of concrete sample is between 1 and 2 . In addition, the length of the confining cell slightly exceeds the sample length in order to keep the sample inside the cell in particular when a dynamic loading is applied (SHPB device). The outer diameter is chosen as a compromise between a sufficient stiffness of the vessel (diameter large enough) and a good sensibility of strain measurements on the external surface of the vessel (small enough diameter). For this purpose, the outer diameter to inner diameter ratio varies from 1.4 [28] to 2.8 [26] with a predominance of value around 2 [6, 30-35].

Two examples of device used for quasi-static and dynamic testing are represented in Figure 4. The set-up represented in Figure 4(a) was used in $[6,31,32]$ to investigate the quasi-static confined behavior of particle-reinforced cement composites. The loading capacity of the press, $1 \mathrm{MN}$, provides a maximum axial stress about $1400 \mathrm{MPa}$ in the concrete sample, with a sample diameter of $30 \mathrm{~mm}$. The compression plugs are fixed to the lower and upper compression plates. The extensometer that was used to measure the change of sample height is attached to two flasks directly screwed into the compression plugs. Four strain gauges are glued on the outer surface of the confining cell.

An experimental SHPB set-up, also called Koslky's apparatus, can be used to perform dynamic QOC tests. The SHPB experimental technique, widely used today, was pioneered by Kolsky [36]. It consists in a striker, an input bar and an output bar (Figure 4(b)). In $[16,30,34]$, the striker, the input bar and the output bar are $80 \mathrm{~mm}$ in diameter, their length is, respectively, 2.2, 6, and $4 \mathrm{~m}$, and the elastic limit of these elements, made of high-strength steel, is $1200 \mathrm{MPa}$. When the striker hits the free end of the input bar, a compressive incident wave is generated in the input bar. Once the incident wave $\left(\varepsilon_{i}(t)\right)$ reaches the specimen, a transmitted pulse $\left(\varepsilon_{t}(t)\right)$ develops in the output bar whereas a reflected pulse $\left(\varepsilon_{r}(t)\right)$ propagates in the opposite direction in the input bar. These three basic waves (cf. Figure 4(c)), recorded by strain gauges glued on the input and the output bars, are used to

\begin{tabular}{|c|c|c|c|c|}
\hline References & $\begin{array}{c}\text { Concretes }^{*} \text { (Maximum aggregates } \\
\text { size in } \mathrm{mm} \text { ) }\end{array}$ & Set-ups & $\begin{array}{l}\text { Sample diameter } \times \\
\text { length }\end{array}$ & $\begin{array}{c}\text { Cell outer diameter } \times \\
\text { length }\end{array}$ \\
\hline$[26,27]$ & Mortar (2), concrete (16) & Press & $\mathrm{D} 50 \times 100$ & $\mathrm{D} 140 \times 106$ \\
\hline$[28,30]$ & MB50 (5) & $\begin{array}{l}\text { Press, } \\
\text { SHPB }\end{array}$ & $\begin{array}{l}\mathrm{D} 30 \times 40 \\
\mathrm{D} 50 \times 40\end{array}$ & $\begin{array}{l}\mathrm{D} 50 \times 50 \\
\mathrm{D} 70 \times 50\end{array}$ \\
\hline$[6,31,32]$ & $\begin{array}{l}\text { M1, M1M, M1Sph, M2, M2S, M2M, } \\
\text { M2Sph (6) }\end{array}$ & Press & $\mathrm{D} 30 \times 40$ & D55 $\times 46$ \\
\hline$[16]$ & MB50 (5) & $\begin{array}{l}\text { Press, } \\
\text { SHPB }\end{array}$ & $\mathrm{D} 29 \times 40$ & $\mathrm{D} 60 \times 45$ \\
\hline [34] & R30A7 (8), HSC (8) & $\begin{array}{l}\text { SHPB, } \\
\text { Press }\end{array}$ & $\mathrm{D} 40 \times 50$ & $\mathrm{D} 80 \times 60$ \\
\hline$[35]$ & R30A7, LC (10) & $\begin{array}{l}\text { SHPB, } \\
\text { Press }\end{array}$ & $\mathrm{D} 40 \times 50$ & $\mathrm{D} 80 \times 60$ \\
\hline
\end{tabular}

"MB50: microconcrete, M1: mortar without silica fume, (M1M, M1Sph): particle-reinforced mortar without silica fume, M2: mortar with silica fume, (M2S, M2M, M2Sph): particle-reinforced mortar with silica fume, R30A7: siliceous aggregate ordinary concrete, HSC: siliceous aggregate high-strength concrete, LC: limestone aggregate ordinary concrete.

Table 1.

List of concretes, experimental set-ups, dimensions of sample and confining cell considered in several works. 


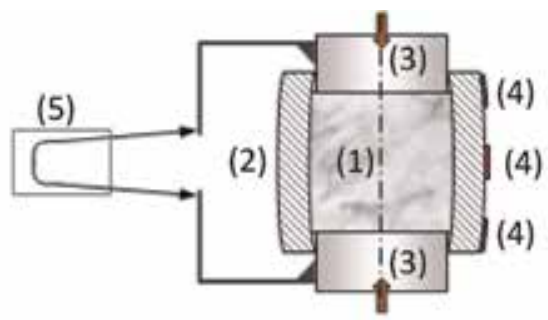

(1) Concrete sample

(2) Confining cell

(3) Steel plugs

(4) Strain gauges

(a)

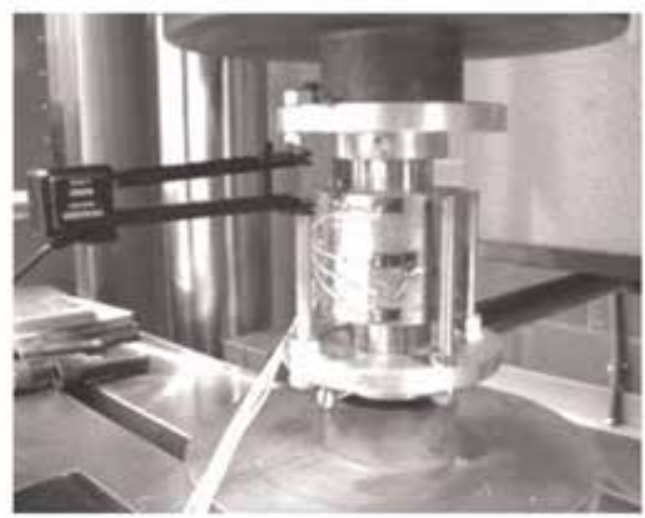

(5) Extensometer
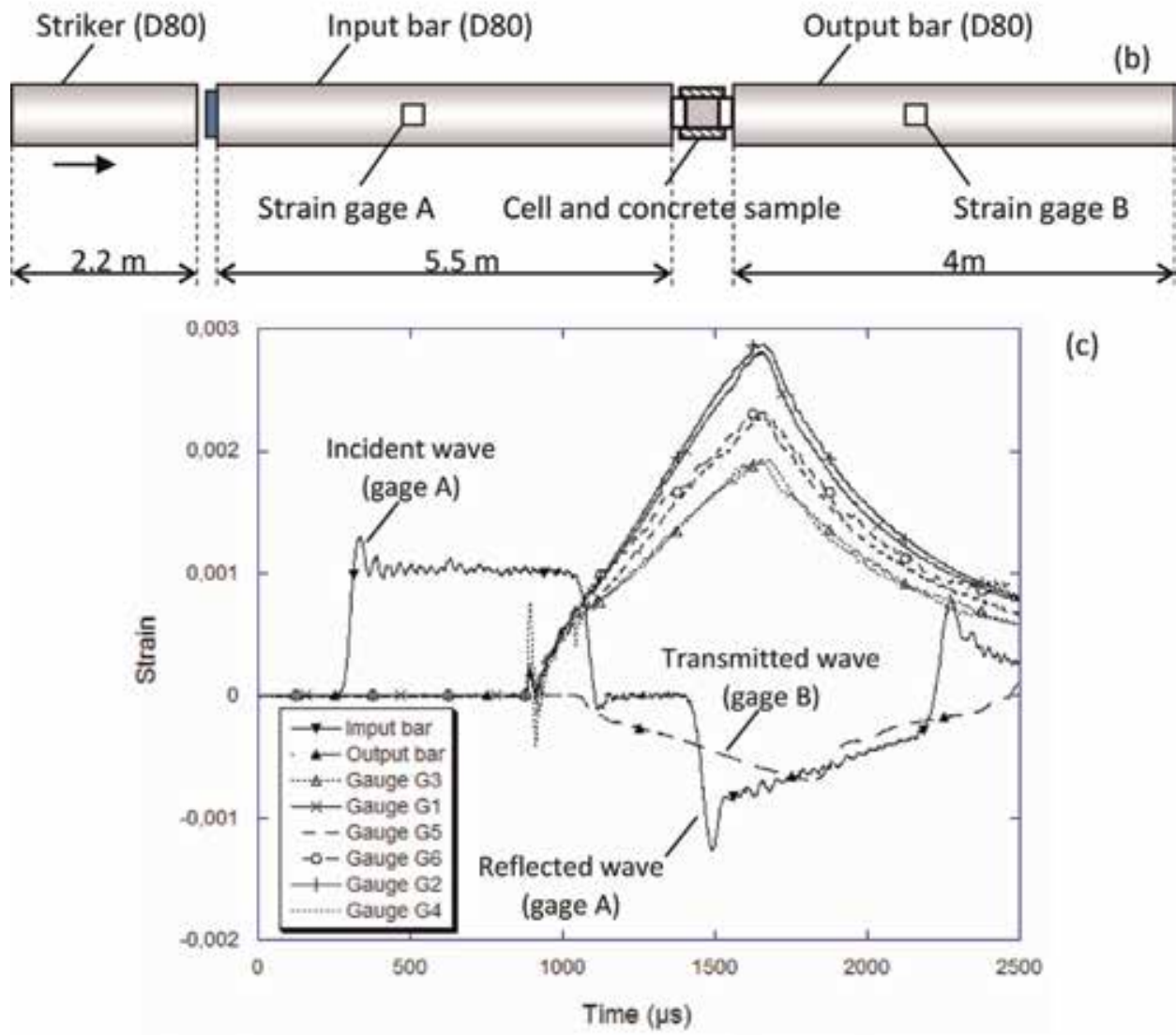

(c)

Figure 4.

Experimental set-up employed for quasi-static and dynamic QOC tests. (a) Hydraulic press used in [6, 31, 32]. (b) Sketch of SHPB system used in [16, 30, 33]. (c) Example of experimental data obtained in [30].

calculate the input and output forces and the input and output velocities at the specimen faces according to the following equations (without taking into account the wave dispersion phenomena that cannot be neglected with large-diameter Hopkinson bars) [36]:

$$
\left\{\begin{array}{c}
F_{\text {in }}(t)=A_{b} E_{b}\left(\varepsilon_{i}(t)+\varepsilon_{r}(t)\right) \\
F_{\text {out }}(t)=A_{b} E_{b}\left(\varepsilon_{t}(t)\right)
\end{array}\right.
$$




$$
\left\{\begin{array}{c}
V_{\text {in }}(t)=-c_{b}\left(\varepsilon_{i}(t)-\varepsilon_{r}(t)\right) \\
V_{\text {out }}(t)=-c_{b}\left(\varepsilon_{t}(t)\right)
\end{array}\right.
$$

where $A_{b}$ is the area of the input and output bars, $E_{b}$ corresponds to their Young's modulus and $c_{b}$ is the speed of a 1D wave propagating in these bars $\left(c_{b}=\sqrt{E_{b} / \rho_{b}}\right)$, considering $\rho_{b}$ as the density of the bars. Finally, the mean axial stress and nominal axial strain in the sample can be deduced:

$$
\begin{gathered}
\bar{\sigma}_{\text {axial }}(t)=\frac{F_{\text {in }}(t)+F_{\text {out }}(t)}{2 A_{S}} \\
\bar{\varepsilon}_{\text {axial }}(t)=\int_{0}^{t} \frac{V_{\text {out }}(u)-V_{\text {in }}(u)}{h_{S}} d u
\end{gathered}
$$

where $h_{S}$ is the sample length. In addition, the elastic limit of the plugs must be significantly higher than the maximum axial stress reached during the dynamic tests so the elastic shortening of the plugs can easily be subtracted from the total measured shortening.

\subsection{Data processing of QOC tests}

A processing technique was proposed in [29] to measure the radial stress in the sample taking into account the barreling deformation of the confining ring and the shortening of the concrete sample during the test. Before this approach was proposed, the closed-form solution of an elastic ring subjected to a uniform internal pressure along its whole length was usually considered but this method can lead to a strongly erroneous estimation of the radial stress in the tested sample. Later, several improvements of the processing methodology have been proposed as listed hereafter. The main advances to process the data of QOC tests are summarized in Table 2.

First, the relation between the radial stress in the specimen and the hoop strain measured thanks to the strain gauge glued on the outer surface of the confining cell must be deduced. The methodology used in [31] is explained in Figure 5. The constitutive behavior of the confining ring was first identified by means of quasi-static tensile tests performed with small samples extracted from a sacrificed ring. Next, this constitutive behavior was introduced in a numerical simulation involving only the confining vessel. Last, two calculations were conducted with the Abaqus/Standard FE code considering an internal pressure which is continuously increased up to $400 \mathrm{MPa}$, and which is applied to the inner surface of the ring along heights of $40 \mathrm{~mm}$ in a first

\begin{tabular}{ll}
\hline References & Advances in the processing methodology \\
\hline$[26,28]$ & $\begin{array}{l}\text { Radial stress estimated based on the close-form solution of an elastic ring subjected to a uniform internal } \\
\text { pressure }\end{array}$ \\
\hline$[29]$ & Radial stress calculated considering the barreling deformation of the cell and the sample shortening \\
\hline$[31]$ & $\begin{array}{l}\text { Radial stress calculated as in [29] and taking into the non-homogeneous and elastoplastic behavior of the } \\
\text { cell } \\
\text { Validation with tests applied to aluminum alloy samples }\end{array}$ \\
\hline$[30-32]$ & $\begin{array}{l}\text { Estimation of the error due to friction and to the interface product by applying the processing } \\
\text { methodology to the data of numerical simulations of QOC tests }\end{array}$ \\
\hline Pro, 32] & $\begin{array}{l}\text { Proposition of two methods to estimate the internal friction based on strain measurements on the outer } \\
\text { surface of the cell }\end{array}$ \\
\hline Improvement of the data processing method taking into account the internal friction and the sample/cell \\
symmetry defect based on strain measurements on the outer surface of the cell
\end{tabular}

Table 2.

Main advances proposed to process the data of QOC tests. 
Investigation of the Quasi-Static and Dynamic Confined Strength of Concretes by Means... DOI: http://dx.doi.org/10.5772/intechopen.89660

(b)

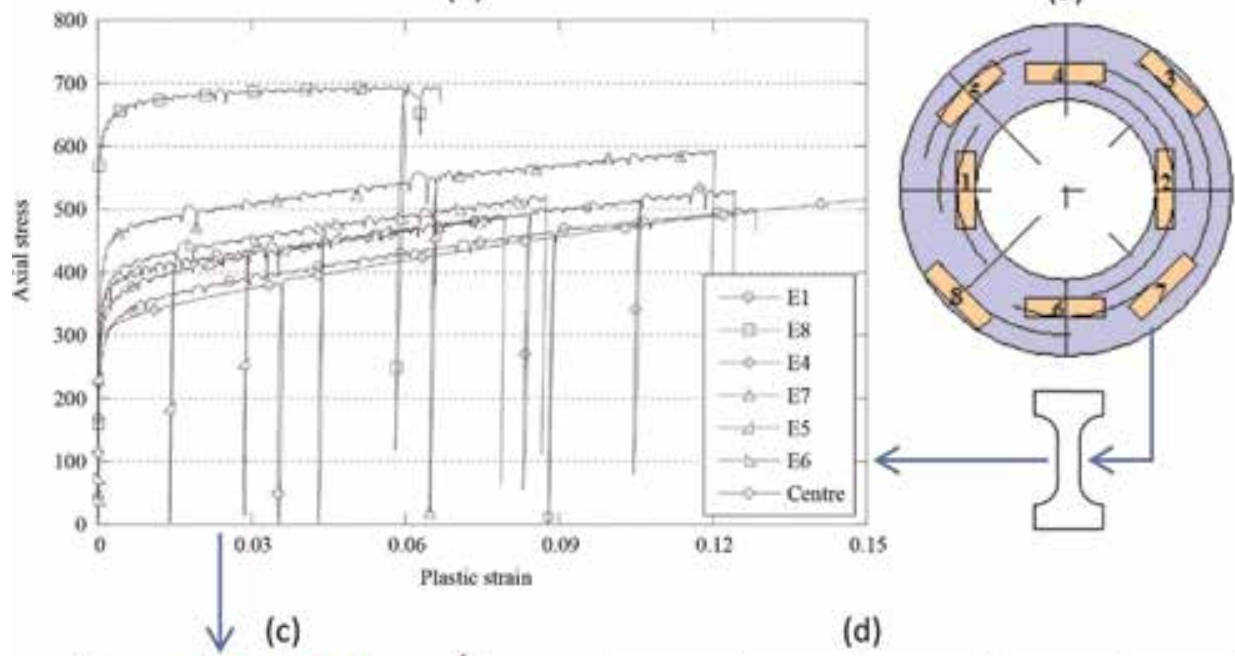

(a)

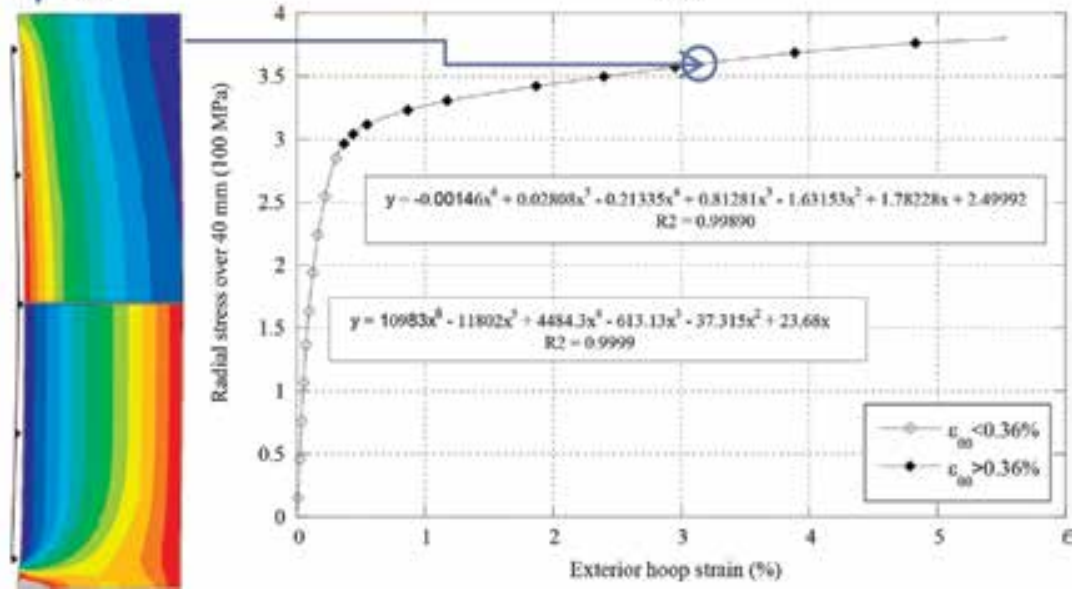

Figure 5.

Methodology to determine the function $\sigma_{\text {radial }(h=40 \mathrm{~mm})}=f_{40}\left(\varepsilon_{\theta \theta}\right)$ [31]. (a) Extraction of small samples from a confining cell. (b) Tensile tests and identification of the elastoplastic behavior for each sample. (c) Numerical simulation of the vessel subjected to an internal pressure of $360 \mathrm{MPa}$ on $40 \mathrm{~mm}$ (upper part: Hoop strain contours, lower part: Radial stress contours), (d) identification of the relation between the radial stress and the outer hoop strain.

calculation and $34 \mathrm{~mm}$ in a second calculation, these heights corresponding to the initial and final lengths of the concrete sample. From these calculations the relations: $\sigma_{\text {radial }\left(h_{S}=40 \mathrm{~mm}\right)}=f_{40}\left(\varepsilon_{\theta \theta}^{(z=0, e x t)}\right)$ and $\sigma_{\text {radial }\left(h_{S}=34 \mathrm{~mm}\right)}=f_{34}\left(\varepsilon_{\theta \theta}^{(z=0, e x t)}\right)$ were deduced, so, assuming a uniform radial stress in the sample, the radial stress was computed knowing the current height of the sample $\left(h_{S}\right)$ according to the following linear interpolation:

$$
\bar{\sigma}_{\text {radial }}(t)=\left(\frac{h_{S}(t)-34}{40-34}\right) f_{40}\left(\varepsilon_{\theta \theta}^{(z=0, e x t)}\right)+\left(\frac{h_{S}(t)-40}{34-40}\right) f_{34}\left(\varepsilon_{\theta \theta}^{(z=0, e x t)}\right)
$$

In a similar way, the (small) radial strain in the sample was deduced based on the data of hoop strains placed at two locations on the cell $\left(\varepsilon_{\theta \theta}^{(z=0, e x t)}, \varepsilon_{\theta \theta}^{(z=18, \text { ext })}\right)$ :

$$
\bar{\varepsilon}_{\text {radial }}(t)=\frac{2}{3}\left(1-\bar{\varepsilon}_{\text {axial }}\left(1+\frac{\bar{\varepsilon}_{\text {axial }}}{2}\right)\right) \alpha_{0}^{0} \varepsilon_{\theta \theta}^{(z=0, e x t)}+\frac{\left(1+\bar{\varepsilon}_{\text {axial }}\right)^{2}}{3} \alpha_{20}^{18} \varepsilon_{\theta \theta}^{(z=18, e x t)}
$$


where $\alpha_{0}^{0}$ and $\alpha_{20}^{18}$ are coefficients identified from the same calculations.

Finally, the deviatoric stress and the hydrostatic pressure were deduced based on Eqs. (2) and (3). The volumetric strain was also calculated in the following way:

$$
\bar{\varepsilon}_{\text {volumetric }}(t)=\left(1+\bar{\varepsilon}_{\text {axial }}\right)\left(1+\bar{\varepsilon}_{\text {radial }}\right)^{2}-1
$$

so the hydrostatic behavior of the concrete (relation between the hydrostatic pressure and the volumetric strain) was obtained. The whole procedure that was used in $[6,30-32]$ is summarized on the sketch of Figure 6.

The use of a confining cell that deforms plastically during a QOC test offers the advantage of providing higher levels of measured strains on the outer surface of the ring than with a cell that remains elastic. However, it presents several main drawbacks. First, each confining cell cannot be used more often than once due to the inelastic deformation after plasticization. Second, the relation between the radial stress in the sample and the outer hoop strain does not account for any influence of the loading rate. Therefore, if the constitutive material of the cell is strain-rate sensitive (such as steel) the relation identified under static loading is no longer valid to process the experimental data of a dynamic QOC test. Therefore, a confining cell made of brass or aluminium having a much smaller strain-rate sensitivity, can be considered [37]. Third, the plasticization of confining cell limits the maximum level of internal pressure to be applied to it. Last, the effect of friction and sample/ring dissymmetry are more difficult to calibrate in the data processing. It is the reason why, in the subsequent works, confining cell made of high strength steel $\left(\sigma_{\mathrm{y}}>1800 \mathrm{MPa}\right)$, which behavior remains elastic during the tests, were used $[16,34,35]$. In that case, the relation between the radial stress and the outer hoop strain (for a constant height of internal pressure) is linear. In the work developed in [16], a method was proposed to estimate the defect of symmetry $\left(\delta_{\mathrm{z}}\right)$ represented in Figure $7(a)$. It is based on the difference of hoop strains $\varepsilon_{\theta \theta}{ }^{(z=+3 H / 8)}$ and $\varepsilon_{\theta \theta}{ }^{(z=-3 H / 8)}$ measured near the top and bottom surfaces of the cell:

$$
\delta_{z}=P_{z}(h) \times\left(\frac{\varepsilon_{\theta \theta}^{\left(z=\frac{3 H}{8}\right)}-\varepsilon_{\theta \Theta}^{\left(z=-\frac{3 H}{8}\right)}}{\varepsilon_{\theta \theta}^{\left(z=\frac{3 H}{8}\right)}+\varepsilon_{\theta \theta}^{\left(z=-\frac{3 H}{8}\right)}}\right),
$$

where $P_{z}(h)$ is a polynomial function of degree 1 valid for the considered cell. Based on a series of numerical simulations performed with different values of $h$ and $\delta_{z}$

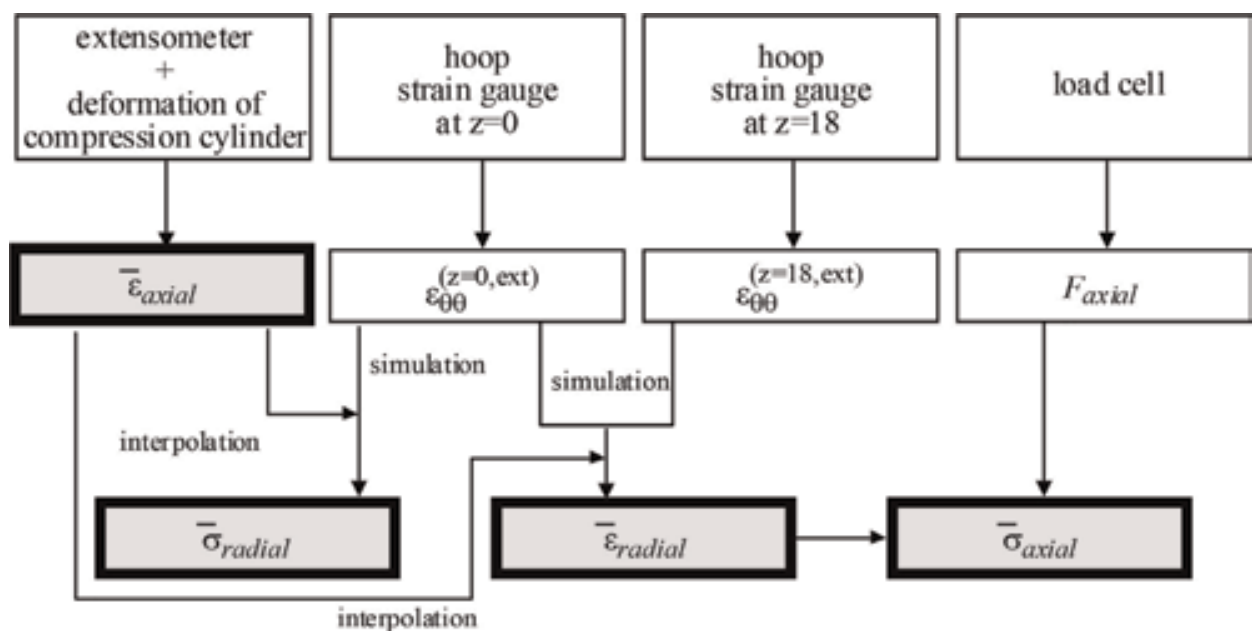

Figure 6.

Procedure applied to process the data of the QOC test [31]. 

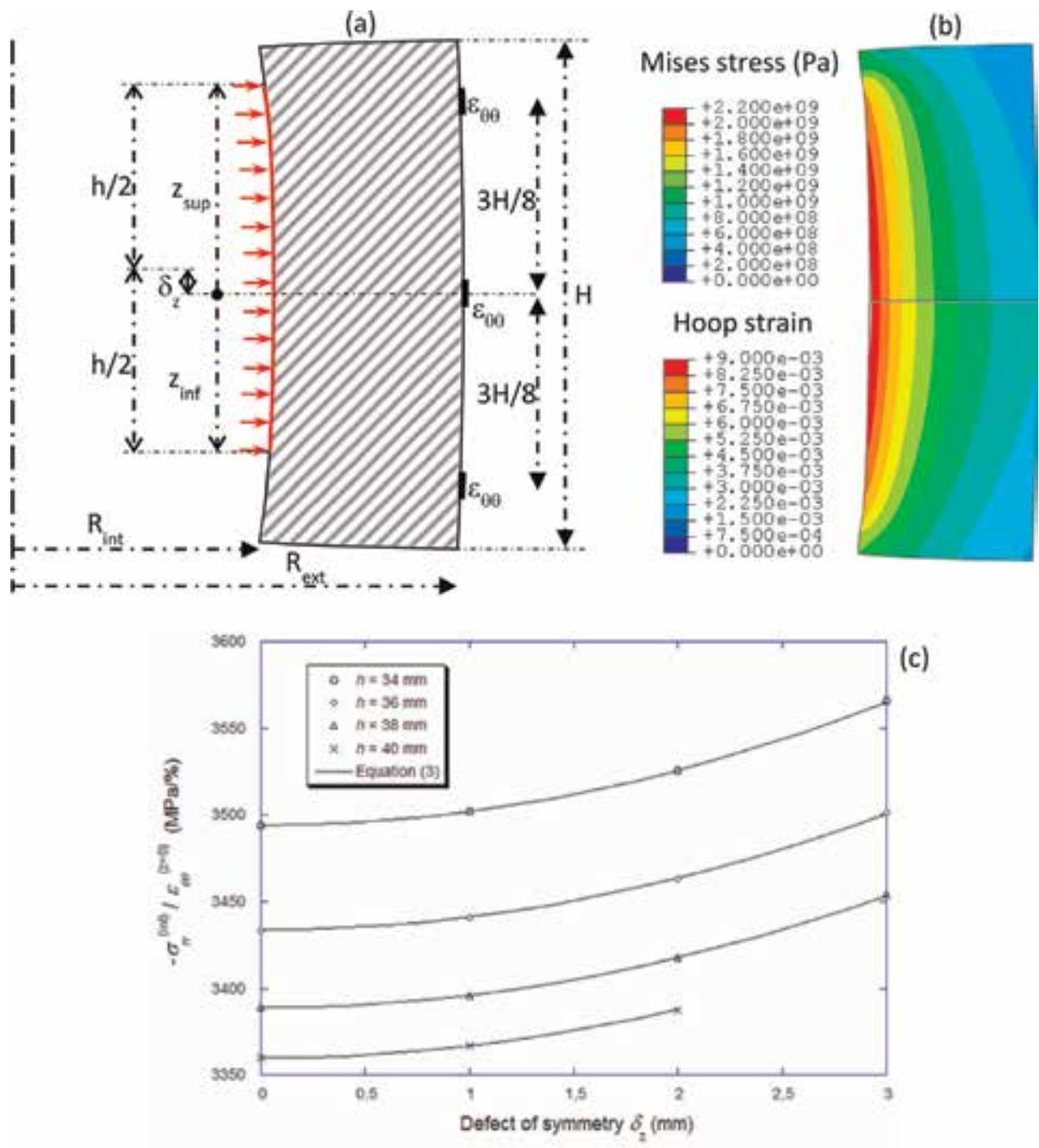

Figure 7.

(a) Definition of the defect of symmetry considered in [16]. (b) Numerical simulation of an elastic cell loaded by an internal pressure of $1 \mathrm{GPa}$ on $40 \mathrm{~mm}$ (upper part: Mises stress, lower part: Hoop strain contours).

(c) Radial stress to outer hoop strain ratio as function of the height of applied pressure and the defect of symmetry.

(cf. Figure 7(b)), the plot of Figure 7(c) was obtained. Finally, the ratio of radial stress to outer hoop strain can be expressed in the following way:

$$
-\frac{\sigma_{\text {radial }}^{(\text {int })}}{\varepsilon_{\theta \theta}^{(z=0, \text { ext })}}=P_{\sigma}(h)+Q_{\sigma}(h) \times\left(\delta_{z}\right)^{2},
$$

where $P_{\sigma}(h)$ and $\mathrm{Q}_{\sigma}(h)$ are polynomial functions of degree 2 whose coefficients need to be identified for the considered cell. In addition, it was demonstrated in [30] that friction and the sample-cell interface was affecting the ratio of outer axial strain to the outer hoop strain at the cell middle point $(z=0)$, which provides a possible way to estimate the friction coefficient in case of a confining cell that remains elastic during the QOC test.

A validation work was developed to evaluate the accuracy and sensitivity of these processing methods to be considered for inelastic or elastic confining cells. Next, it was applied to the experimental data of QOC tests conducted with different types of concretes, mortars and high-strength concrete. The main results are summarized in the next two sections. 


\section{Validation of the data processing methodology}

Several works have been developed to evaluate the validity and accuracy of the results obtained by applying this processing method to QOC tests. In the paper $[30,32]$, a series of numerical simulations of quasi-oedometric tests was conducted considering different behaviors of concrete. The Abaqus/Explicit FE code was selected to benefit from a user subroutine 'Vumat' in which the Krieg, Swenson and Taylor model is implemented [38, 39]. In this model, the hydrostatic behavior is described by a compaction law represented as a piece-wise linear function defined by several points $\left(\varepsilon_{v}{ }^{i}, p_{i}\right)$ (Table 1$)$. On the other hand, the model includes a limitation of the equivalent stress $\sigma_{e q}$ (von Mises criterion) according to the following elliptic equation that depends on the hydrostatic pressure $(P)$

$$
\left(\sigma_{e q}\right)_{\text {limit }}=\sqrt{a_{0}+a_{1} P+a_{2} P^{2}}
$$

The parameters used in KST model in (Forquin et al. [32]) are gathered in Table 3. Next, the processing methodology described in Figure 6 was applied to the numerical data in the same way as experimental data would be processed. Figure 8 presents the results for seven numerical simulations of a quasi-oedometric compression test. The left side of Figure 8 corresponds to the deviatoric behavior and the right-hand column to the hydrostatic behavior. The data processing described in Figure 6 was applied to the numerical calculations in which a friction was introduced at both plug/sample and cell/sample interfaces with a friction coefficient set to 0.1 or 0.2 . Based on these numerical simulations, two methods were proposed to estimate the level of friction encountered during the QOC experiments: the first method relies on the ratio of two hoop strains measured at different locations on the outer surface of the cell. In the second method, the ratio of axial strain to hoop strain in the symmetry plane of the cell is considered. Finally it was concluded that a friction coefficient lower than 0.1 should be expected in the experiments conducted in [32]. In addition, an elastic deformation of the Chrysor ${ }^{\circledR}$ resin was simulated in two simulations with the parameters provided in Table 3. Finally, it was concluded that the maximum error made due to the lack of consideration of friction at plug/sample or cell/sample interfaces or Chrysor ${ }^{\circledR}$ resin in the play between the ring and the sample should not exceed about $4 \%$ regarding the deviatoric behaviour and about $12 \%$ regarding the hydrostatic behavior, whether the friction at the vessel/specimen interface remained below 0.1 .

Another validation strategy was developed in [31] by conducting QOC experiments with cylindrical samples made of aluminum alloy (2017 T4), a reference material which elastoplastic behavior was well-characterized with a uniaxial tensile test. The deviatoric behavior and hydrostatic behavior obtained by data processing of one QOC test are compared with the expected responses in Figure 9. Again, the error made on the estimation of each deviatoric and hydrostatic response can be

\begin{tabular}{|c|c|c|}
\hline \multicolumn{3}{|c|}{ Concrete (Krieg, Swenson and Taylor model) } \\
\hline Elastic parameters & $E, \nu$ & $46 \mathrm{GPa}, 0.2$ \\
\hline Compaction curve ( 3 points) & $\begin{array}{l}\varepsilon_{v}^{(i)}, P^{(i)}{ }^{(i=1)} \\
\varepsilon_{v}^{(i)}, P^{(i)}{ }^{(i=2)} \\
\varepsilon_{v}{ }^{(i)}, P^{(i)}{ }^{(i=3)}\end{array}$ & $\begin{array}{c}-0.0003,7.67 \mathrm{MPa} \\
-0.042,200 \mathrm{MPa} \\
-0.15,580 \mathrm{MPa}\end{array}$ \\
\hline Coefficient of elliptical equation & $a_{0}, a_{1}, a_{2}$ & $625 \mathrm{MPa}^{2}, 270 \mathrm{MPa}, 0.505$ \\
\hline \multicolumn{3}{|c|}{ Chrysor ${ }^{\circledR}$ resin [31] } \\
\hline Elastic parameters & $E, \nu$ & $2.2 \mathrm{GPa}, 0.28$ \\
\hline
\end{tabular}

Table 3.

Parameters used for concrete and Chrysor ${ }^{\circledR}$ resin in the calculation. 


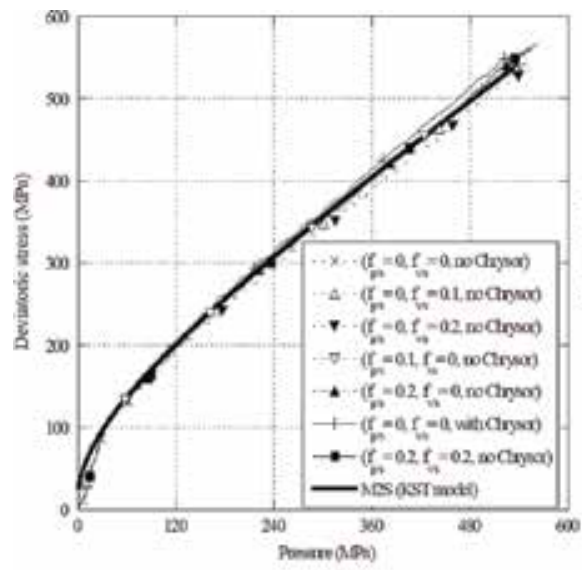

(a)

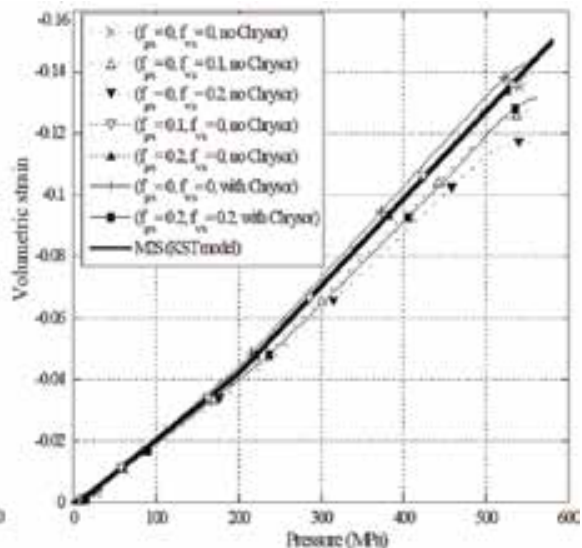

(b)

Figure 8.

Processing of data from a numerical simulation of a quasi-oedometric compression test conducted with $\mathrm{M}_{2} \mathrm{~S}$ small particle-reinforced mortar ( $c f$. Table 4). $\left(f_{p / s}\right.$. Friction at plug/sample interface, $f_{v / s}$. Friction at cell/sample interface, with Chrysor: A gap of thickness $0.3 \mathrm{~mm}$ is filled with a solid which behavior corresponds to a polymeric resin) [32].

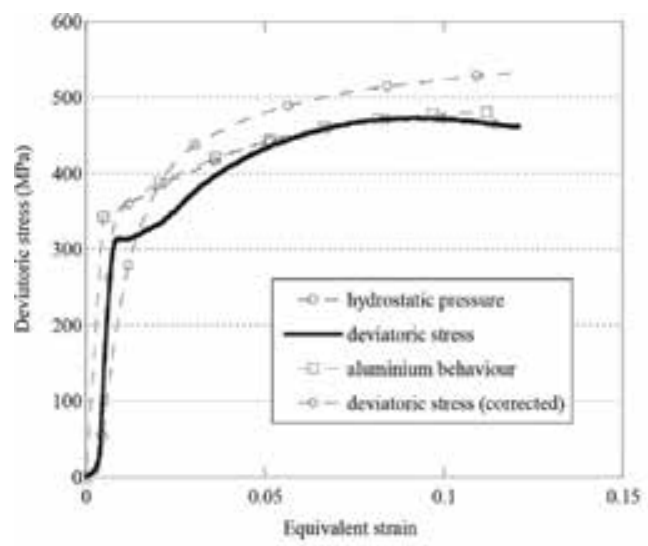

(a)

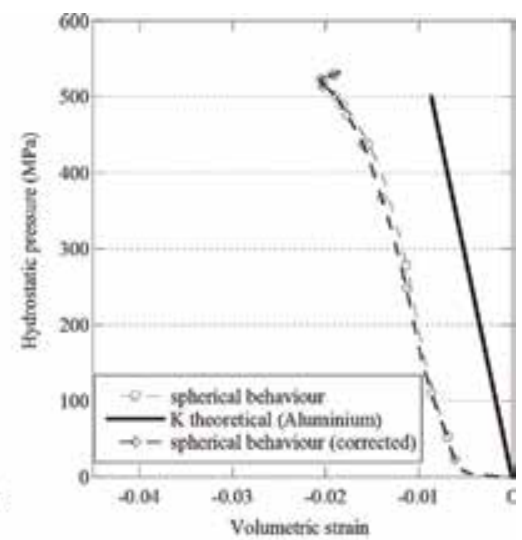

(b)

Figure 9.

Quasi-oedometric compression tests applied to an aluminum alloy sample. (a) Deviatoric behavior and (b) hydrostatic behavior [31].

estimated. One the one hand, whereas the deviatoric strength is slightly underestimated in the range of weak strain it is well predicted above $5 \%$ of equivalent strain. On the other hand, the hydrostatic response shows that a gap seems to be eliminated between the compression plate and the specimen at the beginning of the test. Furthermore, the linear bulk modulus of the aluminum alloy is well captured. Finally, both validation techniques provide an estimation of error that can be made up to a certain level of pressure when applying the data processing methodology to QOC experimental data.

\section{Experimental results obtained with different types of concrete}

\subsection{Composition of concretes tested under QOC tests}

QOC experiments have been conducted and applied to different kinds of concretes, mortars, particle-reinforced mortars, microconcrete and high-strength concrete with the sample dimensions mentioned in Table 1 . Their composition, the 


\begin{tabular}{|c|c|c|c|c|c|c|c|}
\hline Compositions & M1 & M1M & M1Sph & M2 & M2S & M2M & M2Sph \\
\hline Sand (quartz) $\left(\mathrm{kg} / \mathrm{m}^{3}\right)$ & 1366 & \multicolumn{2}{|c|}{965.9} & 1332 & \multicolumn{3}{|c|}{941.5} \\
\hline Silica fume SF $\left(\mathrm{kg} / \mathrm{m}^{3}\right)$ & - & \multicolumn{2}{|c|}{ - } & 55.5 & \multicolumn{3}{|c|}{39.2} \\
\hline Cement $\left(\mathrm{kg} / \mathrm{m}^{3}\right)$ & 569 & \multicolumn{2}{|c|}{402.5} & 555 & \multicolumn{3}{|c|}{392.3} \\
\hline Water $\left(\mathrm{kg} / \mathrm{m}^{3}\right)$ & 260 & \multicolumn{2}{|c|}{183.5} & 253 & \multicolumn{3}{|c|}{178.9} \\
\hline Admixture $\left(\mathrm{kg} / \mathrm{m}^{3}\right)$ & 4.7 & \multicolumn{2}{|c|}{3.4} & 4.6 & \multicolumn{3}{|c|}{3.3} \\
\hline Alumina particles $\left(\mathrm{kg} / \mathrm{m}^{3}\right)$ & 0 & \multicolumn{2}{|c|}{1084.4} & 0 & \multicolumn{3}{|c|}{1084.4} \\
\hline Shape of particles & - & Angular & Spherical & - & \multicolumn{2}{|c|}{ Angular } & Spherical \\
\hline Size of particles (mm) & - & $3-6$ & 4 & - & $1-3$ & $3-6$ & 4 \\
\hline Water/(cement + SF) & \multicolumn{3}{|c|}{0.46} & & \multicolumn{3}{|c|}{0.41} \\
\hline
\end{tabular}

Table 4 .

Composition of mortars and particle-reinforced mortars with and without silica fume used in [6, 31, 32, 40].

\begin{tabular}{lcccc}
\hline Compositions & MB50 & R30A7 & LC & HSC \\
\hline Aggregates $\left(\mathrm{kg} / \mathrm{m}^{3}\right)$ & - & 1008 & 891 & 1008 \\
\hline Sand $\left(\mathrm{kg} / \mathrm{m}^{3}\right)$ & 1783 & 838 & 838 & 795.4 \\
\hline Cement $\left(\mathrm{kg} / \mathrm{m}^{3}\right)$ & 400 & 263 & 263 & 420 \\
\hline Water $\left(\mathrm{kg} / \mathrm{m}^{3}\right)$ & 200 & 169 & 169 & 140 \\
\hline Silica fume SF $\left(\mathrm{kg} / \mathrm{m}^{3}\right)$ & - & - & - & 46.7 \\
\hline Admixture $\left(\mathrm{kg} / \mathrm{m}^{3}\right)$ & 12 & - & 0.64 & 4.7 \\
\hline Water $/(\operatorname{cement}+\mathrm{SF})$ & 0.5 & 0.64 & 10 & 0.30 \\
\hline Max grain size $(\mathrm{mm})$ & 5 & 8 & 8 \\
\hline
\end{tabular}

Table 5 .

Composition of microconcrete $\left(M B_{50}\right)$, siliceous aggregate ordinary concrete $\left(R_{30} A_{7}\right)$ and limestone aggregate ordinary concrete $(L C)$, siliceous aggregate high strength concrete (HSC) used in $[16,30,34,35]$.

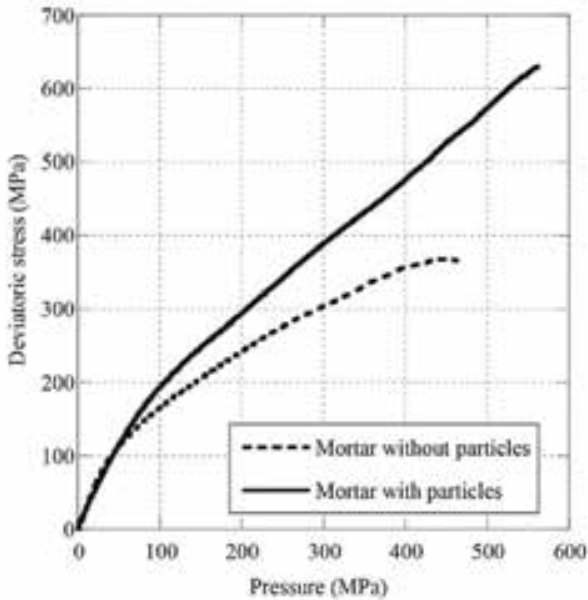

(a)

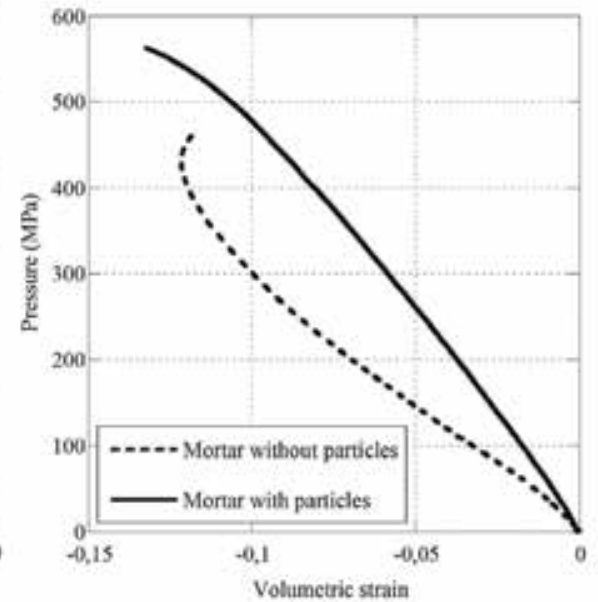

(b)

Figure 10.

Quasi-oedometric compression tests applied to a mortar M2 reinforced or not with aggregates (M2M) [6].

(a) Deviatoric behavior. (b) Hydrostatic behavior. 
water to cement (plus silica fume) ratio and the maximum aggregate size of the different tested materials are gathered in Tables 4 and 5. The most important results obtained from QOC tests are reported in the next subsections.

\subsection{Influence of alumina particles used as mortars reinforcement}

The benefits of alumina particles as reinforcement in two mortars were investigated in $[6,31,32]$ by means of quasi-oedometric compression tests performed considering seven microstructures containing or lacking angular or spherical alumina particles. The tests showed a highly beneficial effect of the presence of particles with respect to both the deviatoric strength and the compaction law in both mortars (with and without silica fume) as illustrated in Figure 10, while more conventional tests (3-point bending and simple compression) did not show a such beneficial effect [40] (especially for the matrix without silica fume), proof that the strength of concretes not under confinement is not indicative of the behavior of the same materials under confined loadings. It was also found that the deviatoric strength was more favored by angular particles than by spherical ones and by the addition of silica fume in the

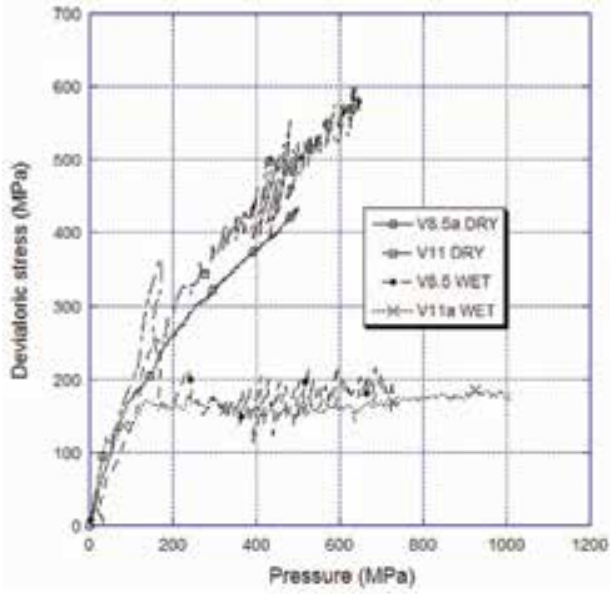

(a)

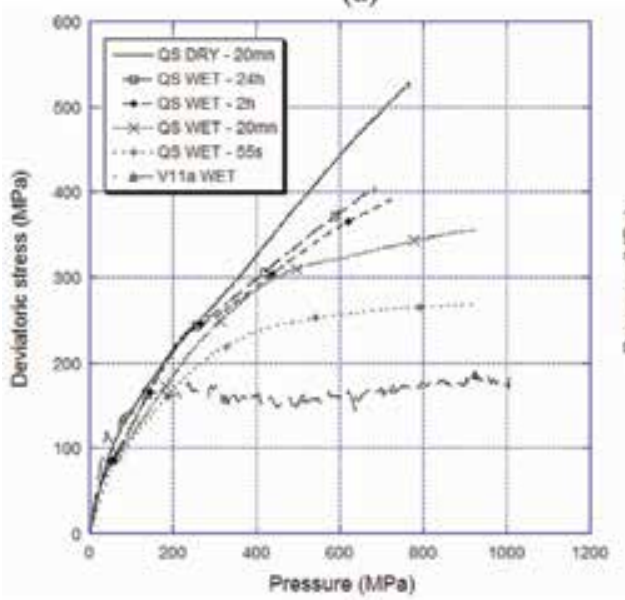

(c)

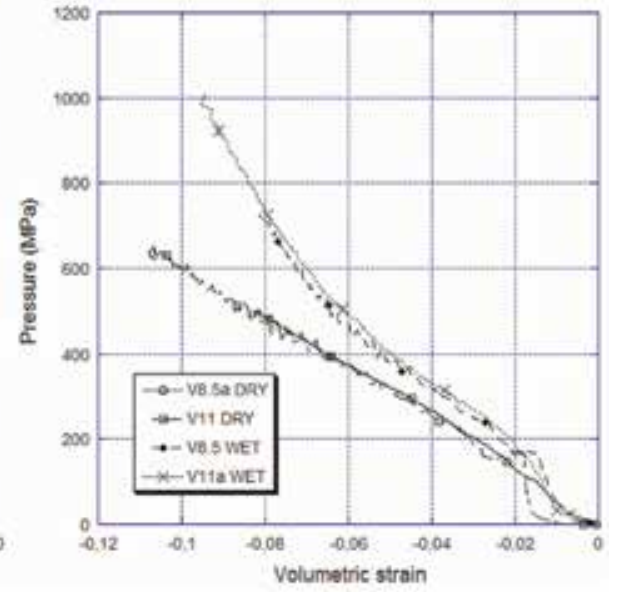

(b)

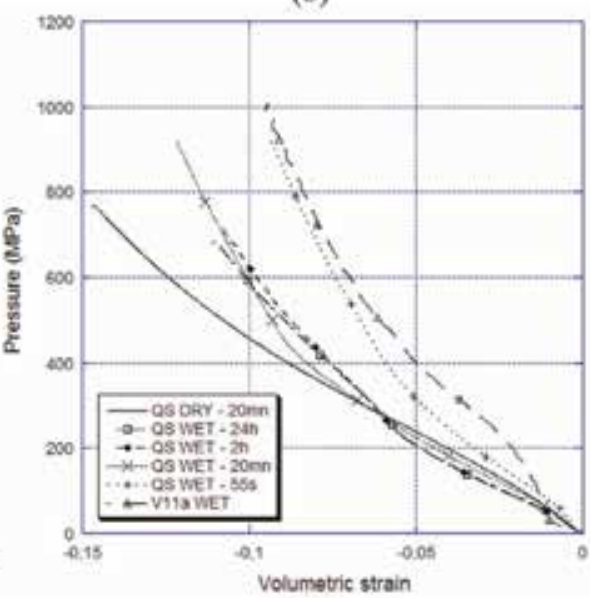

(d)

Figure 11.

Quasi-oedometric compression tests applied to MB50 microconcrete [16]. (a) Deviatoric behavior and (b) hydrostatic behavior in four dynamic tests performed on dried or wet specimens. (c) Deviatoric behavior and $(d)$ hydrostatic behavior in quasi-static and dynamic tests performed on wet specimens (V8.5 and V11 corresponding to the striking velocities equal to $8.5 \mathrm{~m} / \mathrm{s}$ and $11 \mathrm{~m} / \mathrm{s}$ respectively). 
cement paste. In addition, a correlation was noted between the large porosities of millimeter class and the compaction of the concretes under high level of pressure. Finally, it was demonstrated that the experimental data provided by QOC experiments could be used to simulate numerically impact tests involving high levels of confining pressure in front of the projectile head [41].

\subsection{Influence of free water and strain-rate on the confined behavior of microconcrete}

Quasi-static and dynamic QOC tests were performed on dry and water-saturated microconcretes in [16]. The dynamic tests exhibited an important dissimilarity between dry and saturated specimens concerning both deviatoric and hydrostatic behaviors. First, dried microconcretes exhibited a continuous compaction whereas saturated specimens showed a non-linear (hardening) hydrostatic behavior (Figure 11(b)). Moreover, a strong and continuous increase of the strength with pressure was noted with dry samples whereas water-saturated specimens exhibited an almost-perfect saturation of the strength (Figure 11(a)). The quasi-static results allowed highlighting the reason of this dissimilarity (Figure 11(c, d)). On the one hand, dried specimens behave similarly in dynamic tests and no strain rate effect is observed. On the other hand, the behavior of saturated specimens gradually tends to that of dried specimens when the loading rate is decreased, and an expulsion of water during slow quasi-static tests was observed. Finally, it was concluded that, waterpressure inside saturated microconcrete plays a major role on their fast-quasi-static or dynamic confined behavior by reducing drastically their shear strength.

\subsection{Influence of free water and strain-rate on the confined strength of ordinary concrete and high-strength concrete}

The experimental results of quasi-static and dynamic QOC tests performed on dried and saturated ordinary concrete (OC, in this case, R30A7 concrete) and high-strength concrete (HSC) were compared in [34]. The main results obtained regarding their quasi-static and dynamic deviatoric responses are reported in Figure 12. First, under dry conditions, both OC and HSC concretes exhibit similar strength with a slightly higher strength of HSC at low pressure but with a more reduced increase of strength with pressure as compared to OC (Figure 12(a, b)). In addition, it can be noted that the dynamic strength of dried OC and HSC is significantly higher than their quasi-static strength whatever the considered level of pressure. Finally, the influence of strain-rate on the confined strength of dried concretes cannot be neglected.

On the other hand, under saturated conditions, both concretes exhibit completely different strength. In quasi-static conditions, a saturation of strength around $70 \mathrm{MPa}$ was observed with OC, whereas the strength of HSC goes up to $270 \mathrm{MPa}$. In dynamic loading conditions, higher strengths are observed with both concretes compared with their quasi-static strengths and the influence of strain-rate cannot be neglected (Figure 12(c, d)). As in quasi-static loading, the dynamic confined strength of saturated HSC is much higher than that of saturated OC. Now, if dried and saturated concretes are compared, it can be concluded that the confined strength of dried samples is higher than that of saturated samples for both concretes. As concluded with microconcrete, it is supposed that interstitial waterpressure inside saturated concretes reduces their confined strength. In addition, this effect is even more pronounced in OC compared with HSC due to the higher level of porosity $(11.8 \%)$ in OC as compared to HSC $(8.8 \%)$, which explains the much lower 


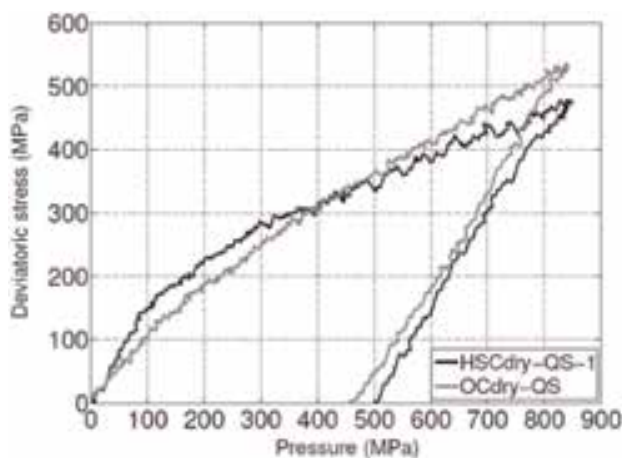

(a)

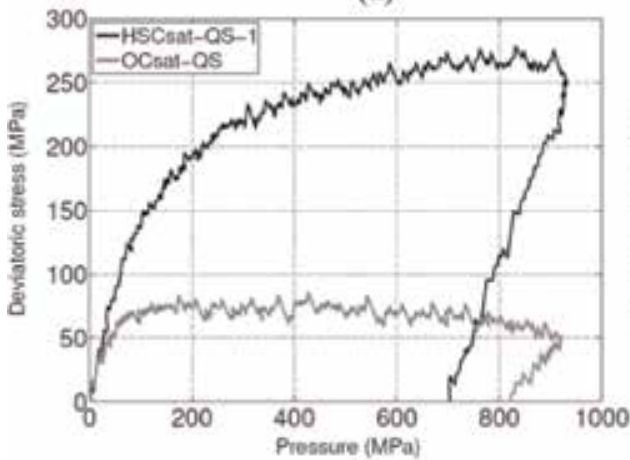

(c)

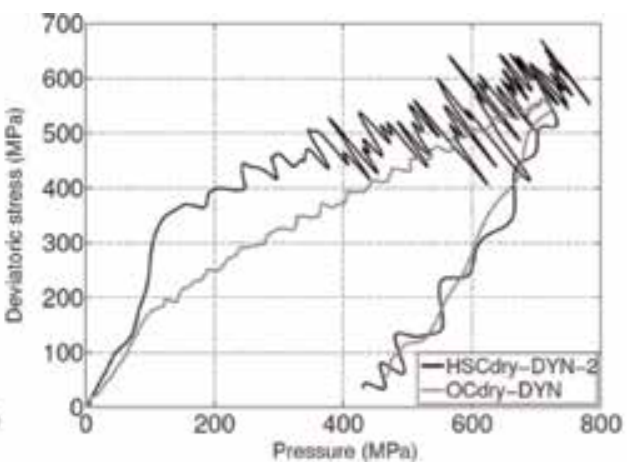

(b)

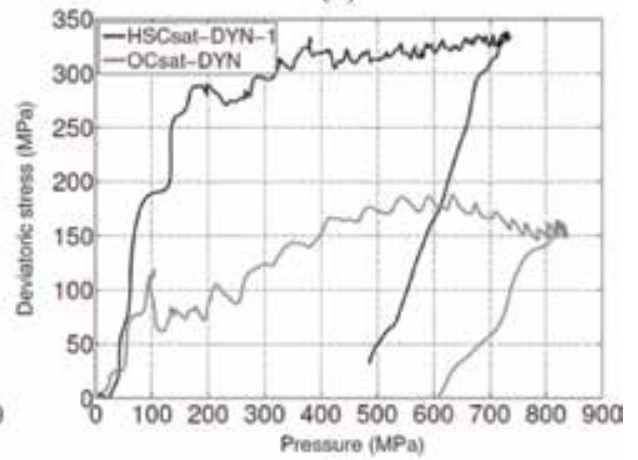

(d)

Figure 12.

Quasi-oedometric compression tests applied to ordinary concrete $\left(R_{3} 0 A 7\right)$ and high-strength concrete in dry and saturated conditions [34]. (a) Quasi-static deviatoric behavior of dry OC and HSC concretes. (b) Dynamic deviatoric behavior of dry OC and HSC concretes. (c) Quasi-static deviatoric behavior of saturated OC and HSC concretes. (d) Dynamic deviatoric behavior of saturated OC and HSC concretes.

strength of OC in saturated condition whereas both concretes present similar strengths in dry condition.

\section{Conclusion}

The quasi-oedometric compression testing technique constitutes one of the most convenient and efficient testing methods to characterize the quasi-static and dynamic confined behavior of concrete and rock-like materials. However, precautionary measures need to be considered in the mounting procedure, to fill the gap between ring and the confining cell, and in the data processing to take into account for the barreling deformation of the cell, the shortening of the sample and, when necessary, for the plastic behavior of the cell, the possible effects of friction at each interface and the axial dissymmetry between the sample and the confining cell. Thus, it is possible to determine the hydrostatic and deviatoric behaviors of these materials under pressure ranging from few tens to a thousand of MPa in quasi-static loading conditions with large capacity hydraulic press or at high strain-rates with a Split-Hopkinson Pressure Bar apparatus. The main obtained results illustrate the beneficial effect of the presence of strong particles added in mortars, a strong influence of free water content on both hydrostatic and deviatoric behaviors of concretes especially in the case of microconcrete and ordinary concrete. Finally, it is concluded that concrete composition and water content have a strong influence on the concrete behavior 
under high confinement and the strain-rate cannot be neglected whatever the concrete types and the water-saturation conditions.

\section{Acknowledgements}

A part of this research has been performed with the financial support of the Gramat Research Center (CEA-Gramat). The author is grateful to Dr. Eric Buzaud (CEA-Gramat) and Dr. Christophe Pontiroli (CEA-Gramat) for their sound technical and scientific advice. The quasi-static characterization in $[6,31,32,40]$ has been perfomed in Department of Continuum Mechanics and Structural Analysis of University Carlos III of Madrid. The author is grateful to Profs. Ramon Zaera and Angel Arias and to the Spanish Comisión Interministerial de Ciencia y Tecnologi' (Project MAT2002-03339), to the Comunidad Autónoma de Madrid (CCG06UC3M/DPI-0796) and to the Délégation Générale pour l'Armement (DGA/France) for their financial support. SHPB dynamic experiments have been performed in the LMS (Laboratoire de Mécanique des Solides, Palaiseau, France). The author is grateful to Prof. Gérard Gary and Philippe Chevallier for their helpful assistance and technical support, and Prof. Patrick Le Tallec, director of the LMS, for the warm welcome.

\section{Author details}

Pascal Forquin

Laboratoire Sols Solides Structures, Risques (3SR), Université Grenoble Alpes, CNRS, Grenoble INP (Institute of Engineering Université Grenoble Alpes), Grenoble, France

*Address all correspondence to: pascal.forquin@3sr-grenoble.fr

\section{IntechOpen}

(C) 2019 The Author(s). Licensee IntechOpen. This chapter is distributed under the terms of the Creative Commons Attribution License (http://creativecommons.org/licenses/ by/3.0), which permits unrestricted use, distribution, and reproduction in any medium, provided the original work is properly cited. (c) BY 


\section{References}

[1] Forquin P. Brittle materials at highloading rates: An open area of research. Philosophical Transactions of the Royal Society A. 2017; 375(2085):20160436. DOI: $10.1098 /$ rsta.2016.0436

[2] Li QM, Reid SR, Wen HM, Telford AR. Local impact effects of hard missiles on concrete targets. International Journal of Impact Engineering. 2005;32:224-284

[3] Hanchak SJ, Forrestal MJ, Young ER, Ehrgott JQ. Perforation of concrete slabs with 48 and 140MPa unconfined compressive strength. International Journal of Impact Engineering. 1992; 12(1):1-7

[4] Xu Y, Keer LM, Luk VK. Elasticcracked model for penetration into unreinforced concrete targets with ogival nose projectiles. International Journal of Solids and Structures. 1997; 34(12):1479-1491

[5] Yankelevsky DZ, Dancygier AN. Uniaxial Compressive Strength Effect on High Velocity Penetration into thick NSC and HSC targets. Symposium ISIEMS; 2001

[6] Forquin P, Arias A, Zaera R. Role of porosity in controlling the mechanical and impact behaviours of cement-based materials. International Journal of Impact Engineering. 2008a;35(3): 133-146

[7] Forquin P, Sallier L, Pontiroli C. A numerical study on the influence of free water content on the ballistic performances of plain concrete targets. Mechanics of Materials. 2015;89:176-189

[8] Grange S, Forquin P, Mencacci S, Hild F. On the dynamic fragmentation of two limestones using edge-on impact tests. International Journal of Impact Engineering. 2008;35:977-991
[9] Saadati M, Forquin P, Weddfelt K, Larsson P-L, Hild F. Granite rock fragmentation at percussive drillingExperimental and numerical investigation. International Journal for Numerical and Analytical Methods in Geomechanics. 2014;38(8):828-843

[10] Saadati M, Forquin P, Weddfelt K, Larsson P-L, Hild F. A numerical study of the influence of pre-existing cracks on granite rock fragmentation at percussive drilling. International Journal for Numerical and Analytical Methods in Geomechanics. 2015;39(5):558-570

[11] Fourmeau M, Kane A, Hokka M. Experimental and numerical study of a drill bit drop tests on Kuru granite. Philosophical Transactions of the Royal Society A. 2017;375(2085):20160176.

DOI: 10.1098/RSTA.2016.0176

[12] Palaniswamy R, Shah SP. Fracture and stress-strain relationship of concrete under triaxial compression. Journal of the Structural Division. 1974; 100:901-916

[13] Hoek E, Franklin JA. Simple triaxial cell for field or laboratory testing of rock. Transactions of the Institution of Mining and Metallurgy. 1968;77:A22

[14] Gabet T, Malécot Y, Daudeville L. Triaxial behaviour of concrete under high stresses: Influence of the loading path on compaction and limit states. Cement and Concrete Research. 2008; 38(3):403-412

[15] Fujikake K, Mori K, Uebayashi K, Ohno T, Mizuno J. Dynamic properties of concrete materials with high rates of tri-axial compressive loads. In: Jones $\mathrm{N}$, Brebbia CA, editors. Structures Under Shock and Impact VI. Vol. 48. United Kingdom: WIT Press; 2000. pp. 511-522

[16] Forquin P, Safa K, Gary G. Influence of free water on the quasi-static and 
dynamic strength of concrete in confined compression tests. Cement and Concrete Research. 2010;40(2):321-333

[17] Safa K. Mise au point d'un essai de compaction dynamique. Application au béton [dissertation]. France: Ecole Polytechnique; 2008

[18] Vu XV, Malecot Y, Daudeville L, Buzaud E. Experimental analysis of concrete behaviour under high confinement: Effect of the saturation ratio. International Journal of Solids and Structures. 2009;46(5):1105-1120

[19] Malecot Y, Zingg L, Briffaut M, Baroth J. Influence of free water on concrete triaxial behavior: The effect of porosity. Cement and Concrete Research. 2019;120:207-216

[20] Vu XH, Malecot Y, Daudeville L, Buzaud E. Effect of the water/cement ratio on concrete behavior under extreme loading. International Journal for Numerical and Analytical Methods in Geomechanics. 2009;33(17): 1867-1888

[21] Zingg L, Briffaut M, Baroth J, Malecot Y. Influence of cement matrix porosity on the triaxial behaviour of concrete. Cement and Concrete Research. 2016;80:52-59

[22] Vu XV, Daudeville L, Malecot Y. Effect of coarse aggregate size and cement paste volume on concrete behaviour under high triaxial compression loading. Construction and Building Materials. 2011;25(10): 3941-3949

[23] Piotrowska E, Malecot Y, Ke Y. Experimental investigation of the effect of coarse aggregate shape and composition on concrete triaxial behavior. Mechanics of Materials. 2014; 79:45-57

[24] Darrigade A, Buzaud E. High Performance Concrete: A Numerical and Experimental Study 9th International Symposium on the Interactions of the Effects of Munitions with Structures. Berlin; 1999

[25] Bažant ZP, Bishop FC, Chang TP. Confined compression tests of cement paste and concrete up to $300 \mathrm{Ksi}$. ACI Journal. 1986;33:553-560

[26] Burlion N. Compaction des bétons: éléments de modélisation et caractérisation expérimentale [dissertation]. France: Ecole Normale Supérieure de Cachan; 1997

[27] Burlion N, Pijaudier-Cabot G, Dahan N. Experimental analysis of compaction of concrete and mortar. International Journal for Numerical and Analytical Methods in Geomechanics. 2001;25:1467-1486

[28] Gatuingt F. Prévision de la rupture des ouvrages en béton sollicités en dynamique rapide [dissertation]. France: Ecole Normale Supérieure de Cachan; 1999

[29] Forquin P. Endommagement et fissuration de matériaux fragiles sous impact balistique, rôle de la microstructure [dissertation]. France: Ecole Normale Supérieure de Cachan; 2003

[30] Forquin P, Gary G, Gatuingt F. A testing technique for concrete under confinement at high rates of strain. International Journal of Impact Engineering. 2008b;35(6):425-446

[31] Forquin P, Arias A, Zaera R. An experimental method of measuring the confined compression strength of geomaterials. International Journal of Solids and Structures. 2007;44(13): 4291-4317

[32] Forquin P, Arias A, Zaera R. Relationship between mesostructure, mechanical behaviour and damage of cement composites under high-pressure 
confinement. Experimental Mechanics. 2008c;49:613-625

[33] Forquin P. Influence of free water and strain-rate on the behaviour of concrete under high confining pressure. Chapter 40. In: Song B, Casem D, Kimberley J, editors. Dynamic Behavior of Materials, Volume 1: Proceedings of the 2014 Annual Conference on Experimental and Applied Mechanics. The Society for Experimental Mechanics. New York: Springer; 2015. pp. 279-283

[34] Piotrowska E, Forquin P. Experimental investigation of the confined behavior of dry and wet highstrength concrete: Quasi static versus dynamic loading. Journal of Dynamic Behavior of Materials. 2015;1(2): 191-200

[35] Piotrowska E, Forquin P, Malecot Y. Experimental study of static and dynamic behavior of concrete under high confinement: Effect of coarse aggregates strength. Mechanics of Materials. 2016;92:164-174

[36] Kolsky H. An investigation of mechanical properties of materials at very high rates of loading. Proceedings of the physical society. Section B. 1949; 62:676-700

[37] Forquin P, Nasraoui M, Rusinek A, Siad L. Experimental study of the confined behaviour of PMMA under quasi-static and dynamic loadings. International Journal of Impact Engineering. 2012;40-41:46-57

[38] Krieg RD. A simple constitutive description for soils and crushable foams. In: SC-DR-7260883, Sandia National Laboratory. Report. USA; 1978

[39] Swenson DV, Taylor LM. A finite element model for the analysis of tailored pulse stimulation of boreholes. International Journal for Numerical and
Analytical Methods in Geomechanics. 1983;7:469-484

[40] Arias A, Forquin P, Zaera R, Navarro C. Relationship between bending and compressive behaviour of particle-reinforced cement composites. Composites Part B Engineering. 2008; 39:1205-1215

[41] Forquin P, Árias A, Zaera R. An experimental method of measuring the confined compression strength of highperformance concretes to analyse their ballistic behaviour. Journal of Physique IV. 2006;134:629-634 

Section 2

\section{Compressive Strength and Durability}





\title{
Compressive Behavior of Concrete under Environmental Effects
}

\author{
Alireza Farzampour
}

\begin{abstract}
Concrete strength is fairly sensitive to environmental effects. Extreme weather conditions and changes in humidity rates significantly affect the concrete compressive strength development. Concrete as one of the substantial material used in residential buildings and infrastructures is subjected to a massive strength change under extreme weather conditions. For understanding, the different concrete's behavioral aspects, various commercial cement types under different temperatures, and humidity rates are investigated in this chapter. The experiments are aimed to investigate the concrete strength development over time when the material is cast at lower to mild temperatures and different humidity index rates. Results show that reducing the curing temperature more than $15^{\circ}$ could result in $20 \%$ reduction in total compressive strength, while decreasing humidity rates by $50 \%$ leads to less than $10 \%$ drop in ultimate strength. To understand the strength developing process, maturity tests are conducted. It is shown that concrete is not able to reach to the expected ultimate strength if the temperature is significantly low regardless of curing time. The effect of temperature change during the curing process is more tangible on strength development compared to cement type and humidity rate values.
\end{abstract}

Keywords: compressive strength, environmental effects, maturity, durability

\section{Introduction}

There is significant need for evaluating the concrete behavior on-site without implementing experimental tools. Concrete if properly placed in extreme weather conditions is able to develop desired ultimate strength [1]. Temperature changes could cause cracks or sapling, distress, and aggregate expansion which leads to concrete strength deterioration. Many different procedures are recommended in codes to reduce the negative effects of low or high ambient temperature $[1,2]$. High temperature, above $100^{\circ} \mathrm{C}$, could lead to color changes in aggregates leading to abrupt loss of compressive strength. While, lower temperature, less than zero, usually ends up in cracking and low resistance against freeze-thaw effects [3-5]. A common practice to reduce the undesirable crack propagation in concrete mixtures under thermal effects is to use fibers due to having persistency in behavior under various environmental conditions [6].

The behavior of the concrete under high temperature values could be affected with several factors. The temperature rate, aggregate type, and stability of the mixture are among the most important factors to be considered under high temperature condition. It is noted that the abrupt temperature rise can cause thermal 
shock, spalling, cracking, and aggregate expansion leading to high distress within the concrete $[2,3]$. Therefore, the strength of concrete is reduced by any significant temperature increase. The strength degradation rate is depended on the initial compressive concrete strength [7]. Concrete in general provides one of the best fire resistance properties due to chemically combined material with thermal conductivity, and high heat capacity which leads to self-protection against extreme temperature conditions (e.g., fire).

On the other hand, the low temperature curing condition is a highly common issue affecting the strength development of the concrete. Pouring and curing concrete in extreme weather conditions require special attention to the code instructions for obtaining desirable performance in structures $[1,2]$. The cold weather condition is defined previously as a period of time in which for more than three consecutive days, either average daily air temperature is less than $5^{\circ} \mathrm{C}$ or the air temperature is not greater than $10^{\circ} \mathrm{C}$ for more than one-half of any $24-\mathrm{h}$ period. The cold condition limits the concrete capability to develop strength by causing significant decrease in hydration process. Another issue with cold ambient temperature is expansion of the water in concrete, especially in high water-cement ratio mixtures, leading to spalling and overall strength degradation $[1,7,8]$. It is well documented that if the concrete in plastic stage freezes, about $50 \%$ of the strength is expected to be reduced and durability loss is inevitable [2].

The durability of the concrete against freeze-thaw cycles is previously investigated as a major factor indicating the ability for resistance against weathering actions [9-11]. For durability improvements, the concrete mixture's water-tocement ratio plays an important role which should be carefully considered $[12,13]$. ACI guide [1] proposes procedures prior and after pouring concrete under harsh weather conditions to avoid any strength loss (Figure 1). It is generally recommended that to use lower water-to-cement design ratio, type-three cement and nonchloride admixtures for the best performance under cold weather conditions.

There are different factors which are indirectly affected by any change in environmental conditions. The setting time issue with cold weather would be twice by each $10^{\circ} \mathrm{C}$, which causes the concrete to be exposed and vulnerable to ambient damages. Therefore, effectively protect the concrete from the harsh ambient conditions is necessary until it gains minimum strength of $3.5 \mathrm{MPa}[1,2,14]$.

Additionally, under harsh environmental conditions, the inner parts of concrete would experience a different hydration process rather than the outer areas. The inner parts commonly have higher temperature due to hydration of the cement with water, while outer layers experience less temperature values. This phenomenon, especially under cold outside temperature, results in significant thermal

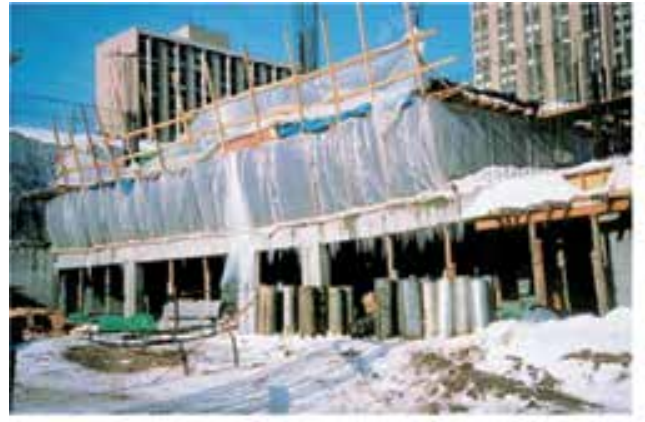

a)

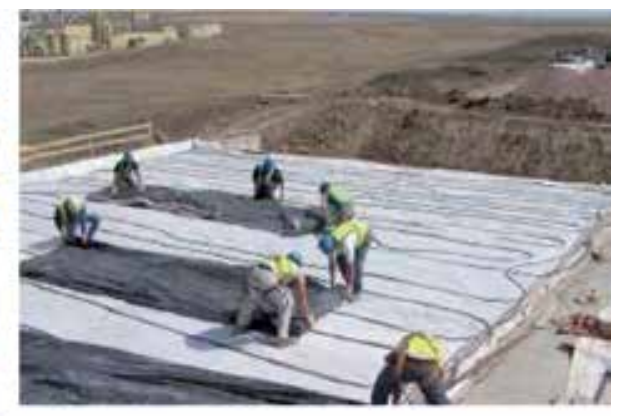

b)

Figure 1.

(a) Concrete in cold weather. (b) Cold weather curing. 


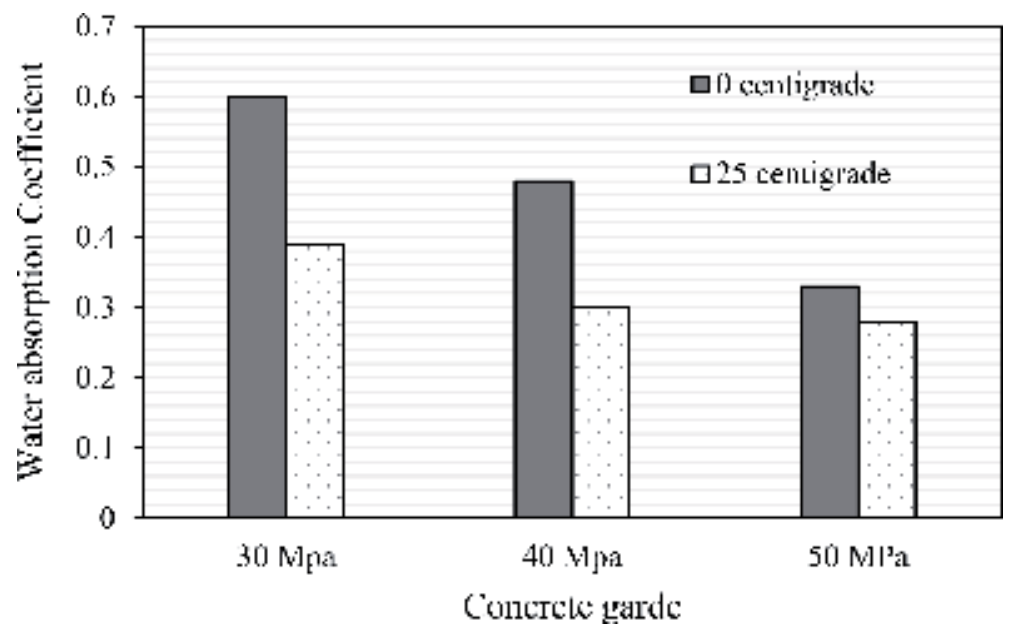

Figure 2.

Influence of the curing temperature on water absorption of the mixture.

cracks causing lower compressive strength values, generating microcracks and adversely affecting the interfacial zone (ASTM C 1074-04). Furthermore, at freezing temperatures, a reduction of $29 \%$ in stiffness after 28 days is expected since the vulnerability against cracks is reduced due to increase in water absorption of the hardened concrete [15]. Figure 2 shows the water absorption coefficient is increased for three different concrete types under cold weather compared to mild weather conditions. These phenomena negatively change the compressive strength and vulnerability against crack propagation showing that water-cement ratio is one most important factors in strength development of the concrete $[15,16]$. In addition, the concrete freezing at initial stages of strength development negatively reduces the capability of the cement matrix to maintain the mixture integrity against freeze-thaw cycles $[16,17]$.

In what follows, the ambient temperature and humidity index effects on various concrete types are investigated. The compressive strength development under temperature changes is discussed in detail. The overview of the harsh weather concreting is established in detail by elaborating on compressive strength, maturity index, and freeze-thaw experiments. The out of this chapter is to understand the behavior of the concrete under various ambient conditions as the most commonly used material for construction and residential buildings.

\section{Material properties used for compressive strength investigation}

To elaborately indicate compressive behavior of the concrete, the results for three different temperatures of 5,10 , and $25^{\circ} \mathrm{C}$ as well as two humidity rate index values are represented. Four cement types with low and high water-cement ratio are taken into account to understand the compressive behavior of the concrete in various environmental effects. The commercially available grout types of BASF, Dayton, Five Star, and Quickrete are prepared and cured with water-cement ratios of $0.12,0.12,0.18$, and 0.18 , respectively. The values of consistency, an indicator of the mobility or fluidity of the mortar, were checked to be in conformity with the limits set in ASTM standards. Table 1 shows a detailed plan of testing plan with the number of samples. The mentioned mortar compositions are selected based on the applicability of them for harsh environmental condition in North USA. 


\begin{tabular}{|c|c|c|c|c|c|c|}
\hline $\begin{array}{l}\text { Temperature } \\
\text { during the first } \\
7 \text { days }\left({ }^{\circ} \mathrm{C}\right)\end{array}$ & $\begin{array}{c}\text { Relative } \\
\text { humidity } \\
\text { during the first } \\
7 \text { days }(\%)\end{array}$ & $\begin{array}{c}\text { Temperature } \\
\text { after } 7 \text { days } \\
\left({ }^{\circ} \mathrm{C}\right)\end{array}$ & $\begin{array}{c}\text { Relative } \\
\text { humidity } \\
\text { after } \\
7 \text { days } \\
\text { (\%) }\end{array}$ & $\begin{array}{l}\text { Number of cubes } \\
\qquad(2 \times 2 \times 2 \text { in. })\end{array}$ & $\begin{array}{l}\text { Number of } \\
\text { cylinders } \\
\text { (maturity) }\end{array}$ & $\begin{array}{c}\text { Number of } \\
\text { rectangular } \\
\text { cubes } \\
\text { (Freeze-thaw) }\end{array}$ \\
\hline \multirow{2}{*}{$\begin{array}{l}23 \\
23\end{array}$} & 100 & \multirow[t]{4}{*}{23} & 100 & 15 & 2 & 2 \\
\hline & 50 & & 50 & 15 & 2 & 2 \\
\hline 10 & & & & 15 & 2 & 2 \\
\hline 5 & & & & 15 & 2 & 2 \\
\hline
\end{tabular}

Table 1.

Testing plane for evaluating the effect of temperature and humidity index.

All the samples were prepared in molds accordingly and consolidated with tamping rods. Roding is done for each layer uniformly on the cross-sectional area with rounded end. The number of strokes varies depending on the type of molds used, which is based on ASTM standards [14]. The samples are subsequently covered with burlaps to effectively initiate the hydration process for $24 \mathrm{~h}$. Subsequently, the samples are demolded after being cured for $24 \mathrm{~h}$, and the compressive strength is monitored for $1,3,7,14$, and 28 days curing time based on the ASTM recommended procedure [14-16]. It is noted that the mixing procedure is based on the ASTM manuals [14-16] for simulating the actual behavior of the concrete under cold, mild, and moderate temperature conditions.

It is noted that samples are remained in temperatures shown in Table $\mathbf{1}$ for a week and then moved to room temperature area with the same humidity afterward. In general, for each grout type at each time interval, three cubic and two cylinders as well as two large rectangular samples for freeze-thaw durability index test are made for compressive strength development investigations.

\section{Investigation of cement matrix compressive strength development under various temperature conditions}

Different concrete types are made and cured for compressive strength test. For each grout, 15 ASTM verified cubes are cured based on the material plan summarized in Table 1. The compressive behavior is evaluated with compressive test machine shown in Figure 3 at each time interval of 1, 3, 7, 14, and 28. For each time interval, the average of three compressive values is selected for accuracy of the results. It is noted that the rate of the compressive loading based on the ASTM manuals [14-16] should be consistent for all the specimens, since the loading rate has a significant effect on the ultimate compressive strength. Figure 3 shows the compressive test machine and cube samples for use in compressive test experiment.

The general behavior of the concrete under different environmental conditions is summarized in Figure 4. Based on the results, it is concluded that the concrete would develop desirable compressive strength at room temperature $\left(23^{\circ} \mathrm{C}\right)$ and $100 \%$ humidity rate. The hydration process in which the cement matrix develops bonds between aggregates is highest before 14 days of curing. It is concluded that the temperature before 14 days of curing is highly important factor in general strength development compared to other factors (e.g., humidity index rate).

The strength behavior is highly affected by the temperature of curing as compared to humidity rate index value. The temperature of curing plays an undeniable role specifically at early stages of curing process. The temperature reduction of $15^{\circ}$ generally ends up in more than $20 \%$ drop in ultimate strength regardless of the 


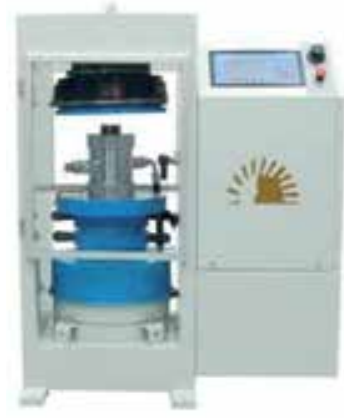

a)

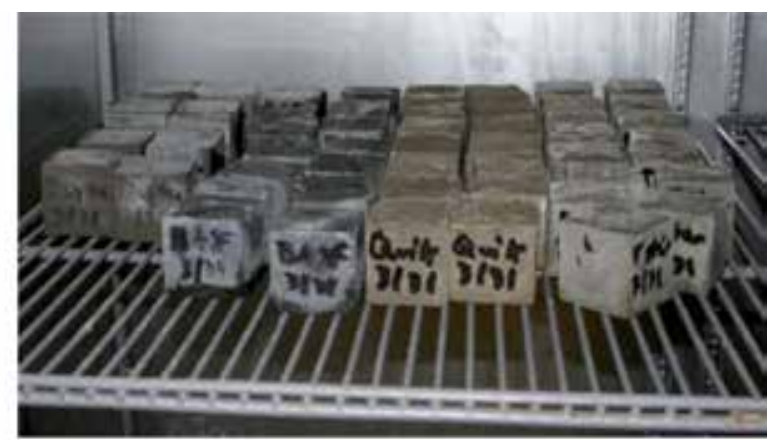

b)

Figure 3.

(a) Compressive test machinery. (b) Cube concrete samples.

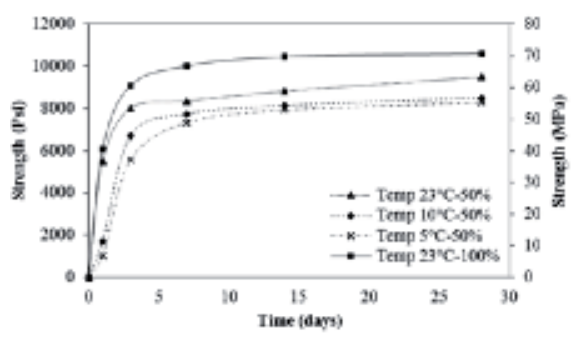

(a)

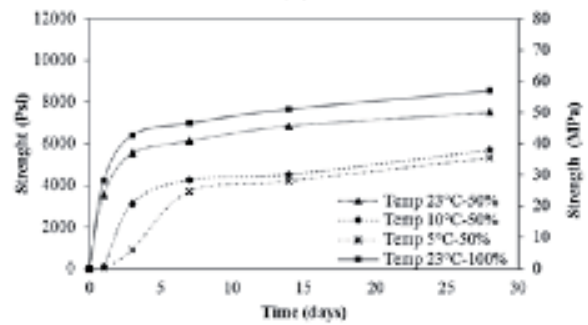

(c)

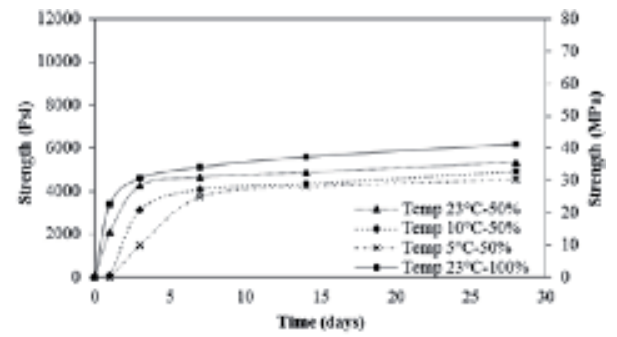

(b)

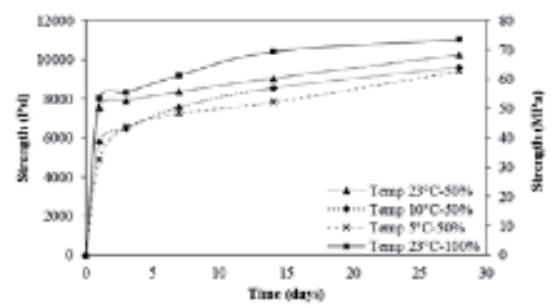

(d)

Figure 4.

The effect of temperature and humidity on various cement types. (a) BASF. (b) Five star. (c) Quickrete. (d) Dayton.

cement types. While, decreasing $50 \%$ of humidity rate leads to about $10 \%$ drop in ultimate strength values. Therefore, to reach to the specific ultimate compressive strength, the temperature should be controlled and monitored at different stages of curing. In addition, more than $75 \%$ of the total strength compressive strength development, for all the specimens, is occurred within the first 14 days of curing. The least compressive strength is associated with lower temperature and drier condition, while the most strength development is related to milder temperature and higher humidity condition.

\section{Investigation of curing process and strength development of concrete with maturity method}

In-place concrete strength evaluation is an important step in achieving the reliable performance of structures and construction scheduling $[18,19]$. The level of maturity is in need of evaluation for deciding the forms' striping time, posttesting, protection 
removal, and progressing with further construction plan. The minimum level of the strength required for concrete is required at different stages before further progress, which imposes careful monitoring of the strength evaluation through curing time. However, concrete under harsh environmental conditions normally experiences unexpected issues that decline the strength development. Significant expenses might be occurred if the concrete curing process is delayed under environmental effects to be assured that the concrete has reached the specified minimum strength.

Maturity in general is estimated by tracking the changes in strength development for fresh concrete under various temperatures over time intervals. As the cement hydrates, the strength increases; however, the amount of hydrated cement depends on many factors, specifically curing temperature. From the strength-maturity index curves of corresponding samples, the strength on-site could be predicted at any moment after concrete placement, which shows how far the hydration is processed. Usually, the concrete reaches the expected strength under warm weather condition, if the temperature is not abruptly increased. However, in cold temperature situation, the fluctuation in temperature during days and nights might stop the cement hydration process. For understanding, the reasonable evaluation of the strength of the placed concrete, maturity-meters shown in Figure 5 are implemented at different stages of curing process.

The concrete strength is directly related to the curing time, humidity index, and temperature fluctuation. The maturity investigation is a method with which the early age concrete strength is monitored and the results subsequently could be implemented for in-site concrete placement $[15,17]$. The main assumption with maturity concept is that the concrete is able to attain the same strength if the mixture reaches the same value of maturity index [18]. Another assumption with maturity evaluation is that the combination of temperature and time leads to the same strength for the considered concrete mixture. Therefore, strength development is a function of time and temperature. This function could be nonlinear or linear with respect to time and temperature. The instrument shown in Figure 5 indicates how mature the concrete mix is which is represented as a number ultimately. The information is subsequently used for establishing maturity curves which are unique for any concrete mixture and related to compressive strength [19-21]. The schematic maturity curve is shown in Figure 6. The maturity curves are based on the time-temperature factor (TTF) which is compatible with the assumption that the maturity is a function of time and temperature.

In general, there are many common methods in obtaining the maturity level of the concrete. The general idea is based on the time-temperature factor which considers the proportional relation between combined temperature-time and compressive strength. The important issue related to this commonly used method shown in Eq. (1) is that the strength development in significantly higher or lower
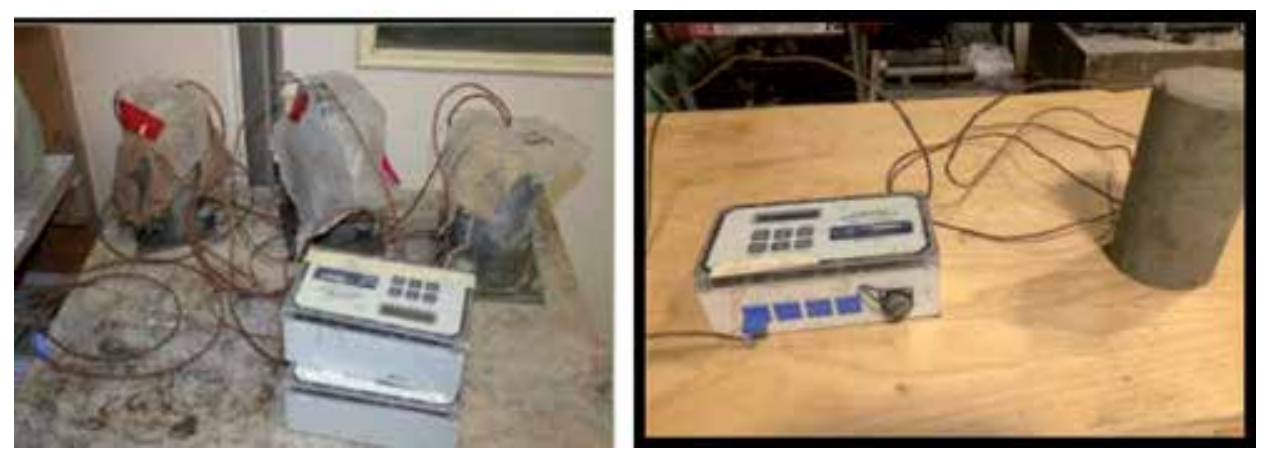

Figure 5.

The maturity-meter device used for concrete strength evaluation. 


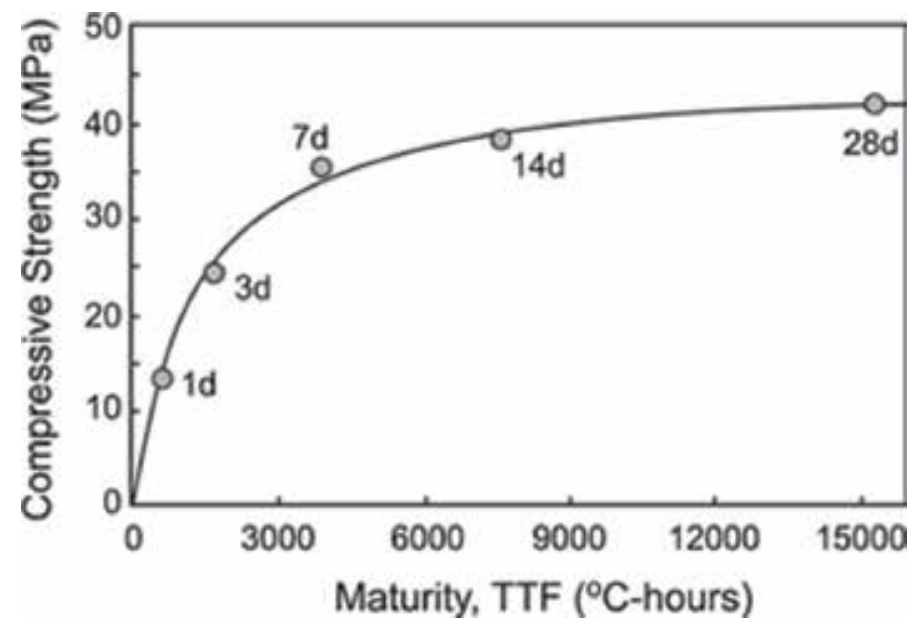

Figure 6.

The schematic maturity-meter curve showing the concrete maturity.

temperatures is not accurate; hence, the careful interpretation of the results in extreme temperature is inevitable.

$$
\mathrm{M}=\sum_{0}^{\mathrm{t}}\left(\mathrm{T}-\mathrm{T}_{0}\right) \Delta \mathrm{t}
$$

where $\mathrm{M}$ is the maturity index in ${ }^{\circ} \mathrm{C} \mathrm{h}$, $\mathrm{T}$ is the average temperature in ${ }^{\circ} \mathrm{C}$ over time interval of $\Delta \mathrm{t}$ per hours, and $\mathrm{T}_{0}$ is the datum temperature usually taken as $0^{\circ} \mathrm{C}$ at which the hydration is stopped and concrete does not gain any strength. $\mathrm{M}$ index is usually referred to as the maturity index related to TTF factor [2]. To understand the assumption in this method, Figure 7 is shown in which the area of temperature over time for a specific mixture under cold condition is $\mathrm{M}_{1}$, and under corresponding mild temperature condition is $\mathrm{M}_{2}$. If $\mathrm{M}_{1}$ and $\mathrm{M}_{2}$, which represents the maturity index of a mixture, are equal, then the compressive concrete strength is expected to be the same. It is highly important that this assumption is only useful if the concrete does not experience any harsh environmental condition (e.g., excessive cold or hot temperature) during initial stages of the curing process.

To further investigate the effect of harsh environmental conditions on maturity and strength development of the concrete, the cylinder-shaped specimens are used for maturity evaluation of the four different concrete mixtures. Different temperatures and rates of humidity are considered for all the mixtures. Figure 8 shows the maturity evaluation for all the concrete mixtures in which the compressive strength of the specimens are extracted at different time intervals. It is noted that the effect of significant humidity change, even though not considered in maturity concept formulation, is clearly observed. It is shown that environmental effects such as very dry conditions could tangibly change the strength development of the concrete; however, the change might not be as much as temperature variations. The lower water-cement ratio leads to significant gain in early stages of curing or lower TTF values, since all the cement materials actively participate in chemical hydration reactions. As the TTF increases or curing progresses, the rate of strength gain decreases until the concrete reaches the ultimate strength conditions.

Figure 8 shows the combined effect of temperature and time on compressive strength by using the maturity index. It is noted that temperature drop significantly affect the hydration process, which leads to less ultimate strength over the same period of the time. It is noted that if the harsh environmental condition such as 


\section{Strength- Maturity relationship}
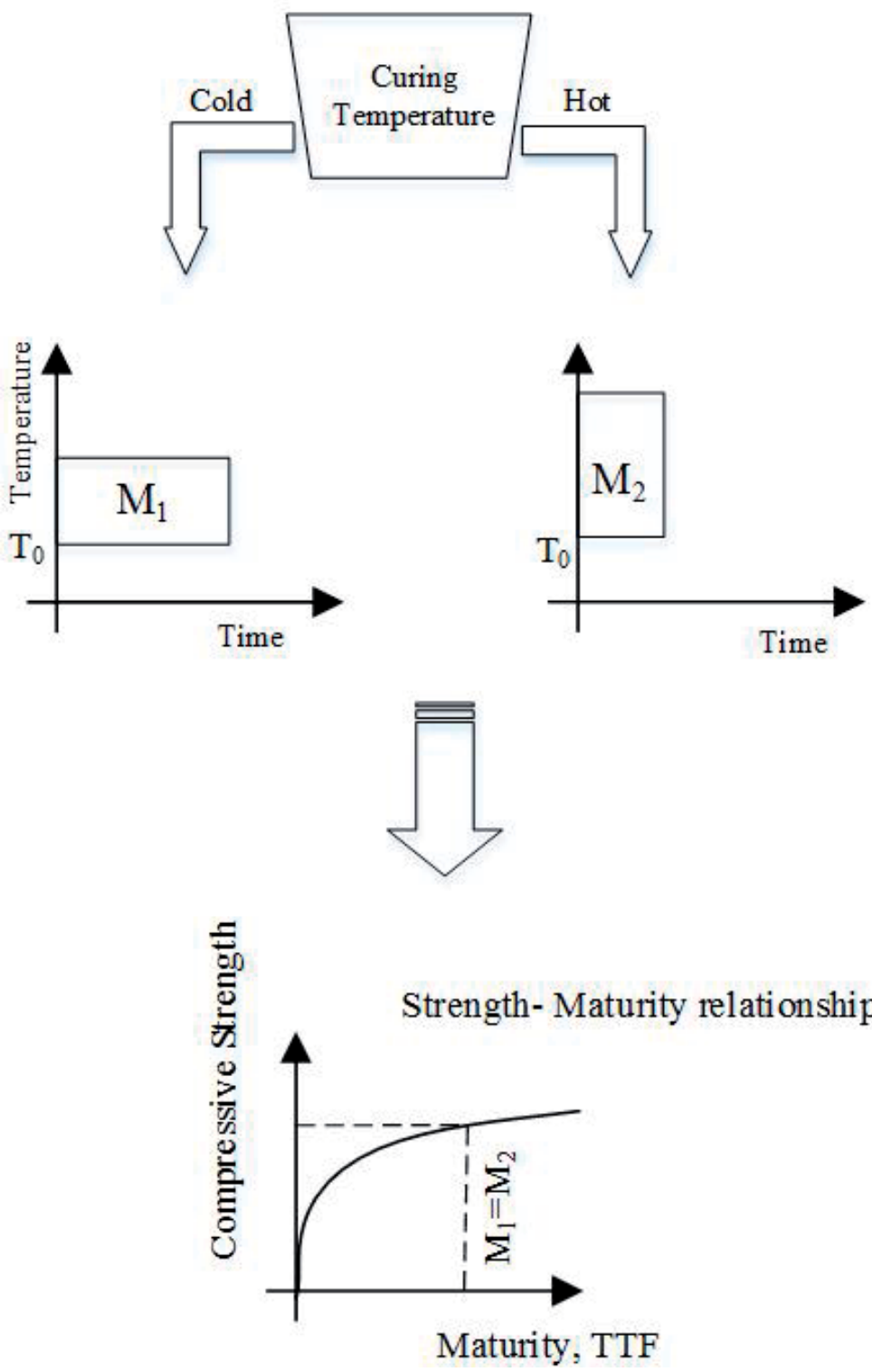

Figure 7.

The schematic representation of the maturity index assumption.

freezing temperature occurs, the hydration is stopped and the concrete would not be able to reach the ultimate expected strength even the sufficient amount of curing time is provided. In another words, the concrete would not develop the expected ultimate strength regardless of the curing time interval. This phenomena is important since the maturity formulation typically shows that by increasing the curing time, the effect of lower temperature could be compensated, which only is valid under specific environmental conditions (e.g., temperature over zero and sufficient humidity). From Figure 8, it is concluded that for all the cylinder samples, as the temperatures decrease significantly during the curing process, the bounding between cementious materials is not fully generated leading to lower ultimate strength even in large period of curing. 


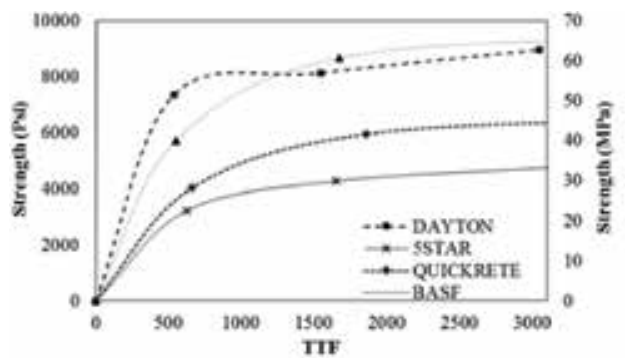

(a)

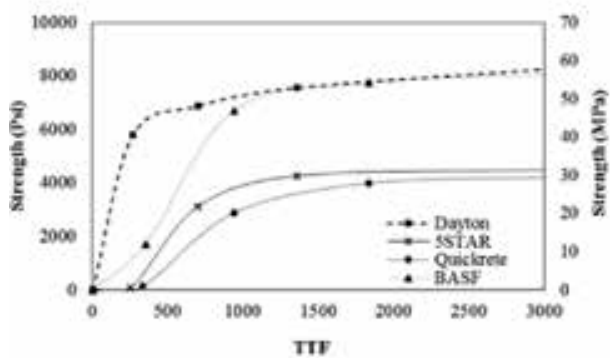

(c)

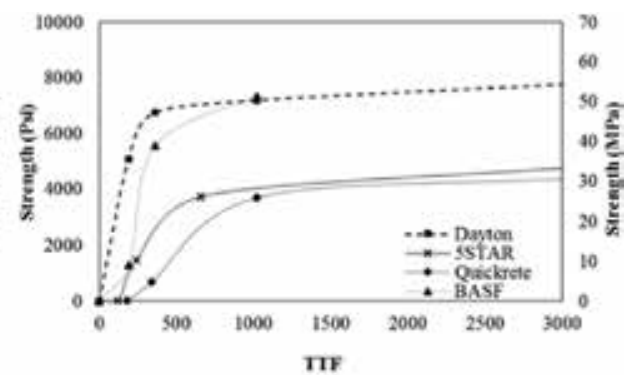

(b)

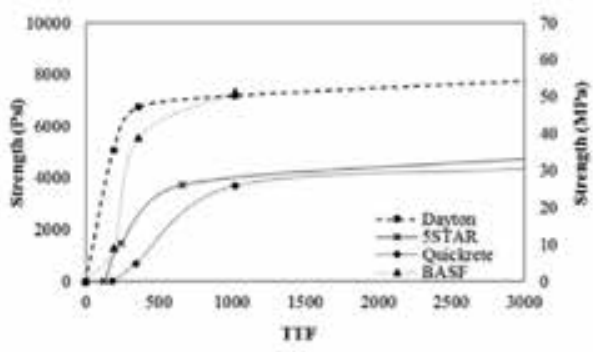

(d)

Figure 8.

Maturity evaluation of different cementious materials. (a) Temperature $23^{\circ} \mathrm{C}$ and $\mathrm{RH} 100 \%$. (b) Temperature $23^{\circ} \mathrm{C}$ and $\mathrm{RH} 50 \%$. (c) Temperature $10^{\circ} \mathrm{C}$ and $\mathrm{RH} 50 \%$. (d) Temperature $5^{\circ} \mathrm{C}$ and $\mathrm{RH} 50 \%$.

The strength of a given mixture placed and cured with the prescribed procedures is estimated from the temperature and time combinations. This method assumes that the only contributing factors to the strength development are time and temperature, while from the results of humidity rate study, it is shown that a drop of $50 \%$ in humidity index values would lead to average of $10 \%$ drop in compressive strength regardless of cement type.

In general, there are limitations of the maturity method implementation in estimating the concrete strength.

First, the implementation of this method is under the assumption that the placed concrete at the site has similar conditions to the concrete made in the laboratory. Any changes in batching accuracy, air content, and used materials could lead to different maturity curves and strength estimations.

Second, the areas that the maturity is evaluated within a specimen should not be only allocated to specific point. The hydration process within a large piece of concrete shows distinctive behavior aspects in outer and inner parts.

Third, the maturity method should be revised and carefully interpreted under extreme environmental conditions, which leads to incorrect estimation at early curing ages.

Fourth, the size of the concrete piece usually is larger than the samples, which means that the hydration process produces more heat and higher temperatures inside. This large temperature difference might affect the compressive strength development, which is not considered in laboratory samples.

\section{Durability of the concrete under cyclic environmental conditions}

The durability of cement mix is defined as the ability for resistance against weathering action, abrasion, and chemical reactions, or generally the processes that 
deteriorate and affect the strength and stiffness. The durable concrete maintains the original quality and serviceability under environmental effects. Concrete is assumed durable if

1. Under extreme environmental effects (e.g., cycles of freeze-thaw), the deterioration is limited and controlled.

2. Minimum impurities such as chlorides, slit, and sulfates are existed.

3. The aggregates are clean and well graded; therefore, the concrete is less permeable.

4. The cement matrix is well structured and dense which appropriately bonds all the components together.

The durability of the concrete is highly depended on the cement content, water-cement ratio, curing process, cover, sufficient compaction, and appropriate mix design. In general, the outer causes of durability loss are: extreme weathering condition, abrupt temperature change, high humidity, chemical attacks, and ettringite formation. The inner causes are volume changes due to thermal properties of the aggregates and high water content, chemical reactions of ingredients, and steel reinforcement corrosion.

For durability assessment of the concrete, ASTM C666 [17] provides an equation which is shown in Eq. (2). If up to 300 cycles, significant cracks are not existed, then the concrete maintains its durability under environmental changes.

$$
D F=P N / M
$$

where DF is the durability factor of the specimen and $\mathrm{P}$ is relative dynamic modulus of elasticity. $\mathrm{M}$ is the specified number of cycles at which the exposure is terminated. $\mathrm{N}$ is the minimum of the cycles' number at which $\mathrm{P}$ reaches the specified minimum value for discontinuing the test, and the specified number of cycles at which the exposure is to be terminated. The general prepared specimens for durability investigation are shown in Figure 9.

For further investigations, the behavior of the concrete samples is monitored for cycles of freeze-thaw. For each type of cement, two specimens are made to sufficiently validate the results of the test. ASTM 666 procedures [17] to build and

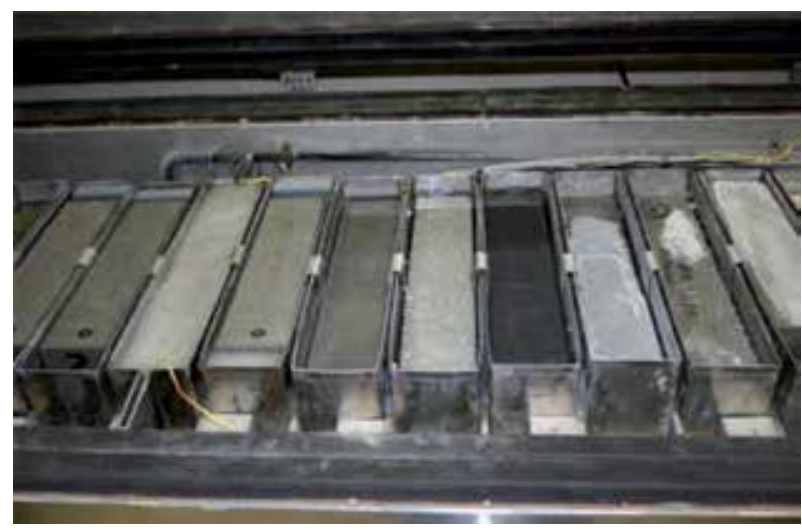

Figure 9.

Durability investigation of the concrete, and freeze-thaw test. 
test the specimens are considered, and the durability index is evaluated accordingly. Figure 10 shows some of the specimens after significant number of freeze-thaw cycles. From this experiment, it is shown that the durability of the concrete is highly dependent on the cement matrix, water-cement ratio, exposure to harmful chemicals, extreme weathering, and concrete mix design.

The durability factor is obtained for each cement type at 30 each cycles, and the results are summarized in Figure 11. It is concluded that cement type and watercement ratio has significant effect on the resistance and durability of the concrete. The high water-cement ratio would lead to higher permeability, which will be filled with water in the next cycles.

The water volume is expanded upon freezing and it is transformed to ice, which eventually causes microcrack propagation in concrete samples. Microcracks
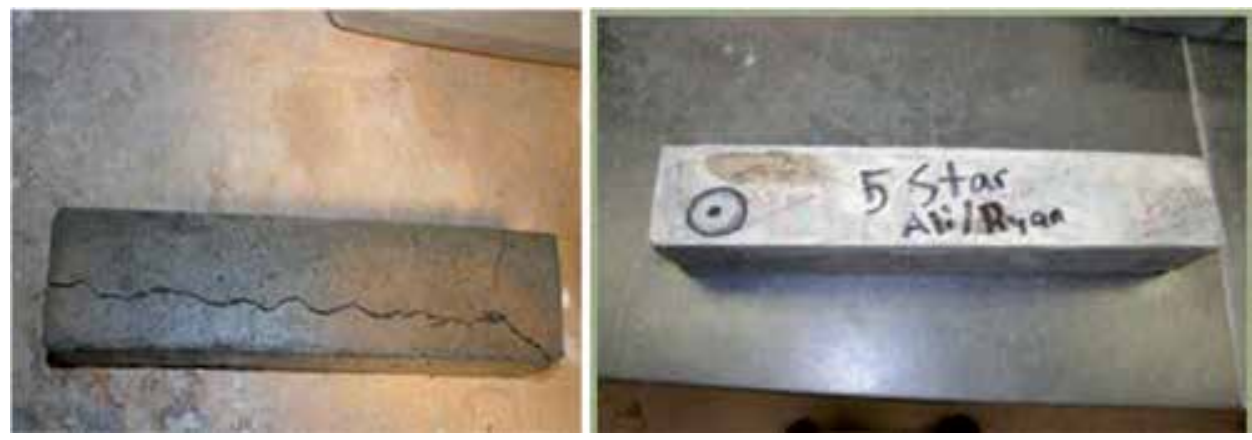

Figure 10.

Significant number of freeze-thaw cycles.

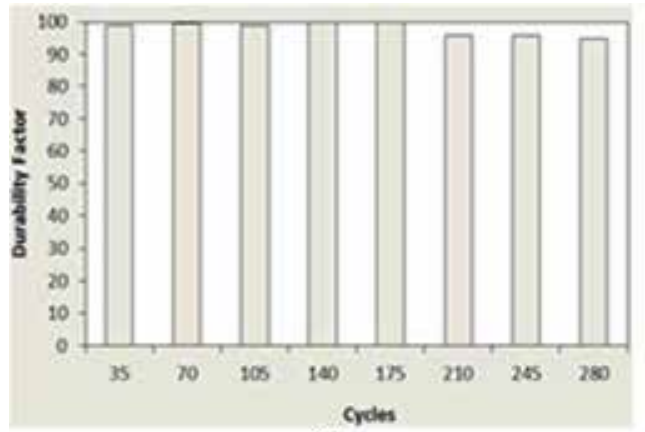

(a)

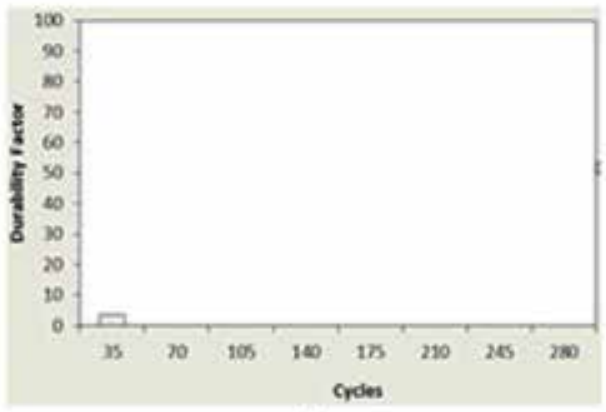

(c)

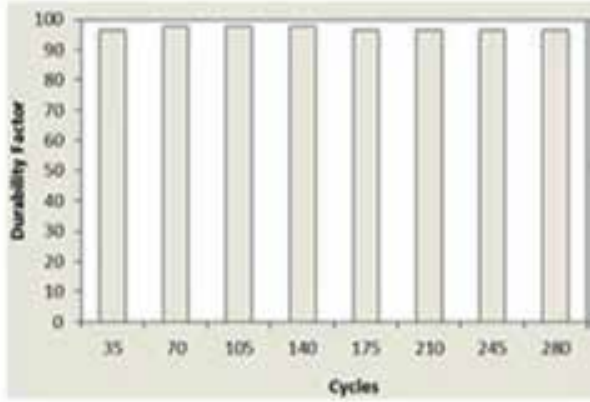

(b)

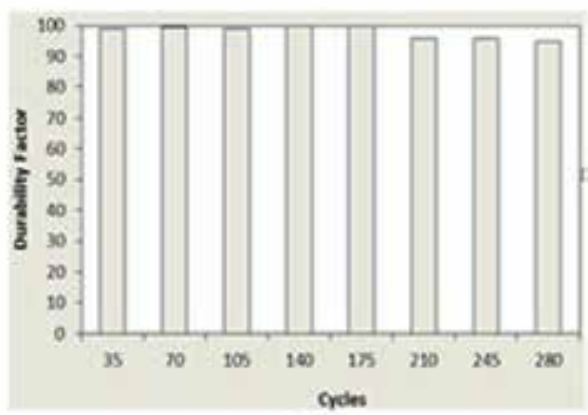

(d)

Figure 11.

Durability of the cement under freeze-thaw cycles. (a) BASF after 300 cycles. (b) Five star after 300 cycles. (c) Quickrete after 34 cycles. (d) Dayton after 300 cycles. 
adversely change the concrete resistance against further freeze-thaw cycles leading to major cracks and abrupt loss of strength. It is recommended that lower watercement ratio mix designs to be used under freeze-thaw possibility to limit the durability loss and maintain compressive strength.

\section{Conclusion}

The environmental conditions play an important role in compressive strength of concrete. Generally, the temperature during the curing time and humidity rate index value are among the most effective factors for achieving reliable concrete structure. It is shown that temperature if drops below the freezing condition, not only slows down the hydration process, but also reduces the durability of the concrete significantly. In general, for appropriately cured concrete, a temperature drop of $15^{\circ}$ leads to $20 \%$, and a $50 \%$ drop in humidity rate index ends up in $10 \%$ reduction in overall compressive strength, if the environmental conditions are not extreme. The concrete cured in significantly low temperature is not able to reach the same expected strength, whereas the higher cured temperature concrete could reach, regardless of the curing time. Therefore, it is recommend to pay close attention to curing procedures under extreme weather conditions. In addition, lower water-cement ratios have better performance under freeze-thaw cycles; however, in higher temperature condition, excessive heat is produced which could cause damages to other particles.

\section{Acknowledgements}

Special thanks to Virginia Tech Open Access Subvention Fund (OASF) for providing me the opportunity to disseminate the results of this study with open-access publishers.

\section{Author details}

Alireza Farzampour

Virginia Tech, Blacksburg, Virginia, USA

*Address all correspondence to: afarzam@vt.edu

IntechOpen

(C) 2019 The Author(s). Licensee IntechOpen. This chapter is distributed under the terms of the Creative Commons Attribution License (http://creativecommons.org/licenses/ by/3.0), which permits unrestricted use, distribution, and reproduction in any medium, provided the original work is properly cited. (cc) BY 


\section{References}

[1] American Concrete Institute. Building Code Requirements for Structural Concrete (ACI 318-14): Commentary on Building Code Requirements for Structural Concrete (ACI 318R-14): An ACI Report. American Concrete Institute. ACI; 2014

[2] Wilson ML, Kosmatka SH. Design and control of concrete mixtures. HighPerformance Concrete. 2011;15:299

[3] Committee on Concrete and Concrete Aggregates American Society for Testing and Materials. Standard practice for petrographic examination of hardened concrete. ASTM C856-18a. 2004

[4] Farzampour A. Temperature and humidity effects on behavior of grouts. Advances in Concrete Construction, An International Journal. 2017;5(6):659-669

[5] Farzampour A, Radlinska A. The effect of temperature and humidity on strength development of grouts. Washington DC, USA 15-18 May 2016 Edited by Kamal H. Khayat. 2016:733

[6] de Castro J, Keller T. Ductile double-lap joints from brittle GFRP laminates and ductile adhesives, part I: Experimental investigation. Composites Part B: Engineering. 2008;39(2):271-281

[7] Kodur V. Properties of concrete at elevated temperatures. ISRN Civil Engineering. 2014;2014:1-15

[8] ASTM C. 94, Standard Specification for Ready Mixed Concrete. C94/ C94M-18. 1916

[9] Gjørv OE. Durability design and quality assurance of major concrete infrastructure. Advances in Concrete Construction. 2013;1(1, 1):45-63

[10] Muhit IB, Raihan MT, Nuruzzaman M. Determination of mortar strength using stone dust as a partially replaced material for cement and sand.
Advances in Concrete Construction. 2014;2(4):249-259

[11] Güneyisi E, Gesoğlu M, Mermerdaş $\mathrm{K}$, İpek S. Experimental investigation on durability performance of rubberized concrete. Advances in Concrete Construction. 2014;2(3):187-201

[12] Zhang B, Cullen M, Kilpatrick T. Spalling of heated high performance concrete due to thermal and hygric gradients. Advances in Concrete Construction. 2016;4(1):1-3

[13] Patil AA, Chore HS, Dodeb PA. Effect of curing condition on strength of geopolymer concrete. Advances in Concrete Construction. 2014;2(1):29-37

[14] ASTM C. Standard practice for making and curing concrete test specimens in the field. C31/C31M-12. 2012

[15] ASTM S. Standard practice for estimating concrete strength by the maturity method. ASTM C 1074. 2004:1074-1093

[16] American Society for Testing and Materials. Committee C-1 on Cement. Standard Test Method for Compressive Strength of Hydraulic Cement Mortars (using 2-in. Or [50-mm] Cube Specimens). ASTM International C 109; 2013

[17] ASTM International Committee C09 on Concrete and Concrete Aggregates. Standard test method for resistance of concrete to rapid freezing and thawing. ASTM International. ASTM C666; 2008

[18] Anderson KW, Uhlmeyer JS, Kinne C, Pierce LM, Muench S. Use of the Maturity Method in Accelerated PCCP Construction. 2009

[19] Kwon O. Application of the maturity method for the prediction 
of early strength of concrete under various curing conditions. [Doctoral dissertation]. University of Florida

[20] Malhotra VM, Carino NJ. The maturity method. In: Handbook on Nondestructive Testing of Concrete. CRC Press; Corporate Blvd., Boca, Raton: Florida; 2003:102-148

[21] Nassif AY, Petrou MF. Influence of cold weather during casting and curing on the stiffness and strength of concrete. Construction and Building Materials. 2013;44:161-167 


\title{
Chapter 6
}

\section{Mechanical Behavior of High-Performance Concrete under Thermal Effect}

\author{
Zine El Abidine Rahmouni and Nadia Tebbal
}

\begin{abstract}
Several studies on the behavior of concrete at high temperatures are the subject of recent concerns, following the latest fires in various European tunnels. In these extreme conditions, significant degradations of concrete structures can be observed (peeling, cracking, breaking of the structure). A priori prediction of concrete behavior during this type of stress is therefore essential and is not possible without a good understanding of the different mechanisms of concrete damage at high temperatures. These mechanisms are often considered as the main causes of cracking and peeling of concrete subjected to high temperatures. Therefore, a fire can strongly modify the behavior of concrete and jeopardize the stability of concrete. In case of fires, it is necessary to know the instantaneous and residual behavior of concrete subjected to temperatures up to $1000^{\circ} \mathrm{C}$. In this work we present a study of the mechanical performance of high-temperature high-performance concrete (HPC) exposed to four maximum temperatures, $200,400,600$, and $900^{\circ} \mathrm{C}$. The results obtained show that the mechanical strength at 28 days increases with the degree of temperature compared with that measured at $20^{\circ} \mathrm{C}$. On the contrary, a clear decrease is observed between 600 and $900^{\circ} \mathrm{C}$.
\end{abstract}

Keywords: HPC, high temperatures, mechanical strength, porosity, mineral additions

\section{Introduction}

High-performance concrete (HPC) is a concrete mixture, which possesses high durability and high strength when compared to conventional concrete [1]. This concrete contains one or more of the cementitious materials such as fly ash, silica fume, or ground granulated blast-furnace slag (GGBFS) and usually a super plasticizer. High strength of concrete is achieved by reducing porosity, inhomogeneity, and microcracks in the hydrated cement paste and the transition zone. Consequently, there is a reduction of the thickness of the interfacial transition zone in high-strength concrete. The densification of the interfacial transition zone allows for efficient load transfer between the cement mortar and the coarse aggregate, contributing to the strength of the concrete. For very high-strength concrete where the matrix is extremely dense, a weak aggregate may become the weak link in concrete strength [2].

The importance in the behavior of concrete at a high temperature mainly results from the many cases of fires taking place in buildings, high-rise buildings, tunnels, and drilling platform structures [3]. During a fire, the temperature may reach up to 
$1100^{\circ} \mathrm{C}$ in buildings and even up to $1350^{\circ} \mathrm{C}$ in tunnels, leading to severe damage in a concrete structure. When concrete is heated under conditions of fire, the increase in temperature in the deeper layers of the material is progressive, but because this process is slow, significant temperature gradients are produced between the concrete member's surface and core inducing additional damage to the element. Fundamental issues related to the impact of high temperature on concrete involve identification of the complex changes that take place in concrete while heated. This concerns both the physical and chemical changes taking place in the cement matrix, as well as the phenomena involved in mass movement (gases and liquids) [4].

The analysis is complicated due to the fact that cement concrete is a composite consisting of two substantially different constituents: cement paste and aggregates. The effects of the various changes taking place in heated concrete are the alterations of its physical, thermal, and mechanical properties [5].

Many research have demonstrated that changes in the strength of concrete as a function of temperature are related to, inter alia, concrete composition, the type of aggregate used, the water/cement ratio, the presence of pozzolana additives, etc. Important factors are also the rate of heating and the time of concrete exposure to high temperature.

\section{References}

\subsection{Effect of curing temperature on cement hydration}

Portland cement hydration is affected by many variables, including chemical composition, the water/cement ratio, the presence of mineral additions, and fineness. Yet another variable, however, is regarded to play a key role, bearing on early hydration kinetics and the properties of the hardened cement paste: that variable is temperature [6].

Parry-Jones et al. studied hydration in cement pastes cured for up to 31 days at temperatures ranging from 20 to $80^{\circ} \mathrm{C}$. These authors calculated the degree of hydration with 29Si MAS NMR. For pastes hydrated from 20 to $55^{\circ} \mathrm{C}$, strength and degree of hydration were linearly correlated, but for a given degree of hydration, the pastes hydrated at $80^{\circ} \mathrm{C}$ had perceptibly lower strength than the pastes cured at lower temperatures [7]. Curing temperature affects both the inner and outer calcium silicate hydrate $(\mathrm{C}-\mathrm{S}-\mathrm{H})$ gel structure. Regourd and Gautier reported that the outer $\mathrm{C}-\mathrm{S}-\mathrm{H}$ formed at $80^{\circ} \mathrm{C}$ was much more fibrous, exhibiting morphology reminiscent of pastes hydrated with calcium chloride accelerators [8].

Kjellsen et al. reported thicker inner C-S-H rims than pastes hydrated at low temperatures. Such brightness is associated with several developments: an increase in the average atomic number, a decrease in the water content or both, or highsulfate concentration in C-S-H gels formed at high temperatures $[9,10]$.

Temperature affects the interaction between additions and cement compounds. Alite hydration was found to rise sharply from a very early age in the presence of slag and volcanic ash but much less abruptly when fly ash was added. Belite hydration was delayed in the presence of fly ash at 40 and $60^{\circ} \mathrm{C}$ but was somewhat enhanced at lower temperatures [11-13].

Escalante et al. noted that for all blended cement pastes, an increase in curing temperature led to greater porosity, with the most prominent differences appearing between 10 and $60^{\circ} \mathrm{C}$. The same authors confirmed that in fly ash-based pozzolanic cement pastes, $\mathrm{Ca}(\mathrm{OH}) 2$ was almost absent in pastes cured at $60^{\circ} \mathrm{C}$, whereas at $10^{\circ} \mathrm{C}$, clusters of $\mathrm{Ca}(\mathrm{OH})_{2}$ were visible in the microstructure [12]. 


\subsection{Effects of high temperature on the residual performance of concretes}

The increase in temperature results in water evaporation, C-S-H gel dehydration, calcium hydroxide and calcium aluminate decomposition, etc. Along with the increase in temperature, changes in the aggregate take place. Due to those changes, concrete strength and modulus of elasticity gradually decrease, and when the temperature exceeds ca. $300^{\circ} \mathrm{C}$, the decline in strength becomes more rapid. When a $500^{\circ} \mathrm{C}$ threshold is passed, the compressive strength of concrete usually drops by $50-60 \%$, and the concrete is considered fully damaged [14].

Many researches showed a heating of cement paste results in drying. Water gradually evaporates from the material. The order in which water is removed from heated concrete depends on the energy that binds the water and the solid. Thus, free water evaporates first, followed by capillary water and finally by physically bound water. The process of removing water that is chemically bound with cement hydrates is the last to be initiated. The mechanical properties of cement paste are strongly affected by chemical bonds and cohesion forces between sheets of calcium silicate hydrate (C-S-H) gel. It is assumed that approximately $50 \%$ of cement paste strength comes from cohesion forces (important C-S-H gel sheet area); therefore, the evaporation of water between $\mathrm{C}-\mathrm{S}-\mathrm{H}$ gel sheets strongly affects the mechanical properties of the cement paste $[15,16]$.

According to the work of Verbeck et al. [17], in the process of simultaneously exposing the material to high pressures and temperature, it may activate the changes in the microstructure of hydrates and often increases cement paste strength. The nature of the phase changes will depend upon the mineralogical composition of the cement, its $\mathrm{C} / \mathrm{S}$ ratio ( $\mathrm{mol}$ of lime per mol of silica; $\mathrm{CaO} / \mathrm{SiO}_{2}$ ), the amount of fine particles (quartz or silica fume), and the temperature and pressure levels that have been reached. Heating the cement paste with a $\mathrm{C} / \mathrm{S}$ ratio around 1.5 to temperature above $100^{\circ} \mathrm{C}$ produces several forms of calcium silicates, in general highly porous and weak. When the $\mathrm{C} / \mathrm{S}$ ratio is close to 1.0 and the temperature is above $150^{\circ} \mathrm{C}$, a $1.5-1.0$ to bemorite gel can form. At temperature between 180 and $200^{\circ} \mathrm{C}$, other silicates such as xonotlite and hillebrandite may be formed [17].

During heating, ettringite decomposes first, even before the temperature reaches $100^{\circ} \mathrm{C}$. C-S-H gel dehydration is progressive and takes place from the very beginning of material heating. In this state the structure of the cement paste is partially damaged due to dehydration at a temperature of $105^{\circ} \mathrm{C}$, which is standard for the drying of materials. As soon as cement paste is heated to temperature of $500-550^{\circ} \mathrm{C}$, the portlandite content rapidly decreases, as it decomposes according to the following reaction:

$$
\mathrm{Ca}(\mathrm{OH})_{2} \rightarrow \mathrm{CaO}+\mathrm{H}_{2} \mathrm{O}
$$

At $550^{\circ} \mathrm{C}$, the peak corresponding to the decomposition of the free limestone $\mathrm{Ca}(\mathrm{OH})_{2} \mathrm{CaO}[18]$.

Hager noticed that the $\mathrm{CaO}$ created in this reaction makes the elements made of the portland cement practically redundant after cooling. The dehydration process of the C-S-H gel reduces its volume, which in turn increases the porosity of the cement matrix. Moreover, during heating, the cement paste experiences a slight expansion up to temperature of approximately $200^{\circ} \mathrm{C}$ although the intense shrinkage begins once this temperature is exceeded. This significantly contributes to the porosity evolution of the cement paste. Due to heating total pore volume increases, as does the average pore size [15].

Reinforced concrete structures exposed to the environment require durable concretes to provide long-lasting performance with minimal maintenance. Low 
permeability is an important characteristic of durable concretes and may be obtained by lowering the water/cementitious material ratio (W/C) and using pozzolans (fly ash and silica fume) or slag as a portion of the cementitious material $[15,18]$.

\subsection{Effect of temperature on durability of slag concrete, fly ash concrete, and silica fume concrete}

During the production of cement, a significant quantity of $\mathrm{CO}_{2}$ is released into the atmosphere. It is estimated that the production of each ton of portland cement releases approximately 1 ton of $\mathrm{CO}_{2}$ gas. The world production of clinker accounts for about $7 \%$ of the total $\mathrm{CO}_{2}$ emissions. The use of these additions as cement replacement decreases the amount of clinker required, resulting in a limiting gas emissions of $\mathrm{CO}_{2}$ and dust in the atmosphere. The cement replacement does not only reduce the production costs but also address some environmental issues providing the enhanced concrete performances (better workability, lower hydration heat, and good durability) [19].

High-performance concrete (HPC) has been used more widely in recent years due to the increasing demand for durable concrete, thus to extend service life and reduce maintenance fee of concrete structures. HPC is known as a concrete which has a compressive strength over $60 \mathrm{MPa}$ [20]. The pozzolana addition influences positively the compressive strength that could be easily increased up to $150 \mathrm{MPa}$. Pozzolanic materials are very important in the production of HPC. Further, HPC may contain materials such as silica fume, fly ash, ground granulated blast-furnace slag, natural pozzolana, chemical admixtures, and other materials, individually or in various combinations.

In slag cements, clinker is the principal activator of the binder. However, the first produced hydrates will be those of the clinker; C-S-H and $\mathrm{Ca}(\mathrm{OH})_{2}$ uniformly cover the grains with the slag and the clinker; there after the lime excess activates the hydration of the slag with a texture of C-S-H similar to that of cements; it results in calcium silicate hydrates and hydrated tetra-calcium aluminates. Other research undertaken on the subject reported that the more fine the slag is, the better is its performance [21].

Tebbal's research indicated that the compressive strength is higher, when the cement is replaced by $5 \%$ silica fumes mainly, the combined mixture of $5 \%$ of silica fume and $10 \%$ of slag, at a maximum value of $170 \mathrm{MPa}$ [22].

During the hydration reaction between portland cement and water, a cementitious gel and lime are formed. Pozzolanic materials react with this lime in the presence of moisture to form additional cementitious gel. Slags also submit to this pozzolanic reaction. This reaction leads to a reduction in the permeability of the concrete and an increase in its strength [23].

Traditionally, slag, silica fume, and fly ash were used in concrete individually. Nowadays, due to the improved access to these materials, concrete producers can combine two or more of such materials to optimize concrete properties at fresh state (workability) and hardened state (strength and durability); a reduction in the rate of penetration of chloride ion concrete reduced the potential of chloride-induced corrosion [20].

Ravindrarajah et al. stated that concrete consists of discrete and interconnected pores of a variety of sizes and shapes and their distribution depends on the binder material type. The refinement of pore size as well as grain size of concrete is attained by the use of fly ash, slag, and silica fume due to its fineness, pozzolanic, and cementitious property. Free water in the gel causes capillary cavities, and combined water in hardened cement paste improves the hydration process. Combined water can be dehydrated at $1000^{\circ} \mathrm{C}$ only due to its stability [24]. 
According to Bingöl et al., there are no significant losses in the compressive strength of lightweight aggregate concrete observed between 150 and $300^{\circ} \mathrm{C}$. The initial strength loss is important for all mix groups at $750^{\circ} \mathrm{C}$. The heating duration does not affect the strength loss significantly, but high temperature is a significant parameter of strength loss. Stephen S. Szoke stated the degradation of pavement color resembles the degradation of cement paste properties [25].

The effect of thermal cycles on the compressive strength of high-volume fly ash concrete has been studied by Srinivasa Rao et al. They are confirmed that the structural elements when exposed to solar radiation, the thermal gradients in the elements are influenced by the degree of humidity. In that way the elements of structures undergo one thermal cycle per day and also are exposed to peak value of heating period and cooling period [26].

Noumowé mentioned that thermal gradients were very significant and generating high compressive stresses at the specimen surface during the heating tests at 210 and $310^{\circ} \mathrm{C}$. This thermal loading causes stresses which are accompanied by the degradations of cement paste due to abrupt changes in volume further leading to a damage of the concrete. Contrasting conditions observed while cooling the temperature in the center of specimen are more in the surface. This condition causes compressive stresses at the center and tensile stresses on the surface. Compressive strength is decreased with the increase in temperature. However, losses were very less between 20 and $110^{\circ} \mathrm{C}$. There was an appreciable reduction in the strength above $210^{\circ} \mathrm{C}$, and loss in compressive strength was $8 \%$ [27].

Falade concluded that the compressive strength of concrete is reduced with increase in water/cement ratio and increase in temperature but increased with increase in curing period. The bond between the concrete within matrix decreases as the temperature increases. The loss in strength of specimens is in between 24 and $40 \%$ at a maximum temperature of $800^{\circ} \mathrm{C} / \mathrm{h}$., which is influenced by the mix proportion and curing age. Lightweight concrete consists of periwinkle shells which are the only appropriate material for structures that will be exposed to temperature lower than $300^{\circ} \mathrm{C}$ [28].

Siddique et al. concluded that concrete with GGBFS can be used in constructions exposed to elevated temperatures. The degradation of mechanical properties of concrete is less between 27 and $100^{\circ} \mathrm{C}$. The values of compressive strength, split tensile strength, and modulus of elasticity are reduced lower than $40 \%$ after exposing to a temperature more than $350^{\circ} \mathrm{C}$. The loss in mass is not very important at temperatures between 200 and $350^{\circ} \mathrm{C}$. GGBFS may contribute to some extent to the residual compressive strength of concrete at elevated temperatures. Similar findings were observed by Siddique and Kaur [29].

Pathan et al. stated that in practice, at a temperature of $250^{\circ} \mathrm{C}$, calcium hydroxide starts to dehydrate generating more amount of water vapor. Further, significant reduction in their compressive strength was observed at temperatures in the range of 300 and $600^{\circ} \mathrm{C}$ [30].

Seshagiri Rao et al. stated that a considerable change in physical structure and chemical composition appears when concrete is exposed to high temperature. Above $100^{\circ} \mathrm{C}$, dehydration of water in C-S-H gel is important. This is added to thermal expansion of aggregates which causes the increase in internal stresses at $300^{\circ} \mathrm{C}$, and further microcracks are developed. $\mathrm{Ca}(\mathrm{OH})_{2}$, the product of hydration of cement paste, separates into $\mathrm{CaO}$ and $\mathrm{H} 2 \mathrm{O}$ at $400-600^{\circ} \mathrm{C}$ subsequently; shrinkage of concrete occurs [31].

Chowdhury stated that at high temperatures, the loss in compressive strength and tensile strength was observed for all three concrete mixes of 100,80 , and $40 \mathrm{MPa}$. The loss in strength for $80 \mathrm{MPa}$ mix was about $44 \%$ when exposed to $400^{\circ} \mathrm{C}$ for $12 \mathrm{~h}$. At $60^{\circ} \mathrm{C}$, the loss in tensile strength for $80 \mathrm{MPa}$ mix was about $18 \%$ for $72 \mathrm{~h}$ of exposure. A nonlinear relationship was observed between weight loss and maximum temperature, but loss was least in the case of the highest strength 
mix for every temperature and duration of high temperature exposure. An easy way to comply with the conference paper formatting requirements is to use this document as a template and simply type your text into it [32].

According to Santosh Kumar et al. [33], the materials like pozzalonas may be natural and artificial like industrial wastes or by-products which require less energy to make fine particles. These materials exhibit cementitious properties and combine with calcium hydroxide producing cementitious material [34].

Gowri et al. presents the results of experimental studies conducted on performance of High Volumes of Slag Concrete (HVSC) exposed to elevated temperatures up to $600^{\circ} \mathrm{C}$. In HVSC, $50 \%$ of cement is replaced with Ground Granulated Blast Furnace Slag (GGBS). In this experimental studies, HVSC of $100 \mathrm{~mm}$ cubes are cast and tested for various water/binder ratios ranging from 0.55 to 0.27 . The specimens are exposed to elevated temperatures of $200^{\circ} \mathrm{C}, 400^{\circ} \mathrm{C}$ and $600^{\circ} \mathrm{C}$ for $4,8,12$ hours. Result of compressive strengths and weights of cubes after expose to high temperature are estimated. Percentage loss in compressive strengths and weights are also evaluated. The results illustrate that the loss in compressive strength and weights are more for higher temperatures for longer duration for higher water/binder ratios [35].

According to Jawed et al., percentage loss of compressive strength is higher with an increase amount of fly ash in concrete samples, i.e., for $20 \%$ fly ash concrete. This is due to high impermeability and moisture gained in longer curing period resulting in high pore pressure but low initial strength gain [36].

In 2004, Yüzer et al. carried out a study on the effects of fire, and extinguishing on the properties of concrete, mortars with and without silica fume were exposed to different temperatures, such as $100,200,300,600,900$, and $1200^{\circ} \mathrm{C}$ and cooled slowly in the air and fast in water in two groups. Flexural and compressive strength tests were performed on the samples which were cooled up to room temperature, and changes in compressive strength in color were determined by Munsell color system. High temperature has caused damages to decrease in mechanical strengths at $600^{\circ} \mathrm{C}$. Researchers observed that the changes in color hue component and the compressive strength have similarities. Test results show that residual color changes in mortar can give an idea about the effect of high temperatures on mechanical properties of mortar during a fire [37].

Ahmad's research includes an experimental investigation to study the effect of high temperatures on the mechanical properties of concrete containing admixtures. A comparative study was conducted on concrete mixes, reference mix without an additive, and that with an admixture. Concrete was exposed to three levels of high temperatures $\left(200,400,600^{\circ} \mathrm{C}\right)$, for duration of $1 \mathrm{~h}$, without any imposed load during the heating. Super plasticizer, plasticizer, retarder, water-reducing admixture, an accelerator, and an air entraining admixture, five types of admixtures, were used. Mechanical properties of concrete were studied at different high temperatures, including compressive strength, splitting tensile strength, modulus of elasticity, and ultimate strain. Test results showed a reduction in the studied properties by different rates for different additives, and for each temperature, the decrease was very limited at a temperature up to $200^{\circ} \mathrm{C}$ but was clear at $400-600^{\circ} \mathrm{C}$ [38].

\section{Tebbal et al.s research on the effect of temperature on high-performance concrete}

This study examines the effect of the additions of silica fume and super plasticizer on the mechanical performance of high-performance concretes at high temperatures. The tested concretes are formulated with $5 \%$ silica fume and two dosages of super plasticizers in the ratio of $(2 \%, 2.5 \%)$ the weight of cement after having been exposed to four maximum temperatures, $200,400,600$, and $900^{\circ} \mathrm{C}$, without any imposed 
load during the heating. The results obtained show that the mechanical resistance at 28 days increases with the degree of temperature compared to that measured at $20^{\circ} \mathrm{C}$. On the contrary, a clear decrease is observed between 600 and $900^{\circ} \mathrm{C}$. However, material composition seems to have great influence on the mechanical strength.

In the present study, three factors were studied at high temperatures:

- The influence of super plasticizer on the mechanical strength

- The additions of silica fume on the behavior of HPC

- The internal structure, X-ray diffraction (XRD) patterns and gravimetric and differential thermal analyses (ATG and ATD) of concrete subjected at high temperature

\subsection{Materials and methods}

The portland cement-type CEM II/A 42.5 from Hammam Dalâa local factory was used in this experimental study. The used cement type has an absolute density, consistency, and fineness values of $3.1 \mathrm{~g} / \mathrm{cm}^{3}, 28 \%$, and $4000 \mathrm{~cm}^{2} / \mathrm{g}$, respectively. The chemical composition of the cement is shown in Table 1.

The silica fume is obtained from GRANITEX in Algeria region. It results from melting the silicon and ferrosilicon. The reduction of high-purity quartz to silicon at temperatures up to $2000^{\circ} \mathrm{C}$ produces $\mathrm{SiO}_{2}$ vapors, which oxidize and condense in the low-temperature zone to tiny particles consisting of noncrystalline silica [39]. The physical properties and particle size by laser granulometer (Mastersizer 2000) of silica fume are shown in Table 1 and Figure 1.

The natural fine aggregates used were dune sand with particles ranging from 0.08 to $5 \mathrm{~mm}$ in size, with a fineness modulus, Mf, of 2.44. This natural sand was

\begin{tabular}{|c|c|c|c|c|c|c|}
\hline & \multicolumn{4}{|c|}{ Cement (\%) } & \multicolumn{2}{|c|}{ Silica fume (\%) } \\
\hline $\mathrm{SiO}_{2}$ & \multicolumn{4}{|c|}{20.7} & \multicolumn{2}{|c|}{$>85$} \\
\hline $\mathrm{Al}_{2} \mathrm{O}_{3}$ & \multicolumn{4}{|c|}{04.75} & \multicolumn{2}{|c|}{-} \\
\hline $\mathrm{Fe}_{2} \mathrm{O}_{3}$ & \multicolumn{4}{|c|}{03.75} & \multicolumn{2}{|c|}{-} \\
\hline $\mathrm{CaO}$ & \multicolumn{4}{|c|}{62.92} & \multicolumn{2}{|c|}{-} \\
\hline $\mathrm{MgO}$ & \multicolumn{4}{|c|}{01.90} & \multicolumn{2}{|c|}{-} \\
\hline $\mathrm{SO}_{3}$ & \multicolumn{4}{|c|}{1.98} & \multicolumn{2}{|c|}{$<2.5$} \\
\hline CL & \multicolumn{4}{|c|}{ - } & \multicolumn{2}{|c|}{$<0.2$} \\
\hline \multicolumn{7}{|c|}{ Mineralogical composition of cement } \\
\hline \multirow[t]{2}{*}{ Item content } & $\mathrm{C}_{3} \mathrm{~S}$ & & & $\mathrm{C}_{3} \mathrm{~A}$ & \multicolumn{2}{|c|}{$\mathrm{C}_{4} \mathrm{AF}$} \\
\hline & 59 & \multicolumn{2}{|c|}{14} & 6 & \multicolumn{2}{|c|}{10} \\
\hline \multicolumn{7}{|c|}{ Physical properties of silica fume } \\
\hline Particle size & \multicolumn{2}{|c|}{ Density } & \multicolumn{2}{|c|}{ Specific surface } & \multicolumn{2}{|c|}{$\begin{array}{c}\text { Moisture by storing } \\
\text { at } 105^{\circ} \mathrm{C}\end{array}$} \\
\hline$<0.1$ microns & \multicolumn{2}{|c|}{$<0.5$} & \multicolumn{2}{|c|}{$>15 \mathrm{~m}^{2} / \mathrm{g}$} & \multicolumn{2}{|c|}{$<1 \%$} \\
\hline \multicolumn{7}{|c|}{ Characteristics of the chemical admixture } \\
\hline Super plasticizer & Form & Color & $\mathrm{PH}$ & Density & $\begin{array}{l}\text { Chlorine } \\
\text { content }\end{array}$ & $\begin{array}{c}\text { Dry } \\
\text { extract }\end{array}$ \\
\hline Medaplast SP40 & Liquid & Brown & 8.2 & $1.2 \pm 0.01$ & $<1 \mathrm{~g} / 1$ & $40 \%$ \\
\hline
\end{tabular}

Table 1.

The chemical and physical properties of cement and silica fume [18]. 


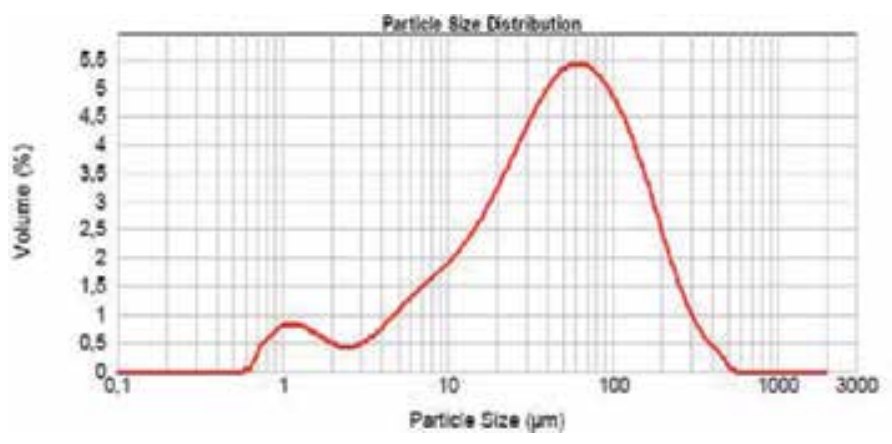

Figure 1.

Particle size distributions of silica fume [18].

taken from the region of Bou Sâada ( $250 \mathrm{~km}$ east of Algiers). The sieve analysis is performed according to the European standard NF EN 933-1. The mineralogical composition determined by X-ray diffraction shows that the siliceous sand is more than $95 \%$ of quartz and calcite traces.

The coarse fraction of aggregate is gravel (G1) of size $3 / 8 \mathrm{~mm}$ and gravel (G2) of size $8 / 15 \mathrm{~mm}$. The adjuvant used is a super plasticizer which is highly water reducing (Medaplast SP40). It is a solution of $\mathrm{pH}=8.2$ and a density of 1.22 , with $40 \%$ of solids. Its normal use scale is fixed by the manufacturer's recommendation which is between 0.6 and $2.5 \%$ of the cement weight. The tap water used all through the study from mixing was taken from the laboratory of civil engineering.

\subsection{Mixture design}

Fresh concrete mixes were prepared in a modified laboratory mixer; the mixing procedure is explained in Table 2 . The concrete specimens were preserved in their molds in a wet place at a temperature of $20^{\circ} \mathrm{C}$ and $95 \%$ relative humidity $(\mathrm{RH})$ during $24 \mathrm{~h}$. After demolding, they were immersed in water at $20^{\circ} \mathrm{C}$ until the age of testing. The physical and mechanical characteristics of the concretes with and without the addition of silica fume have been compared. The silica fume is added at a dosage of $5 \%$ cement weight and the super plasticizer at 2 and $2.5 \%$, respectively. The final compositions of high-performance concrete (HPC), after optimization, are reported in Table 3 [19, 22].

The following acronyms will be used henceforth:

$\mathrm{CR}_{2.5}$ : Concrete without silica fume and $2.5 \%$ (by weight of cement) of the chemical admixture.

$\mathrm{HPC}_{2.5}$ : Concrete dosed at $5 \%$ of silica fume and $2.5 \%$ of the chemical admixture. $\mathrm{HPC}_{2}$ : Concrete dosed at $5 \%$ of silica fume and $2 \%$ of the chemical admixture.

\begin{tabular}{ll}
\hline Time,s & Mixing procedure \\
\hline 60 & Mixing of aggregates, silica fume, cement \\
\hline 30 & Addition $100 \%$ of water and a third of the volume of super plasticizer \\
\hline 180 & Mixing \\
\hline 30 & Addition of the remaining super plasticizer \\
\hline 60 & Mixing \\
\hline
\end{tabular}

Table 2.

Mixing procedure [18]. 


\begin{tabular}{|c|c|c|c|c|c|c|}
\hline \multirow[t]{2}{*}{$\operatorname{Mix}\left(\mathrm{kg} / \mathrm{m}^{3}\right)$} & \multirow[t]{2}{*}{ Cement } & \multirow[t]{2}{*}{ Sand } & \multirow[t]{2}{*}{ Gravel $(3 / 8,8 / 15)$} & \multirow[t]{2}{*}{ Water } & \multicolumn{2}{|c|}{ Additions } \\
\hline & & & & & Silica fume (\%) & Super plasticizer (\%) \\
\hline $\mathrm{CR}_{2.5}$ & 400 & 662 & 1090 & 220 & - & 2.5 \\
\hline $\mathrm{HPC}_{2.5}$ & 444 & 645 & 1042 & 119 & 5 & 2.5 \\
\hline $\mathrm{HPC}_{2}$ & 444 & 662 & 1042 & 122 & 5 & 2 \\
\hline
\end{tabular}

Table 3.

Compositions of concrete with and without silica fume [18].

After 28 days, specimens with dimensions $\left(100 \mathrm{~mm} \times 100 \mathrm{~mm} \times 100 \mathrm{~mm}^{3}\right)$ are dried in an oven (at $100^{\circ} \mathrm{C}$ ), until stabilization of their mass. All specimens are subjected to high temperatures, $200,400,600$, and $900^{\circ} \mathrm{C}$, according to the timetemperature schedule of ASTM E 119-00 [39]. After cooling, they were subjected to compression tests.

The slump values were obtained for all three mixtures according to the NF EN 12390-4 and EN 12390-5 [40, 41]. The axial compressive strength was tested at 28 days according to NF EN 12390-4 [40] for the concrete at $20^{\circ} \mathrm{C}$ that was not subjected to high temperatures.

The protocol of porosity accessible to water conforms the recommendations of AFREM group [42]. The open porosity allows us to appreciate the evolution of hydration and structuration of hydrated products; this is a key for identification of the most sustainable concrete [43]. The test pieces for testing of water porosity are dried in an oven at a temperature of $100^{\circ} \mathrm{C}$ to constant weight and then returned to room temperature in a desiccator.

The porosity test is carried out on test pieces of dimensions $10 \times 10 \times 10 \mathrm{~cm}^{3}$, by applying the following steps:

- Dry in an oven at $105^{\circ} \mathrm{C}$ the sample for at least $24 \mathrm{~h}$ until obtaining a constant mass. This mass is denoted as "A."

- Immerse the sample in water for $24 \mathrm{~h}$.

- Heat to boil for $5 \mathrm{~h}$, and then weigh the sample in air (i.e., the weight is denoted as “C”).

- Then hydrostatic weigh (the weight is denoted as “ $\mathrm{D}$ ”).

The porosity was calculated by the formula:

$$
P(\%)=\frac{C-A}{C-D} \times 100
$$

Phase compositions of these concretes were investigated on the fine powders using X-ray diffraction method. The powder samples of concrete heat-treated aggregates at 20,600 , and $900^{\circ} \mathrm{C}$ were collected after abrasion. X-ray diffraction analysis was performed on an X-ray diffractometer (X'Pert) coupled to a computer system. The essential purpose of this analysis is to identify the different phases of crystal present in a sample.

Gravimetric and differential thermal analyses (ATG and ATD) make it possible to quantify portlandite; these techniques are used to characterize degradations. 


\subsection{Results and discussion}

\subsubsection{High-temperature effects on surface properties of concrete}

As seen in Figure 2, some color changes happen on the surface of concrete samples due to high temperature effects. As a result of these color changes the range of temperature values can be certainly appraised. It can be seen that cracking, rupture, and color changes happened much more in the concrete samples exposed to $900^{\circ} \mathrm{C}$ than the ones with 400 and $600^{\circ} \mathrm{C}$.

\subsubsection{Loss of concrete's mass related to temperature}

Figure 3 shows the evolution of mass loss during the heating cycle of the studied specimens. Before $100^{\circ} \mathrm{C}$, the mass's exchange is very low. The mass loss in this temperature range corresponds mainly to the water's escape from concrete's pore, because the water chemically bound to the silicates becomes free. The chemical bonds in the $\mathrm{C}-\mathrm{S}-\mathrm{H}$ break, and the gel buildup water is released and can be evacuated.

Between 100 and $600^{\circ} \mathrm{C}$, a strong mass loss for all concrete specimens was tested. Each concrete lost from 3 to $12 \%$ of its original mass. Most of the water in each concrete specimen evaporated during heating between 100 and $400^{\circ} \mathrm{C}$. The increase is almost linear up to a temperature of $600^{\circ} \mathrm{C}$. This is due to the evaporation of water and the progressive dehydration of C-S-H gel. Several authors, Noumowé et al., confirm that beyond $600^{\circ} \mathrm{C}$, there is no more water in the concrete specimen $[43,44]$.

\subsubsection{Result of the crushing of concrete after cooling}

The compressive strength of all concrete mixtures at ambient temperature and after heating at $200,400,600$, and $900^{\circ} \mathrm{C}$ is illustrated in Figure 4.
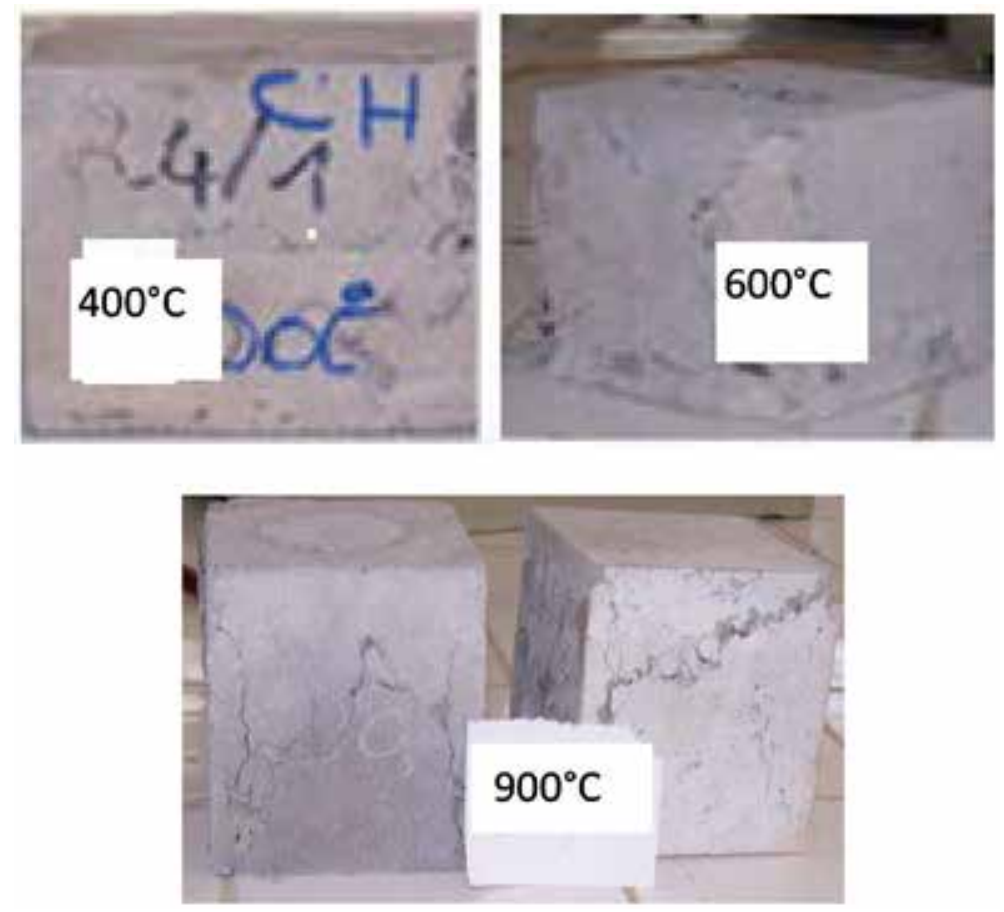

Figure 2.

Concrete samples exposed to high temperature [18]. 


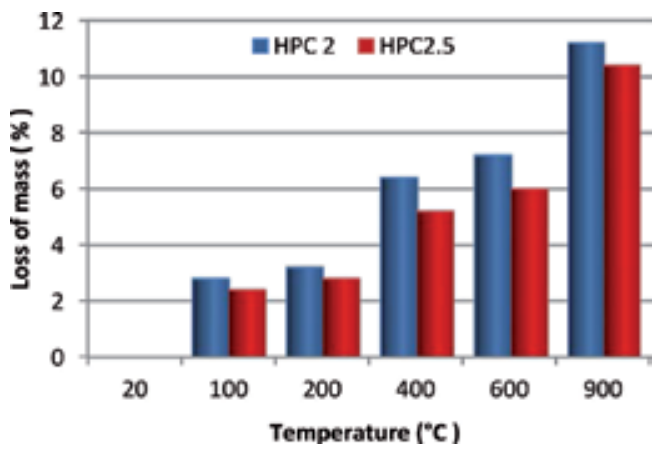

Figure 3.

Evolution of mass loss related to temperature [18].

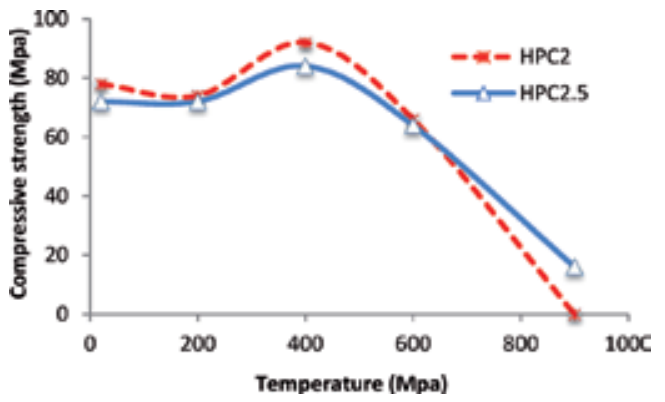

Figure 4 .

Compressive strength after cooling relative the initial strength [18].

This figure clearly shows that the compressive strength of all concrete mixtures decreases at elevated temperature. According to the results obtained from the present investigation, the strength of concrete $\mathrm{HPC}_{2}$ after heated at 200,600, and $900^{\circ} \mathrm{C}$ decreases by 3,11 , and $78 \%$ of its unheated strength, respectively.

The concrete $\mathrm{HPC}_{2.5}$ exhibited the greatest loss in strength, about 4, 15.38, and $100 \%$ of its unheated strength when heated at 200,600 , and $900^{\circ} \mathrm{C}$, respectively. We observe a stress peak at $400^{\circ} \mathrm{C}$ indicating a maximum value of the compressive strength of the concretes. The decomposition temperature of $\mathrm{Ca}(\mathrm{OH})_{2}$ varies between 400 and $600^{\circ} \mathrm{C}$. If static temperature conditions are maintained, $\mathrm{Ca}(\mathrm{OH})_{2}$ will decompose at $400^{\circ} \mathrm{C}$. This temperature seems to be the critical temperature for a portland cement concrete [45].

Kalifa et al.s work has shown the role of water on the performance of HPC temperature. Pressure values observed in HPC of 100-4 MPa were only $3 \mathrm{~cm}$ deep from the heated side to the vicinity of $250^{\circ} \mathrm{C}$ [46]. This further explains the prestressing force caused by the water trough described by Burlion et al. [47].

After the evaporation of physically and chemically bound water, a pressure is built up which leads to an extensive inner cracking. This inner cracking is the main reason for the reduction in strength of all concrete mixtures. Apart from it, the cement paste contracts, and aggregate expands due to loss of water at higher temperature which leads to loss of the bond between paste and aggregates.

\subsubsection{Influence of super plasticizer on the mechanical strength}

At $900^{\circ} \mathrm{C}$, we notice a low resistance for concrete with $2 \%$ adjuvant and a bursting of the concrete to those dosed of $2.5 \%$ super plasticizer (Figure 4 ). This can be explained by: 
- The concretes with superplasticizer have high resistance. The role of the super plasticizer in the distribution of cement particles in improving the compactness of concrete is highlighted. The concrete mixes containing superplasticizer are affected by high temperatures especially at $600^{\circ} \mathrm{C}$ and above compared to those with less super plasticizer dosage.

- The decrease of resistance estimated at $78 \%$ for HPC with $2 \%$ super plasticizer exposed to a temperature of $900^{\circ} \mathrm{C}$, on the other hand, is zero for ordinary concrete. During these processes, some cracks occur, and concrete is crumbled and becomes a porous material [48]. Aggregate's effect on concrete at high temperatures is related to their mineral structures. This process results in volume increase and damage $[18,19]$.

\subsubsection{Influence of silica fume on the mechanical strength}

In this part of the study, we want to highlight the influence of silica fume on the mechanical behavior of HPC. After the passage in the oven, the concrete specimens were cooled for $24 \mathrm{~h}$ in the laboratory, at a temperature of $20 \pm 5^{\circ} \mathrm{C}$ before submitting to compressive strength test. The specimens of HPC exposed at high temperature are schematized as shown in Figure 5.

As expected, the replacement of cement by $5 \%$ of silica fume increased the compressive strength approximately $30 \%$ at 28 days. This is due to the reaction of the silica fume with calcium hydroxide formed during the hydration of cement that caused the formation of calcium silicate hydrate (C-S-H) as well as filler role of very fine particles of silica fume. In general, it can be concluded that concretes containing silica fume had significantly higher strength than that of CR concretes at room temperature. After exposure to $200^{\circ} \mathrm{C}$, significant reductions occurred in the compressive strength of concretes without SF. Results showed the strength recovery of $18 \%$ for the concretes $\mathrm{HPC}_{2.5}$ after heating to $400^{\circ} \mathrm{C}$ when compared to $200^{\circ} \mathrm{C}$. The compressive strength gains at $400^{\circ} \mathrm{C}$ are attributed to the increase in the forces between gel particles (van der Waals forces) due to the removal of water content [48].

In the range of $400-600^{\circ} \mathrm{C}$, severe strength losses occurred in two concretes, $\mathrm{HPC}_{2.5}$ and $\mathrm{CR}_{2.5}$. During exposure to high temperatures, cement paste contracts, whereas aggregates expand. Thus, the transition zone and bonding between aggregates and paste are weakened. After heating to $600^{\circ} \mathrm{C}$, the compressive strengths of CR were lower than those of the concretes $\mathrm{HPC}_{2.5}$. This is attributed to the presence and amount of silica fume in concretes that produced very denser transition zone between aggregates and paste due to its ultrafine particles as filler and its pozzolanic reactions.

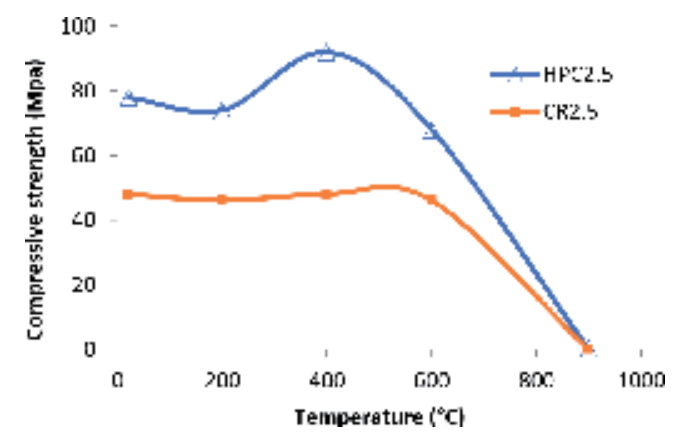

Figure 5.

Compressive strength of $\left(H P C_{2.5}\right)$ and $\left(C R_{2.5}\right)$ with temperatures [18]. 
At $600^{\circ} \mathrm{C}$, the quick losses in compressive strength for $\mathrm{HPC}_{2.5}$ concretes are attributed to the dense microstructure in this type of concretes, which caused the buildup of higher internal pressure due to the water vapor transition of the interlayer water. As a result, this process as well as chemical decomposition of hydration products causes severe deteriorations and strength loses in concrete after subjecting to high temperatures. It seems that the dosage of silica fume has no significant effect on the relative residual compressive strength at $200^{\circ} \mathrm{C}$. However, between 200 and $400^{\circ} \mathrm{C}$, the amount of $5 \%$ of silica fume has significant effects on the residual compressive strength. The greatest relative residual strength losses of concrete $\mathrm{HPC}_{2.5}$ and without silica fume were observed at $600^{\circ} \mathrm{C}$, which were 24 and $2 \%$.

Beyond $600^{\circ} \mathrm{C}$, the concrete may lose the majority of these properties, i.e., there are properties that can cancel out, and one can say that the concrete has become weak.

When temperature increases beyond $400^{\circ} \mathrm{C}$, the concrete strength decreases more rapidly due to the degradation of calcium silicate hydrate (C-S-H). The second phase of the C-S-H decomposes in the temperature range from 600 to $800^{\circ} \mathrm{C}$ forming $\beta$-C2S [16]. At a temperature of $900^{\circ} \mathrm{C}$, the $\mathrm{C}-\mathrm{S}-\mathrm{H}$ breaks down completely. Therefore, the critical temperature for concrete ranges from approximately $400-900^{\circ} \mathrm{C}$. In this range concrete loses most of its strength.

\subsubsection{Porosity}

The results of the porosity for the HPC after various heat treatments ranging from 20 to $900^{\circ} \mathrm{C}$ are shown in Figure 6 .

- For all high-performance concretes, a monotonic and fairly regular increase in porosity with temperature is observed.

- For $\mathrm{CR}_{2.5}$, the porosity values are higher than that of the HPC for all the temperatures.

Between 20 and $200^{\circ} \mathrm{C}$, the porosity increases very little. The HPC shows a decrease of $0.26 \%$. Kalifa explains that the decrease in the porosity of HPC is associated with the densification due to the complementary hydration of HSC.

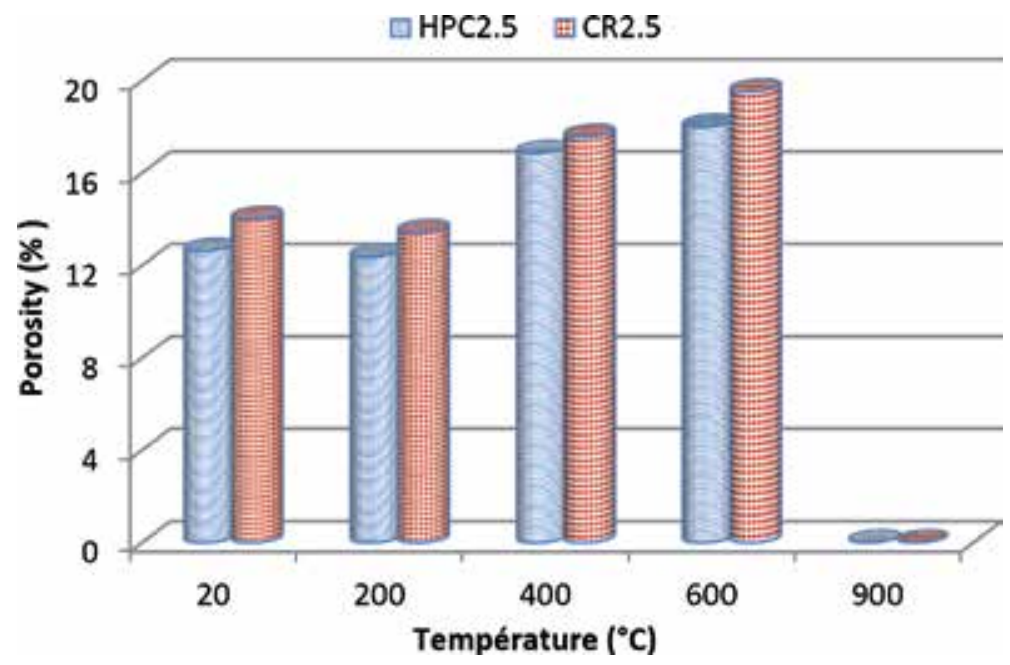

Figure 6.

Porosity as a function of temperature [18]. 
Between 200 and $400^{\circ} \mathrm{C}$, the porosity increases by $4.5 \%$ for the HPC. This growth is associated with the discharge of water, whether present in the water network or chemically bonded. Kalifa explains that the decrease in porosity of CR between 200 and $300^{\circ} \mathrm{C}$ compared to HPC is associated with densification due to complementary hydration and carbonation of portlandite under internal autoclaving conditions, that is to say, under a pressure higher than atmospheric pressure. On the other hand, this densification is not observable in the HPC which contains very little portlandite, thanks to the presence of silica fume.

At $600^{\circ} \mathrm{C}$, the porosity value has substantially increased by $6.1 \%$ compared with that of $20^{\circ} \mathrm{C}$. For the concrete $\mathrm{CR}_{2.5}$ and is almost $6.33 \%$ for the HPC. The evaluation of the porosity at $900^{\circ} \mathrm{C}$ is practically impossible as the test tubes that have undergone severe damage and have disintegrated.

Concerning the porosity of cement paste at high temperature, Piasta has shown that the porosity increases in a parabolic manner according to the temperature [49]. This increase, also noted in other works by Bazant et al., is accompanied by an increase in the average pore size and total pore volume. This is due in part to the internal fracture of the C-S-H gel structure during the dehydration process [49].

\subsection{Internal structure, ATG, and ATD of concrete}

Dehydration of the cement paste, thermal expansion and cracking, crystal processing, and mineral decomposition of aggregates are important reasons for the deterioration of concrete at high temperature.

Internal structure XRD patterns, ATG, and ATD of concrete subjected at high temperature are shown in Figures 7 and 8.

The analysis by X-ray diffraction is carried out in the physics laboratory of the University of M'sila by an X-ray diffractometer (X'Pert) coupled to a computer system. The essential purpose of this analysis is to identify the different crystalline phases present in a sample.

The analysis of the spectrum in Figure 7 is used to report the following findings:

The diffractogram of a heated concrete $\left(20^{\circ} \mathrm{C}\right)$ reveals the presence of portlandite, calcite, or $\alpha$-quartz.

To a more severe heat treatment $\left(400\right.$ and $\left.600^{\circ} \mathrm{C}\right)$, all the peaks relative to the portlandite disappear (dehydroxylation between 400 and $600^{\circ} \mathrm{C}$ ). This transformation was observed on ATD and ATG. Also, it does not detect the allotropic transformations of $\alpha$-quartz in $\beta$-quartz between the diffractograms of 400 and $600^{\circ} \mathrm{C}$ since it is about a reversible transformation.

At higher temperatures $\left(900^{\circ} \mathrm{C}\right)$, crystalline transformation of aggregates occurs, e.g., $\alpha$ - to $\beta$-quartz transformation in siliceous aggregates. Decarbonation of carbonates plays a prominent part if the concrete contains limestone aggregates.

Figure $7 \mathrm{C}$ shows that the peak intensity at the position that $2 \theta$ is $55^{\circ} \mathrm{C}$ increases. Therefore, it can be concluded that a new production was formed.

The results of the ATG and ATD powder of HPC at 20,600 , and $900^{\circ} \mathrm{C}$ are shown in Figure 8. A test sample of $200 \mathrm{mg}$ of the concrete was analyzed according to linear heating from ambient temperature to $1400^{\circ} \mathrm{C}$, with a speed of $10^{\circ} \mathrm{C} / \mathrm{min}$.

Six endothermic peaks were observed: 110-130, 180, 400, 450-550, 573, and $800^{\circ} \mathrm{C}$. These thermal flux peaks are essentially related to the phase exchange temperatures of the different hydrates of the cement paste.

At a double peak of 110 and $130^{\circ} \mathrm{C}$, the free water starts evaporating rapidly. In the temperature range from 80 to $150^{\circ} \mathrm{C}$, dehydration of ettringite takes place followed by the decomposition of gypsum between 150 and $170^{\circ} \mathrm{C}$ [50].

In contrast, a small endothermic peak is observed at a temperature of $180^{\circ} \mathrm{C}$; this peak indicates the dehydration of the calcium monocarboaluminate hydrate [51]. 


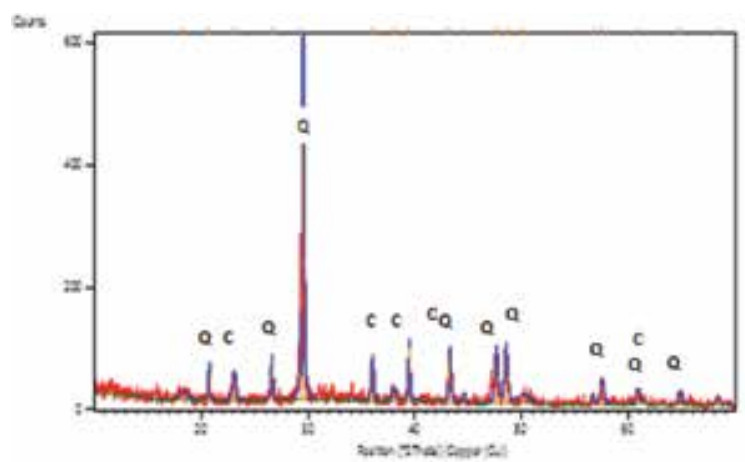

(A)

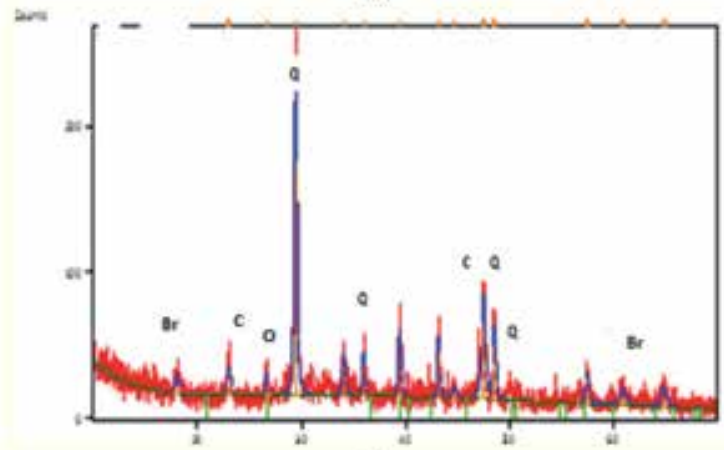

(B)

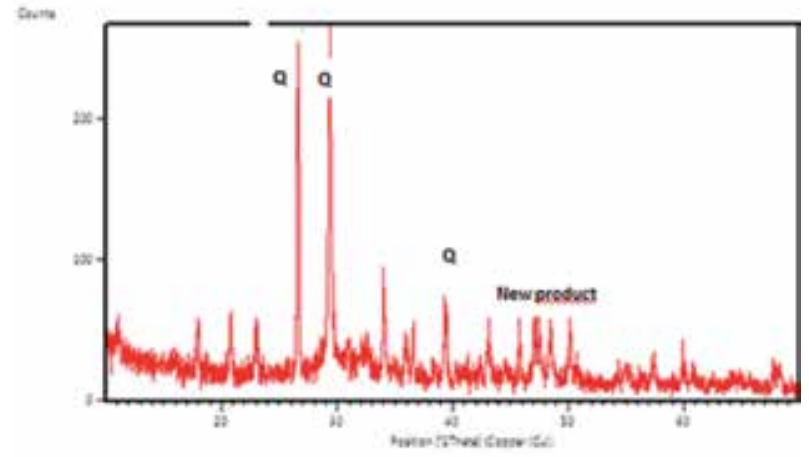

(C)

Figure 7.

$X R D$ patterns of powder of $H P C$ at $(A) 20^{\circ} \mathrm{C},(B) 600^{\circ} \mathrm{C}$, and $(C) 900^{\circ} \mathrm{C}$ (notes: $C$, calcite; $Q$, quartz; and Br, brucite) [18].

Between 200 and $300^{\circ} \mathrm{C}$, a so-called water plug develops in concrete pores, and there are slight variations in flux to the continuous dehydration of C-S-H [51].

At $400^{\circ} \mathrm{C}$, a small peak was observed which we could not identify clearly the phase. A similar transformation was observed by Sha et al., on cement pastes [52].

These authors attribute this change of crystalline state or dehydration of a solid solution of $\mathrm{Fe}_{2} \mathrm{O}_{3}$. But other sources [53] attribute this peak to the decomposition of brucite $\left[\mathrm{Mg}(\mathrm{OH})_{2}\right]$.

Between 450 and $550^{\circ} \mathrm{C}$, the peak corresponds to the decomposition of the free limestone $\mathrm{Ca}(\mathrm{OH})_{2} \mathrm{CaO}[54]$.

At $573^{\circ} \mathrm{C}$, the allotropic transformation of the quartz- $\alpha$ and quartz- $\beta$ is accompanied by a phenomenon of expansion (cracking of the siliceous aggregates) [54]. Between 600 and $700^{\circ} \mathrm{C}, \mathrm{C}-\mathrm{S}-\mathrm{H}$ decomposes and transforms into a new form of 


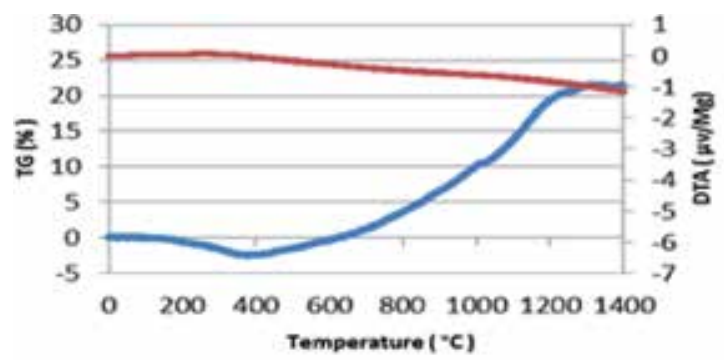

(a)

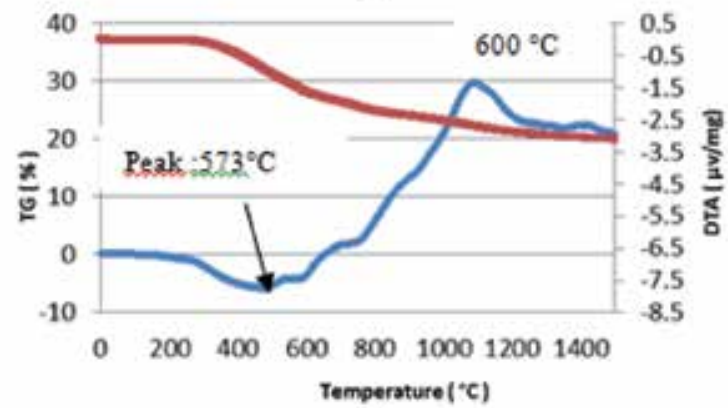

(b)

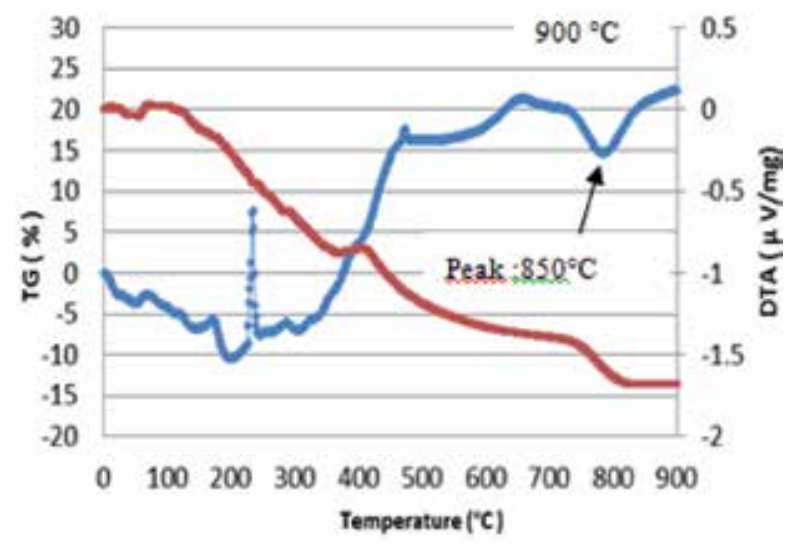

(c)

Figure 8.

$A T G$ and $A T D$ powder of concrete $H P C$ at $(a) 20^{\circ} \mathrm{C}$, (b) $600^{\circ} \mathrm{C}$, and $(c) 900^{\circ} \mathrm{C}[18]$.

hydrates less rich in water and donation without it being formed of anhydrous compounds. These are mainly di-calcium silicates $(\beta-\mathrm{C} 2 \mathrm{~S})$ and $\beta$-wollastonite $(\beta-C S)[53]$.

The last peak coincides with the temperature of $800^{\circ} \mathrm{C}$. It is well defined that in the temperature range from $700-900^{\circ} \mathrm{C}$, the limestone decomposes, so this peak indicates the decomposition of calcium carbonates $\left(\mathrm{CaCO}_{3}\right)$, also known as "calcite," by releasing lime accompanied by a release of $\mathrm{CO}_{2}$ [5] according to the highly endothermic reaction which is as follows:

$$
\mathrm{CaCO}_{3} \mathrm{CaO}+\mathrm{CO}_{2} \text {. }
$$

A quasi-linear decrease is observed up to $800^{\circ} \mathrm{C}$, and the concrete exhibits a severe decrease in the density above $800^{\circ} \mathrm{C}$. This decrease in density is related to two phenomena, i.e., complete dehydration and anhydrous formation, which take place only at temperatures in the region of $900^{\circ} \mathrm{C}$. 


\section{Conclusions}

From the study, one can conclude that, when using HPC specimen, the speed of temperature rising influences the drop in strength between 400 and $600^{\circ} \mathrm{C}$.

- The critical temperature, which causes maximum attenuation of different properties (compressive strength, mass loss), is between 400 and $600^{\circ} \mathrm{C}$.

- Beyond $600^{\circ} \mathrm{C}$ the concrete may lose the majority of these properties, i.e., there are properties that can cancel out; one can say that the concrete has become weak.

- The concretes with super plasticizer are affected by high temperatures especially at $600^{\circ} \mathrm{C}$ and above compared with less super plasticizer dosage.

- For a more resistant concrete, the addition of silica fume leads to lower resistance $(24 \%)$ in the temperature range tested, between 400 and $600^{\circ} \mathrm{C}$.

- The HPC specimens containing silica fume have high compressive stress compared to HPC specimen without silica fume (CR).

- Color changes were observed on concrete under the effect of high temperature.

\section{Author details}

Zine El Abidine Rahmouni ${ }^{1 *}$ and Nadia Tebbal ${ }^{2}$

1 Geomaterials Development Laboratory, Civil Engineering Department, Faculty of Technology, M’sila University, M’sila, Algeria

2 Geomaterials Development Laboratory, Institute of Technical Urban

Management, University of M’sila, M'sila, Algeria

*Address all correspondence to: zineelabidine.rahmouni@univ-msila.dz

\section{IntechOpen}

(C) 2020 The Author(s). Licensee IntechOpen. This chapter is distributed under the terms of the Creative Commons Attribution License (http://creativecommons.org/licenses/ by/3.0), which permits unrestricted use, distribution, and reproduction in any medium, provided the original work is properly cited. (cc) BY 


\section{References}

[1] Umamaheswaran V, Sudha C, Ravichandran PT, Kannan

Rajkumar PR. Use of M sand in high strength and high performance concrete. Indian Journal of Science and Technology. 2015;8(28):1-8

[2] Avinas D, Madhumitha M. Study on high performance concrete using fumed silica and sulphonated melamine formaldehyde. International Journal of Pure and Applied Mathematics. 2018;119(10):139-148

[3] Vashisth V, Pal S, Mahure NV, Vyas S. Pankaj Sharma5, impact of high temperatures on multiblended concretes. International Research Journal of Engineering and Technology (IRJET). 2015;02(02):563-570

[4] Fire Design of Concrete Structures Materials, Structures and Modelling, Bulletin 38. Lausanne; 2007. p. 97

[5] Khoury GA. Compressive strength of concrete at high temperatures: A reassessment. Magazine of Concrete Research. 1992;44(161):291-309

[6] Ortiz Lozano JA, Aguado de Cea A, Agulló L, García Vicente T, Zermeño de León ME. Experimental study of the effect of temperature on the strength of ready-mixed concrete. Materiales de Construcción. 2008;58:291

[7] Al-Dulaijan SU, Parry-Jones G, Al Tayyib AHJ, Al-Mana AI. Si magicangle-spinning nuclear magnetic resonance study of hydrated cement paste and mortar. Journal of the American Ceramic Society. 1990;73:736

[8] Regourd M, Gautier E. Comportement des ciments soumis au durcissement accéléré. Annales de l'Institut Technique du Bâtiment et des Travaux Publics. 1980;387(198):83-96
[9] Kjellsen KO, Detwiller RJ, Gjov OD. Cement and Concrete Research. 1991;21:179

[10] Kjellsen KO, Detwiller RJ, Gjov OD. Cement and Concrete Research. 1990;20:308

[11] Escalante-García JI, Sharp JH. Cement and Concrete Research. 2001;31:695

[12] Escalante-García JI, Sharp JH. Cement and Concrete Research. 1998;28:1259

[13] Halse Y, Jensen HU, Pratt PL. Proceedings of 8th International Congress on the Chemistry of Cement. Vol. IV. Rio deJaneiro; 1986. p. 176

[14] EN 1992-1-2, Eurocode 2 - Design of Concrete Structures. Part 1.2: General Rules - Structural Fire Design; 2004. p. 97

[15] Hager I. Behaviour of high performance concretes at high temperature - evolution of mechanical properties [PhD thesis]. Champs-surMarne, France: Ecole National des Ponts et Chaussées; 2004

[16] Hager I. Colour change in heated concrete, Fire Technology 49, CD-ROM; 2013

[17] Verbeck G, Copeland LE. Some physical and chemical aspects of high pressure steam curing. Menzel Symposium on High Pressure Steam Curing. ACI SP-32. 1972:1-131

[18] Tebbal N, Rahmouni Z, Maza M. Combined effect of silica fume and additive on the behavior of high performance concretes subjected to high temperatures. Mining Science. 2017;24:41-49, 129-145 
[19] Rahmouni Z, Tebbal N. Influence de la nature des granulats sur le comportement rhéologique du béton à hautes températures. MATEC Web of Conferences. 2014;11:01010

[20] Aïtcin PC. Bétons haute performance, Edition Eyrolles; 2001

[21] Chaid R, Jauberthie R, Abadlia MT, BALI A. Étude expérimentale de la durabilité des BHP aux ajouts cimentaires locaux. Science and Technology. 2008;2(27):57-62

[22] Tebbal N, Rahmouni Z, Belagraa L. Combined effect of granulated slag and silica fume on the characteristics of high performance concrete. International Review of Civil Engineering (IRECE). 2016;7(2)

[23] Mehta PK. Concrete structure, properties, and materials. In: Mehta NJ, Kumar P, editors. Concrete. Englewood Cliffs: Prentice-Hall Inc.; 1986

[24] Sri RR, Lopez R, Reslan H. Effect of Elevated Temperature on the Properties of High-Strength Concrete containing Cement Supplementary Materials. In: 9th International Conference on Durability of Building Materials and Components. Brisbane, Australia; 17-20th March, 2002

[25] Szoke SS. Resistance to Fire and High Temperatures. West Conshohocken, Pennsylvania: ASTM International; 2006

[26] Sravana P, Srinivasa Rao P, Sravana P. Effect of thermal cycles on compressive strength of high volume fly ash concrete. In: 31st Conference on Our World in Concrete \& Structures. Singapore; 16-17 August 2006

[27] Noumowé A, Siddique R, Ranc G. Thermomechanical characteristics of concrete at elevated temperatures up to $310^{\circ} \mathrm{C}$. Nuclear Engineering and Design. 2009;239:470-476
[28] Falade F, Ikponmwosa EE, Ojediran NI. Behaviour of lightweight concrete containing periwinkle shells at elevated temperature. Journal of Engineering Science and Technology. 2010;5(4):379-390

[29] Siddique R, Kaur D. Properties of concrete containing ground granulated blast furnace slag (GGBFS) at elevated temperatures. Journal of Advanced Research. 2012;3(1):45-51

[30] Pathan MA, Jamnu MA. Compressive strength of conventional concrete and high strength concrete with temperature effect, International Journal of Advanced Engineering Research and Studies, IJAERS/Vol. I/ Issue III/April-June, 2012/101-102

[31] Srinivasa Reddy V, Seshagiri

Rao MV, Sreenivasa Rao D,

Rahul K. Studies on bacterial concrete exposed to elevated temperatures and thermal cycles. Engineering Science and Technology (ESTIJ). 2013;3(1):2250-3498

[32] Chowdhury SH. Effect of elevated temperature on mechanical properties of high strength concrete. In: Smith ST, editor. 23rd Australasian Conference on the Mechanics of Structures and Materials (ACMSM23). Byron Bay, Australia; 9-12 December 2014

[33] Santosh Kumar K, Rama Rao GV, Markandeya Raju P. Strength and Durability Studies on GGBS Concrete. SSRG International Journal of Civil Engineering. 2015;2(10):34-41

[34] Vijaya Gowri T, Sravana P, Srinivasa RP. Effect of temperature on durability of high volumes of slag concrete. IJCE, International Journal of Civil Engineering, SSRG. 2016;3(2):6-12

[35] Jawed A, Vashsith V, Sharma B. Effect of high temperature on fly ash concrete. IJCE, International Journal 
of Civil Engineering, SSRG.

2017;4(6):48-51

[36] Yüzer N, Aköz F, Öztür KL. Compressive strength - Color change relation in mortars at high temperature. Cement and Concrete Research. 2004;34(10):1803-1807

[37] Ahmad AH, Abdulkareem OM. Effect of high temperature on mechanical properties of concrete containing admixtures. AL-Rafdain Engineering Journal. 2010;18(4):43-54

[38] Siddique R, Khan MI. Silica fume, supplementary cementing materials, pp 67-119. In: Part of the Engineering Materials Book Series (ENG. MAT., Vol. 37). Heidelberg, Dordrecht, London, New York: Springer; 2011

[39] ASTM E 119-00a. Standard test methods for fire test of building construction and materials. American National Standards Institute, Committee E05; 2000

[40] NF EN 12390-4 EN 12390-5. Essai pour béton durci, Partie 5: Résistance à la flexion sur éprouvettes; 2009

[41] NF EN 12390-5 EN 12390-5. Essai pour béton durci, partie 5: résistance à la flexion sur éprouvettes; 2009

[42] AFPC-AFREM, Groupe de travail Durabilité des bétons. Recommended test methods for measuring the parameters associated to durability. In: Proceeding des Journées Techniques AFPC-AFREM: Durabilité des Bétons; December 11-12, 1998

[43] Noumowé A. Study of high strength concretes at raised temperature up to $200^{\circ} \mathrm{c}$ : thermal gradient and mechanical behaviour. In: 16th International Conference on Structural Mechanics in Reactor Technology 2001 (smirt 16), vol. 1. Washington, DC, USA; 2001

[44] Sabeur H, Colina H. Effect of heating-cooling cycles on transient creep strain of high performance, high strength and ordinary concrete under service and accidental conditions. Materials and Structures. 2015;48(5):1561-1579

[45] Dias WPS, Khoury GA, Sullivan PJE. Mechanical properties of hardened cement paste exposed to temperatures up to $700 \mathrm{C}(1292 \mathrm{~F})$. Materials. 1990;87(2):160-166

[46] Kalifa P, Chene G, Galle C. Hightemperature behaviour of HPC with polypropylene fibres: From spalling to microstructure. Cement and Concrete Research. 2001;31(10):1487-1499

[47] Burlion N, Skoczylas F, Dubois T. Induced anisotropic permeability due to drying of concrete. Cement and Concrete Research. 2003;33(5):679-687

[48] Castillo C, Durrani AJ. Effect of transient high-temperature on highstrength concrete-closure. ACI Materials Journal. 1990;87(6):653-653

[49] Bažant ZP, Kaplan MF, Bazant ZP. Concrete at High Temperatures: Material Properties and Mathematical Models. Harlow: Longman; 1996. p. 424

[50] Hager I. Behaviour of cement concrete at high temperature. The Bulletin of the Polish Academy of Sciences: Technical Sciences. 2013;61(1):145-154

[51] Nonnet E, Lequeux N, Boch P. Elastic properties of high alumina cement castables from room temperature to 1600 C. Journal of the European Ceramic Society. 1999;19(8):1575-1583

[52] Sha W, O’Neill EA, Guo Z.

Differential scanning calorimetry study of ordinary Portland cement. Cement and Concrete Research. 1999;29(9):1487-1489

[53] Platret G. Suivi de l'hydratation du ciment et de l'évolution des phases solides dans les bétons par 
Mechanical Behavior of High-Performance Concrete under Thermal Effect DOI: http://dx.doi.org/10.5772/intechopen.89916

analyse thermique, caractéristiques microstructurales et propriétés relatives à la durabilité des bétons. Méthodes de mesure et d'essai de laboratoire, Méthode d'essai. 2002;58

[54] Tufail M, Shahzada K, Gencturk B. Effect of elevated temperature on mechanical properties of limestone, quartzite and granite concrete. International Journal of Concrete Structures and Materials (IJCSM). 2017;11(1):17-28 



\title{
Fundamental Properties of Industrial Hybrid Cement Important for Application in Concrete
}

\author{
Ivan Janotka, Pavel Martauz, Michal Bačuvčík \\ and Vojtěch Václavík
}

\begin{abstract}
Hybrid cement (H-Cement/HC) takes advantages of the material properties of cement and alkali-activated cement with the resulting benefit on utility properties so that hybrid cement can replace in large quantities ordinary Portland cement (PC) as follows: $\mathrm{H}$-Cement is used by the same way as traditional cements; $\mathrm{H}$-Cement is suitable for use in ready-mixed concrete up to $\mathrm{C} 30 / 37$ strength class; $\mathrm{H}$-Cement has shrinkage-reducing and alkali-aggregate-mitigating property; $\mathrm{H}$-Cement shows the same sulphate resistance with sulphate-resistant Portland cement with $\mathrm{C}_{3} \mathrm{~A}=0$; $\mathrm{H}$-Cement is a suitable binder for use in concrete containing the swelling steel slag aggregate as a full replacement of natural aggregate. This low-energy, low-cost and environmentally friendly hybrid cement belongs to the group of advanced cements, in which parameters predetermine it to overcome PC serviceability in certain applications. The objective of this chapter is to characterize fundamental properties and some durability aspects of $\mathrm{H}$-Cement in concrete.
\end{abstract}

Keywords: hybrid cement, concrete, utility properties, durability

\section{Introduction}

Global annual production of cement accounts for about 5\% of the total anthropogenic $\mathrm{CO}_{2}$ emission [1]. About 4.2 GJ energy is required to produce 1 metric ton $\mathrm{PC}$, resulting approximately in 0.8-1.0 metric ton of $\mathrm{CO}_{2}$ release into the atmosphere [2]. A second problem besides $\mathrm{CO}_{2}$ emissions is connected with the negative ecological and health impact of red and brown mud ponds in the manufacture of aluminium-containing high-alkaline waste water rich in $\mathrm{NaOH}$. Landfilling of this hazardous waste raises other problems due to the high concentrations of heavy metals and the variety in chemical composition depending to a large extent on the season and weather conditions. The main task of the current research is the development of less energy-intensive but more ecological cements. One solution is the production of innovative cement binders like alkali-activated cements, geopolymers and hybrid alkaline cements with Portland clinker addition [3, 4]. The hybrid alkaline cements have various compositions of alkali-activated aluminosilicates with 
low Portland clinker content [5]. In spite of the low clinker content, the hybrid binders can obtain useful early-age mechanical strengths [6]. Hybrid cements take advantage of the material properties of a cement and ordinary geopolymer with the resulting benefit on the acquired properties, so that hybrid cement can replace in large quantities energy-intensive PC [7]. The novel hybrid cement $\mathrm{H}$-Cement is produced on the base of industrial by-products and wastes according to the patent application [8]. The content of clinker is always under $30 \mathrm{wt} \%$. A typical feature for $\mathrm{H}$-Cement binding phase formation is the combined effect of hydraulic properties of Portland clinker, pozzolanic properties of fly ashes, latent hydraulic properties of granulated blast furnace slag (GBFS) and geopolymeric properties coming from the alkaline inorganic polycondensing reactions of aluminosilicate materials. Such inorganic material is activated by addition of alkaline waste water separated from the caustic red mud ponds and $\mathrm{Na}_{2} \mathrm{SO}_{4}$ obtained from alkaline waste water neutralization by $\mathrm{H}_{2} \mathrm{SO}_{4}$. In the presence of these alkaline agents, the $\mathrm{pH}$ value of cement mixture is increased. This results in fly ash (FA) and GBFS dissolution leading to final geopolymerization effect. At the same time, $\mathrm{Ca}(\mathrm{OH})_{2}$ addition coming from Portland clinker hydration promotes the binding reactions of fly ash and GBFS. $\mathrm{H}$-Cement is characterized by lower early strength and hydration heat but higher long-term strengths. $\mathrm{H}$-Cement possesses high chemical resistance against aggressive action of sulphate, magnesium, chloride and acidic waters [9]. When autoclaving at an elevated temperature and pressure, $\mathrm{H}$-Cement provided volume stability and strength increase in concrete with steel slag replacing a natural aggregate as opposed to PC concrete with steel slag which was disintegrated after the test [10].

The production of $\mathrm{H}$-Cement does not require additional heat treatment. It is cured in the same way as traditional cements and owns the certificate of conformity [11] issued on the base of SK Technical Assessment [12]. H-Cement is a sustainable cement which, due to its material composition, does not meet the categorization of cements according to STN EN 197-1 [13].

This article shows that one possible solution for innovative binders with improved durability and decreased energy requirements is the production of hybrid cement. It is demonstrated that:

- $\mathrm{H}$-Cement is suitable for production of ready-mixed concrete strength classes up to $\mathrm{C} 30 / 37$.

- Shrinkage-reducing and alkali-silica reaction (ASR)-mitigating character of $\mathrm{H}$ Cement is especially relevant because it prevents propagation of shrinkage or expansive cracking during the service life of the concrete.

- H-Cement is specified after 5-year impact of 5\% wt. sodium sulphate solution by the same sulphate resistance with the sulphate-resistant CEM I 42.5 R-SR O with $\mathrm{C}_{3} \mathrm{~A}=0$.

- H-Cement is suitable for making concrete with mostly landfilled steel slag when replacing a natural aggregate.

\section{Experimental procedure}

\subsection{Materials and methods}

The novel H-Cement and CEM I/42.5 $\mathrm{R}$ as a reference were tested. Both are produced by the cement plant Považská cementáreň, a. s., Ladce in Slovakia; 
$\mathrm{H}$-Cement is according to internal standard. The cement was used in combination with river aggregates of $0 / 4,4 / 8$ and $8 / 16 \mathrm{~mm}$ fraction from Jelka (Slovakia). For the tests with steel slag, the river aggregate was completely replaced by the slag of the same fraction. All river aggregate properties met the requirements of STN EN $12620+\mathrm{A} 1$ [14]. The compatibility of H-Cement was verified with seven types of plasticizers [15]. The concrete without admixture was examined as a reference. The shrinkage-reducing ability was confirmed on the concrete made from $\mathrm{H}$-Cement, $\mathrm{PC}$ and selected blended systems [15]. The H-Cement suitability for mitigating alkali-silica reaction was verified on the cement mortars by the procedure reported in STN 721179 [16] (the related ASTM Standards: C289-03 for Chemical method; ASTM C1293-08b for length change of concrete). Resistance to sulphate and higher temperature/pressure attack was verified by own methodologies [10,17].

\subsection{Casting}

Specimens of ready-mixed concrete were made according to STN EN 12390-2 [18]. Fresh concrete was compacted on a vibration table $(40 \mathrm{~Hz})$ for $60 \mathrm{~s}$ and casted into $150 \mathrm{~mm}$ cubes or $100 \times 100 \times 400 \mathrm{~mm}$ prisms. Casting of the specimens for verification of specific properties of $\mathrm{H}$-Cement is reported separately for each experiment, either shrinkage-reducing or ASR-mitigating property, sulphate resistance and volume stability of steel slag concrete.

\subsection{Curing}

The moulds were stored at more than $95 \%$ relative humidity of air (abbreviated as $\mathrm{RH})$ at $(20 \pm 1)^{\circ} \mathrm{C}$ for the first $24 \mathrm{~h}$, and then the concrete specimens were cured according to the test. A method of treating the specimens for special properties verification is given separately for each test.

\subsection{Testing procedures for cement}

Both cements were tested for chemical composition by STN EN 196-2 [19]; the Bogue mineral composition was also determined. Standard consistency, initial and final setting, and soundness were verified by STN EN 196-3+A1 [20] and hydration heat by STN EN 196-8 [21]. After 2-, 28- or 90-day cure, flexural and compressive strengths of the mortars with cement-to-sand ratio 1:3 by weight were obtained according to STN EN 196-1 [22]. H-Cement is sensitive to excess of water; the PC and $\mathrm{H}$-Cement mortars therefore differ in water-to-cement ratios.

\subsection{Testing procedure for fresh and hardened concrete}

The consistency of fresh concrete was estimated by slump by STN EN 12350-2, volume density by STN EN 12350-6 and air content in the fresh mixture by STN EN 12350-7 [23-25]. Concrete specimens were tested for cube compressive strengths [26], compressive strengths of the edges of prisms of standard size [27] and dynamic elasticity modulus [28].

\subsection{Partially accelerated test of sulphate resistance}

\subsubsection{Materials}

Cement CEM I 42.5 R (PC) produced by Považská cementáreň, a. s., Ladce cement plant (PCLA) and $\mathrm{C}_{3} \mathrm{~A}$-free sulphate-resistant CEM I 42.5 R-SR O (SRC) 
produced by Lafarge Zementwerke $\mathrm{GmbH}$, Mannersdorf (Austria) according to STN EN 197-1, both as reference, were chosen for the investigation. H-Cement was tested as the verified sample.

\subsubsection{Specimens, casting and curing}

Mortars with cement-to-sand ratio of $1: 3$ by weight adjusted on the constant consistency of $140 \pm 1 \mathrm{~mm}$ were prepared as prismatic specimens of size $40 \times 40 \times 160 \mathrm{~mm}$. All specimens were kept for 5-year exposure in 5\% wt. sodium sulphate $\left(\mathrm{Na}_{2} \mathrm{SO}_{4}\right)$ solution and water as reference medium after 28-day water curing (BC) at $(20 \pm 1)^{\circ} \mathrm{C}$. The tests of chemical resistance were conducted by own methodology of "partially accelerated test" based on keeping the mortars in strongly over-concentrated aggressive solution for a sufficient long time. The aggressive storage was specified by the following way: each $1 \mathrm{~cm}^{2}$ of the exposed area of prism must be in permanent contact with at least of $10 \mathrm{~cm}^{3}$ of $5 \%$ wt. $\mathrm{Na}_{2} \mathrm{SO}_{4}$ [33802.8 $\mathrm{mg}$ aggressive $\mathrm{SO}_{4}{ }^{2-}$ per 1 litre solution]. The sulphate solution and reference water were refreshed every 30 days within 90 days of testing, every 45 days between 90 and 365 days and every 60 days up to 5 years of exposure, respectively.

\subsubsection{Items of investigation}

Consistency, density and fresh air content of the mortars were determined according to relevant STN EN Standards. The mortars were continuously tested for length changes, dynamic modules of elasticity (DME) and periodically flexural and compressive strength. After destructive tests the microstructure and pore structure were identified by X-ray diffraction (XRD), thermogravimetry-differential thermal analysis (TG-DTA), mercury intrusion porosimetry (MIP) and scanning electron microscopy (SEM) techniques. The ground material was sieved through a $0.063 \mathrm{~mm}$ mesh to receive the powder suitable for testing. For the X-ray diffraction, the Philips diffractometer was used in a $2 \Theta$ range of $5-65^{\circ}$. CuK $\alpha$ radiation and $\mathrm{Ni}$ filter were applied. Thermal analysis was performed on the Netzsch apparatus STA $449 \mathrm{~F} 3$ Jupiter in air at heating rate $10^{\circ} \mathrm{C} / \mathrm{min}$. Basic parameters of the pore structure were identified by MIP using the high-pressure porosimeter Quantachrome PoreMaster 60 GT using small mortar fragments for testing. The JEOL $7500 \mathrm{~F}$ was used to study microstructure by scanning electron microscopy. Chemical composition, with special emphasis on the bound $\mathrm{SO}_{3}$ content, was estimated by STN EN 196-2 [19].

\subsection{Concrete based on H-Cement and steel slag}

Two types of binders (PC and H-Cement as HC) were chosen to prepare concrete based on steel slag. The Sika ${ }^{\circledR}$ ViscoCrete ${ }^{\circledR}-225$ powder superplasticizer was used to improve the consistency of the fresh concrete mixture. It provides water reduction, excellent fluidity and cohesion, together with a self-compacting effect. Tap water from the water supply system was used as the mixing water.

Two mixes designated as HC concrete and PC concrete were used within the scope of the experimental research.

- HC concrete contained 0/8 mm steel slag fraction as filler, $380 \mathrm{~kg}$ of $\mathrm{H}$ Cement, $241 \mathrm{~kg}$ of water, Sika superplasticizer in the amount of $0.5 \%$ of the cement weight and a retardant additive (Retardal 540) in the amount of $0.4 \%$ of the cement weight. 
- PC concrete contained 0/8 mm steel slag fraction as filler, $380 \mathrm{~kg}$ of CEM I 42,5 $\mathrm{N}, 241 \mathrm{~kg}$ of water and Sika superplasticizer in the amount of $0.5 \%$ of the cement weight. No retardant admixture was used.

The production of the specimens used to test the properties of fresh and hardened concrete based on steel slag was carried out in two stages. The first stage involved the production of the specimens for testing cube strength after 3, 7, 14, 21, 28 and 90 days of age. The second stage involved the production of the specimens for the comparison of cube and prism strengths after 28 days of curing.

The following properties of hardened concrete were tested: cube and prism concrete strengths. The durability of the concrete based on steel slag was tested in the conditions of a higher temperature and pressure. Determination of the volume changes of the concrete was carried out in a 540-1 laboratory autoclave at the maximum saturated steam pressure of $1.2 \mathrm{MPa}$ and a maximum temperature of $189^{\circ}$ C. Cubes of $150 \mathrm{~mm}$ were used as the test specimens. The temperatures and pressures in the testing laboratory autoclave were set by this way to determine the volume changes of the concrete based on the steel slag as aggregate [10].

\section{Experimental results and discussion}

\subsection{Basic characterization of $\mathrm{H}-$ Cement}

Chemical composition of main constituents of H-Cement (HC) and Portland cement (PC) clinker are listed in Tables $\mathbf{1}$ and 2. Table 3 confirms that H-Cement shows different chemical and mineral compositions compared to PC. Both hydrated cements differ in typical characteristic values as stated in Table 4. The results suggest that hybrid cement can be used prospectively in concrete for the same purposes as the blended cements of lower-strength classes, e.g., CEM III-V, probably CEM II/B-S according to STN EN 197-1, preferably in massive constructions due to low hydration heat and aggressively exposed media because of low Portland clinker (and therefore $\mathrm{C}_{3} \mathrm{~A}$ ) content.

$\mathrm{H}$-Cement consists essentially in a blend of materials containing 20-30\% wt. Portland clinker and 70-80\% alkaline cement, in turn a combination of fly ash, granulated blast furnace slag and alkaline sulphates.

\begin{tabular}{lccccccccc}
\hline \% wt. & $\mathrm{CaO}$ & $\mathrm{SiO}_{2}$ & $\mathrm{Al}_{2} \mathrm{O}_{3}$ & $\mathrm{Fe}_{2} \mathrm{O}_{3}$ & $\mathrm{MgO}$ & $\mathrm{SO}_{3}$ & $\mathrm{~K}_{2} \mathrm{O}$ & $\mathrm{Na}_{2} \mathrm{O}$ & L.O.I \\
\hline FA & 3.36 & 51.42 & 26.93 & 7.27 & 2.10 & 0.87 & 3.28 & 0.17 & 1.84 \\
\hline GBFS & 39.24 & 40.13 & 7.19 & 0.27 & 10.04 & 1.50 & 0.52 & 0.31 & 1.10 \\
\hline
\end{tabular}

Abbreviations: FA, fly ash; GBFS, granulated blast furnace slag; LOI, loss on ignition.

Table 1.

Chemical composition of fly ash (FA) and blast furnace slag (GBFS).

\begin{tabular}{lccccccccc}
\hline \% wt. & $\mathrm{CaO}$ & $\mathrm{SiO}_{2}$ & $\mathrm{Al}_{2} \mathrm{O}_{3}$ & $\mathrm{Fe}_{2} \mathrm{O}_{3}$ & $\mathrm{MgO}$ & $\mathrm{SO}_{3}$ & $\mathbf{K}_{2} \mathrm{O}$ & $\mathbf{N a}_{2} \mathrm{O}$ & $\mathbf{P}_{2} \mathrm{O}_{5}$ \\
\hline Clinker & 64.4 & 20.80 & 4.80 & 3.08 & 1.45 & 0.47 & 1.05 & 0.28 & 0.49 \\
\cline { 2 - 8 } & $\mathrm{C}_{3} \mathrm{~S}$ & $\mathrm{C}_{2} \mathrm{~S}$ & $\mathrm{C}_{3} \mathrm{~A}$ & $\mathrm{C}_{4} \mathrm{AF}$ & Free CaO & Arcanite & Periclase \\
\hline & 65.1 & 10.60 & 8.40 & 9.72 & 1.40 & 0.82 & 0.58 \\
\hline
\end{tabular}

Table 2.

Chemical and mineralogical composition of Portland clinker. 


\begin{tabular}{lccccccccc}
\hline \% wt. & $\mathrm{CaO}$ & $\mathrm{SiO}_{2}$ & $\mathrm{Al}_{2} \mathrm{O}_{3}$ & $\mathrm{Fe}_{2} \mathrm{O}_{3}$ & $\mathrm{MgO}$ & $\mathrm{Na}_{2} \mathrm{O}$ & $\mathrm{Na}_{2} \mathrm{O}$ & $\mathrm{SO}_{3}$ & $\mathrm{TiO}_{2}$ \\
\hline $\mathrm{HC}$ & 30.73 & 48.57 & 20.13 & 6.81 & 2.13 & 2.51 & 3.22 & 4.67 & 1.14 \\
\cline { 2 - 9 } & $\mathrm{C}_{3} \mathrm{~S}$ & $\mathrm{C}_{2} \mathrm{~S}$ & $\mathrm{C}_{3} \mathrm{~A}$ & $\mathrm{C}_{4} \mathrm{AF}$ & $\mathrm{Q}$ & $\mathrm{ARC}$ & $\mathrm{ANH}$ & $\mathrm{PER}$ \\
\cline { 2 - 10 } & 33.66 & 11.75 & 11.54 & 6.64 & 28.34 & 1.30 & 1.18 & 0.50 \\
\hline \multirow{2}{*}{$\mathrm{PC}$} & $\mathrm{CaO}$ & $\mathrm{SiO}_{2}$ & $\mathrm{Al}_{2} \mathrm{O}_{3}$ & $\mathrm{Fe}_{2} \mathrm{O}_{3}$ & $\mathrm{MgO}$ & $\mathrm{K}_{2} \mathrm{O}$ & $\mathrm{SO}_{3}$ & $\mathrm{P}_{2} \mathrm{O}_{5}$ & $\mathrm{Cl}^{-}$ \\
\cline { 2 - 9 } & 64.09 & 21.54 & 4.07 & 2.64 & 1.24 & 1.05 & 3.37 & 0.34 & 0.07 \\
\hline & $\mathrm{C}_{3} \mathrm{~S}$ & $\mathrm{C}_{2} \mathrm{~S}$ & $\mathrm{C}_{3} \mathrm{~A}$ & $\mathrm{C}_{4} \mathrm{AF}$ & $\mathrm{ARC}$ & $\mathrm{G}$ & $\mathrm{BAS}$ & $\mathrm{PER}$ & $\mathrm{Cc}$ \\
\hline & 61.63 & 7.18 & 7.86 & 8.72 & 1.39 & 4.22 & 3.57 & 0.51 & 3.34 \\
\hline
\end{tabular}

Abbreviations: $Q$ quartz; ARC, arcanite; ANH, anhydrite; PER, periclase; G, gypsum; BAS, bassanite; Cc, calcite.

Table 3.

Chemical and mineralogical composition of $H C$ and PC.

\begin{tabular}{|c|c|c|c|}
\hline Technical parameters & Unit & HC & PC \\
\hline Initial setting time & Minute & $200 \pm 20$ & $190 \pm 20$ \\
\hline Final setting time & Minute & $300 \pm 40$ & $250 \pm 30$ \\
\hline Standard consistency & $\%$ & $32 \pm 2.0$ & $29.1 \pm 1.8$ \\
\hline 2-day compressive strength & $\mathrm{MPa}$ & $\begin{array}{l}17.5 \pm 3.0 \\
\mathrm{w} / \mathrm{c}=0.4^{*}\end{array}$ & $33.7 \pm 2.0 \mathrm{w} / \mathrm{c}=0.5$ \\
\hline 28-day compressive strength & $\mathrm{MPa}$ & $\begin{array}{c}36.5 \pm 4.0 \\
w / c=0.4\end{array}$ & $59.2 \pm 1.6 \mathrm{w} / \mathrm{c}=0.5$ \\
\hline 90-day compressive strength & $\mathrm{MPa}$ & $\begin{array}{l}41.5 \pm 3.0 \\
w / c=0.4\end{array}$ & $63.1 \pm 1.9 \mathrm{w} / \mathrm{c}=0.5$ \\
\hline 2-day flexural strength & $\mathrm{MPa}$ & $\begin{array}{c}3.5 \pm 0.5 \\
w / c=0.4\end{array}$ & $6.4 \pm 0.4 \mathrm{w} / \mathrm{c}=0.5$ \\
\hline 28-day flexural strength & $\mathrm{MPa}$ & $\begin{array}{l}4.4 \pm 0.4 \\
w / c=0.4\end{array}$ & $8.9 \pm 0.4 \mathrm{w} / \mathrm{c}=0.5$ \\
\hline 90-day flexural strength & $\mathrm{MPa}$ & $\begin{array}{l}9.0 \pm 0.3 \\
w / c=0.4\end{array}$ & $9.3 \pm 0.3 \mathrm{w} / \mathrm{c}=0.5$ \\
\hline Le Chatelier (soundness) & $\mathrm{mm}$ & 0.5 & 0.01 \\
\hline Content of $\mathrm{Cr}^{\mathrm{VI}}$ & $\mathrm{ppm}$ & 1.0 & 1.23 \\
\hline Content of $\mathrm{C}_{3} \mathrm{~A}$ & $\%$ wt. & $2.0 \pm 0.5$ & $7.5 \pm 0.8$ \\
\hline Hydration heat & $\mathrm{J} / \mathrm{g}$ & 185 & 359 \\
\hline
\end{tabular}

Table 4.

Comparison of characteristic values of $H$-cement and reference $P C$.

\subsection{Ready-mixed concrete}

The cube compressive strengths of ready-mixed concretes of C8/10 to C30/37 strength class for reaching a slump of 100-150 mm (slump class S3 according to [23]) without the use of plasticizers are listed in Table 5. The consistency and cube compressive strength of ready-mixed concretes prepared with different plasticizers with slump values $\geq 220 \mathrm{~mm}$ [slump class S5] are reported in Table 6. Laboratorymade ready-mixed concrete specimens were prepared with the following types of plasticizers coming from various producers: M1, no admixture; M2, lignosulfonate; M3, modified polycarboxylate ( $<22 \%$ polycarboxylate content); M4, 
Fundamental Properties of Industrial Hybrid Cement Important for Application in Concrete DOI: http://dx.doi.org/10.5772/intechopen.88060

\begin{tabular}{lccc}
\hline Concrete strength class & \multicolumn{3}{c}{ Cube compressive strength $(\mathbf{M P a})$} \\
\cline { 2 - 4 } & $\mathbf{2}$ days & $\mathbf{7}$ days & $\mathbf{2 8}$ days \\
\hline $\mathrm{C} 8 / 10$ & 4.8 & 10.4 & 16.0 \\
\hline $\mathrm{C} 12 / 15$ & 5.7 & 11.4 & 18.7 \\
\hline $\mathrm{C} 16 / 20$ & 6.9 & 14.6 & 22.2 \\
\hline $\mathrm{C} 20 / 25$ & 8.0 & 16.8 & 25.0 \\
\hline $\mathrm{C} 30 / 37$ & 14.6 & 29.4 & 42.6 \\
\hline
\end{tabular}

Table 5 .

Ready-mixed concrete compositions with H-Cement at slump $S_{3}$.

\begin{tabular}{lccccccc}
\hline $\begin{array}{l}\text { Concrete } \\
\text { mixture }\end{array}$ & $\begin{array}{c}\text { Entrapped } \\
\text { air (\% vol.) }\end{array}$ & \multicolumn{2}{c}{ Slump (mm) } & \multicolumn{2}{c}{ Cube compressive strength (MPa) } \\
\cline { 2 - 7 } & After mixing & After mixing & After $\mathbf{6 0}$ min & 2 days & 28 days & 56 days & 90 days \\
\hline M1 & 1.2 & 220 & 120 & 11.0 & 23.6 & 24.8 & 26.3 \\
\hline M2 & 2.1 & 220 & 130 & 11.0 & 25.0 & 27.1 & 28.4 \\
\hline M3 & 1.7 & 220 & 60 & 10.6 & 21.8 & 22.5 & 22.6 \\
\hline M4 & 1.6 & 220 & 70 & 9.3 & 21.2 & 22.5 & 22.7 \\
\hline M5 & 1.7 & 220 & 110 & 10.1 & 23.6 & 26.6 & 25.4 \\
\hline M6 & 1.4 & 220 & 170 & 8.6 & 22.6 & 24.1 & 23.7 \\
\hline M7 & 2.3 & 220 & 40 & 7.1 & 24.0 & 24.6 & 29.9 \\
\hline M8 & 1.3 & 220 & 190 & 9.4 & 22.2 & 21.1 & 24.6 \\
\hline
\end{tabular}

Table 6.

Properties of fresh ready-mixed concrete mixtures $\mathrm{C20} / 25$ with different kinds of plasticizers.

polycarboxylate (30\% water-reducing effect); M5, modified polycarboxylate (more than 22\% polycarboxylate content); M6, polycarboxylate (35\% water-reducing effect); M7, melamine; and M8, lignosulfonate modified by polycarboxylate.

The results show that $\mathrm{H}$-Cement is suitable for the production of ready-mixed concrete between C8/10 and C30/37 strength classes [29]. Workability of the concretes made from $\mathrm{H}$-Cement is dependent on the specific plasticizer type being used. Admixtures based on a lignosulfonate and a combined lignosulfonate/ polycarboxylate mixture are found best to ensure the workability of fresh concrete mixtures and also after the elapsed $60 \mathrm{~min}$.

\subsection{Shrinkage-reducing property}

The concretes were prepared from the cement mixture made of two cements, $\mathrm{HC}$ and PC, in the selected ratios (expressed as \% wt.) as reported in Table 7. The specimens were stored in water at $(20 \pm 1)^{\circ} \mathrm{C}$ and in air at $(20 \pm 1)^{\circ} \mathrm{C}$ with $60 \% \mathrm{RH}$ and at $(40 \pm 1)^{\circ} \mathrm{C}$ with an average $\mathrm{RH}$ of $15 \%$ in order to minimize the length changes within the 90-day period of curing. The concretes were prepared with a constant water-to-cement ratio of 0.475 according to the proportion: $400 \mathrm{~kg} / \mathrm{m}^{3}$ of cement (PCHC 1.00 or HCPC 1.00) or cement blend, $190 \mathrm{l}$ of water and dried river aggregates-0/4 mm, $630 \mathrm{~kg} ; 4 / 8 \mathrm{~mm}, 390 \mathrm{~kg}$; and 8/16 mm, $775 \mathrm{~kg}$ from Jelka (Slovakia). No admixture was used at the concrete production to preclude its influence on the measured length changes. The measurements were performed on the prisms $100 \times 100 \times 400 \mathrm{~mm}$ having a length comparator according to STN 


\begin{tabular}{|c|c|c|c|}
\hline \multirow{2}{*}{$\begin{array}{l}\text { Cement mixture in } \\
\text { concrete }\end{array}$} & \multicolumn{2}{|c|}{ Content of cements (\% wt.) } & \multirow[t]{2}{*}{ Curing regime } \\
\hline & $\mathrm{HC}$ & PC & \\
\hline PCHC 1.00 & 0 & 100 & In water at $20^{\circ} \mathrm{C}$ and in air at 20 and $40^{\circ} \mathrm{C}$ \\
\hline PCHC 0.95 & 5 & 95 & In water at $20^{\circ} \mathrm{C}$ \\
\hline PCHC 0.90 & 10 & 90 & \\
\hline PCHC 0.85 & 15 & 85 & \\
\hline HCPC 0.50 & 50 & 50 & In water at $20^{\circ} \mathrm{C}$ and in air at 20 and $40^{\circ} \mathrm{C}$ \\
\hline HCPC 0.85 & 85 & 15 & In air at 20 and $40^{\circ} \mathrm{C}$ \\
\hline HCPC 0.90 & 90 & 10 & \\
\hline HCPC 0.95 & 95 & 5 & \\
\hline HCPC 1.00 & 100 & 0 & In water at $20^{\circ} \mathrm{C}$ and in air at 20 and $40^{\circ} \mathrm{C}$ \\
\hline
\end{tabular}

Table 7.

Content of cements in the concrete mixtures with $w / c=0.475$.

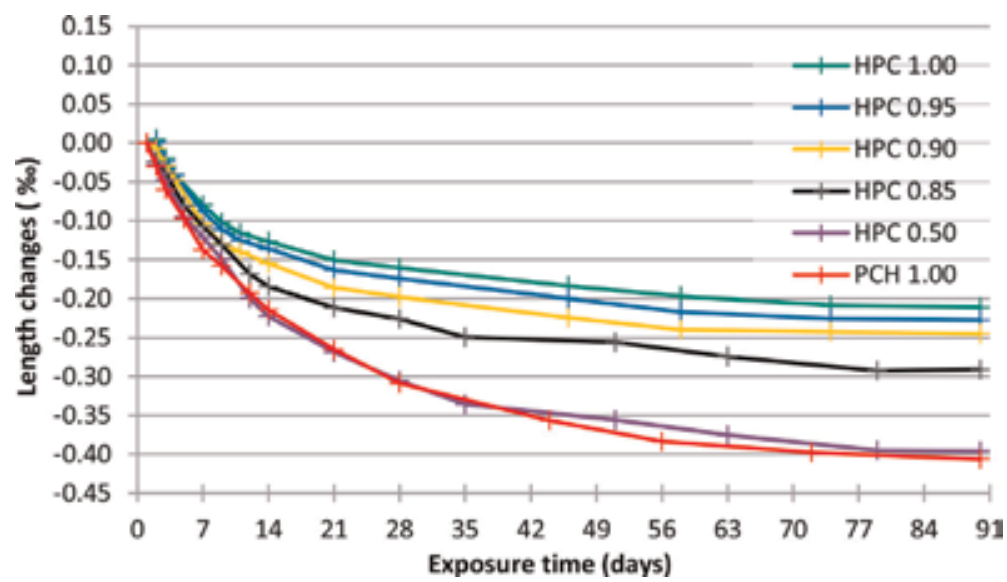

Figure 1.

Length changes of concrete stored 90 days at $20^{\circ} \mathrm{C}$ and $60 \% \mathrm{RH}$.

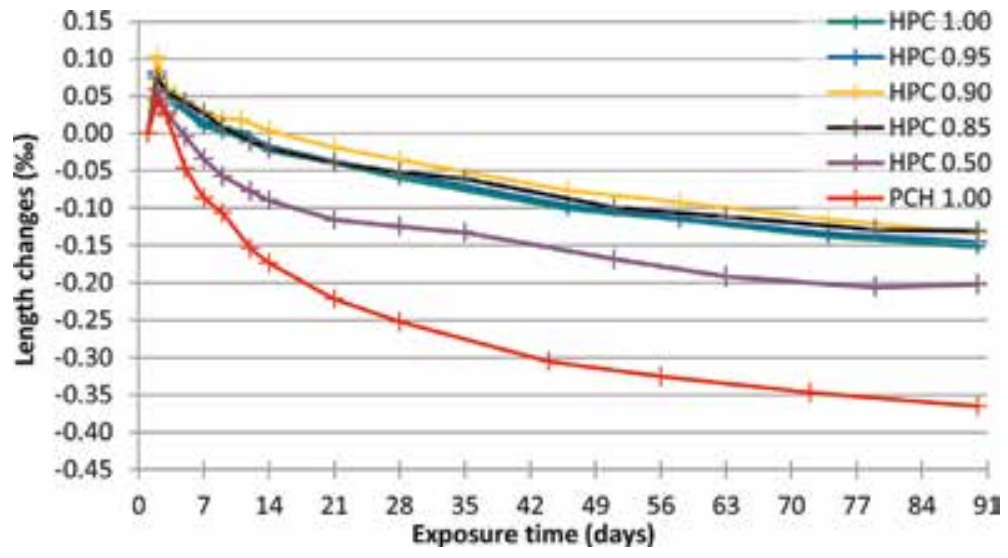

Figure 2.

Length changes of concrete stored 90 days at $40^{\circ} \mathrm{C}$ and $15 \% \mathrm{RH}$. 
731320 [30] (the related ASTM Standard: C157/C157M-08) and are illustrated in Figures 1 and 2. Mechanical properties of the specimens are listed in Table 8.

The results show that $\mathrm{H}$-Cement has reduced shrinkage. All concretes slightly expand when permanently cured in water. $\mathrm{H}$-Cement concrete (HC concrete) expands by $21.6 \%$ less than PC concrete after 90 -day immersion in water. The shrinkage of $\mathrm{HC}$ concrete exposed for 90 days in $20^{\circ} \mathrm{C} / 60 \% \mathrm{RH}$ air cure and $40^{\circ} \mathrm{C} /$ $15 \% \mathrm{RH}$ air cure is about 48 and $58 \%$ smaller than that of PC concrete. The shrinkage-reducing effect is also recorded by the blended systems.

Depending on its cement blend composition and curing regime, however, blending HC with PC contributes to raising the compressive strength values compared to plain HC concrete. The 90-day compressive strength of HCPC 1.00 (100\% wt. HC), HCPC 0.50 (50\% wt. of both cements) and PCHC 1.00 (100\% wt. PC) in 20 and $40^{\circ} \mathrm{C}$ air cure is 32.3 and $30.6 \mathrm{MPa}, 41.0$ and $38.5 \mathrm{MPa}$ and 42.0 and 39.0 $\mathrm{MPa}$, respectively.

\subsection{ASR-mitigating property}

The andesite aggregate with a proven susceptibility to ASR according to the criteria for evaluation of the chemical test according to STN 721179 [16] was used

\begin{tabular}{|c|c|c|c|c|c|c|}
\hline \multirow{3}{*}{$\begin{array}{l}\text { Concrete } \\
\text { mixture }\end{array}$} & \multirow[t]{3}{*}{ HC (\% wt.) } & \multirow[t]{3}{*}{ Curing } & \multirow{3}{*}{$\begin{array}{c}\text { 28-day basic curing } \\
\text { Compressive strength } \\
(\mathrm{MPa})\end{array}$} & \multicolumn{3}{|c|}{ 90-day curing } \\
\hline & & & & \multirow{2}{*}{$\begin{array}{l}\text { DME } \\
(\mathrm{GPa})\end{array}$} & \multicolumn{2}{|c|}{ Prism strength (MPa) } \\
\hline & & & & & Flexural & Compressive \\
\hline \multirow[t]{3}{*}{ HCPC 1.00} & 100 & W20 & 27.2 & 46.6 & 5.4 & 34.2 \\
\hline & & $\mathrm{A} 20$ & 27.6 & 41.7 & 2.4 & 32.3 \\
\hline & & A40 & 28.7 & 36.7 & 2.3 & 30.6 \\
\hline \multirow[t]{2}{*}{ HCPC 0.95} & 95 & A20 & 29.3 & 41.4 & 2.8 & 32.9 \\
\hline & & A40 & 30.0 & 36.7 & 2.4 & 31.8 \\
\hline \multirow[t]{2}{*}{ HCPC 0.90} & 90 & $\mathrm{~A} 20$ & 31.3 & 41.3 & 2.9 & 34.8 \\
\hline & & A40 & 32.0 & 36.6 & 2.5 & 33.0 \\
\hline \multirow[t]{2}{*}{ HCPC 0.85} & 85 & $\mathrm{~A} 20$ & 32.4 & 41.4 & 3.0 & 37.2 \\
\hline & & A40 & 33.2 & 36.6 & 2.6 & 34.7 \\
\hline \multirow[t]{3}{*}{ HCPC 0.50} & 50 & W20 & 35.7 & 50.3 & 5.5 & 49.1 \\
\hline & & $\mathrm{A} 20$ & 38.1 & 41.2 & 3.3 & 41.0 \\
\hline & & A40 & 38.5 & 36.5 & 3.2 & 38.5 \\
\hline PCHC 0.85 & 15 & W20 & 40.5 & 55.1 & 5.5 & 50.6 \\
\hline PCHC 0.90 & 10 & W20 & 40.5 & 55.9 & 5.5 & 50.7 \\
\hline PCHC 0.95 & 5 & W20 & 41.0 & 56.6 & 5.5 & 51.4 \\
\hline \multirow[t]{3}{*}{ PCHC 1.00} & 0 & W20 & 41.6 & 56.6 & 5.6 & 54.5 \\
\hline & & A20 & 40.2 & 39.3 & 3.7 & 42.0 \\
\hline & & $\mathrm{A} 40$ & 39.1 & 33.4 & 3.8 & 39.0 \\
\hline
\end{tabular}

Abbreviations: W20, water at $20^{\circ} \mathrm{C} ; A 20$, air at $20^{\circ} \mathrm{C} ; A 40$, air at $40^{\circ} \mathrm{C} ; \mathrm{DME}$, dynamic modulus of elasticity; $B C$, basic curing specified by 1-day cure in the chamber at $(20 \pm 1)^{\circ} \mathrm{C}$ at $100 \% \mathrm{RH}$ air and 27-day curing in water at $(20 \pm 1)^{\circ} \mathrm{C}$.

Table 8.

Mechanical properties of the concretes made from a mixture of $\mathrm{HC}$ and $P C$ stored for 90 days in water at $20^{\circ} \mathrm{C}$ (W2O), in air at $20^{\circ} \mathrm{C} / 60 \% \mathrm{RH}\left(\mathrm{A}_{20} \mathrm{O}\right)$ and at $40^{\circ} \mathrm{C} / 15 \% \mathrm{RH}$ (A40) after 28 -day basic curing. 
for the tests. The alkali content expressed as $\mathrm{Na}_{2} \mathrm{O}$ equivalent in both cements was estimated. From this content, the amount of $\mathrm{NaOH}$ required to achieve the desired $\mathrm{Na}_{2} \mathrm{O}$ eq. $(1.30+0.05) \%$ wt. by the standard was calculated. The tap water was enriched with a calculated amount of $\mathrm{NaOH}$ during laboratory production of the mortars. Prediction criteria of andesite aggregate susceptibility to ASR are given in Table 9. The composition of mortars for 6 -month length change test cured at 20 and $40^{\circ} \mathrm{C} / 100 \% \mathrm{RH}$ moist air took into account the requirements of the above standard. Length changes are illustrated in Figure 3.

The results show that $\mathrm{H}$-Cement is characterized by ASR-mitigating property. $\mathrm{H}$-Cement mortar (abbreviated as HC 20 and HC 40), in contrast with PC (abbreviated as PC 20 and PC 40), clearly reduces the expansion markedly below the maximum allowable standard limit [16] of $0.1 \%(<1 \%)$ regardless of the long-term treatment. ASR-mitigating effect under maximum allowable limit of $0.1 \%(<1 \%)$ is confirmed also for the blended cement consisting of 70\% wt. PC and 30\% wt. HC (abbreviated as HM 20 and HM 40 in Figure 3).

The contemplated cause of ASR mitigation is the presence of alkali-activated pozzolans in the substitution of up to $80 \%$ by weight of the PC clinker, which could prevent the expansion [31]. The cause of ASR is a complicated problem and is still not fully understood. In this research focused on the need for industry, the achieved effect was investigated, and its cause is not studied in detail.

\subsection{Sulphate resistance}

Basic physical properties and standard strengths are summarized in Table 10. $\mathrm{HC}$ compared to $\mathrm{PC}$ is characterized by low $\mathrm{C}_{3} \mathrm{~A}$ content. Such composition predisposes such cement to be chemically more resistant than PC. Properties of fresh mortars are listed in Table 11. HC mortar compared to both reference is characterized by the higher specific surface area and standardized density. In spite of that

\begin{tabular}{cccccc}
\hline Aggregate & $\begin{array}{c}\text { Loss of } \\
\text { alkalinity } \mathrm{R} \\
(\mathbf{m m o l} / \mathbf{l})\end{array}$ & $\begin{array}{c}\text { Molar } \\
\text { concentration of } \\
\mathrm{SiO}_{2} \mathrm{~S}(\mathbf{m m o l} / \mathbf{l})\end{array}$ & $\begin{array}{c}\text { Criterion } \\
\text { for } \mathrm{R} \text { value } \\
\text { in }[16]\end{array}$ & $\begin{array}{c}\text { Criterion } \\
\text { for } \mathrm{S} \text { value } \\
\text { in }[\mathbf{1 6}]\end{array}$ & $\begin{array}{c}\text { Assumption that } \\
\text { aggregate contains } \\
\text { reactive forms of } \mathrm{SiO}_{2}\end{array}$ \\
\hline Andesite & 132.42 & 400.04 & $\mathrm{R}>70$ & $\mathrm{~S}>\mathrm{R}$ & Yes \\
\hline
\end{tabular}

Table 9.

Prediction of andesite susceptibility to ASR by the chemical test.

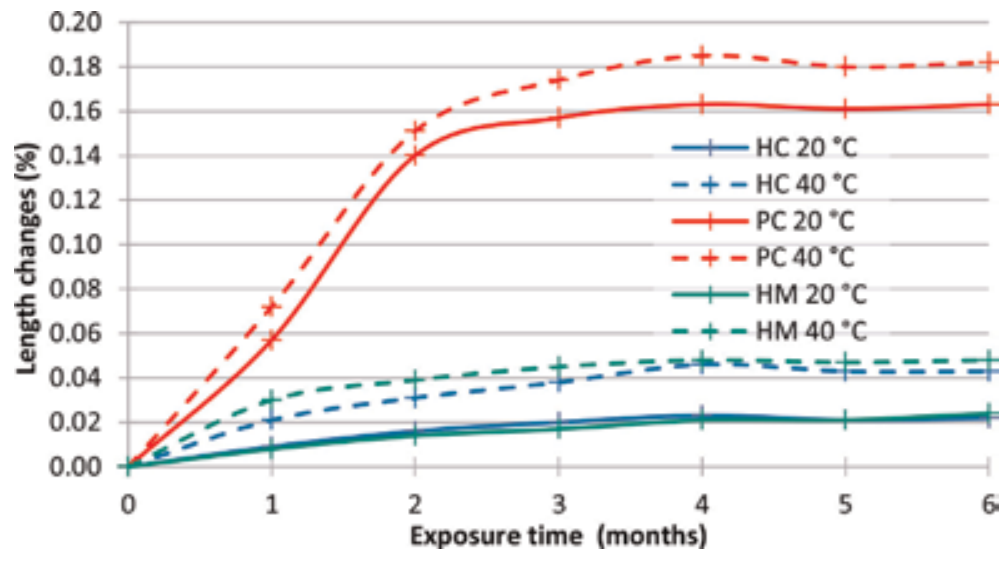

Figure 3.

Length changes of the mortars with the ASR aggregate andesite. 
fact, water-to-cement ratio of HC mortar is 0.42 compared to 0.5 of PC mortar when both are adjusted on the same consistency of $140 \pm 1 \mathrm{~mm}$. H-Cement shows plasticity effect in the mortar; however, it is unable to reach the strength level of both reference mortars, as reported in Table 10. The second reference mortar was prepared from $\mathrm{C}_{3} \mathrm{~A}$-free industrially made Portland cement (abbreviated as SR). HC and PC mortars were adjusted on the same consistency; that of SR differs. SR and PC were produced with the same w/c ratio of 0.5 .

Chemical composition of PC and HC mortar after 28-day basic curing in water at $(20 \pm 1)^{\circ} \mathrm{C}$ is listed in Table 12.

The cements confirm a substantial difference, especially in $\mathrm{CaO}$ content, also evident in $\mathrm{Al}_{2} \mathrm{O}_{3}$ and detectable in $\mathrm{Na}_{2} \mathrm{O}$ eq. amounts. Low $\mathrm{CaO}$ in hybrid cement is a prerequisite for the increased chemical resistance. Higher levels of $\mathrm{Al}_{2} \mathrm{O}_{3}$ and $\mathrm{Na}_{2} \mathrm{O}$ eq., as opposed to $\mathrm{PC}$ mortar, induce the occurrence of the alkali-activated binder based on pozzolanic components as an inorganic polymer characterized by a binder potential alongside the minor portion of hydrated PC clinker.

Dynamic modulus of elasticity (DME) of mortars after 5 years of exposure in the sulphate and water environment is shown in Figure 4. No evident changes were

\begin{tabular}{|c|c|c|c|c|c|c|c|c|}
\hline \multirow[t]{2}{*}{$\begin{array}{l}\text { Cement } \\
\text { kind }\end{array}$} & \multirow{2}{*}{$\begin{array}{c}\mathrm{C}_{3} \mathrm{~A} \\
\text { content } \\
\text { (\% wt.) }\end{array}$} & \multirow{2}{*}{$\begin{array}{c}\text { Specific } \\
\text { surface area } \\
\left(\mathbf{m}^{2} / \mathbf{k g}\right)\end{array}$} & \multirow{2}{*}{$\begin{array}{c}\text { Standard } \\
\text { density } \\
\text { (\% wt.) }\end{array}$} & \multirow{2}{*}{$\begin{array}{l}\text { Initial and } \\
\text { final set } \\
(\mathrm{min})\end{array}$} & \multicolumn{2}{|c|}{$\begin{array}{c}\text { Compressive } \\
\text { strength }(\mathrm{MPa})\end{array}$} & \multicolumn{2}{|c|}{$\begin{array}{c}\text { Flexural } \\
\text { strength (MPa) }\end{array}$} \\
\hline & & & & & 2 days & 28 days & 2 days & 28 days \\
\hline $\mathrm{HC}$ & 1.95 & 696.8 & 33.0 & $230 / 285$ & 14.9 & 39.0 & 4.1 & 7.8 \\
\hline SR & 0.03 & 354.9 & 27.2 & $185 / 225$ & 26.2 & 52.8 & 4.7 & 8.4 \\
\hline PC & 14.31 & 344.7 & 25.8 & $220 / 285$ & 26.5 & 56.5 & 5.4 & 8.5 \\
\hline
\end{tabular}

Table 10.

Basic properties of the cements.

\begin{tabular}{lcccc}
\hline Mortar & Consistency $(\mathbf{m m})$ & Bulk density $\left(\mathbf{k g} / \mathbf{m}^{\mathbf{3}}\right)$ & Air content $(\% \mathbf{~ v o l})$. & w/c \\
\hline HC mortar & 141 & 2200 & 5.2 & 0.42 \\
\hline SR mortar & 186 & 2210 & 6.3 & 0.50 \\
\hline PC mortar & 142 & 2240 & 4.7 & 0.50 \\
\hline
\end{tabular}

Table 11.

Properties of fresh mortars.

\begin{tabular}{lcc}
\hline Constituent & PC mortar (\% wt.) & HC mortar (\% wt.) \\
\hline Ignition loss & 9.43 & 6.79 \\
\hline $\mathrm{SiO}_{2}$ & 64.69 & 71.50 \\
\hline $\mathrm{CaO}$ & 18.07 & 6.38 \\
\hline $\mathrm{Al}_{2} \mathrm{O}_{3}$ & 1.86 & 7.91 \\
\hline $\mathrm{Fe}_{2} \mathrm{O}_{3}$ & 1.17 & 2.28 \\
\hline $\mathrm{MgO}$ & 3.54 & 3.37 \\
\hline $\mathrm{SO}_{3}$ & 0.98 & 1.17 \\
\hline $\mathrm{Cl}^{-}$ & 0.03 & 0.02 \\
\hline $\mathrm{Na}_{2} \mathrm{O}$ eq. & 0.09 & 0.41 \\
\hline
\end{tabular}

Table 12.

Differences in chemical composition of PC and HC mortar after basic curing. 
observed in 5\% wt. $\mathrm{Na}_{2} \mathrm{SO}_{4}$ for $\mathrm{HC}$ and SR mortar, while drops in DME values are found for PC mortar, slightly after 2-year exposure and dramatically after 3-year attack. Elasticity modules at the water curing remain approximately the same.

The effect of sulphate action on the expansion of the mortars is depicted in Figure 5. The HC and SR mortar show negligible expansion in sulphate exposure. PC mortar is specified by negligible length changes underwater, while evident expansion is observed in the sodium sulphate.

Flexural and compressive strength of PC mortar is 9.0 and 63.9 MPa after 4-year curing in water; contrary evident destruction is observed in the sodium sulphate. Determination of the strength was therefore impossible. Excellent resistance of $\mathrm{H}$ Cement to sulphate attack is demonstrated by 5 -year strength of HC mortar. Data in Table 13 show that only a slight decrease in flexural and compressive strength is observed between reference water and aggressive sulphate exposure.

The structural integrity of SR and HC mortar is not disturbed, despite the found slight differences between the 5-year strength parameters. The observed HC mortar's sulphate resistance is determined by the material composition of $\mathrm{H}$-Cement

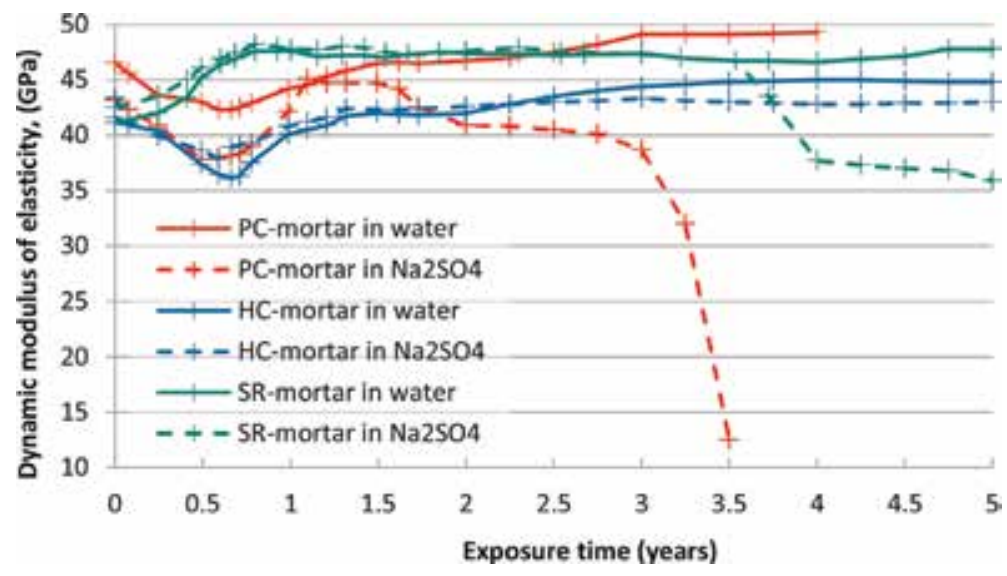

Figure 4.

Changes in DME of mortars in $5 \% \mathrm{Na}_{2} \mathrm{SO}_{4}$ solution and water over time.

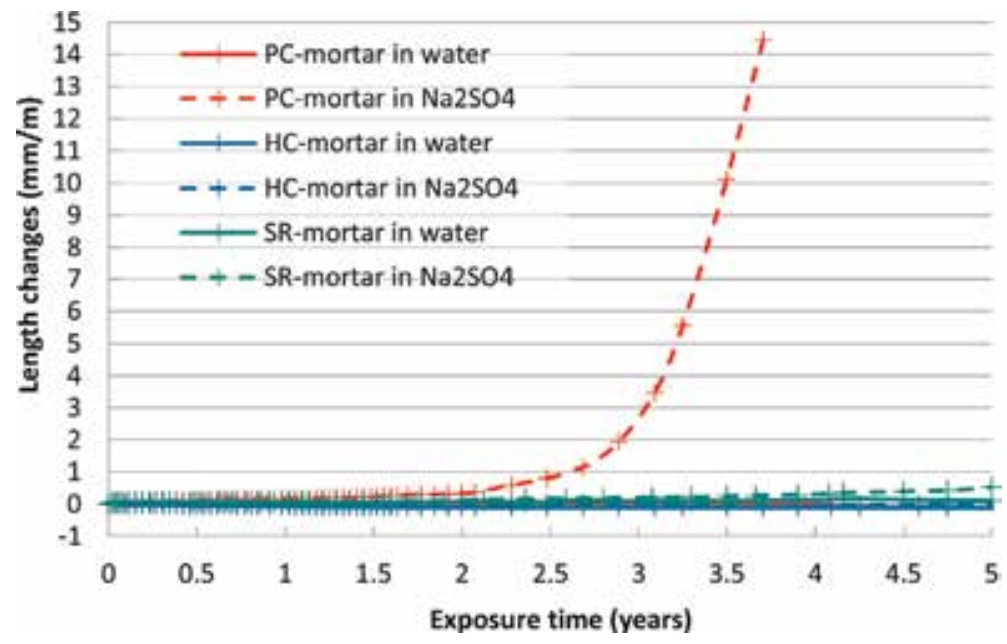

Figure 5 .

Length changes of mortars in $5 \% \mathrm{Na}_{2} \mathrm{SO}_{4}$ solution and water over time $(1 \mathrm{~mm} / \mathrm{m}=1 \%)=0.1 \%$. 


\begin{tabular}{lcc}
\hline \multirow{2}{*}{ HC mortar kept in } & \multicolumn{2}{c}{ Strength (MPa) } \\
\cline { 2 - 3 } & Flexural & Compressive \\
\hline Reference water & 9.1 & 47.1 \\
\hline Aggressive $5 \% \mathrm{Na}_{2} \mathrm{SO}_{4}$ & 6.7 & 44.8 \\
\hline
\end{tabular}

Table 13.

HC mortar strength characteristics at 5-year age from the production in 2012.

that is not sensitive to sulphate attack as well as CEM I 42.5 R-SR 0 but not for the same reason. The cause of high sulphate resistance of $\mathrm{H}$-Cement is explained later.

It is approved in Table $\mathbf{1 4}$ that PC mortar is characterized by extremely high bound $\mathrm{SO}_{3}$ and ignition loss values after 4 -year exposure in $5 \%$ wt. $\mathrm{Na}_{2} \mathrm{SO}_{4}$ opposite to $\mathrm{HC}$ and $\mathrm{SR}$ mortar. The $\mathrm{CaO}$ content is dramatically reduced in sulphate exposure as compared to that of HC and SR mortar. HC mortar behaves in the sodium sulphate as well as SR mortar; even the difference between the $\mathrm{SO}_{3}$ bound in $\mathrm{HC}$ mortar in sulphate and water exposure is smaller than that in SR mortar.

Qualitative and quantitative differences in mineral and phase composition of PC and $\mathrm{HC}$ mortar after 28 -day basic curing (BC) in $(20 \pm 1)^{\circ} \mathrm{C}$ water are recognized in Figures 6-9. The basic feature of the difference in the mineral composition of both mortars lies in the absence of portlandite $\mathrm{Ca}(\mathrm{OH})_{2}$ in the mortar with the hybrid cement. Hydrated hybrid cement without the developed $\mathrm{Ca}(\mathrm{OH})_{2}$ assumes a realistic chemical resistance in terms of sulphate resistance.

The results of thermal analysis confirmed that $\mathrm{H}$-Cement generates a hydrated phase without the formation of crystalline $\mathrm{Ca}(\mathrm{OH})_{2}$. This fact can decisively improve the increase in resistance to sulphate aggressiveness.

Mineral and phase compositions of the long-term exposed mortars are given in Figures 10-14. PC mortar in water contains quartz $\mathrm{SiO}_{2}(\mathrm{Q})$ from the standardized sand and calcium hydroxide $\mathrm{Ca}(\mathrm{OH})_{2}(\mathrm{CH})$ as a reaction product of cement hydration, also calcite $\mathrm{CaCO}_{3}(\mathrm{Cc})$ as minor mineral. The high content of gypsum $\mathrm{CaSO}_{4} \cdot 2 \mathrm{H}_{2} \mathrm{O}(\mathrm{G})$ and, to a less extent, more voluminous ettringite $3 \mathrm{CaO} \cdot \mathrm{Al}_{2} \mathrm{O}_{3} .3$. $\mathrm{CaSO}_{4} \cdot 32 \mathrm{H}_{2} \mathrm{O}(\mathrm{E})$ are detected in 4-year-old PC mortar exposed to $5 \%$ wt. $\mathrm{Na}_{2} \mathrm{SO}_{4}$ solution. Contrary, 5-year-old SR mortar shows a reduced content of $\mathrm{CH}$ in the sodium sulphate compared to water exposure and only a slight indication of the presence of $\mathrm{CaSO}_{4} \cdot 2 \mathrm{H}_{2} \mathrm{O}$ arising as a reaction product of sulphate attack. $\mathrm{HC}$ mortar records in the same time negligible differences in mineral composition. The presence of $\mathrm{CH}$ and any reaction products of sulphate attack ( $\mathrm{G}$ and $\mathrm{E}$ ) are not confirmed; a negligible share of the marginal sodium thiosulfate pentahydrate $\mathrm{Na}_{2} \mathrm{~S}_{2} \mathrm{O}_{3} \cdot 5 \mathrm{H}_{2} \mathrm{O}(\mathrm{SH})$ and mirabillite $\mathrm{Na}_{2} \mathrm{SO}_{4} \cdot 10 \mathrm{H}_{2} \mathrm{O}(\mathrm{MI})$ is detected. Both of the latter minerals would be considered as reaction products of sulphate attack, however, with no negative impact on degradation of the mortar. TG-DTA plot confirms the presence of reaction products of sulphate attack in PC mortar by endotherm with maximum peak at $160^{\circ} \mathrm{C}$ (Figure 13), compared to $\mathrm{HC}$ mortar (Figure 14). The presence of $\mathrm{CH}$ was not recognized in $\mathrm{HC}$ mortar in water and $\mathrm{Na}_{2} \mathrm{SO}_{4}$ exposure. The minimum presence of calcite $\mathrm{CaCO}_{3}(\mathrm{Cc})$ is also negligible in terms of mortar damage.

Basic parameters of the pore structure of the mortars are considered in Table 15.

PC mortar is characterized by evident coarsening of the pore structure after 4 years of exposure to the sodium sulphate. This finding is proven by one order of increased permeability in contrast to water treatment. HC and SR mortars show no significant differences in the pore structure parameters after 5 years of exposure.

The insignificant detrimental effect of 5-year sulphate attack on HC and SR mortar is also proven by the permeability values, which remain for each mortar the 


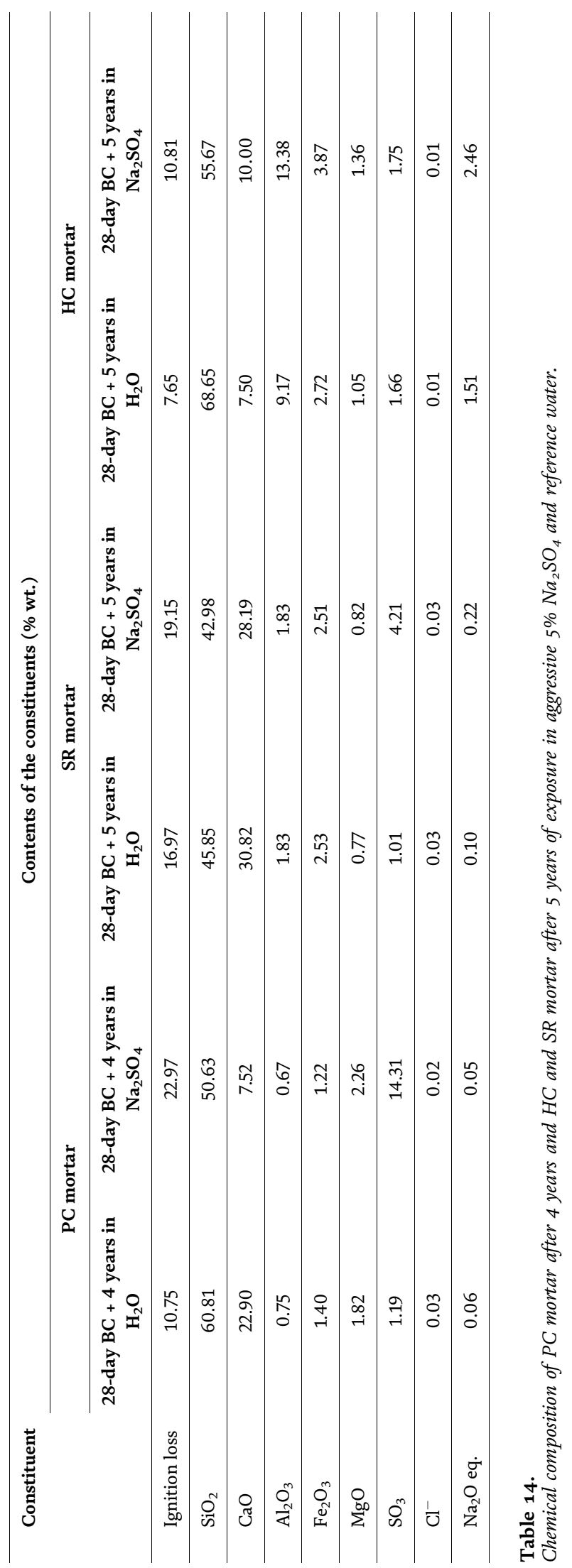


Fundamental Properties of Industrial Hybrid Cement Important for Application in Concrete DOI: http://dx.doi.org/10.5772/intechopen.88060

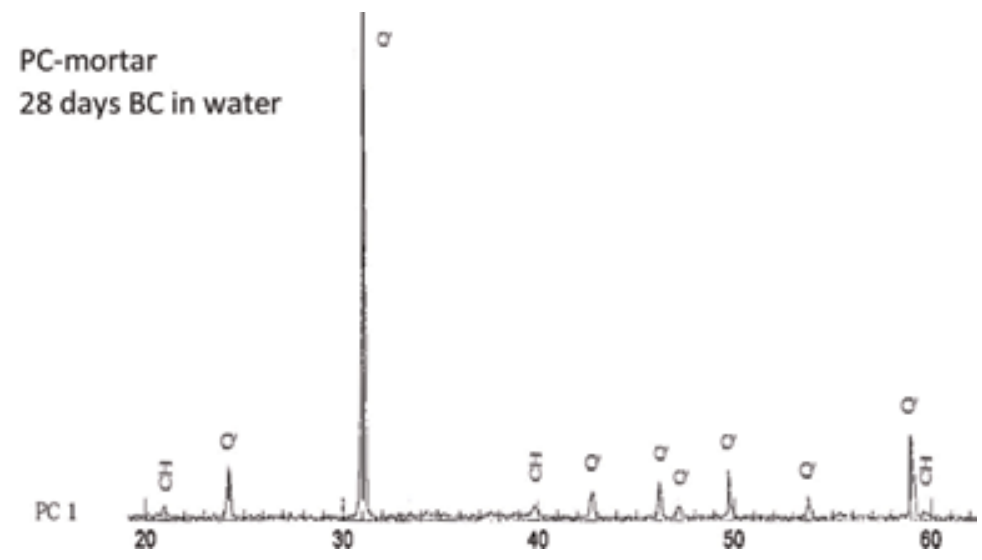

Figure 6.

Mineral composition of PC mortar after 28-day basic curing in water.

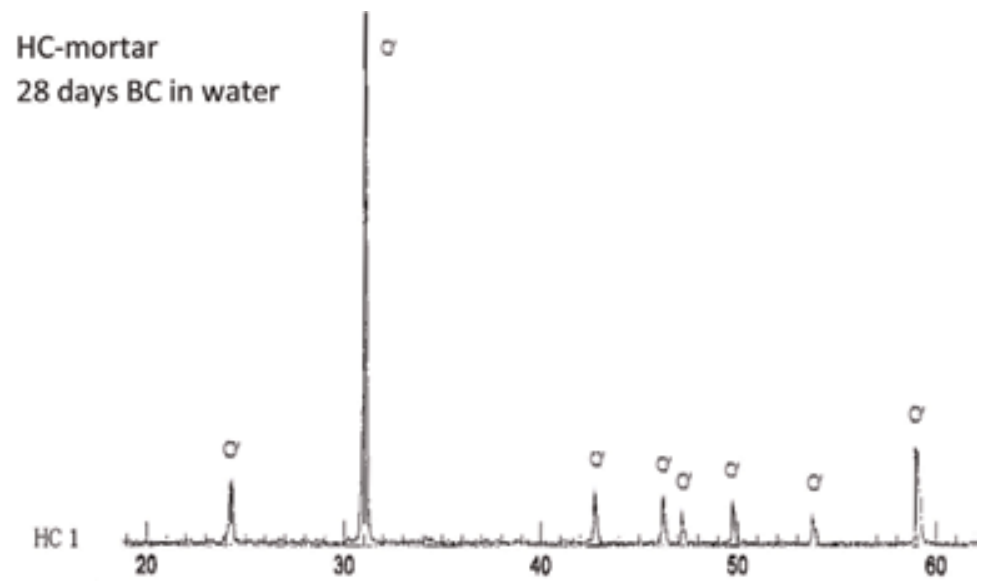

Figure 7.

Mineral composition of HC mortar after 28-day basic curing in water.

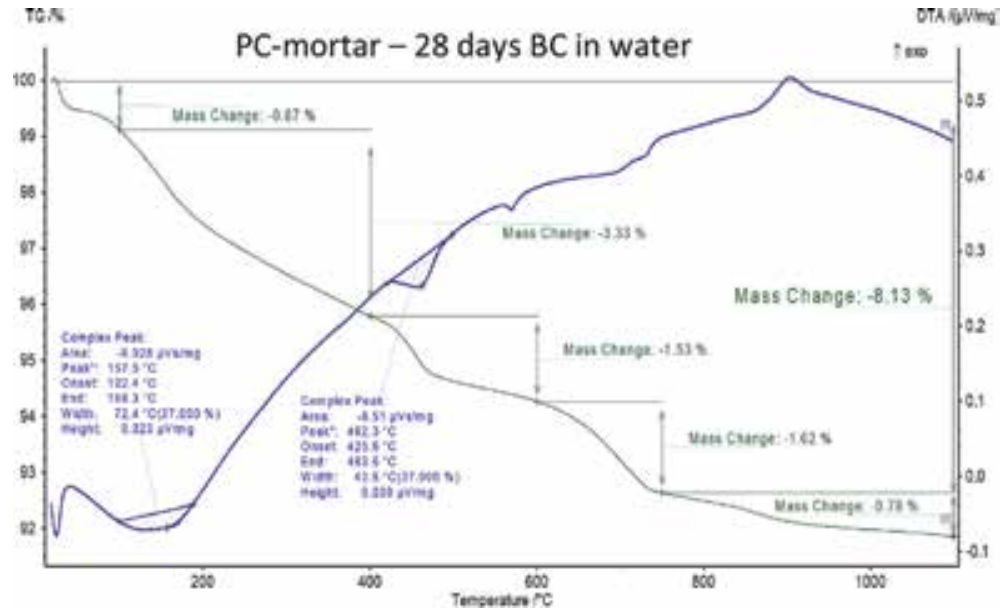

Figure 8.

TG-DTA plots of PC mortar after 28-day basic curing in water. 


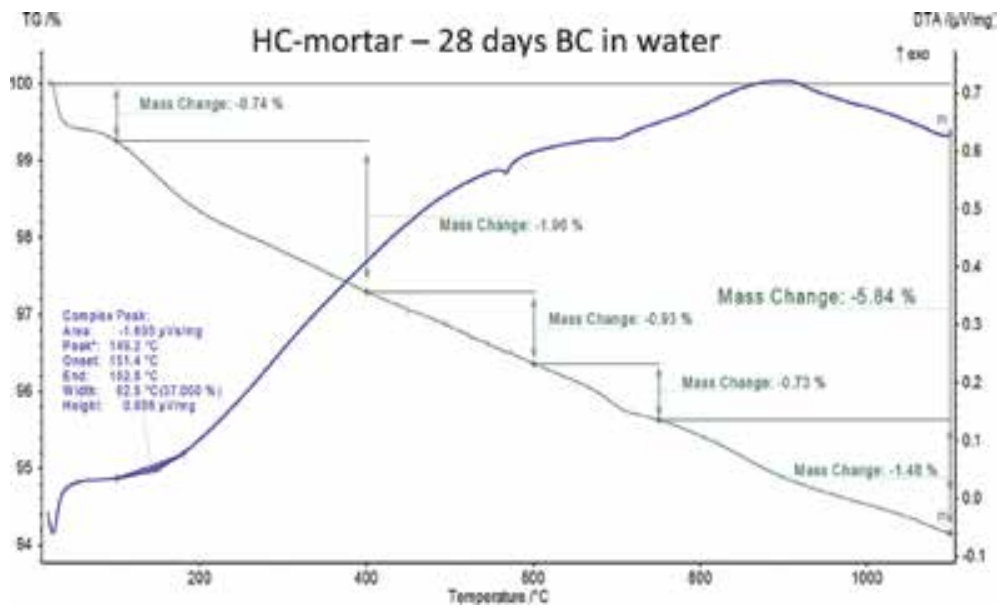

Figure 9.

TG-DTA plots of HC mortar after 28-day basic curing in water.

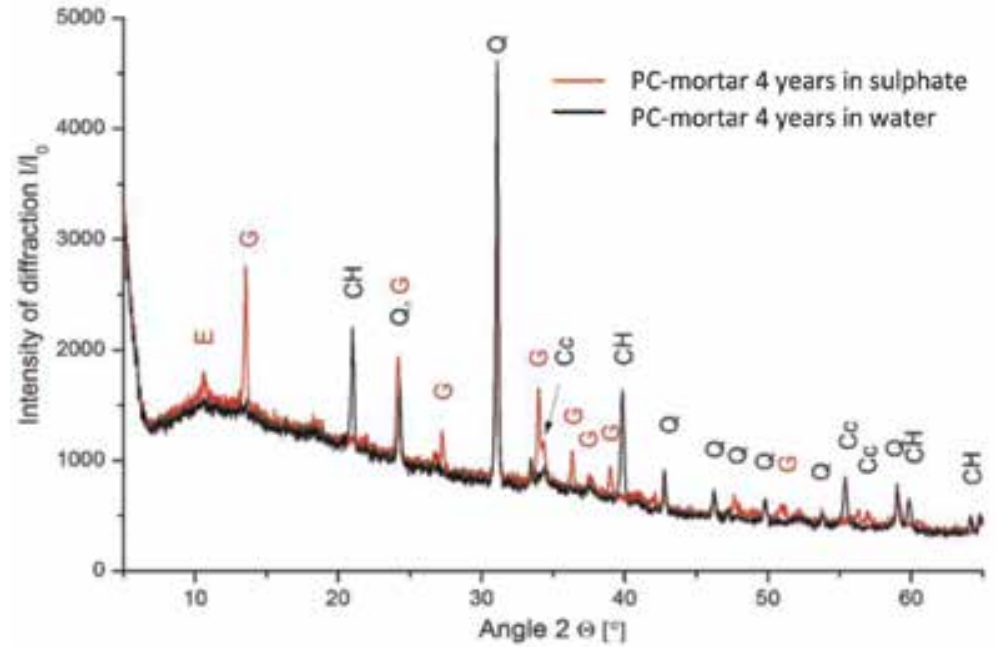

Figure 10.

$X R D$ patterns of $P C$ mortar after 4 years in $5 \%$ wt. sodium sulphate and water.

same in both exposure conditions (reference water vs. aggressive sulphate), while that of PC mortar is increased by one order even after 4-year exposure to sulphate attack.

Visual and microscopy observations support the previous finding that sulphate resistance of $\mathrm{H}$-Cement is the same with that of the sulphate-resistant Portland cement. Visual observations prove that 5-year-old HC mortar is characterized by well-preserved structural integrity, while PC mortar is considerably destroyed in the sodium sulphate after 4 years of exposure (Figure 15).

The gypsum and ettringite presence is confirmed in PC mortar after 4-year exposure in the sodium sulphate, while the same reaction products are not detected in $\mathrm{HC}$ and SR mortar after 5 -year exposure in $\mathrm{Na}_{2} \mathrm{SO}_{4}$ (Figure 16). The property of high non-permeability, which is a consequence of the formed hydrate phase character, is a basic condition for the high chemical resistance of a mortar and, in the conveyed meaning of the word, also a concrete made of the same binder system as that which occurred in 5-year-old HC mortar. 
Fundamental Properties of Industrial Hybrid Cement Important for Application in Concrete DOI: http://dx.doi.org/10.5772/intechopen.88060

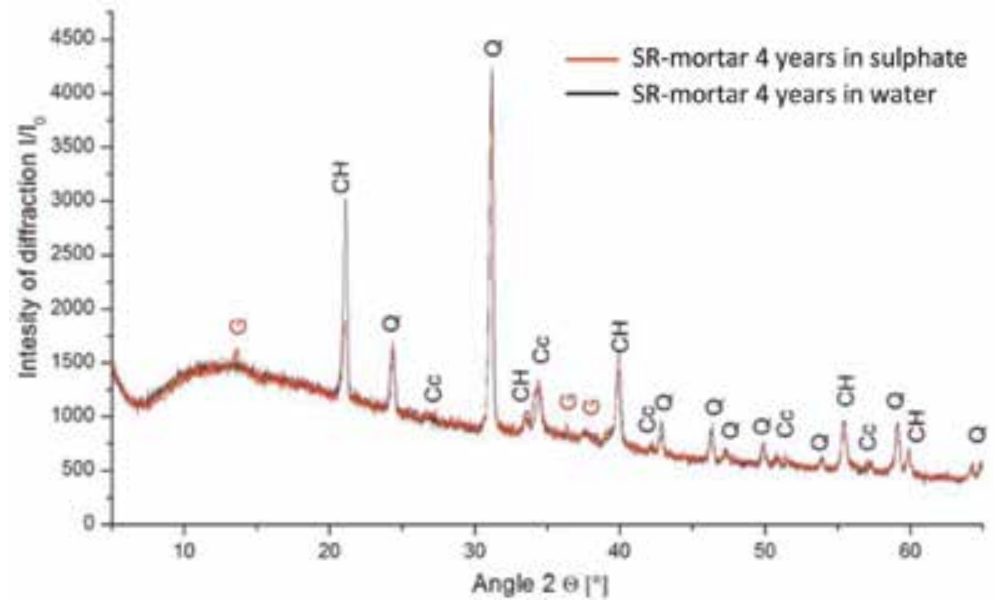

Figure 11.

$X R D$ patterns of SR mortar after 5 years in $5 \%$ wt. sodium sulphate and water.

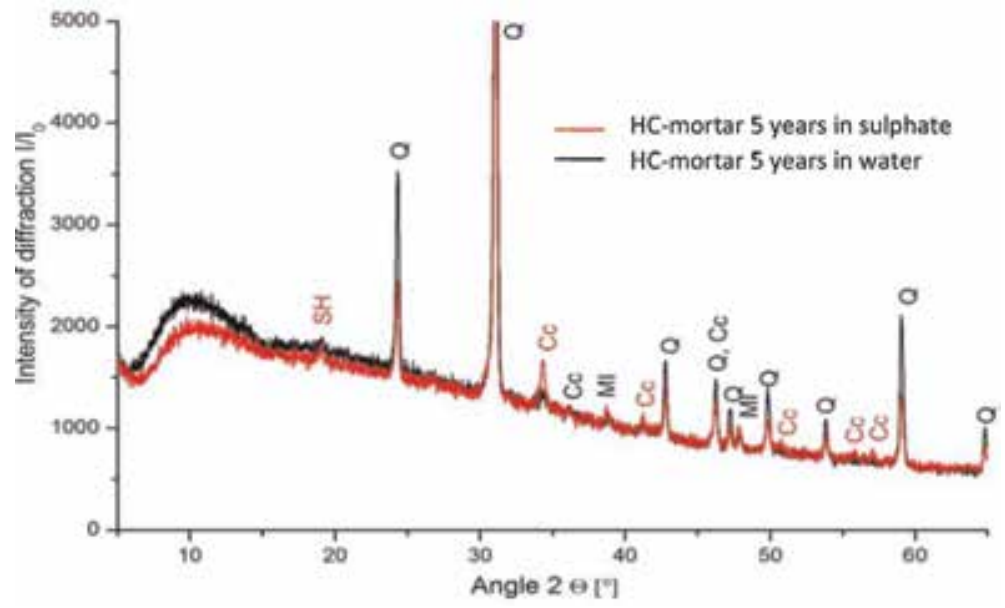

Figure 12.

XRD patterns of HC mortar after 5 years in 5\% wt. sodium sulphate and water.

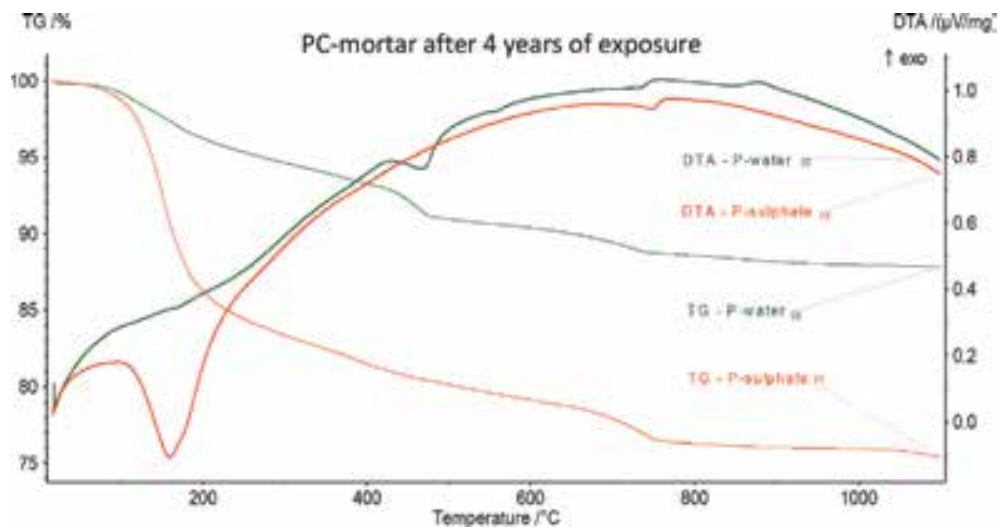

Figure 13.

TG-DTA plots of PC mortar stored 4 years in $5 \% \mathrm{wt}$. sodium sulphate and water. 


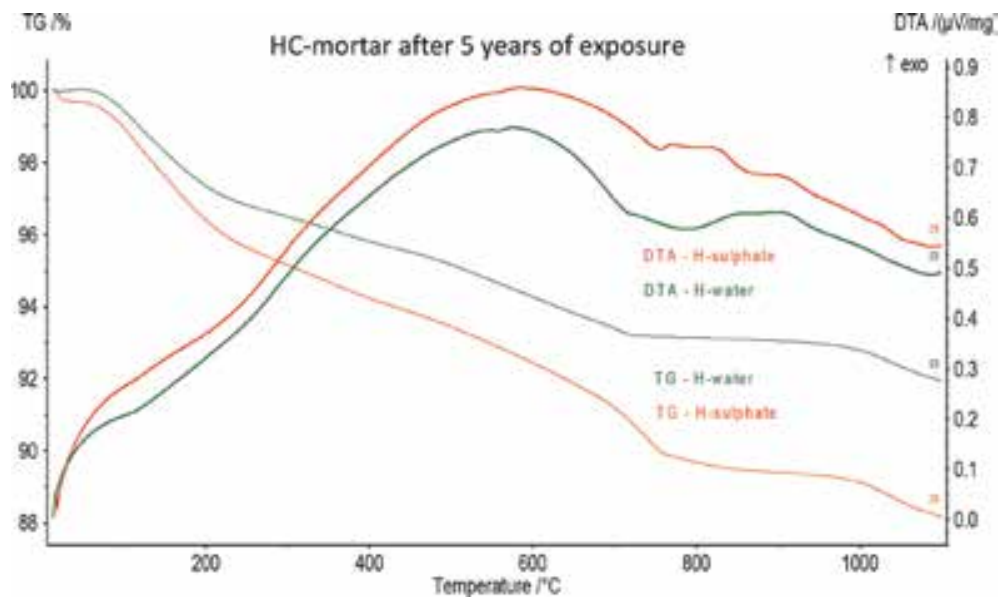

Figure 14.

TG-DTA plots of HC mortar after 5 years in $5 \%$ wt. sodium sulphate and water.

\begin{tabular}{lcccccc}
\hline Mortar & SSAP $\left(\mathbf{m}^{2} / \mathbf{g}\right)$ & VTP $\left(\mathbf{c m}^{3} / \mathbf{g}\right)$ & MTP $(\mathbf{n m})$ & MMP $(\mathbf{n m})$ & TP $(\%)$ & K (m/s) \\
\hline PC & 5.32 & 0.100 & 252.00 & 84.65 & 19.39 & $3.3 \times 10^{-10}$ \\
\hline SR & 2.90 & 0.55 & 55.40 & 28.51 & 11.95 & $2.2 \times 10^{-12}$ \\
\hline HC & 11.17 & 0.100 & 31.46 & 19.91 & 19.67 & $8.0 \times 10^{-11}$ \\
\hline
\end{tabular}

Abbreviations: SSAP, specific surface area of total open pores; VTP, volume of total open pores $(1.82-0.534 \mathrm{~nm})$; MTP, total pore median radius; MMP, micropore median radius (1.82-5250 nm); TP, total open porosity (1.82-0.534 $\mathrm{nm}) ; \mathrm{K}$, permeability coefficient (calculated from the MIP results).

Table 15.

Basic pore structure parameters of PC mortar after 4-year immersion as well as SR and HC mortar after 5-year exposure in aggressive $5 \% \mathrm{Na}_{2} \mathrm{SO}_{4}$.
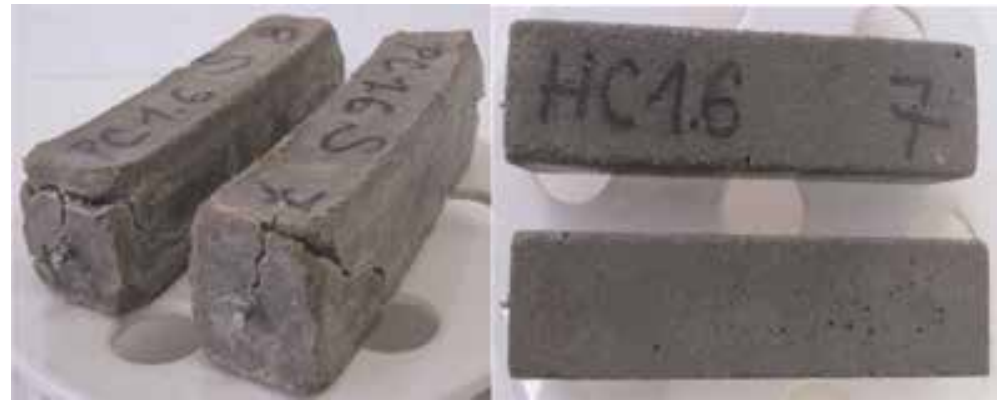

Figure 15.

Destroyed integrity of PC mortar after 4 years of aggressive attack with sodium sulphate (left) and intact state of $\mathrm{H}$-cement after 5 years of aggressive attack of $5 \% \mathrm{wt} . \mathrm{Na}_{2} \mathrm{SO}_{4}$ (right).

\subsection{Explanation of sulphate resistance of hybrid cement}

Degradation of the hydrate phase of cement-based composite by sulphate attack is characterized by the formation of gypsum $\mathrm{CaSO}_{4} \cdot \mathrm{H}_{2} \mathrm{O}\left(\mathrm{CSH}_{2}\right)$ together with ettringite $(\mathrm{CaO})_{3}\left(\mathrm{Al}_{2} \mathrm{O}_{3}\right)\left(\mathrm{CaSO}_{4}\right)_{3} \cdot 32 \mathrm{H}_{2} \mathrm{O}\left(\mathrm{C}_{6} \mathrm{AS}_{3} \mathrm{H}_{32}\right)$. Gypsum is formed by the reaction of sulphate ions with $\mathrm{Ca}(\mathrm{OH})_{2}$ or calcium silicate hydrate $(\mathrm{C}-\mathrm{S}-\mathrm{H})$ :

$$
2 \mathrm{OH}-+\mathrm{SO}_{4}{ }^{2-}+\mathrm{Ca}^{2+} \rightarrow \mathrm{CSH}_{2} \text { or }
$$




$$
\begin{gathered}
\mathrm{C}-\mathrm{S}-\mathrm{H}+\mathrm{SO}_{4}{ }^{2-} \rightarrow \mathrm{CSH}_{2} \text { when a reaction proceeds in } \mathrm{Na}_{2} \mathrm{SO}_{4} \text { solution } \\
2 \mathrm{Na}^{+}+\mathrm{SO}_{4}{ }^{2-}+\mathrm{Ca}^{2+}+\text { aq. } \rightarrow 2 \mathrm{Na}^{+}+\mathrm{CSH}_{2}+\text { aq. }
\end{gathered}
$$

The formed gypsum binds to tricalcium aluminate $\left(\mathrm{C}_{3} \mathrm{~A}\right)$, in particular to ettringite, but also monosulphate $(\mathrm{CaO})_{3}\left(\mathrm{Al}_{2} \mathrm{O}_{3}\right)\left(\mathrm{CaSO}_{4}\right) 12 \mathrm{H}_{2} \mathrm{O}\left(\mathrm{C}_{4} \mathrm{ASH}_{12}\right)$ is secondary generated:

$$
\mathrm{C}_{3} \mathrm{~A}+3 \mathrm{CSH}_{2}+26 \mathrm{H} \rightarrow \mathrm{C}_{6} \mathrm{AS}_{3} \mathrm{H}_{32}
$$

Ettringite formation is also accompanied by another minor reaction:

$$
\mathrm{C}_{4} \mathrm{ASH}_{12}+2 \mathrm{CSH}_{2}+16 \mathrm{H} \rightarrow \mathrm{C}_{6} \mathrm{AS}_{3} \mathrm{H}_{32}
$$

Reaction products of sulphate attack (gypsum and ettringite) are high-volume salts that cause destructive expansion of hydrated cement matrix. The tested $\mathrm{H}$ Cement is specified by the major portion of the cement-less inorganic polymer (80\% wt.) and the minor portion of the PC clinker (20\% wt.). It contains a little $\mathrm{C}_{3} \mathrm{~A}$ and when hydrated no $\mathrm{Ca}(\mathrm{OH})_{2}$. Therefore, just the composition of $\mathrm{H}$-Cement is the cause of its high sulphate resistance because degradation processes, as described by Eqs. (1)-(5), cannot be applied with H-Cement use. Sulphate resistance of H-Cement is therefore regarded the same as sulphate-resistant CEM I 42.5 R-SR 0.

\subsection{Concrete based on steel slag as aggregate}

The temperatures and pressures in the testing laboratory autoclave were set according to the autoclave curves presented in Figure 17 in order to determine the volume changes of the concrete based on steel slag. The properties of the steel slag used for experimental research are shown in Tables 16 and 17. Figure 18 shows a gradual increase in the cube strength of concretes based on H-Cement and steel slag (HC concrete) as the aggregate compared with that consisting of PC with steel slag (PC concrete). HC concrete reports a smaller increase in strength, which equals that of PC concrete after 90 days of exposure in water. The characteristic concrete strength after 90 days in the case of the HC concrete and PC concrete is approximately the same, $38 \mathrm{MPa}$.

The gradual increase in the cube strength of concretes based on H-Cement is caused by the fact that the hybrid cement generates lower hydration heat during the

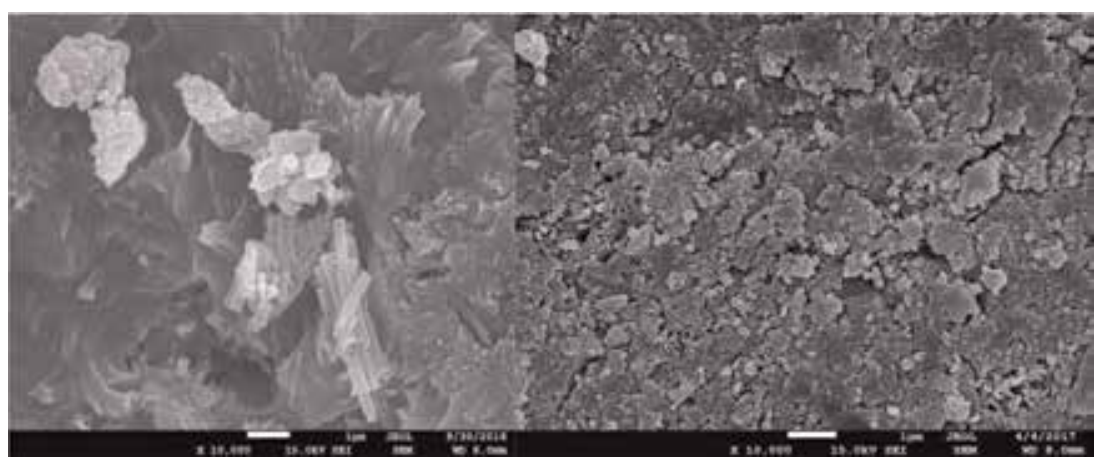

Figure 16.

SEM image of SR mortar (left) and HC mortar (right) after 5 years of exposure in sodium sulphate (10,000 $\times$ magnification). 


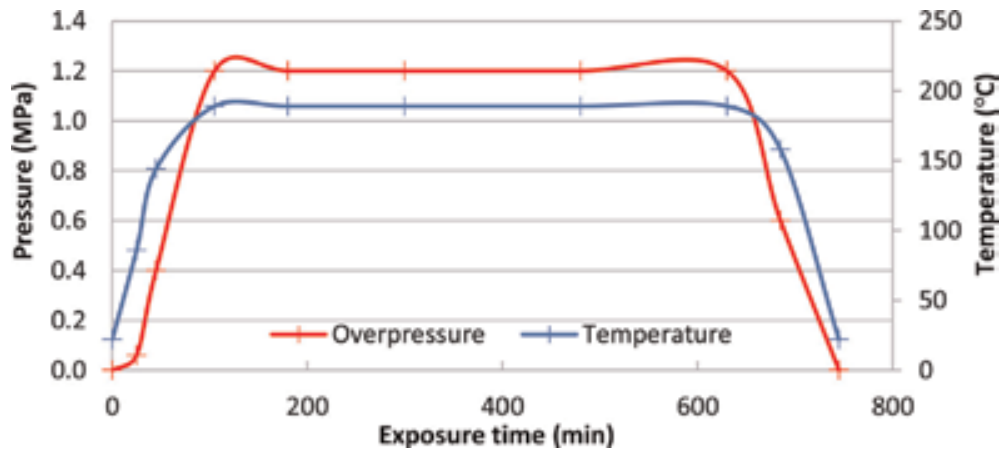

Figure 17.

Temperature-pressure conditions and concrete autoclaving time.

\begin{tabular}{lc}
\hline Bulk density of grains & $3.742 \mathrm{Mg} \mathrm{m}^{-3}$ \\
\hline Bulk density of grains after drying in a dryer & $3.439 \mathrm{Mg} \mathrm{m}^{-3}$ \\
\hline Bulk density of grains saturated with water and surface dried & $3.520 \mathrm{Mg} \mathrm{m}^{-3}$ \\
\hline WA24 water absorption & $2.34 \%$ \\
\hline
\end{tabular}

Table 16.

Values of bulk density and absorption power of steel slag with the fraction of o/8 $\mathrm{mm}$.

\begin{tabular}{lcccccc}
\hline Constituent & Unit & Result & Uncertainty & Element & Unit & Result \\
\hline $\mathrm{Na}_{2} \mathrm{O}$ & \% wt. & 0.46 & \pm 0.10 & $\mathrm{~V}$ & $\mathrm{mg} / \mathrm{kg}$ & 570 \\
\hline $\mathrm{MgO}$ & \% wt. & 10.2 & \pm 1.2 & $\mathrm{Cr}$ & $\mathrm{mg} / \mathrm{kg}$ & 3900 \\
\hline $\mathrm{Al}_{2} \mathrm{O}_{3}$ & \% wt. & 2.43 & \pm 0.27 & $\mathrm{Ni}$ & $\mathrm{mg} / \mathrm{kg}$ & 25 \\
\hline $\mathrm{SiO}_{2}$ & \%wt. & 13.7 & \pm 1.3 & $\mathrm{Cu}$ & $\mathrm{mg} / \mathrm{kg}$ & 38 \\
\hline $\mathrm{P}_{2} \mathrm{O}_{5}$ & \%wt. & 0.91 & \pm 0.09 & $\mathrm{Zn}$ & $\mathrm{mg} / \mathrm{kg}$ & 63 \\
\hline $\mathrm{SO}_{3}$ & \%wt. & 0.50 & \pm 0.06 & $\mathrm{Sr}$ & $\mathrm{mg} / \mathrm{kg}$ & 130 \\
\hline $\mathrm{K}_{2} \mathrm{O}$ & \%wt. & $<0.003$ & & $\mathrm{Zr}$ & $\mathrm{mg} / \mathrm{kg}$ & 140 \\
\hline $\mathrm{CaO}^{2}$ & \%wt. & 38 & \pm 2 & $\mathrm{Nb}$ & $\mathrm{mg} / \mathrm{kg}$ & 67 \\
\hline $\mathrm{TiO}_{2}$ & \%wt. & 0.29 & \pm 0.02 & $\mathrm{Mo}$ & $\mathrm{mg} / \mathrm{kg}$ & 36 \\
\hline $\mathrm{MnO}$ & \%wt. & 3.02 & \pm 0.13 & $\mathrm{Ba}$ & $\mathrm{mg} / \mathrm{kg}$ & 200 \\
\hline $\mathrm{Fe}$ total & \%wt. & 22 & & $\mathrm{Ta}$ & $\mathrm{mg} / \mathrm{kg}$ & 110 \\
\hline $\mathrm{CaO}$ free & \%wt. & 2.34 & \pm 0.24 & $\mathrm{~W}$ & $\mathrm{mg} / \mathrm{kg}$ & 86 \\
\hline- & - & - & - & Loss by annealing & $\%$ wt. & -0.74 \\
\hline
\end{tabular}

Table 17.

Results of chemical analysis of steel slag.

initial hydration and thus makes it possible to reduce the volume changes during setting and hardening of the concrete mixture based on steel slag.

Table 18 compares the average values of cube strengths after 28 and 90 days and prism strengths after 28 days from the first and second stages of the experiment.

When comparing the results of the cube strength from the first and second stage of the experiment, the next partial observations may be drawn: 
- After 28 days, HC concrete shows a lower strength by $1.2 \mathrm{MPa}(4.1 \%)$.

- After 28 days, PC concrete shows a lower strength by $5.4 \mathrm{MPa}(15.6 \%)$.

- After 90 days, HC concrete shows a lower strength by $5.0 \mathrm{MPa}(13.0 \%)$.

- After 90 days, PC concrete shows a lower strength by $6.5 \mathrm{MPa}(17.1 \%)$.

It is therefore evident that:

- The difference between the prism strength of HC concrete is $4 \mathrm{MPa}(13.8 \%)$.

- The difference in prism strength of PC concrete is $0.9 \mathrm{MPa}(2.8 \%)$.

The results of durability tests of the concrete based on steel slag showed the suitability of $\mathrm{H}$-Cement as a binder for the production of the concrete based on steel slag in an environment with a higher temperature and pressure. The above-stated fact is well-confirmed by Figure 19, where the comparison of test specimens after the autoclaving process is shown. The PC concrete with steel slag as aggregate was disintegrated into rubbles, while that composed of $\mathrm{H}$-Cement remained compact and without any apparent damage. The autoclaving process (see Figure 17) of concrete containing steel slag and CEM I (PC concrete) resulted in a disruption of the cement compound due to shrinkage with increasing temperature. The autoclaving process accelerated the calcium disintegration and the magnesium disintegration of steel slag, which is associated with volume changes. This process has caused the disintegration of the test specimens. The autoclaving process of concrete

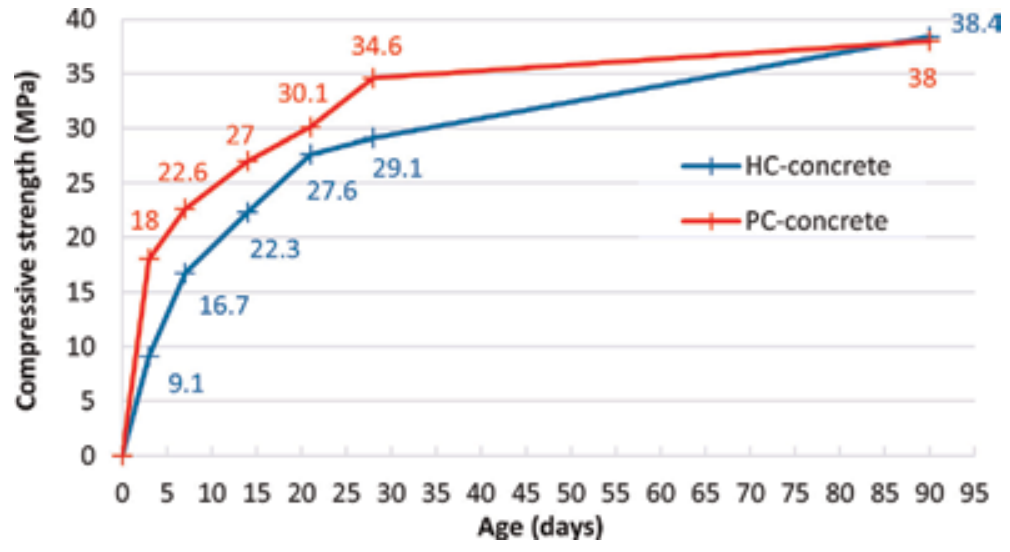

Figure 18.

Average values of cube strengths from the first stage of the experiment.

\begin{tabular}{lcccc}
\hline \multirow{2}{*}{ Age of concrete } & \multicolumn{2}{c}{ HC concrete $(\mathrm{MPa})$} & \multicolumn{2}{c}{ PC concrete (MPa) } \\
\cline { 2 - 5 } & First stage & Second stage & First stage & Second stage \\
\hline Cube 28 days & 29.1 & 27.9 & 34.6 & 29.2 \\
\hline Cube 90 days & 38.4 & 33.4 & 38.0 & 31.5 \\
\hline Prism 28 days & 29.0 & 25.0 & 31.2 & 32.1 \\
\hline
\end{tabular}

Table 18.

Comparison of cube and prism strengths after 28 and 90 days from the first and second stage of the experiment. 


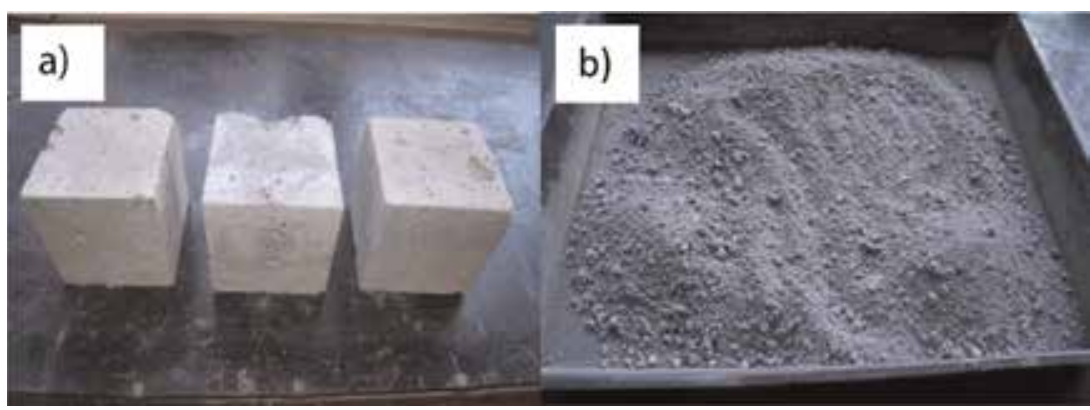

Figure 19.

View on (a) HC concrete and (b) PC concrete after autoclaving.

containing steel slag and $\mathrm{H}$-Cement (HC concrete) has eliminated the volume changes of the steel slag (calcium and magnesium expansion). There was no disruption of the cement compound and the contact zones between the grain of steel slag and the cement compound. This is confirmed by an increase in the concrete strength after the autoclaving process from 29.1 to $43.0 \mathrm{MPa}$ (increase by $32 \%$ ).

\section{Conclusions}

From the results of our experimental investigation, it is possible to formulate the following conclusions:

a. H-Cement with the composition that is found to be outside of the EN 197-1 can be used similarly to traditional cements of medium-strength classes like $32.5 \mathrm{R}$ and $42.5 \mathrm{~N}$ and for high long-term flexural strength. No kind of additional heat treatment during early and later hydration is needed.

b. H-Cement is suitable for use in ready-mixed concrete up to C30/37 strength class with a variety of plasticizers, which are compatible with it in the same way as traditional cements. Lignosulfonate-based and combined lignosulfonate-polycarboxylate plasticizers have been found to be the best in terms of workability of fresh mixtures standing for $60 \mathrm{~min}$.

c. H-Cement has under the conditions tested shrinkage-reducing properties. Shrinkage-reducing effect is also recorded in cement blends at replacement level of H-Cement by $5-15 \%$ wt. PC. No shrinkage-reducing admixture is necessary in concrete when $\mathrm{H}$-Cement is used.

d.H-Cement has under the conditions tested ASR-mitigating property. The expansion of concrete is also suppressed when using cement blend with replacement level of PC by $30 \%$ wt. H-Cement.

e. High sulphate resistance of $\mathrm{H}$-Cement is the result of a special composition; sulphate resistance of $\mathrm{H}$-Cement was found by a 5-year test, the same with that of sulphate-resistant CEM I 42.5 R-SR 0.

f. H-Cement is suitable for use in concrete with $100 \%$ replacement of natural aggregate by the artificial steel slag aggregate. No detrimental processes leading to disintegration of such concrete exposed to high temperature and pressure were recognized. 
Fundamental Properties of Industrial Hybrid Cement Important for Application in Concrete DOI: http://dx.doi.org/10.5772/intechopen.88060

\section{Acknowledgements}

The financial support of this research project based on the contract related to the utility properties and durability of developed new cement kinds by the Považská cementáreň, a. s., cement plant, Ladce (Slovakia), is greatly appreciated.

\section{Conflict of interest}

The authors do not register any conflict of interest.

\section{Author details}

Ivan Janotka ${ }^{1 *}$, Pavel Martauz ${ }^{2}$, Michal Bačuvčík $^{1}$ and Vojtěch Václavík ${ }^{3}$

1 Building Testing and Research Institute, Bratislava, Slovakia

2 Považská Cementáreň Cement Plant, Ladce, Slovakia

3 Faculty of Mining and Geology, VŠB-Technical University of Ostrava, Ostrava, Czech Republic

*Address all correspondence to: janotka@tsus.sk

\section{IntechOpen}

(C) 2019 The Author(s). Licensee IntechOpen. This chapter is distributed under the terms of the Creative Commons Attribution License (http://creativecommons.org/licenses/ by/3.0), which permits unrestricted use, distribution, and reproduction in any medium, provided the original work is properly cited. (cc) BY 


\section{References}

[1] Schneider M. $\mathrm{CO}_{2}$-Minderung Weltweite Anforderungen. In:

Proceedings of Technisch

Wissenschaftliche-Zementtagung; Düsseldorf, Germany; September 28, 2011. pp. 1-27

[2] Gartner E. Industrially interesting approaches to "low- $\mathrm{CO}_{2}$ " cements. Cement and Concrete Research. 2004; 34:1489-1498. DOI: 10.1016/j. cemconres.2004.01.021

[3] Palomo A, Krivenko P, GarcíaLodeiro I, Kavalerova E, Maltseva O, Fernández-Jimenénez A. A review on alkaline activation: New analytical perspectives. Materiales de Construcción. 2014;64:315. DOI: 10.3989/mc2014.00314. Article e022

[4] García-Lodeiro I, Maltseva O, Palomo A, Fernández-Jiménez A. Hybrid alkaline cements. Part I: Fundamentals. Romanian Journal of Materials. 2012;42(4):330-335. https:// www.researchgate.net/publication/ 281535506

[5] Palomo A, Maltseva O, GarcíaLodeiro I, Fernández-Jiménez A. Hybrid alkaline cements. Part II: The clinker factor. Romanian Journal of Materials. 2013;43(1):74-80. https:// www.researchgate.net/publication/ 286987203

[6] Fernández-Jiménez A, GarcíaLodeiro I, Donatello S, Maltseva O, Palomo, A. Specific examples of hybrid alkaline cements. In: MATEC Web of Conferences, International Congress on Materials and Structural Stability; 26-30 November 2013; Article 01001. Rabat, Morocco; 2014. p. 3

[7] Qu B, Martin A, Pastor JY, Palomo A, Fernandéz-Jimenéz A. Characterization of pre-industrial hybrid cement and effect of pre-curing temperature. Cement and Concrete Composites.
2016;73(10):281-288. DOI: 10.1016/j. cemconcomp.2016.07.019

[8] Strigáč J, Martauz P. Combined binder on the base of wastes. Patent Application No. 50024. Banská Bystrica, Slovakia: Industrial Property Office of the Slovak Republic; 2012

[9] Janotka I, Bačuvčík M, Martauz P, Strigáč J. Chemical resistance of novel hybrid cement in various aggressive solutions In: Proceedings of RILEM International Workshop on Performance-based Specification and Control of Concrete Durability. Article ID006; June 11-13, 2014; Zagreb, Croatia; 2014. pp. 17-24

[10] Martauz P, Václavík V, Cvopa B. The use of steel slag in concrete. IOP Conference Series. Earth and Environmental Science. 2017;92:012041. DOI: 10.1088/1755-1315/92/1/012041.

[11] Certificate of Conformity. H-Cement No. SK04-ZSV-1800. Bratislava, Slovakia: Building Testing and Research Institute (TSÚS); 2013

[12] SK-Technical Assessment. HCement No. TO-13/0074. Bratislava, Slovakia: Building Testing and Research Institute (TSÚS); 2013

[13] STN EN 197-1 Cement. Part 1: Composition, Specifications and Conformity Criteria for Common Cements. Bratislava, Slovakia: Slovak Office of Standards, Metrology and Testing; 2012

[14] STN EN 12620+A1: 2008 Aggregates for concrete. Bratislava, Slovakia: Slovak Office of Standards, Metrology and Testing; 2008

[15] Janotka I. Martauz P. Bačuvčík M. Preferable use of hybrid cement intended for industrial applications. In: Proceedings of the 10th ACI/RILEM 
International Conference on

Cementitious Materials and Alternative

Binders for Sustainable Concrete;

October 2-4, 2017; Montreal, Canada:

ACI Technical Publication SP-320-02;

2017. pp. 21-33

[16] STN 721179 Determination of the Alkali-Silica Expansion (Alkali-Silica Reaction). Bratislava, Slovakia: Slovak Office of Standards, Metrology and

Testing; 2014

[17] Janotka I, Martauz P, Bačuvčík M. Resistance of hybrid cement after 5 years of exposure to $5 \% \mathrm{Na}_{2} \mathrm{SO}_{4}$. In: Proceedings of Fourteenth International Conference on Recent Advances in Concrete Technology and Sustainable Issues; October 30-November 2, 2018; Beijing, China: ACI technical Publication SP-330-08; 2018. pp. 77-92

[18] STN EN 12390-2 Testing Hardened Concrete. Part 2: Making and Curing Specimens for Strength Tests.

Bratislava, Slovakia: Slovak Office of Standards, Metrology and Testing; 2010

[19] STN EN 196-2 Methods of Testing Cement. Part 2: Chemical Analysis of Cement. Bratislava, Slovakia: Slovak Office of Standards, Metrology and Testing; 2013

[20] STN EN 196-3+A1 Methods of Testing Cement. Part 3: Determination of Setting Time and Soundness.

Bratislava, Slovakia: Slovak Office of Standards, Metrology and Testing; 2009

[21] STN EN 196-8 Methods of Testing Cement. Part 8: Heat of Hydration. Solution Method. Bratislava, Slovakia: Slovak Office of Standards, Metrology and Testing; 2010

[22] STN EN 196-1 Methods of Testing Cement-Part 1: Determination of Strength. Bratislava, Slovakia: Slovak Office of Standards, Metrology and

Testing; 2016
[23] STN EN 12350-2 Testing Fresh Concrete. Part 2: Slump-test. Bratislava, Slovakia: Slovak Office of Standards, Metrology and Testing; 2010

[24] STN EN 12350-6 Testing Fresh Concrete. Part 6: Density. Bratislava, Slovakia: Slovak Office of Standards, Metrology and Testing; 2011

[25] STN EN 12350-7 Testing Fresh Concrete. Part 7: Air Content. Pressure Methods. Bratislava, Slovakia: Slovak Office of Standards, Metrology and Testing; 2011

[26] STN EN 12390-3/AC Testing Hardened Concrete. Part 3: Compressive Strength of Test Specimens. Bratislava, Slovakia: Slovak Office of Standards, Metrology and Testing; 2010

[27] STN ISO 6784 Concrete. Determination of Static Modulus of Elasticity in Compression. Bratislava, Slovakia: Slovak Office of Standards, Metrology and Testing; 1993

[28] STN 731371 Method of Ultrasonic Pulse Testing of Concrete. Bratislava, Slovakia: Slovak Office of Standards, Metrology and Testing; 1981

[29] STN EN 206 + A1 Concrete. Specification, Performance, Production and Conformity. Bratislava, Slovakia: Slovak Office of Standards, Metrology and Testing; 2017

[30] STN 731320 Determination of Volume Changes. Bratislava, Slovakia: Slovak Office of Standards, Metrology and Testing; 1987

[31] ACI 221.1R-98 Report on alkaliaggregate reactivity. Reported by ACI Committee 221. 19 August 1998 by American Concrete Institute; Reapproved 2008. p. 30 


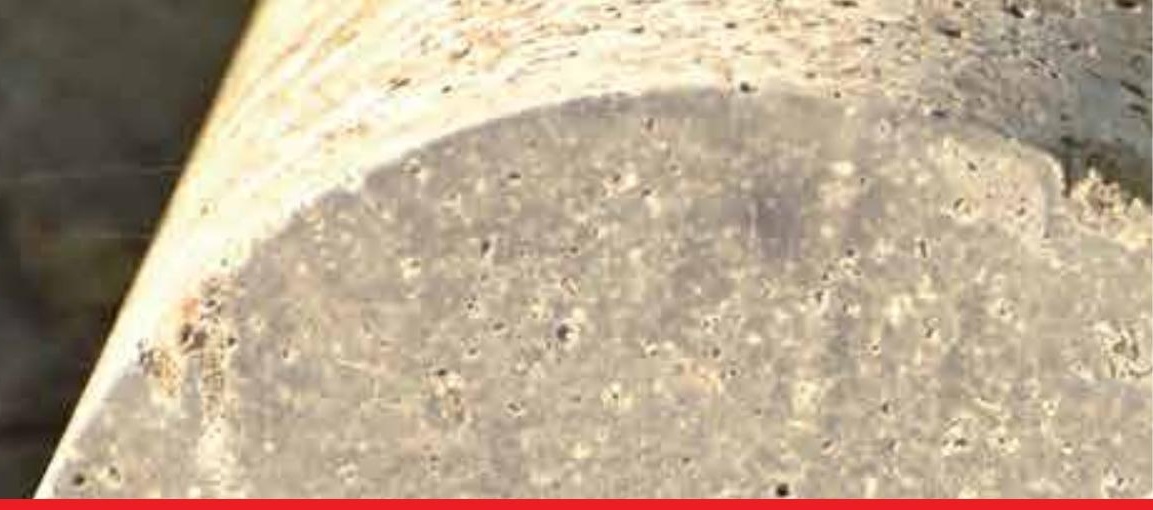

\section{Edited by Pavel Krivenko}

Concrete made using mineral cements, the raw materials which on earth are practically endless, is known as one of the oldest building materials and during the last decades of the twentieth century has become a dominant building material for general use. At the same time, the requirements of the quality of concrete and its performance properties, in particular compressive strength, durability, economical

efficiency, and low negative impact of its manufacture on the environment have not yet been completely met. Bearing these requirements in mind, researchers and engineers worldwide are working on how to satisfy these requirements. This book has been written by researchers and experts in the field and provides the state of the art on recent progress achieved on the properties of concrete, including concrete in which industrial by-products are utilized. The book is dedicated to graduate students, researchers, and practicing engineers in related fields.

\section{IntechOpen}
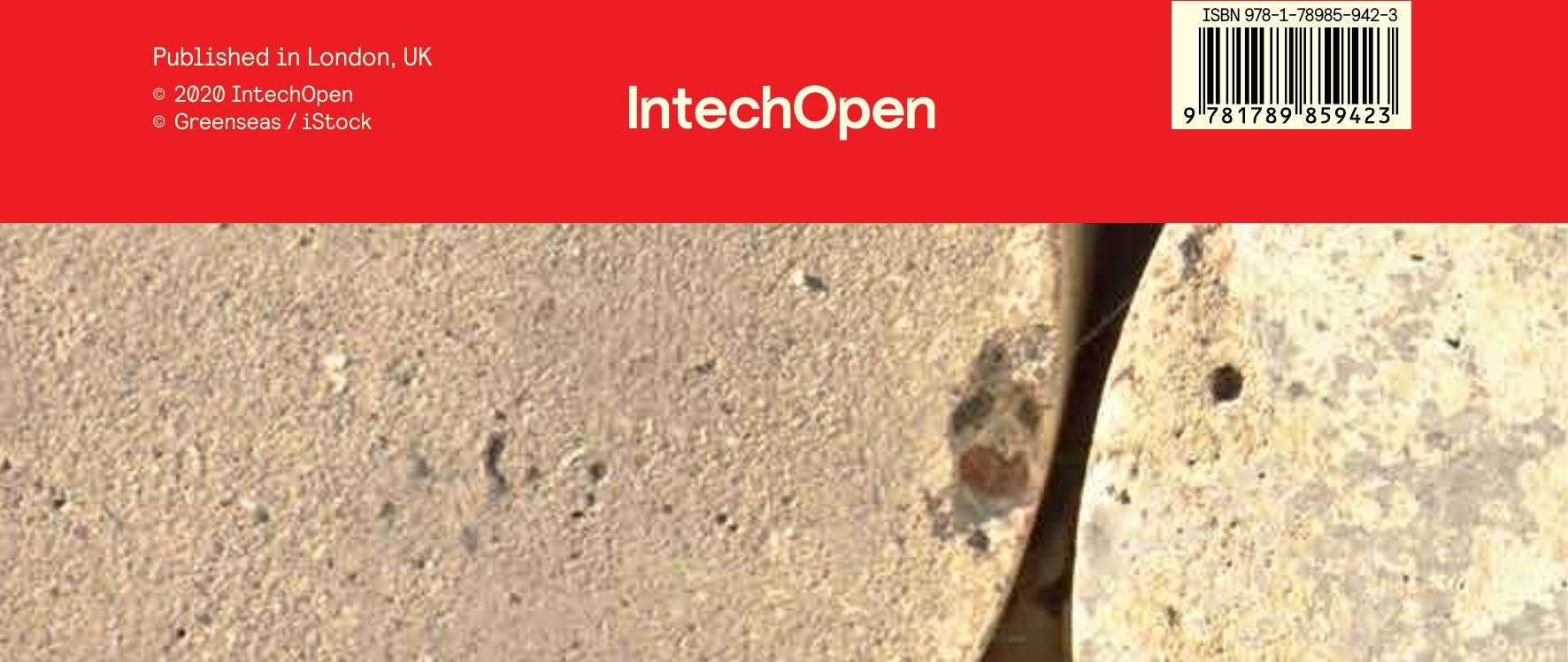